Universidade de São Paulo

Faculdade de Medicina da Universidade de São Paulo

Raphael Ximenes

\title{
Risco de dengue para turistas no Brasil na Copa do Mundo da FIFA 2014 e nos Jogos Olímpicos Rio 2016, utilizando modelagem matemática
}

\author{
Tese apresentada à Faculdade de Medicina \\ da Universidade de São Paulo para \\ obtenção do título de Doutor em Ciências \\ Programa de: Patologia \\ Orientador: Prof. Dr. Eduardo Massad
}

Versão corrigida. Resolução CoPGr 5890, de 20 de Dezembro de 2010.

A versão original está disponível na Biblioteca da FMUSP.

São Paulo 

Universidade de São Paulo

Faculdade de Medicina da Universidade de São Paulo

Raphael Ximenes

\title{
Risco de dengue para turistas no Brasil na Copa do Mundo da FIFA 2014 e nos Jogos Olímpicos Rio 2016, utilizando modelagem matemática
}

\author{
Tese apresentada à Faculdade de Medicina \\ da Universidade de São Paulo para \\ obtenção do título de Doutor em Ciências \\ Programa de: Patologia \\ Orientador: Prof. Dr. Eduardo Massad
}

Versão corrigida. Resolução CoPGr 5890, de 20 de Dezembro de 2010.

A versão original está disponível na Biblioteca da FMUSP.

São Paulo 
Dados Internacionais de Catalogação na Publicação (CIP)

Preparada pela Biblioteca da

Faculdade de Medicina da Universidade de São Paulo

Creprodução autorizada pelo autor

Ximenes, Raphael

Risco de dengue para turistas no Brasil na Copa do Mundo FIFA 2014 e nos Jogos Olímpicos do Rio 2016, utilizando modelagem matemática / Raphael Ximenes. -São Paulo, 2017.

Tese(doutorado)--Faculdade de Medicina da Universidade de São Paulo.

Programa de Patologia.

Orientador: Eduardo Massad.

Descritores: 1.Risco 2.Dengue 3.Modelos matemáticos 4.Saúde do viajante 5.Doenças transmissíveis 6.Epidemiologia

USP/FM/DBD-029/17 
Dedico este trabalho a todos que me trouxeram até aqui. Aos que me ouviram, que discutiram, aos que me ensinaram e que me deram suporte e potência para continuar.

À minha família, Aos meus professores, Aos meus amigos,

E àqueles que infelizmente sucumbiram e ainda vão sucumbir à dengue, motivo principal deste trabalho. 



\section{Agradecimentos}

Tenho muito a agradecer. Consciente de que nenhuma história começa e termina em si, eu agradeço àqueles que participaram de forma direta ou indireta da construção deste trabalho e do que eu represento neste momento.

Agradeço aos meus pais, Élide e Cílio, e aos meus irmãos Juliana e Caio pelo apoio incondicional.

Aos meus avôs e avós Lourdes, Cílio, Nadir e Oswaldo.

À toda família, ao Daniel, à Carol e aos meus tios, tias e primos.

À Aline, pelo enorme apoio, força e ideias no início deste trabalho e por encorajarme a ser um cientista.

Aos tão queridos Nilton e Felipe, pelas inúmeras discussões acerca da ciência.

À Berbel, à Michele e à Fátima, por todo apoio recebido.

À Soledad, por me ajudar a encontrar novos caminhos.

Ao professor Eduardo Massad, por ter aceitado me orientar e por todo apoio dado até aqui.

Ao professor Jianhong Wu por aceitar me orientar no Canadá.

Ao professor David Greenhalgh por aceitar me orientar na Escócia.

Aos professores, em ordem alfabética, Franciane Silva de Azevedo, Francisco Antonio Bezerra Coutinho, José Henrique Hildebrand Grisi Filho, Luis Fernandez Lopez, Marcelo Nascimento Burattini, Marcos Amaku e Neli Regina Siqueira Ortega.

À Franciane, pelos momentos de discussão, estudo e enorme aprendizado sobre ciência e sobre a vida.

Aos incríveis amigos Elídio, Evandro, Filipe, Jonas, Leandro, Maria e Sabrina pelo acolhimento.

Ao Marco pela poesia.

Ao Gabriel, pelas tardes em que tocou piano enquanto eu escrevia esta tese.

À Ana, por encorajar-me.

À Flávia, Juliana, Luana, Mariana, Samara e aos tão queridos Bóris, Eduardo e Hugo, pela parceria, pelos momentos de descontração e por todo o apoio.

À Lenita, que teve grande importância e influência em minha decisão de estudar nesta universidade que tanto admiro e sinto orgulho.

À Claire, pela enorme ajuda.

Aos meus amigos e à todas as pessoas que tive contato e que, por algum motivo, me trouxeram até aqui e possibilitaram a conclusão desta etapa.

À Universidade de São Paulo e à Faculdade de Medicina da USP. 
Ao Ministério da Saúde do Brasil, pelos dados utilizados neste trabalho.

A todos os colaboradores que me incentivaram e possibilitaram a experiência no Canadá.

Aos alunos de pós-graduação do grupo de pesquisa da Disciplina de Informática Médica, que ao meu lado dividiram o prazer de estudar nesta universidade: Ana, Hélio, Letícia, Rosângela e Teresa.

Aos funcionários da DIM: Iracene, Vilma e Paulo César, pelo importante suporte técnico administrativo.

Por fim, à FAPESP pelo suporte financeiro oferecido para a execução deste doutorado e ao $\mathrm{CNPq}$ pelo suporte financeiro para a execução do doutorado sanduíche. 
O Sol nasce e ilumina

As pedras evoluídas

Que cresceram com a força

De pedreiros suicidas

Cavaleiros circulam

Vigiando as pessoas

Não importa se são ruins

Nem importa se são boas

E a cidade se apresenta

Centro das ambições

Para mendigos ou ricos

E outras armações

Coletivos, automóveis,

Motos e metrôs

Trabalhadores, patrões,

Policiais, camelôs

A cidade não pára

A cidade só cresce

0 de cima sobe

E O de baixo desce

A cidade não pára

A cidade só cresce

0 de cima sobe

E o de baixo desce

A cidade se encontra

Prostituída

Por aqueles que a usaram

Em busca de uma saída

Ilusora de pessoas

De outros lugares,
A cidade e sua fama

Vai além dos mares

E no meio da esperteza

Internacional

A cidade até que não está tão mal

E a situação sempre mais ou menos

Sempre uns com mais e outros com menos

A cidade não pára

A cidade só cresce

0 de cima sobe

E o de baixo desce

A cidade não pára

A cidade só cresce

0 de cima sobe

E o de baixo desce

Eu vou fazer uma embolada,

Um samba, um maracatu

Tudo bem envenenado

Bom pra mim e bom pra tu

Pra gente sair da lama e enfrentar os urubus

Num dia de Sol, Recife acordou

Com a mesma fedentina do dia anterior.

A cidade - Chico Science 



\section{Lista de abreviaturas e siglas}

AIC Akaike Information Criterion - Critério de informação Akaike

Anvisa Agência Nacional de Vigilância Sanitária

CDC Centers for Disease Control and Prevention

DENV-1 ou DENV1 Dengue sorotipo 1

DENV-2 ou DENV3 Dengue sorotipo 2

DENV-3 ou DENV3 Dengue sorotipo 3

DENV-4 ou DENV4 Dengue sorotipo 4

DC Dengue clássica

EQM Erro Quadrático Médio

FHD Febre hemorrágica da dengue

IC Intervalo de confiança

NTDs Neglected tropical diseases - Doenças tropicais negligenciadas

ONU Organização das Nações Unidas

OMS Organização Mundial da Saúde

PGF Função Geradora de Probabilidade

SARS Severe Acute Respiratory Syndrome (Síndrome Respiratória Aguda Severa)

SCD Síndrome do choque de dengue

SE Semana epidemiológica

SINAN Sistema de Informação de Agravos de Notificação

UNLIREC United Nations Office for Disarment Affairs - Gabinete das Nações Unidas para os Assuntos de Desarmamento 



\section{Lista de símbolos}

a

$\mathrm{b}$

$\mathrm{C}$

$\mu_{H}$

$\gamma_{H}$

$\mu_{M}$

$1 / \gamma_{M}$

$\alpha$

$S_{H}$

$I_{H}$

$R_{H}$

$N_{H}$

$S_{M}$

$L_{M}$

$I_{L}$

IDHM

$\lambda$

$\pi$
Taxa diária de picadas dos mosquitos

Probabilidade de transmissão dos mosquitos para os humanos

Probabilidade de picadas que são devidas aos mosquitos infectados

Taxa diária de mortalidade dos humanos

Taxa diária de recuperação da infecção por dengue

Taxa diária de mortalidade dos mosquitos

Período de latência média, em dias, dos mosquitos

Taxa de mortalidade diária de seres humanos induzida pela dengue

Humanos suscetíveis

Humanos infectados

Humanos recuperados

População total

Mosquitos suscetíveis

Mosquitos latentes

Mosquitos infectados

Índice de Desenvolvimento Humano Municipal

Força de infecção

Risco de infecção 



\section{Lista de ilustrações}

Figura 1 - Ciclo Aedes aegypti . . . . . . . . . . . . . . . . 9

Figura 2 - Ciclo da infecção da dengue . . . . . . . . . . . . . . . . . 11

Figura 3 - Distribuição de países ou áreas de risco de transmissão da dengue, em todo o mundo, 2014 . . . . . . . . . . . . . . 12

Figura 4 - Mudanças na distribuição dos sorotipos de dengue em 1970 (a) e 2004 (b) . . . . . . . . . . . . . . . . . 14

Figura 5 - Cronograma dos jogos . . . . . . . . . . . 35

Figura 6 - Sorotipo da dengue circulante no Brasil por ano. . . . . . . . . 37

Figura 7 - Distribuição da força de infecção por cidade-sede. . . . . . . . . 38

Figura 8 - Desagregação da força de infecção . . . . . . . . . . . . . 39

Figura 9 - Ajuste da força de infecção semanal - Belo Horizonte . . . . . . 40

Figura 10 - Ajuste da força de infecção semanal - Brasília . . . . . . . . . . 41

Figura 11 - Ajuste da força de infecção semanal - Cuiabá . . . . . . . . . . 41

Figura 12 - Ajuste da força de infecção semanal - Curitiba . . . . . . . . . . 42

Figura 13 - Ajuste da força de infecção semanal - Fortaleza . . . . . . . . . 42

Figura 14 - Ajuste da força de infecção semanal - Manaus . . . . . . . . . . 43

Figura 15 - Ajuste da força de infecção semanal - Natal . . . . . . . . . . . 43

Figura 16 - Ajuste da força de infecção semanal - Porto Alegre . . . . . . . 44

Figura 17 - Ajuste da força de infecção semanal - Recife . . . . . . . . . . . 44

Figura 18 - Ajuste da força de infecção semanal - Rio de Janeiro . . . . . . 45

Figura 19 - Ajuste da força de infecção semanal - Salvador . . . . . . . . . . 45

Figura 20 - Ajuste da força de infecção semanal - São Paulo . . . . . . . . . 46

Figura 21 - Casos acumulados de dengue por semana epidemiológica - Rio de Janeiro . . . . . . . . . . . . . . . . . . . . . . . . . 58

Figura 22 - Ajuste casos sintomáticos ano 2000 . . . . . . . . . . . . 60

Figura 23 - Ajuste casos assintomáticos ano 2000 . . . . . . . . . . . . 60

Figura 24 - Ajuste casos sintomáticos ano 2001 . . . . . . . . . . . . . 61

Figura 25 - Ajuste casos assintomáticos ano 2001 . . . . . . . . . . . . . 61

Figura 26 - Ajuste casos sintomáticos ano 2002 . . . . . . . . . . . . . . . 62

Figura 27 - Ajuste casos assintomáticos ano 2002 . . . . . . . . . . . . 62

Figura 28 - Ajuste casos sintomáticos ano 2003 . . . . . . . . . . . . 63

Figura 29 - Ajuste casos assintomáticos ano 2003 . . . . . . . . . . . 63

Figura 30 - Ajuste casos sintomáticos ano 2004 . . . . . . . . . . . . . 64

Figura 31 - Ajuste casos assintomáticos ano 2004 . . . . . . . . . . . . . . 64

Figura 32 - Ajuste casos sintomáticos ano $2005 \ldots$. . . . . . . . 65 
Figura 33 - Ajuste casos assintomáticos ano 2005 . . . . . . . . . . . . 65

Figura 34 - Ajuste casos sintomáticos ano 2006 . . . . . . . . . . . . 66

Figura 35 - Ajuste casos assintomáticos ano 2006 . . . . . . . . . . . 66

Figura 36 - Ajuste casos sintomáticos ano 2007 . . . . . . . . . . . . 67

Figura 37 - Ajuste casos assintomáticos ano 2007 . . . . . . . . . . . . 67

Figura 38 - Ajuste casos sintomáticos ano 2008 . . . . . . . . . . . . . . . 68

Figura 39 - Ajuste casos assintomáticos ano 2008 . . . . . . . . . . . . 68

Figura 40 - Ajuste casos sintomáticos ano 2009 . . . . . . . . . . . . . . . . 69

Figura 41 - Ajuste casos assintomáticos ano 2009 . . . . . . . . . . . . . . 69

Figura 42 - Ajuste casos sintomáticos ano 2010 . . . . . . . . . . . . 70

Figura 43 - Ajuste casos assintomáticos ano 2010 . . . . . . . . . . . . . 70

Figura 44 - Ajuste casos sintomáticos ano 2011 . . . . . . . . . . . . . . 71

Figura 45 - Ajuste casos assintomáticos ano 2011 . . . . . . . . . . . . . . 71

Figura 46 - Ajuste casos sintomáticos ano 2012 . . . . . . . . . . . . . 72

Figura 47 - Ajuste casos assintomáticos ano $2012 \ldots$. . . . . . . . . . 72

Figura 48 - Ajuste casos sintomáticos ano 2013 . . . . . . . . . . . . . . 73

Figura 49 - Ajuste casos assintomáticos ano 2013 . . . . . . . . . . . . 73

Figura 50 - Ajuste casos sintomáticos ano 2014 . . . . . . . . . . . . . . 74

Figura 51 - Ajuste casos assintomáticos ano 2014 . . . . . . . . . . . . . 74

Figura 52 - Ajuste casos sintomáticos ano 2015 . . . . . . . . . . . . 75

Figura 53 - Ajuste casos assintomáticos ano 2015 . . . . . . . . . . . 75

Figura 54 - Sorotipo da dengue circulante em 2014 nos Estados-sede dos jogos da Copa do Mundo FIFA . . . . . . . . . . . . . . . . 84

Figura 55 - Número de casos de dengue reportados no Rio de Janeiro entre 2000 e Julho de $2014 \ldots$. . . . . . . . . . . . . . . . 88

Figura 56 - Precipitação em Julho e Agosto - Rio de Janeiro . . . . . . . . . 91

Figura 57 - Sorotipo da dengue circulante no Brasil por ano. . . . . . . . . . 127

Figura 58 - Dinâmica da população de humanos infectados . . . . . . . . . 128

Figura 59 - Número total de mortes devido à dengue (DENV2-DENV3) versus: $((\mathrm{a})) \nu_{h}$ e $((\mathrm{b})) p \ldots \ldots$. . . . . . . . . . . . . 128

Figura 60 - Número total de mortes devido à dengue - DENV2-DENV3 - 3D 129

Figura 61 - Risco per capita de mortes devido à dengue (DENV2-DENV3) versus: $((\mathrm{a})) \nu_{h}$ e $((\mathrm{b})) p \ldots \ldots$. . . . . . . . . . . . 130

Figura 62 - Risco per capita de mortes devido à dengue - DENV2-DENV3 3D . . . . . . . . . . . . . . . . 130

Figura 63 - Número total esperado de dias de incidência de dengue (DENV2DENV3) versus: $((\mathrm{a})) \nu_{h}$ e $((\mathrm{b})) p \ldots . \ldots . . \ldots . . \ldots 131$ 
Figura 64 - Número total esperado de dias de incidência de dengue - DENV2DENV3 - 3D . . . . . . . . . . . . . . 131

Figura 65 - Número total esperado de casos de dengue (DENV2-DENV3)

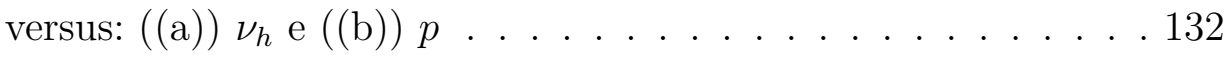

Figura 66 - Número total esperado de casos de dengue - DENV2-DENV3 - 3D132 Figura 67 - Número total de dias de infecção secundária esperado (DENV2DENV3) versus: $((\mathrm{a})) \nu_{h}$ e $((\mathrm{b})) p \ldots . \ldots . . \ldots . . \ldots 133$

Figura 68 - Número total de dias de infecção secundária esperado - DENV2DENV3 - 3D . . . . . . . . . . . . . . . . . 133

Figura 69 - Número total esperado de casos secundários de dengue (DENV2-

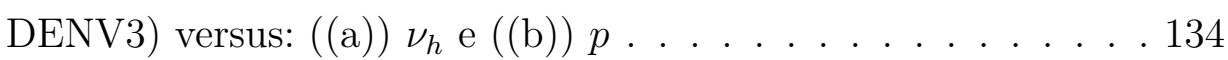

Figura 70 - Número total esperado de casos secundários de dengue - DENV2DENV3 - 3D . . . . . . . . . . . . . . 134

Figura 71 - Custo econômico 1 (DENV2-DENV3) versus: ((a)) $\nu_{h}$ e ((b)) $p .135$ Figura 72 - Custo econômico 1 - DENV2-DENV3 - 3D . . . . . . . . . . 135 Figura 73 - Custo econômico 2 (DENV2-DENV3) versus: ((a)) $\nu_{h}$ e ((b)) $p .136$ Figura 74 - Custo econômico 2 - DENV2-DENV3 - 3D . . . . . . . . . . . 136 Figura 75 - Custo econômico 3 (DENV2-DENV3) versus: ((a)) $\nu_{h}$ e ((b)) $p .137$ Figura 76 - Custo econômico 3 - DENV2-DENV3 - 3D . . . . . . . . . . . 137 Figura 77 - Custo econômico 4 (DENV2-DENV3) versus: ((a)) $\nu_{h}$ e ((b)) p . 138 Figura 78 - Custo econômico 4 - DENV2-DENV3 - 3D . . . . . . . . . . 138 Figura 79 - Custo econômico 5 (DENV2-DENV3) versus: ((a)) $\nu_{h}$ e ((b)) p . 139 Figura 80 - Custo econômico 5 - DENV2-DENV3 - 3D . . . . . . . . . . . 139 



\section{Lista de tabelas}

Tabela 1 - Parâmetros do modelo matemático . . . . . . . . . . . . 24

Tabela 2 - Variáveis: Humanos . . . . . . . . . . . . . . 25

Tabela 3 - Variáveis: Mosquitos . . . . . . . . . . . . . 25

Tabela 4 - Ajuste exponencial e coeficiente de determinação $\left(R^{2}\right)$. . . . . 39

Tabela 5 - Parâmetros do ajuste da força de infecção semanal pela função exponencial. . . . . . . . . . . . . 4 46

Tabela 6 - Estádios e número de turistas estrangeiros esperados por partida 48

Tabela 7 - Número de turistas internacionais e de casos sintomáticos de dengue esperados em cada cidade-sede . . . . . . . . . . 48

Tabela 8 - Número de casos sintomáticos de dengue esperados em turistas e risco de infecção sintomática individual, para cada cronograma 49

Tabela 9 - Número de casos sintomáticos de dengue esperados em turistas e risco de infecção sintomática individual, com dados de 2014 . 51

Tabela 10 - Número de turistas internacionais e de casos sintomáticos de dengue esperados em cada cidade-sede, com dados de 2014 . . . 52

Tabela 11 - Projeção população suscetível - Sintomáticos 1:1 . . . . . . . . 56

Tabela 12 - Projeção população suscetível - Assintomáticos 1:2 e 1:4 . . . . 57

Tabela 13 - Projeção população suscetível - Assintomáticos 1:6 e 1:10 . . . . 57

Tabela 14 - Número de casos esperados por cenário (sintomático/assintomático) 76

Tabela 15 - Risco Individual - Sintomáticos - Por cenário . . . . . . . . . . 77

Tabela 16 - Risco individual - Assintomáticos (1:2 e 1:4) - Por cenário . . . 77

Tabela 17 - Risco individual - Assintomáticos (1:6 e 1:10) - Por cenário . . . 78

Tabela 18 - Casos de dengue até a $14^{a}$ semana epidemiológica . . . . . . . . 82

Tabela 19 - Precipitação no Município do Rio de Janeiro, em milímetros . 91 



\section{Sumário}

INTRODUÇÃO $\ldots \ldots \ldots \ldots \ldots \ldots \ldots$

1.1

Dengue. . . . . . . . . . . . . . . . . . 7

1.2

Aedes aegypti

$1.3 \quad 0$ ciclo do mosquito $\ldots \ldots \ldots \ldots \ldots$

1.3.1 Modo de transmissão . . . . . . . . . . . . . . . 11

$1.3 .2 \quad \mathrm{O}$ vírus da dengue $\ldots \ldots \ldots \ldots \ldots \ldots \ldots$

$1.3 .3 \quad$ Histórico . . . . . . . . . . . . . . . . . . . . . . . . . . . . 14

$1.4 \quad$ Dengue clássica . . . . . . . . . . . . . . . . . . . 17

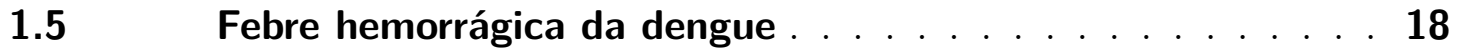

1.6 Outras doenças relacionadas ao mosquito Aedes aegypti . . . 18

$1.6 .1 \quad$ Febre Amarela $\ldots \ldots \ldots \ldots \ldots$

$1.6 .2 \quad$ Febre Chikungunya . . . . . . . . . . . . . . . . . . 19

1.6.3 Doença do vírus da Zika . . . . . . . . . . . . . . . . 19

$2-\quad$ OBJETIVOS $\ldots \ldots \ldots \ldots \ldots \ldots \ldots \ldots \ldots \ldots$

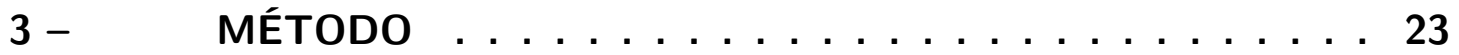

3.1 O Modelo da dinâmica de dengue para população local . . . 23

3.2 Aproximação estocástica SI para o risco de dengue para os turistas . . . . . . . . . . . . . . . . . . . 25

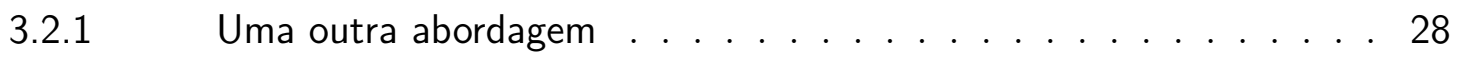

$3.3 \quad$ Determinando o risco $\ldots \ldots \ldots \ldots$

4 - $\quad$ COPA DO MUNDO DA FIFA $2014 \ldots \ldots \ldots$

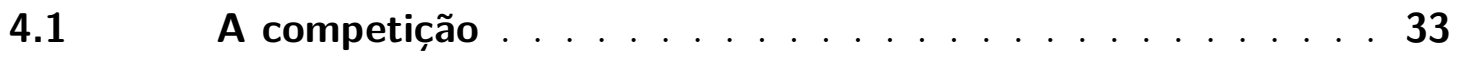

$4.2 \quad$ Cronograma dos jogos . . . . . . . . . . . . . 34

4.3 Determinação da força de infecção . . . . . . . . . 36

$4.4 \quad$ Ajustes . . . . . . . . . . . . . . . . . 39

$4.5 \quad$ Risco de infecção . . . . . . . . . . . . . . . . . . . . 47

4.6 Resultados - Risco de dengue em turistas na Copa do Mundo 47

$4.7 \quad$ Validando a previsão a partir das notificações de $2014 \ldots 50$

5 - JOGOS OLÍMPICOS DE VERÃO - RIO $2016 \ldots \ldots$

$5.1 \quad$ Os Jogos Olímpicos Rio $2016 \ldots \ldots \ldots$

$5.2 \quad$ Probabilidade de infecção per capita . . . . . . . . . . 54 
5.2.1 População suscetível . . . . . . . . . . . . . . . . . . . 54

5.3 Estimando a força de infecção da dengue no Rio de Janeiro . 57

5.4 Resultados - Risco de dengue em turistas nos Jogos Olímpi$\cos 2016 \ldots \ldots \ldots 9$

$5.5 \quad$ Tabelas de resultados $\ldots \ldots \ldots \ldots \ldots$

$6-\quad$ DISCUSSÃO $\ldots \ldots \ldots \ldots \ldots \ldots \ldots$

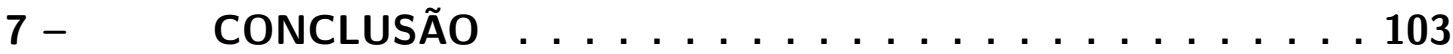

Referências . . . . . . . . . . . . . . . 105

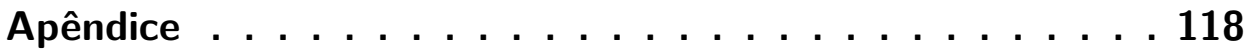




\section{Resumo}

XIMENES, Raphael. Risco de dengue para turistas no Brasil na Copa do Mundo da FIFA 2014 e nos Jogos Olímpicos Rio 2016, utilizando modelagem matemática. 2017. 116 f. Tese (Doutorado) - Faculdade de Medicina, Universidade de São Paulo. São Paulo, 2017.

A Organização Mundial da Saúde estima que 3.9 bilhões de pessoas, em 128 países, vivem atualmente em áreas de risco para contrair dengue em todo o mundo, e que anualmente, 390 (284-528) milhões de infecções ocorrem, sendo apenas 96 (67-136) milhões de casos com manifestações clínicas. Estima-se que 500.000 casos de dengue hemorrágica aconteçam por ano, muitos deles em crianças, causando milhares de mortes (Bhatt et al., 2013; WHO, 2015a).

A urbanização, a superpopulação, aglomeração, a pobreza, a infra-estrutura de saúde pública enfraquecida, além das mudanças demográficas globais, são fatores que interferem na incidência da dengue e contribuem para a perpetuação e o crescente número de casos da doença (Farmer, 1996; Guzmán and Kouri, 2002). Além destes fatores, as viagens internacionais também implicam no aumento da incidência da dengue, porque o viajante ajuda a introduzir novas estirpes de diferentes partes do mundo ao chegar doente em seu destino, ou ao voltar para casa portando a doença (Wilder-Smith and Schwartz, 2005).

O Brasil sediou em 2014 a Copa do Mundo da FIFA e, em 2016, recebeu os Jogos Olímpicos de Verão, no Rio de Janeiro, dois dos maiores eventos esportivos da atualidade, e por isso esperava receber centenas de milhares de turistas em cada um dos eventos.

Embora exista uma vacina contra a dengue, sua eficácia não é suficiente para a prevenção ampla, e a curto prazo, da população suscetível e, por estas razões, este trabalho pretende, através da modelagem matemática, estimar o risco de contágio de dengue para turistas não imunes no Brasil no período da Copa do Mundo da FIFA 2014, em cada uma das 12 cidades-sede do evento e também estimar o risco de contágio de dengue para turistas não imunes no Brasil no período dos Jogos Olímpicos Rio 2016.

Para a Copa do Mundo da FIFA, o risco obtido variou de $3,61 \times 10^{-6}$ no melhor cenário a $8,33 \times 10^{-4}$, no pior. Já para os Jogos Olímpicos, o pior risco individual obtido foi igual a $5.84 \times 10^{-5}$ (IC $95 \%$ : $5.21 \times 10^{-5}-6.47 \times 10^{-5}$ ).

Palavras-chave: risco; dengue; modelos matemáticos; saúde do viajante; doenças transmissíveis; epidemiologia 



\section{Abstract}

XIMENES, Raphael. Risco de dengue para turistas no Brasil na Copa do Mundo da FIFA 2014 e nos Jogos Olímpicos Rio 2016, utilizando modelagem matemática. 2017. 116 f. Tese (Doutorado) - Faculdade de Medicina, Universidade de São Paulo. São Paulo, 2017.

The World Health Organization estimates that 3,9 billion people in 128 countries currently live in areas at risk of dengue worldwide, and that 390 (284-528) million infections occur annually, of which 96 (67 -136) million cases with clinical manifestations. It is estimated that 500,000 cases of dengue hemorrhagic occur annually, many of them in children, causing thousands of deaths (Bhatt et al., 2013; WHO, 2015a).

Urbanization, overpopulation, agglomeration, poverty, weakened public health infrastructure, and global demographic changes are factors that interfere with the incidence of dengue and contribute to the perpetuation and increasing number of cases of the disease (Farmer, 1996; Guzmán and Kouri, 2002).

In addition to these factors, international travel also increase in the incidence of dengue, because an infected traveller may introduce new strains from different parts of the world when they arrive at their destination, or when they return home with the disease (Wilder-Smith and Schwartz, 2005).

Brazil hosted the 2014 FIFA World Cup and hosted the 2016 Summer Olympics in Rio de Janeiro, two of the biggest modern sporting events, and it was predicted that each event would receive hundreds of thousands of tourists in each of events. Although a vaccine against dengue exists, its efficacy is not sufficient for the broad and short-term prevention of the susceptible population. As a result, this work intends, through mathematical modelling, to estimate the risk of contagion of dengue for non-immune tourists in Brazil during the period of 2014 FIFA World Cup in each of the 12 host cities of the event and also estimate the risk of contagion of dengue for non-immune tourists in Brazil during the period of Rio 2016 Olympic Games.

During the FIFA World Cup, the risk obtained ranged from $3,61 \times 10^{-6}$ in the best scenario up to $8,33 \times 10^{-4}$ in the worst case scenario. For the Olympic Games, the worst individual risk was $5.84 \times 10^{-5}$ (IC $95 \%$ : $5.21 \times 10^{-5}-6.47 \times 10^{-5}$ ).

Keywords: risk; dengue; mathematical models; travelers' health; communicable diseases; epidemiology 



\section{Introdução}

Desde a antiguidade as viagens internacionais associadas ao comércio já eram relacionadas ao risco de contaminação por novas doenças. Medidas de quarentena eram impostas a viajantes e mercadorias, e mesmo sem evidências sobre a natureza do contágio, a associação entre novos surtos epidêmicos e a chegada de pessoas e mercadorias era amplamente reconhecida (de Almeida Pereira, 2013).

No período das Grandes Navegações, a consequente chegada dos primeiros europeus ao Novo Mundo em 1492 foi responsável por uma das maiores epidemias causada por viajantes da história.

Embora existam divergências entre historiadores sobre o tamanho total da população das Américas no período antecedente à invasão Europeia, doenças como varíola, sarampo, gripe e cólera, além das venéreas, foram responsáveis, junto à violência da invasão Europeia, por dizimar de $25 \%$ a até $96 \%$ da população indígena, segundo Sánchez-Albornoz (1973) citado por da Cunha (2013) nos primeiros séculos após a colonização. Dobyns (1966) estimou que a população pré-contato era de 90 a 112 milhões em toda América, enquanto estimativas mais conservadoras apontam que a população era de 57 a 70 milhões de pessoas (Thornton, 1987).

Darcy Ribeiro, em "O Povo Brasileiro", diz que "É de todo provável que alcançasse, ou pouco excedesse, a 5 milhões o total da população indígena brasileira quando da invasão" (Ribeiro, 2015). Para comparação, em 1500 Portugal possuía população em torno de 1 milhão de habitantes (Ribeiro, 2015) enquanto na Europa, excluindo-se o Império Otomano e a Rússia, havia cerca de 61 milhões de habitantes (Town, 2015).

\footnotetext{
"Missões com cerca de 12 mil almas viram-se, em pouco tempo, reduzidas a mil. Nessa situação desesperadora é que ocorrem as epidemias de varíola, de 1562 a 1563, que não atingem os portugueses, mas em três meses matam mais de 30 mil índios e negros." (Ribeiro, 2015)
}

Uma epidemia inicia com o encontro de uma população suscetível com um agente infeccioso. Viajantes contribuem a ampliar o alcance das epidemias ao tornarem-se vetores de doenças, por viajarem infectados, ou simplesmente por portar em seus pertences de viagem o agente causador da doença, como no caso de 1665, em que Alexander Hadfield, um alfaiate da aldeia de Eyam, que importara um baú de roupas vindas de Londres e, infelizmente, infestadas por pulgas infectadas pelo agente causador da peste, levando seu assistente e outras 256 pessoas, dos 350 
moradores da aldeia, à morte (Massad et al., 2004).

Na Europa, no séc. XIV, a peste bubônica assolou o continente atingindo cerca de $60 \%$ da população daquele continente e matando milhares de pessoas (Benedictow, 2004; CDC, 2015). Alguns séculos mais tarde, a gripe espanhola, favorecida pelo tráfego dos viajantes, espalhou-se por todo o mundo, matando entre 50 e 100 milhões de pessoas (Lopez et al., 2016). Em 2003, um turista americano, exportou SARS (do inglês Severe Acute Respiratory Syndrome) da China para o Vietnã iniciando um surto global da doença (Wilder-Smith and Freedman, 2003).

Mais recentemente, outras epidemias assustaram o mundo pela capacidade de difusão das doenças, que ligadas ao intenso tráfego de pessoas pelo mundo e de contêineres de mercadorias, ajudaram a espalhar as doenças para diversos países. Em 2009, houve a pandemia causada pelo vírus H1N1, conhecida por gripe suína, com início no México e que logo espalhou-se por todo o planeta. E com início em 2013, o surto de Ebola, que atingiu diversos países do continente africano, causando mais de 11 mil mortes (WHO, 2016a).

Séculos mais tarde após a invasão europeia ao Novo Mundo, e após o impressionante avanço da ciência no controle, na prevenção e no tratamento de diversas doenças infecciosas, as viagens internacionais permanecem sendo motivo de atenção e preocupação quanto à disseminação de doenças infecciosas.

Eventos de massa costumam gerar grande preocupação pelo potencial risco de espalhamento de doenças infecciosas para diversos países, já que estes eventos podem concentrar viajantes dos mais longínquos pontos do planeta em um mesmo local.

\footnotetext{
"Eventos de Massa são reuniões de grande contingente de pessoas, em geral motivados por atividades laborais, políticas, esportivas, religiosas ou lúdicas, que ocorre de forma pré-programada ou não, e que, em geral, acarretam consequências em diversos setores da sociedade, inclusive na Saúde Pública."(Castro et al., 2014)

"Mais do que o número específico de pessoas (que pode ser tão poucos como 1000 pessoas para mais de $25 \mathrm{mil}$ ) em um local específico para uma finalidade específica (função social, um grande evento público ou uma competição desportiva) por um período definido de tempo." (Organization et al., 2008)
}

O Brasil foi escolhido para sediar diversos eventos internacionais entre os anos de 2007 e 2016, atraindo expressiva quantidade de turistas em alguns desses eventos, como:

- XV Jogos Pan-Americanos - Rio de Janeiro - 2007; 
- V Jogos Mundiais Militares do Conselho Internacional do Desporto Militar Rio de Janeiro - 2011;

- Conferência das Nações Unidas sobre o Desenvolvimento Sustentável - Rio de Janeiro - 2012;

- Copa das Confederações da FIFA Brasil - 2013;

- XXVIII Jornada Mundial da Juventude - Rio de Janeiro - 2013;

- Copa do Mundo da FIFA Brasil - 2014;

- I Jogos Mundiais dos Povos Indígenas - Palmas - 2015;

- Jogos da XXXI Olimpíada e Jogos da XV Paralimpíada de verão - Rio de Janeiro - 2016

O Brasil buscou sediar tais eventos, em especial a Copa do Mundo da FIFA e os Jogos Olímpicos de Verão, para através deles buscar promover a consolidação do Brasil como destino turístico. O governo brasileiro argumenta que a preparação e a execução destes eventos são importantes potenciais para a promoção da economia brasileira, e que a sociedade receberá legados positivos com a realização destes eventos em função dos investimentos aplicados em cada cidade.

Apesar da promessa da geração de diversos pontos positivos ao executar-se grandes eventos como estes, há também que atentar-se para a possibilidade de que ocorram problemas. Sempre que eventos de massa acontecem a comunidade internacional preocupa-se com a possibilidade de importação e exportação de doenças infecciosas e o perigo destes eventos contribuírem para o surgimento de novos surtos e epidemias.

\footnotetext{
"De tempo em tempo o mundo é posto em alerta, disparado por alguma, frequentemente desconhecida, doença infecciosa exótica, propagada por turistas de rotas internacionais para regiões anteriormente não infectadas."(Stannard, 1993), citado por (Lopez et al., 2016)
}

Não é raro turistas retornarem doentes para casa, e em alguns casos, uma pessoa infectada pode ser responsável por iniciar um surto ou epidemia, dependendo das condições locais do destino final do turista, como em 2012, quando eclodiu um surto de dengue na Ilha da Madeira, em Portugal, com mais de 2200 casos após a importação do vírus DENV-1 para a ilha que já era infestada de mosquitos do gênero Aedes (Wilder-Smith et al., 2014). 
O histórico da dengue no Brasil, que entre os anos 2000 e 2016 somou mais de 8.6 milhões de casos notificados de infecção por dengue, e a escolha do país para sediar dois dos maiores eventos esportivos da atualidade que, se somadas as expectativas, esses eventos devem atrair ao Brasil mais de 1 milhão de visitantes internacionais, motivaram-nos a realizar este estudo que visa determinar o risco individual de infecção por dengue dos turistas no Brasil durante o período dessas competições. Além disso, a motivação acompanha a preocupação com o potencial de exportação do vírus da dengue para outros países.

Segundo a Organização Mundial da Saúde (OMS), metade da população mundial está sob o risco da dengue, sendo uma das principais causas de hospitalização e morte nas regiões de trópicos e subtrópicos. A estimativa é de que 3,9 bilhões de pessoas, em 128 países, vivem sob risco de infecção com o vírus da dengue (Brady et al., 2012), com 390 milhões (284 - 528 milhões) de infecções por ano, das quais 96 milhões (67 - 136 milhões) com manifestações clínicas (Bhatt et al., 2013; WHO, 2015a).

A falta de uma vacina amplamente eficaz contra a dengue e o crescente número de casos, reforçam a necessidade da elaboração de novos métodos de controle e combate desta doença. Assim, as análises de determinação de risco podem ser utilizadas como uma importante ferramenta para este controle, auxiliando os órgãos de saúde na tomada de decisão e aplicações dos recursos.

Tendo isto em vista, este trabalho alinha-se à preocupação da comunidade internacional que na véspera dos Jogos Olímpicos do Rio de Janeiro, por exemplo, motivada pelo recente surto do vírus da Zika no Brasil, discutiu muito sobre a necessidade, ou não, de que Jogos Olímpicos fossem cancelados afim de se evitar a contaminação dos turistas pelo Zika durante o evento esportivo.

Em carta aberta para a OMS, 150 cientistas de diferentes grupos de pesquisa pediram o cancelamento dos Jogos Olímpicos no Rio de Janeiro, pois, segundo eles, os Jogos Olímpicos poderiam ser o estopim para o surgimento de uma epidemia mundial de Zika (Attaran et al., 2016a).

\footnotetext{
"Na atualidade as viagens e o comércio internacional explodiram em número, velocidade e dispersão e, como consequência, facilitaram a disseminação de microrganismos patogênicos e das doenças a eles associadas. É hoje possível dar a volta ao mundo em menos tempo que o período de incubação de muitas doenças infecciosas." (de Almeida Pereira, 2013)
}

Antes desta carta ser publicada, em (Burattini et al., 2016), apresentamos um primeiro estudo com a previsão de que o número de turistas que seriam 
infectados por Zika durante as Olimpíadas seria baixo. Após a divulgação da carta aberta, e o sucessivo aumento do número de notícias sobre o risco de contaminação por Zika, o número de publicações científicas sobre o assunto também aumentou e muitas dessas publicações utilizaram, como base da argumentação, os resultados encontrados aqui neste trabalho.

Codeço et al. (2016), ao argumentar em defesa da continuação do evento, afirmando que os turistas não deveriam deixar de ir ao Rio de Janeiro por causa do vírus da Zika, argumenta sobre o sucesso da previsão do número de casos de dengue em turistas durante a Copa do Mundo publicado por Massad et al. (2014b), resultado deste trabalho. Além disso, para tal defesa, também cita o número de casos esperados de dengue em turistas durante os Jogos Olímpicos aqui obtido e publicado por Ximenes et al. (2016).

Em resposta à carta, Grubaugh and Andersen (2016); Massad et al. (2016a,b) também utilizaram os resultados das previsões publicadas por Ximenes et al. (2016), Massad et al. (2014b) e Massad et al. (2014a) para defender a manutenção dos Jogos no Rio de Janeiro.

\footnotetext{
"Infelizmente, o vírus Zika vai se espalhar, como a dengue, chikungunya, e vírus do Nilo Ocidental fizeram antes. A realização dos Jogos Olímpicos no Brasil não terá, ou será extremamente limitado, o efeito sobre esse processo."(Grubaugh and Andersen, 2016)
}

Embora os nossos resultados fossem voltados exclusivamente para a determinação do risco de infecção por dengue, devido à dinâmica do vírus da Zika também depender, embora não exclusivamente, do vetor $A$. aegypti para ser transmitido, a relação entre os risco de infecção por dengue e o risco do Zika deu um maior destaque a este trabalho aqui apresentado.

McConnell et al. (2016); The (2016), reforçaram a defesa, também utilizando nossos resultados nos argumentos, afirmando que o "vírus da Zika representa uma ameaça mínima para os visitantes dos jogos".

Em contrapartida Attaran (2016); Attaran et al. (2016b) foram enfáticos ao criticar os argumentos de que os turistas estariam sob baixo risco de infecção por Zika, embora tenham utilizado para isto apenas análises superficiais dos dados de infecções.

Este comportamento da comunidade internacional também foi observado na véspera da Copa do Mundo da FIFA, sediada por 12 cidades brasileiras. 
Apesar de algumas previsões publicadas terem sido alarmistas, tal como Hay (2013), que previu risco alto de infecção nos estados do nordeste brasileiro e Lowe et al. (2014), que apresentou uma previsão com centenas de casos de dengue durante a Copa do Mundo, veremos aqui que o método de determinação do risco de dengue proposto neste estudo foi preciso ao determinar um risco baixo de infecção para os turistas durante a Copa do Mundo da FIFA em 2014, o que pôde ser comprovado após a competição, e ainda repetiu a previsão de baixo risco individual para os turistas não imunes durante os Jogos Olímpicos do Rio de Janeiro, prevendo um resultado de poucas infecções por dengue nestes turistas durante a competição olímpica.

Apresentaremos aqui a determinação do risco de dengue para turistas no Brasil durante dois importantes eventos de massa: A Copa do Mundo da FIFA e os Jogos Olímpicos de Verão.

Para isso utilizamos 2 métodos de determinação da força de infecção da dengue, que é necessária para a determinação do risco de infecção. No primeiro método, utilizado na determinação da força de infecção da dengue para o período da Copa do Mundo, levou-se em consideração apenas os casos notificados de dengue nas semanas correspondentes à competição entre os anos 2010 e 2013, enquanto que, para o período olímpico, utilizou-se os dados de notificação das 52 semanas epidemiológicas entre os anos 2000 e 2015 e, a partir destes dados, utilizou-se um modelo matemático baseado no modelo de Ross-Macdonald (Macdonald, 1952) para reprodução do histórico de dengue em todas as cidades-sede.

Dada a força de infecção $\lambda$ calculada a partir da reprodução do histórico de dengue, utilizou-se uma aproximação estocástica para a determinação do risco individual de infecção por dengue para os turistas.

O risco individual previsto para a Copa do Mundo variou de acordo com os diversos cenários de possibilidade entre $3,81 \times 10^{-5}\left(1,18 \times 10^{-5}-8,63 \times 10^{-5}\right)$ até $4,46 \times 10^{-4}\left(1,07 \times 10^{-4}-7,11 \times 10^{-4}\right)$, enquanto para os Jogos Olímpicos o risco esperado foi igual a $5,84 \times 10^{-5}\left(5,21 \times 10^{-05}-6,47 \times 10^{-5}\right)$, no pior cenário, que considerou apenas os casos notificados (sintomáticos).

Assim, a partir do risco individual e da expectativa do número de turistas internacionais não imunes à dengue que frequentariam os eventos, obteve-se o número total de infecções por dengue esperadas em cada evento esportivo, sendo 32 (0-73) casos durante a Copa do Mundo e 23 (21-26) casos no pior cenário (sintomáticos) para os Jogos Olímpicos do Rio. 


\subsection{Dengue}

A Organização Mundial da Saúde (OMS) classifica a dengue como uma doença tropical negligenciada (NTDs - em inglês) e a descreve como a doença viral transmitida por artrópodes mais importante dos seres humanos (WHO, 2009). A dengue é importante problema de saúde pública internacional, sendo que em 2012, a ela foi classificada como a doença viral transmitida por vetor de mais rápida propagação. Sua incidência tem aumentado de 30 vezes nos últimos 50 anos (WHO, 2015b).

A OMS classifica a dengue como um importante problema de saúde pública internacional devido à expansão geográfica, tanto do vírus quanto do mosquito vetor, ao aumento da frequência de epidemias, à cocirculação de vários sorotipos do vírus e ao surgimento da dengue hemorrágica em novas áreas. As razões que levam à emergência e reemergência da dengue são diversas, entre elas destacamse as mudanças demográficas globais, tal como o crescimento populacional e a urbanização sem o devido planejamento, resultando em condições precárias de moradia, sistemas inadequados de abastecimento de água e de gestão de resíduos (Guzmán and Kouri, 2002). Além disso, as alterações climáticas, a evolução do vírus e as viagens internacionais também contribuem (Wilder-Smith and Schwartz, 2005). E por fim, um sistema público de saúde enfraquecido somado ao insuficiente controle do vetor agravam ainda mais a situação.

Todos os fatores citados acima estão intimamente ligados à transmissão da dengue. "No entanto, as condições de vida, especificamente, a pobreza, as desigualdades sociais e o analfabetismo constituem o contexto geral" (Farmer, 1996).

Metade da população mundial está sob o risco da dengue (WHO, 2015b) e as alterações climáticas podem piorar ainda mais este risco pois o acréscimo de 1 a $2^{\circ} \mathrm{C}$ na temperatura do planeta pode aumentar a população de risco em várias centenas de milhões de pessoas, aumentando os casos fatais em mais 20.000 a 30.000 (Guzmán and Kouri, 2002).

Nas regiões de trópicos e subtrópicos a dengue é uma das principais causas de hospitalização e morte, principalmente de crianças (CDC, 2013). As regiões da Ásia e América Latina tem a dengue como um dos maiores fardos pois ela é uma das principais causas de mortes de crianças (WHO, 2015a).

A dengue é uma das doenças mais frequentes no Brasil com recorrentes surtos epidêmicos em todo o país.

Desde 1986 o número de epidemias no Brasil têm aumentado e não é raro o 
aumento da severidade dos casos. No período de 1990 a 2015, foram registrados mais de 7,6 milhões de casos de dengue em todo o Brasil (Brasil, 2015a), com a ocorrência de 5.267 óbitos (Brasil, 2015c).

No ano de 2015 foram registrados 1,6 milhão de casos de dengue em todo o Brasil, superando o recorde computado em 2013, quando houve 1.452 .489 casos de dengue.

\begin{abstract}
"As epidemias explosivas são causadas pela introdução de um sorotipo viral em uma localidade cuja população encontra-se suscetível ao mesmo. Entretanto, para que isso ocorra, é necessária a existência do mosquito em altos índices de infestação predial e de condições ambientais que permitam o contato desse vetor com aquela população." (Coura, 2005)
\end{abstract}

O primeiro caso de febre hemorrágica da dengue que se tem notícia aconteceu na década de 1950, nas Filipinas e Tailândia, quando deixou-se de acreditar que a dengue era uma doença benigna. Após a década de 60, a presença do vírus intensificou-se nas Américas. Pesquisadores identificaram vários sorotipos da doença, numerados de 1 a 4, dependendo do grau de letalidade do vírus (Brasil, 2005a).

O sorotipo 1, o mais leve, apareceu pela primeira vez em 1977, inicialmente na Jamaica, mas foi a partir de 1980 que foram notificadas epidemias em vários países, inclusive no Brasil, em 1981. O sorotipo 2, encontrado em Cuba, foi o responsável pelo primeiro surto de febre hemorrágica ocorrido fora do Sudoeste Asiático e Pacífico Ocidental. O segundo surto ocorreu na Venezuela, em 1989 (Brasil, 2005b).

"No Brasil, há referências de epidemias desde 1916, em São
Paulo, e em 1923, em Niterói, no Rio de Janeiro, sem comprova-
ção laboratorial. A primeira epidemia, documentada clínica e
laboratorialmente, ocorreu entre os anos de 1981 e 1982, em Boa
Vista, Roraima, causada pelos sorotipos 1 e 4, considerado o
mais perigoso. A partir de 1986, ocorreram epidemias, atingindo
o Rio de Janeiro e algumas capitais da região Nordeste. Desde
então, a dengue vem ocorrendo no Brasil de forma continu-
ada, intercalando-se com a ocorrência de epidemias, geralmente
associadas com a introdução de novos sorotipos em áreas anteri-
ormente ilesas. Na epidemia de 1986, identificou-se a ocorrência
da circulação do sorotipo 1, inicialmente no estado do Rio de
Janeiro, disseminando-se, a seguir, para outros seis estados até
1990. Nesse mesmo ano, foi identificada a circulação do sorotipo
2, também no estado do Rio de Janeiro." (Brasil, 2006)

Alguns estudos têm apontado que o valor real do número de casos em todo o mundo é muito mais alarmante do que o total de casos notificados presentes nos 
relatórios de notificações. Uma estimativa recente, de 2013, indica que 390 milhões de pessoas são infectadas por ano (IC 95\%: 248 - 528 milhões), dos quais de 67 a 136 milhões apresentam manifestação clínica com qualquer gravidade (Bhatt et al., 2013). Um outro estudo estima que 3,9 bilhões de pessoas, em 128 países, estejam sob risco de infecção com o vírus da dengue (Brady et al., 2012), portanto, metade da população mundial, segundo o levantamento das Nações Unidas (Nations, 2016).

Assim, a determinação do risco de infecção por dengue nos eventos de massa sediados pelo Brasil, é uma importante ferramenta para o controle do surgimento de novas epidemias pelo mundo pois, dado o risco de um turista ser infectado pode-se intensificar os métodos de intervenção contra a expansão da doença, tanto no Brasil quanto no destino final dos turistas, concentrando a aplicação de recursos de maneira mais eficaz.

\subsection{Aedes aegypti}

O Aedes aegypti é de origem africana, possui cor café ou preta com listras brancas em todo o corpo e mede menos de um centímetro.

O mosquito costuma picar nas primeiras horas da manhã e nas últimas da tarde, evitando o sol forte, mas, mesmo nas horas quentes, ele pode atacar à sombra, dentro ou fora de casa.

\subsection{O ciclo do mosquito}

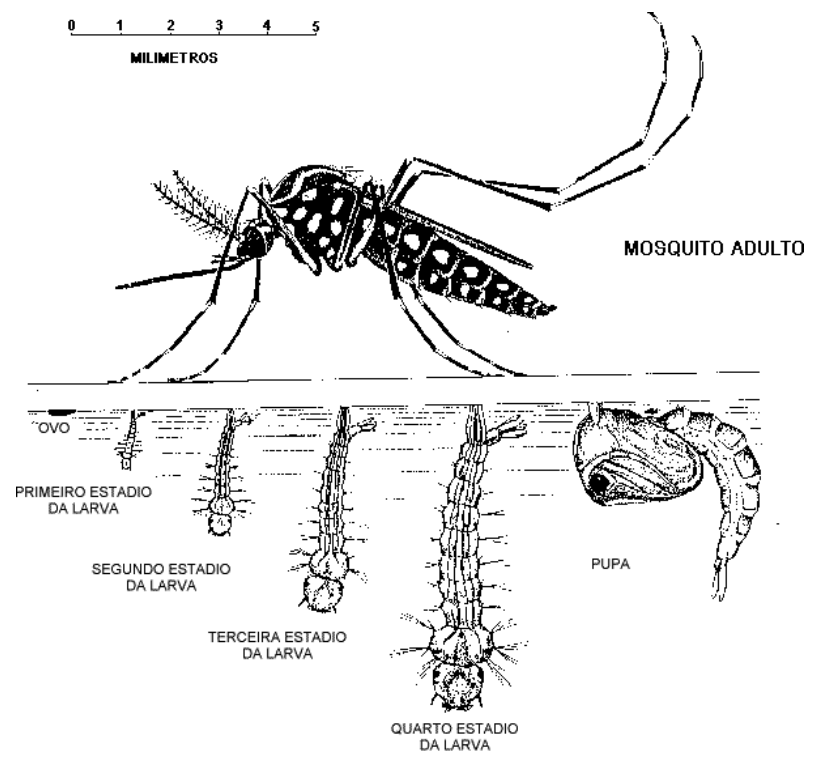

Figura 1 - Ciclo Aedes aegypti 
O ciclo do Aedes aegypti (figura 1), principal vetor de transmissão da dengue, é composto por quatro fases: ovo, larva, pupa e adulto.

O aumento do número de ovos se dá pela oviposição e a eclosão dos ovos aumenta o número de larvas. As larvas transformam-se em pupas e que desenvolvemse em mosquitos adultos. As larvas se desenvolvem em água parada. O seu controle é difícil, pois o mosquito é muito versátil na escolha dos criadouros para o depósito dos seus ovos, que são extremamente resistentes, podendo sobreviver por mais de um ano à condições avessas ao desenvolvimento até que a chegada de água propicie a incubação.

O desenvolvimento completo do embrião se dá, em condições favoráveis de temperatura e umidade, em 48 horas. As condições para o desenvolvimento são de alta temperatura e água parada, preferencialmente limpa.

As larvas, resultado do desenvolvimento dos ovos, alimentam-se de substâncias orgânicas, protozoários, fungos e bactérias presentes na água. Nas condições favoráveis de temperatura, que pode variar de $25^{\circ} \mathrm{C}$ a $29^{\circ} \mathrm{C}$, esta fase pode chegar a 10 dias, podendo prolongar-se em algumas semanas. Abaixo e acima dessas temperaturas o Aedes aegypti diminui sua atividade, e acima de $42^{\circ} \mathrm{C}$ e abaixo de $5^{\circ} \mathrm{C}$ ele morre (SANOFI, 2007).

A fase pupal dura aproximadamente dois dias e, nesta etapa, o futuro mosquito não se alimenta, apenas respira. É nesta etapa do desenvolvimento em que acontece a metamorfose do estágio larval para o mosquito adulto. Os mosquitos adultos, tanto o macho quanto a fêmea, alimentam-se de néctar e sulcos vegetais. Com a chegada a fase de acasalamento a fêmea passa a alimentar-se de sangue, necessário para a maturação dos ovos. Uma única inseminação é suficiente para fecundar todos os ovos que a fêmea venha a produzir durante sua vida. A busca por sangue ocorre geralmente durante o dia - nas primeiras horas da manhã e ao anoitecer. É na fase adulta e na fase do acasalamento dos mosquitos, em que as fêmeas precisam de sangue para garantir o desenvolvimento dos ovos, que a transmissão da doença para os humanos acontece (SANOFI, 2007).

Há quatro distintos, mas intimamente relacionados, vírus que causam a dengue. A recuperação da infecção de um dos vírus fornece imunidade vitalícia contra esse sorotipo, porém não oferece contra os outros tipos da doença (Brasil, 2013). A imunidade cruzada, ou heteróloga, permanece por apenas 2 e até 12 meses (Wichmann and Jelinek, 2004). Existem boas evidências de que a infecção sequencial aumenta o risco de doença mais grave, resultando em dengue hemorrágica (WHO, 2012). 


\subsubsection{Modo de transmissão}

A transmissão ocorre pelo ciclo ser humano - Aedes aegypti - ser humano.

Após a ingestão de sangue infectado pela fêmea do mosquito, na sua fase de acasalamento, transcorre na fêmea um período de incubação.

Após esse período, o mosquito torna-se apto a transmitir o vírus e assim permanece durante toda a vida.

Não há transmissão pelo contato de um doente ou suas secreções com uma pessoa sadia, nem fontes de água ou alimento.

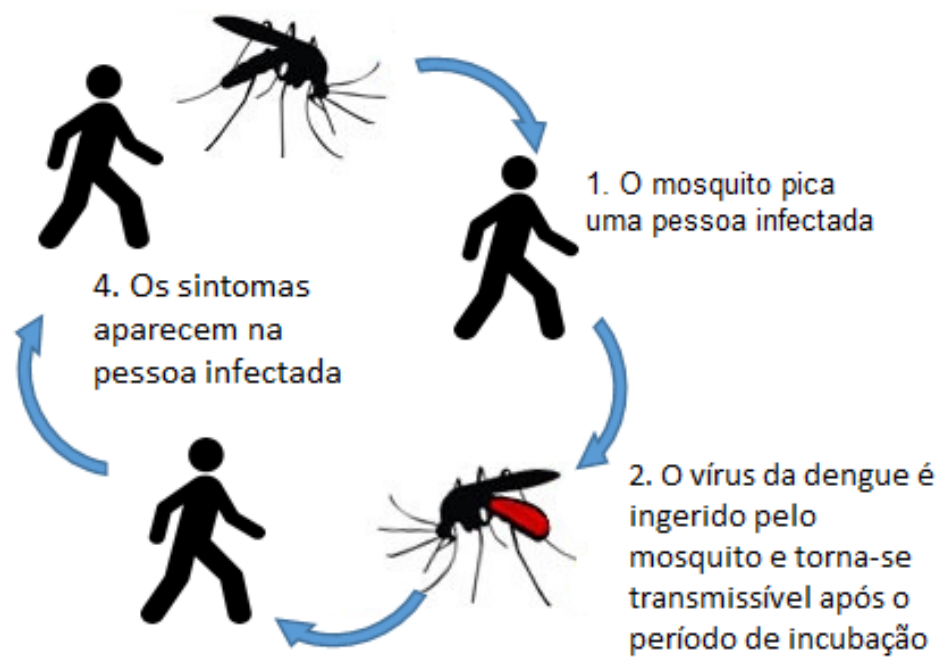

3. Um mosquito contendo o vírus infecta outra pessoa saudável

Figura 2 - Ciclo da infecção da dengue

O período de incubação extrínseco, isto é, aquele que acontece fora do ser humano, portanto no mosquito, varia de acordo com as condições climáticas. Pode-se encontrar diversos intervalos na literatura, variando de 5 a 33 dias (a 25 ${ }^{\circ} \mathrm{C}$ ) e de 2 a 15 dias $\left(\mathrm{a} 30^{\circ} \mathrm{C}\right.$ ), conforme (Chan and Johansson, 2012), e de 8 a 12 dias, segundo CDC (2010). No caso da incubação intrínseca os intervalos mais citados na literatura são os divulgados pela OMS e CDC: de 4 a 10 dias (WHO, 2015a) e de 4 a 7 dias (CDC, 2010).

Os ovos, depois de maturados, em contato com água limpa, eclodem em poucos minutos. Em um período de 5 a 7 dias a larva passa por três fases até dar origem a um novo mosquito, dependendo da temperatura e da umidade do ar (Massad and Forattini, 1998).

A dengue pode ser transmitida por duas espécies de mosquitos (Aedes aegypti e Aedes albopictus), sendo o primeiro, o principal vetor da dengue no Brasil. 
Os transmissores de dengue, principalmente o Aedes aegypti, proliferam-se dentro, ou nas proximidades, de habitações (casas, apartamentos, hotéis), em recipientes onde se acumula água (vasos de plantas, pneus velhos, cisternas etc.).

A infecção por dengue nos mosquitos não encurta sua vida média nem cria imunidade (Ferreira and Yang, 2003). Uma vez infectado o mosquito permanecerá infectado, e infectante, por toda sua vida (6 a 8 semanas).

A dengue é uma doença tropical, presente em toda a faixa tropical do planeta com algumas variações locais fortemente influenciada pela temperatura, pela chuva e pelo grau de urbanização. O número total de casos de dengue em todo o mundo é incerto.

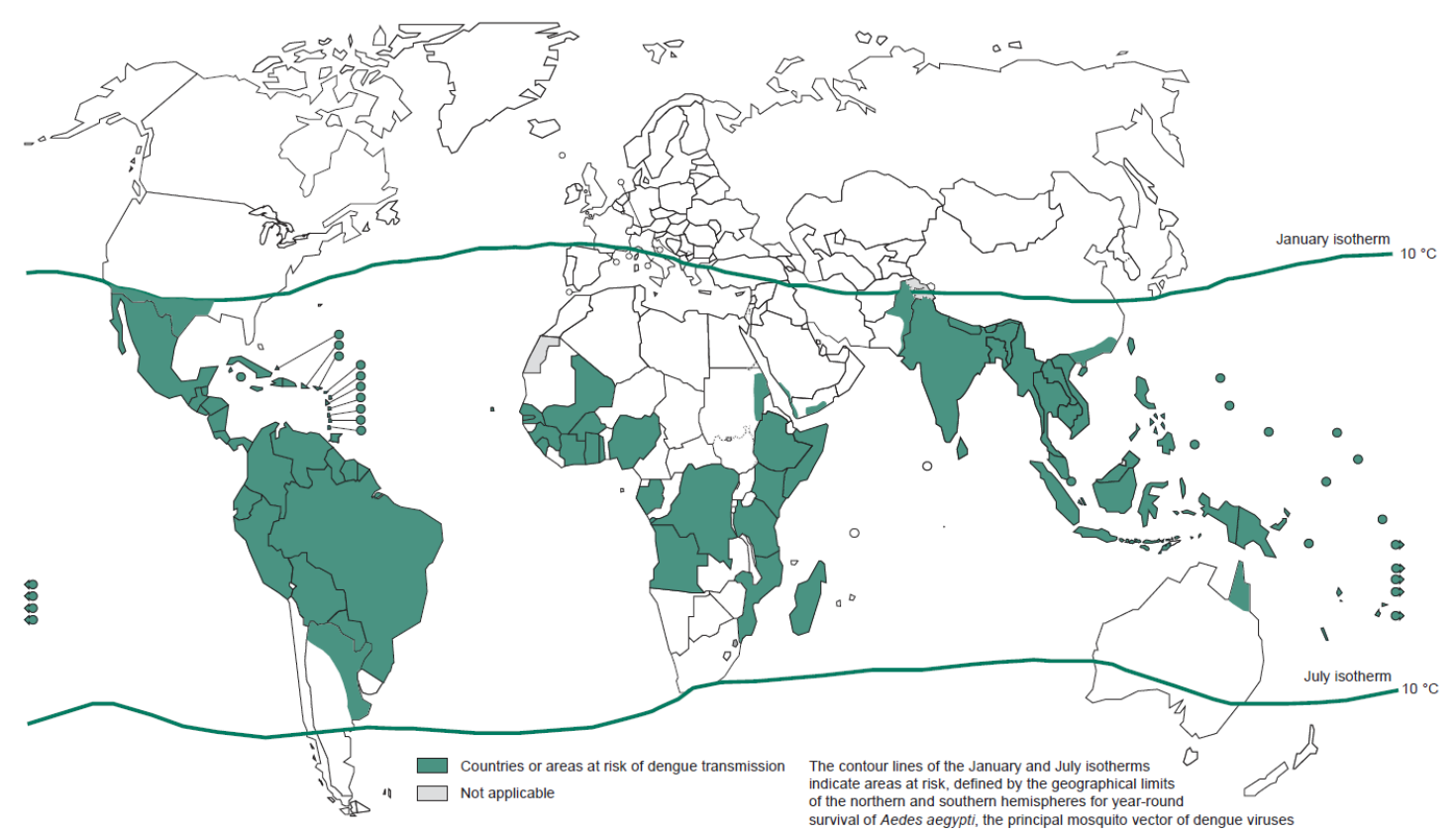

Figura 3 - Distribuição de países ou áreas de risco de transmissão da dengue, em todo o mundo, 2014

Fonte: Investing to overcome the global impact of neglected tropical diseases: third WHO report on neglected diseases 2015 (WHO, 2015d)

Segundo (WHO, 2015d) são diversos os motivos que dificultam a obtenção do número real de infecções por dengue, entre elas destacam-se:

- presença de outras doenças de sintomas similares (principalmente malária);

- falta de sensibilização dos prestadores de saúde;

- insuficientes diagnósticos clínicos e exames laboratoriais; 
- quantidade desconhecida de casos assintomáticos (que contribuem para a infecção de mosquitos suscetíveis).

Para a OMS, os principais vetores da dengue tem se espalhado silenciosamente pelo mundo com o auxílio do mercado de exportações e a circulação de mercadorias entre países através de materiais de reúso, como por exemplo, pneus usados e até mesmo em plantas contendo ovos de mosquitos secos em seu interior, e hoje já podem ser encontrados em mais de 150 países (McMichael, 2000; WHO, 2015d).

Os motivos para o agravamento da situação da dengue está intimamente ligado ao desenvolvimento urbano não planejado, condições sanitárias insatisfatórias, saneamento básico precário e armazenamento de água incorreto. Estas são condições que favorecem a proliferação do Aedes aegypti, que é o principal vetor da dengue e consequentemente essas condições favorecem o aumento no número de casos de dengue.

\subsubsection{O vírus da dengue}

O vírus da dengue é um vírus do gênero Flavirus na família Flaviviridae. O primeiro vírus isolado é o que conhecemos hoje como DEN-1. Ele foi isolado pela primeira vez em 1943, através de amostras de sangue de pacientes de uma epidemia de dengue em Nagasaki, no Japão, por Ren Kimura e Susumu Hotta.

A dengue é causada por 4 sorotipos de vírus estreitamente relacionados chamados de DEN-1, DEN-2, DEN-3 e DEN-4. Todos causam a mesma doença e os mesmos sintomas. Os sorotipos recebem diferentes nomes, pois cada sorotipo reage de forma distinta com os anticorpos dos humanos. Eles partilham $65 \%$ dos seus genomas (education, 2014b).

A dengue tem expandido fronteiras e atingido áreas que anteriormente não eram afetadas. Hoje os 4 sorotipos estão em praticamente todas as regiões afetadas pela dengue. Na década de 1970, apenas DEN-1 e DEN-2 foram encontrados na América Central e na África, enquanto que no Sudeste Asiático os 4 sorotipos já eram presentes. Em 2004 os quatro sorotipos já haviam se espalhado amplamente, circulando em conjunto em regiões tropicais e subtropicais em todo o mundo (education, 2014b).

Acredita-se que o vírus da dengue evoluiu na África ou no Sudeste da Ásia em primatas não humanos e então o crescimento populacional levou as habitações à região de selva, deixando os humanos suscetíveis aos mosquitos vetores e permitindo o salto do vírus entre as espécies entre 500 e 1.000 anos atrás (education, 2014b). Os 

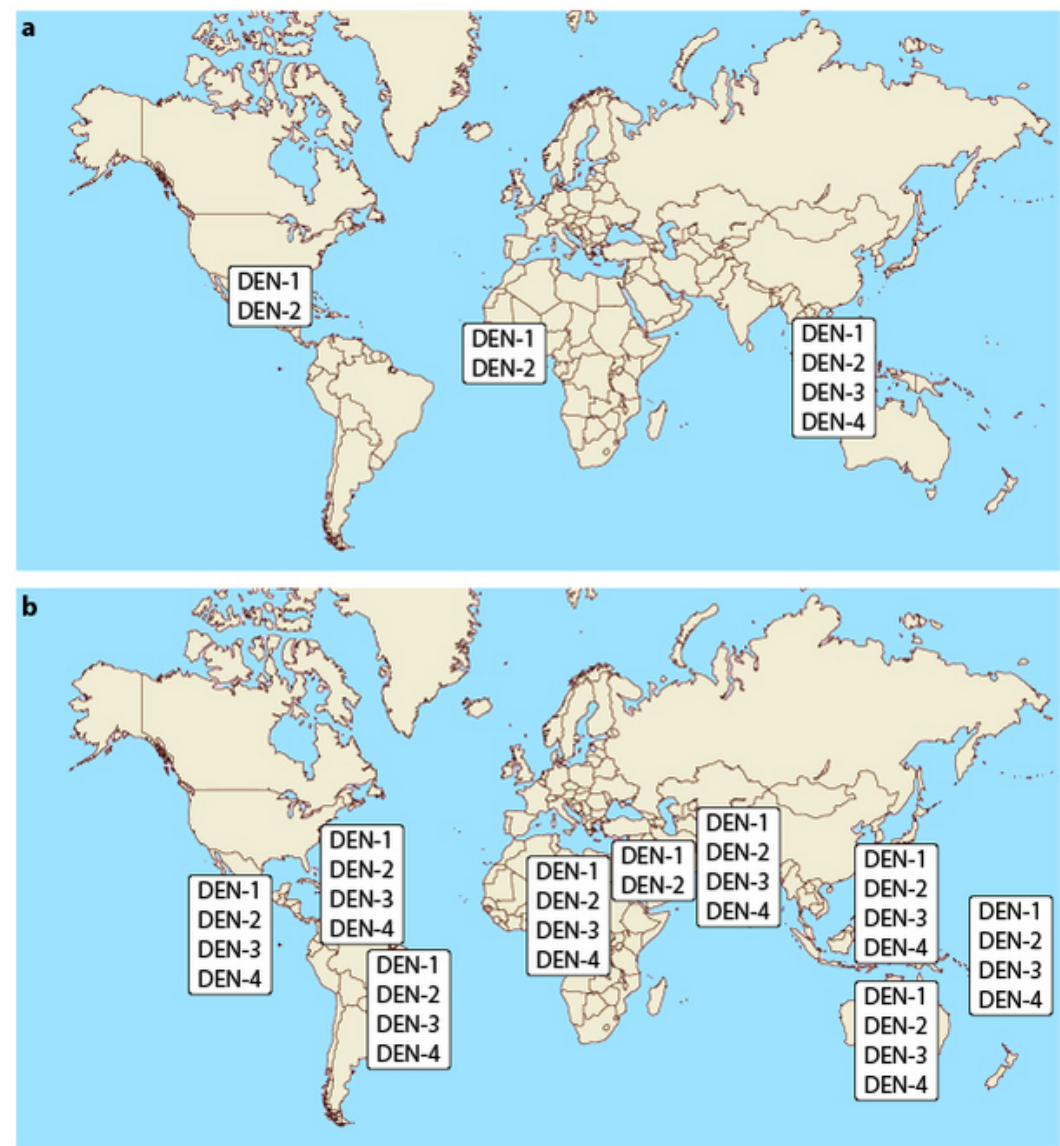

Figura 4 - Mudanças na distribuição dos sorotipos de dengue em 1970 (a) e 2004 (b). Fonte: 2014 Nature Education. (education, 2014b)

humanos são o principal reservatório do vírus da dengue. No entanto, os primatas não humanos da Ásia e África ainda podem ser infectados (Wilder-Smith and Schwartz, 2005).

Uma pessoa infectada por um sorotipo adquire imunidade permanente contra este sorotipo em particular e imunidade temporária contra os sorotipos restantes após a primeira infecção por dengue. Essa imunidade temporária pode variar de 2 a 12 meses e após esse período a pessoa volta a ser suscetível para os três sorotipos de dengue restantes. A segunda infecção por dengue pode causar um quadro mais grave, mas isto não acontece em todos os casos.

\subsubsection{Histórico}

A dengue humana é possivelmente tão antiga quanto a humanidade (Fried et al., 2010). Apesar da origem da dengue ser incerta, acredita-se que ela é originária das florestas asiáticas e que sua dinâmica envolvia mosquitos e primatas. Os primeiros relatos de casos com sintomas equivalentes à dengue são encontrados 
em uma enciclopédia chinesa da dinastia Jin (265 - 420) D.C., onde uma doença associada a insetos voadores é descrita como "veneno da água".

Os primeiros registros de surtos aconteceram muitos anos mais tarde, no Caribe, entre 1635 e 1699. Em 1771, um médico do hospital militar em San Juan, Porto Rico, chamado José Sabater, recomendou o tratamento da dengue com pequenas quantidades de rum. Naquela época a doença era conhecida como "febre quebra-ossos", pois além da febre alta, os sintomas eram de severa dor óssea e dores nas articulações, como se os ossos estivessem quebrados (education, 2014a).

Em 1779 foi a vez de surtos simultâneos na Batavia (Jacarta) e no Cairo (Henchal and Putnak, 1990; Siler et al., 1926), e depois, na Filadélfia (1780), ano em que o Dr. Benjamin Rush descreveu uma doença chamada de "febre remitente biliosa", em que os sintomas eram febre, dores articulares e musculares, dor de cabeça, erupção cutânea, fraqueza, náuseas, vômitos e sangramentos.

A origem do nome, apesar de ser incerta, é possivelmente derivada de dinga na frase do idioma swahili Ka-dinga pepo, que descreve a doença com cãibras súbitas como causa de um espírito maligno (CDC, 2006). Em 1801 a dengue já era conhecida por esse nome, quando a rainha da Espanha, Maria Luísa, em uma carta datada de 12 de junho de 1801 diz:

\footnotetext{
"Eu estou me sentindo melhor, porque foi um resfriado como de costume, que eles chamam de dengue, e desde ontem eu tenho tido sangramento, o que me deixa desconfortável, e após falar algum tempo a garganta dói." (Rigau-Pérez, 1998).
}

Em 1818 uma epidemia grave aconteceu no Peru, com 50.000 pessoas foram infectadas pela doença. Os surtos continuaram a aparecer em Zanzibar (1823 e 1870), Calcutá (1824, 1853, 1871, 1905), Índias Ocidentais (1827) e em Hong Kong (1901) (Henchal and Putnak, 1990) e o primeiro registro de pandemia de dengue aconteceu entre os anos 1827 e 1828 afetando as Ilhas Virgens, Jamaica, Cuba, Venezuela, Estados Unidos e México (education, 2014a).

Em 1906, a transmissão da dengue através do mosquito Aedes aegypti foi confirmada, e no ano seguinte, tornou-se a segunda doença na história a ter a etiologia confirmada, após a febre amarela, com a demonstração de que a dengue é causada por um vírus (Henchal and Putnak, 1990).

Foi durante a Segunda Guerra Mundial que a dengue se espalhou para regiões do planeta em que não havia registros da doença. O primeiro caso de dengue hemorrágica aconteceu em Manila, nas Filipinas, em 1953, e continuou a se espalhar pela Ásia pelos próximos 20 anos. Durante as décadas de 1960 e 1970 a quantidade de epidemias nas Américas (Central e do Sul) diminuiu devido a 
esforços para eliminar os focos de dengue, porém, os esforços reduziram e com isso a quantidade de infecções voltou a acontecer em toda esta região (education, 2014a).

O primeiro caso de dengue registrado no Brasil aconteceu no ano de 1685, em Recife (PE). O mosquito teria chegado vindo em navios negreiros. No ano de 1692, em Salvador (BA), 2.000 pessoas morreram devido à dengue, naquele que teria sido o primeiro surto registrado no Brasil. Em 1792 aconteceu outro surto, também em Salvador.

Em 1846, após a epidemia de dengue atingir São Paulo, Rio de Janeiro e Salvador, o mosquito Aedes aegypti tornou-se mais conhecido no país e sucessivas epidemias aconteceram em São Paulo $(1851,1852,1853,1916)$ e em Niterói (1923).

A dengue foi anunciada como erradicada no Brasil em 1957, resultado direto da luta contra a epidemia de febre amarela, dissipada pelo mesmo vetor da dengue. Anos antes, Oswaldo Cruz, em 1903, então diretor do Departamento Nacional de Saúde Pública, inciou um programa à moda militar para lutar contra doenças como a febre amarela, varíola e peste bubônica, que assolavam o Rio de Janeiro. A luta contra tais doenças envolvia desde a reforma de locais insalubres até demolições. A população era tratada com certa truculência e o ápice da resistência foi a chamada revolta da Vacina (1904), quando houve até uma tentativa de golpe (Grandelle, 2016).

\footnotetext{
"A prevenção obrigatória contra a varíola foi estopim de uma rebelião contra o trabalho de Oswaldo Cruz. Casas eram invadidas e demolidas por causa do Aedes, e as mulheres queixavam-se de ter que mostrar o braço para os vacinadores da varíola, um atentado à moral da época." (Grandelle, 2016)
}

Embora oficialmente erradicada em territórios brasileiros, casos de dengue continuaram a aparecer até 1982, ano em que houve uma epidemia em Roraima.

Em 1986, os Estados do Rio de Janeiro, Alagoas e Ceará apresentaram epidemias, seguidos por outros estados nos anos seguintes.

A primeira epidemia comprovada laboratorialmente no Brasil aconteceu em Boa Vista (RR) em 1981-1982, quando comprovou-se a presença dos sorotipos 1 e 4. Anos mais tarte uma nova epidemia aconteceu no Rio de Janeiro e em algumas capitais do Nordeste do país. Hoje o mosquito da dengue é encontrado em todos os estados brasileiros (Cruz).

Anos mais tarde, com a introdução do DENV-2 no Brasil, no Estado do Rio de Janeiro, foi confirmado o primeiro caso de dengue hemorrágica causada 
pelo DENV-2. Além do Estado do Rio de Janeiro, também houve casos graves em outras regiões do país.

Em Janeiro de 2001, o sorotipo 3 foi isolado em Nova Iguaçu (RJ) e, em 2010, foi a vez do sorotipo 4 ser isolado a partir de casos detectados em Roraima e no Amazonas. Em Janeiro e Março de 2011, no Pará e Rio de Janeiro, respectivamente, foram confirmados os primeiros casos de DENV-4 pelo Instituto Oswaldo Cruz (Cruz, 2013).

Desde então, todos os sorotipos da dengue circulam no Brasil, e constantemente acontecem epidemias pelo país, geralmente associadas com o surgimento de novos sorotipos em áreas até então livres deste novo sorotipo.

\footnotetext{
"No período entre 2002 a 2011, a dengue se consolidou como um dos maiores desafios de saúde pública no Brasil. Nele, a epidemiologia da doença apresentou alterações importantes, destacando-se o maior número de casos e hospitalizações, com epidemias de grande magnitude, o agravamento do processo de interiorização da transmissão, com registro de casos em municípios de diferentes portes populacionais e a ocorrência de casos graves acometendo pessoas em idades extremas (crianças e idosos)." (Brasil, 2014b)
}

Em 2006, o número de casos de dengue voltou a crescer no país. Segundo dados do Ministério da Saúde, entre os meses de Janeiro e Setembro de 2006 foram registrados 279.241 casos de dengue, o equivalente a 1 caso (não fatal) para cada $30 \mathrm{~km}^{2}$ do território brasileiro. Estes dados equivalem a um crescimento de 26,3\% em relação ao mesmo período quando comparado ao ano anterior, e o Sudeste foi a região de maior incidência (Brasil, 2015d).

\subsection{Dengue clássica}

A dengue clássica (DC) tem como característica o início abrupto de febre alta $\left(39^{\circ} \mathrm{C}\right.$ a $\left.40^{\circ} \mathrm{C}\right)$ seguida por cefaleia, mialgia, artralgia, prostração, astenia, dor retroorbital, náuseas, vômitos, exantema, prurido cutâneo. Hepatomegalia dolorosa pode ocorrer, ocasionalmente, desde o aparecimento da febre. Alguns aspectos clínicos dependem da idade do paciente. Desse modo, dor abdominal generalizada tem sido observada mais frequentemente entre crianças, enquanto as manifestações hemorrágicas, tais como petéquias, epistaxe, gengivorragia e metrorragia, têm sido observadas com maior frequência em adultos. A doença tem duração de 5 a 7 dias, mas o período de convalescença pode ser acompanhado de grande debilidade física, e prolongar-se por várias semanas (Brasil, 2010). 


\subsection{Febre hemorrágica da dengue}

A febra hemorrágica da dengue (FHD) inicia com os mesmos sintomas apresentados pelo DC, porém há um agravamento do quadro, geralmente entre o $3^{\circ}$ e o $4^{\circ}$ dia de doença, em geral ao final da etapa febril, com o aparecimento de manifestações hemorrágicas e colapso circulatório. Outras manifestações hemorrágicas incluem o aparecimento de petéquias, gengivorragia, equimoses, epistaxe, hemorragia em diversos órgãos (gastrintestinal, intracraniana, etc.) e hemorragia espontânea pelos locais de punção venosa. Nos casos graves de FHD, o choque geralmente ocorre entre o terceiro e sétimo dias da doença e geralmente é precedido por dor abdominal.

O choque tem curta duração e pode levar o paciente ao óbito em 12 a 24 horas ou à rápida recuperação, após terapia antichoque apropriada.

Caracteriza-se por pulso rápido e fraco, com diminuição da pressão de pulso e arterial, extremidades frias, pele pegajosa e agitação. Alguns pacientes podem ainda apresentar manifestações neurológicas, como convulsões e irritabilidade (Brasil, 2010).

\subsection{Outras doenças relacionadas ao mosquito Aedes aegypti}

Além de ser o principal vetor da dengue, objeto de estudo deste trabalho, o mosquito Aedes aegypti também é vetor de outras doenças infecciosas, conforme apresentado a seguir:

\subsubsection{Febre Amarela}

A febre amarela é uma doença infecciosa grave causada por um flavivirus para o qual existe vacina altamente eficaz.

A doença se manifesta repentinamente apresentando: Cansaço, febre alta, calafrios, dor de cabeça, dor muscular, náuseas e vômitos por cerca de três dias. A forma mais grave da doença é rara e costuma aparecer após um breve período de bem-estar (até dois dias), quando podem ocorrer insuficiências hepática e renal, icterícia (olhos e pele amarelados), manifestações hemorrágicas e cansaço intenso. A maioria dos infectados se recupera bem e adquire imunização permanente contra a febre amarela.

A forma mais comum da febre amarela é a silvestre, transmitida principalmente pelo mosquito Haemagogus. Casos de febre amarela urbana são raros. 


\subsubsection{Febre Chikungunya}

A Febre Chikungunya é uma doença menos letal, porém causa dores intensas que podem limitar os movimentos temporariamente e até mesmo manter-se perene.

O período de incubação é de 2 até 12 dias e os sintomas mais comuns à febre chikungunya são febre acima de $39^{\circ} \mathrm{C}$ de início repentino, dores intensas nas articulações dos pés e mãos, tornozelos e pulsos. Pode ocorrer, também, dor de cabeça, dores nos músculos e manchas vermelhas na pele. Cerca de $30 \%$ dos casos não chegam a desenvolver sintomas (Brasil, 2015b).

\subsubsection{Doença do vírus da Zika}

Segundo a OMS a Febre do Zika é uma doença viral aguda causada pelo vírus Zika (ZIKV). Os sintomas podem durar de dois a sete dias e aparecem entre três e doze dias após a picada do mosquito vetor, consistindo de febre leve, erupções cutâneas que podem espalhar-se por todo o corpo, conjuntivite, dores de cabeça e nas articulações do corpo (especialmente nos pés e mãos) além de dor muscular (WHO, 2015c).

A transmissão do vírus se dá por diversas formas (perinatal, sexual e por transfusão), mas a principal é por vetores do gênero Aedes. Existe a possibilidade de infectar-se simultaneamente por dengue e Zika vírus. Como as duas doenças possuem sintomas semelhantes, deve-se ter o devido cuidado no tratamento, pois este agravo apresenta elevado potencial de complicações e demanda medidas clínicas específicas, incluindo-se a classificação de risco, hidratação e monitoramento (Brasil, 2016f).

Recentemente descobriu-se a relação entre o vírus da Zika e microcefalia, uma malformação congênita, onde o cérebro não se desenvolve de maneira adequada e os bebês nascem com perímetro cefálico menor que o normal, ou que para de crescer normalmente após o nascimento (Cruz, 2015).

Não há tratamento específico nem vacina para o Zika vírus e assim como acontece com as outras doenças transmitidas pelo $A$. aegypti, o tratamento da febre zika é sintomático e baseado no uso de acetaminofeno (paracetamol) para febre e dor. Assim como na dengue, não é indicado o uso de ácido acetilsalicílico (aspirina) e medicamentos anti-inflamatórios devido ao alto risco de complicações hemorrágicas.

Embora a co-circulação das três doenças espalhadas pelo vetor $A$. aegypti (dengue, chikungunya e zika) não ser frequente, há evidências de co-infecção tripla, conforme Villamil-Gómez et al. (2016a,b). 



\section{Objetivos}

Este trabalho tem por objetivo a determinação do risco individual de infecção por dengue para turistas no Brasil durante a Copa do Mundo da FIFA 2014 e durante os Jogos Olímpicos de Verão Rio 2016 utilizando para isso modelagem matemática.

Dessa maneira, baseado no modelo clássico de infecções transmitidas por vetores de Ross-Macdonald (Macdonald, 1952) pretendeu-se:

- Reproduzir a dinâmica de distribuição da dengue nas cidades-sede dos dois maiores eventos esportivos da atualidade: Copa do Mundo da FIFA, com 12 cidades-sede, e Jogos Olímpicos do Rio;

- A partir dos dados reproduzidos e utilizando aproximação estocástica, pretendese introduzir o cálculo do risco para cada conjunto de dados e determinar o risco individual de infecção por dengue em turistas internacionais não imunes à dengue durante a Copa do Mundo da Fifa 2014;

- Determinar o total de casos de dengue em turistas internacionais não imunes à dengue durante a Copa do Mundo da FIFA 2014;

- Aplicar ao modelo de previsão proposto os dados de incidência de dengue de 2014 e comparar o resultado à previsão obtida por este trabalho;

- Utilizar diferentes proporções de casos sintomáticos/assintomáticos para a reprodução da dinâmica da dengue;

- Determinar o risco individual de infecção por dengue em turistas internacionais não imunes à dengue durante os Jogos Olímpicos de Verão no Rio de Janeiro;

- Determinar o total de casos de dengue em turistas internacionais não imunes à dengue durante os Jogos Olímpicos do Rio, em 2016. 



\section{Método}

"Modelagem matemática é uma tentativa de descrever uma parte do mundo real em termos matemáticos. É um esforço tão velho quanto a antiguidade, mas tão novo quanto o jornal de amanhã." (Meyer, 2012).

\subsection{O Modelo da dinâmica de dengue para população local}

O modelo apresentado a seguir, baseia-se no modelo clássico de infecções transmitidas por vetores de Ross-Macdonald (Macdonald, 1952) e descreve a dinâmica de transmissão da dengue.

Este modelo assume que a população de seres humanos e de mosquitos são subdivididos em 6 compartimentos: humanos suscetíveis $S_{H}$, humanos infectados $I_{H}$, humanos recuperados (e imunes) $R_{H}$, mosquitos suscetíveis $S_{M}$, mosquitos infectados e latentes $L_{M}$ e mosquitos infectados e infectantes $I_{M}$.

A dinâmica de um modelo ideal é descrito pelo conjunto de equações apresentado a seguir, onde não são consideradas as formas imaturas do mosquito, isto é, considera-se apenas mosquitos adultos:

$$
\text { Humanos }\left\{\begin{array}{l}
\frac{d S_{H}(t)}{d t}=-a b I_{M}(t) \frac{S_{H}(t)}{N_{H}(t)}-\mu_{H} S_{H}(t)+\mu_{H} N_{H}(t)+\alpha_{H} I_{H}(t) \\
\frac{d I_{H}(t)}{d t}=a b I_{M}(t) \frac{S_{H}(t)}{N_{H}(t)}-\left(\mu_{H}+\gamma_{H}+\alpha_{H}\right) I_{H}(t) \\
\frac{d R_{H}(t)}{d t}=\gamma_{H} I_{H}(t)-\mu_{H} R_{H}(t)
\end{array}\right.
$$




$$
\text { Mosquitos }\left\{\begin{array}{c}
\frac{d S_{M}(t)}{d t}=-a c S_{M}(t) \frac{I_{H}(t)}{N_{H}(t)}+\mu_{M}\left(N_{M}(t)-S_{M}(t)\right) \\
\frac{d L_{M}(t)}{d t}=a c S_{M}(t) \frac{I_{H}(t)}{N_{H}(t)}-\mu_{M} L_{M}(t)-\gamma_{M} L_{M}(t) \\
\frac{d I_{M}(t)}{d t}=\gamma_{M} L_{M}(t)-\mu_{M} I_{M}(t) \\
N_{H}(t)=S_{H}(t)+I_{H}(t)+R_{H}(t)
\end{array}\right.
$$

A tabela 1 apresenta a descrição biológica de cada parâmetro do modelo matemático descrito.

\begin{tabular}{cc}
\hline Parâmetro & Significado biológico \\
\hline a & Taxa diária de picadas dos mosquitos \\
b & $\left(n^{\circ}\right.$ médio de picadas que cada mosquito inflige aos humanos $)$ \\
$\mathrm{c}$ & Probabilidade de transmissão dos mosquitos para os humanos \\
$\mu_{H}$ & Probabilidade de picadas que são devidas aos mosquitos infectados \\
$\gamma_{H}$ & Taxa diária de mortalidade geral dos humanos \\
$\mu_{M}$ & Taxa diária de recuperação por infecção da dengue \\
$1 / \gamma_{M}$ & Taxa diária de mortalidade dos mosquitos \\
$\alpha$ & Período de latência média, em dias, nos mosquitos \\
& Taxa de mortalidade diária de seres humanos induzida pela dengue \\
\hline
\end{tabular}

Tabela 1 - Parâmetros do modelo matemático

As quantidades $S_{H}, I_{H}, R_{H}, S_{M}, L_{M}$ e $I_{M}$, são densidades (Amaku et al., 2015) e a interpretação das equações dos compartimentos dos humanos do modelo é a apresentada a seguir: $-a b I_{M}(t) S_{H}(t)$ é o número de infecções diárias da população de humanos suscetíveis que é picada por mosquitos infectados. Esta variável é subtraída do compartimento de humanos suscetíveis e adicionada ao compartimento de humanos infectados. $a b \frac{I_{M}(t)}{N_{H}(t)}$ é a força de infecção da doença, $-\mu_{H} S_{H}$ é a população de humanos suscetíveis que morrem por outras causas, $\mu_{H} N_{H}$ é o número total de novos nascimentos, que é igual à soma do número total de mortes (dessa forma a população é mantida constante no sistema), $\mu_{H} I_{H}(t)$ é o de mortes de infectados, porém, não devido à dengue, $\gamma_{H} I_{H}(t)$ é o número de humanos infectados que se recuperam da dengue, portanto esta variável é subtraída do compartimento de humanos infectados e adicionada ao compartimento de recuperados, $\alpha_{H} I_{H}(t)$ é o número de humanos que morrem devido à dengue, e 


\begin{tabular}{cc}
\hline Variável & Significado biológico \\
\hline $\mathrm{S}_{H}$ & População de humanos suscetíveis \\
$\mathrm{I}_{H}$ & População de humanos infectados \\
$\mathrm{R}_{H}$ & População de humanos recuperados \\
\hline
\end{tabular}

Tabela 2 - Variáveis: Humanos

$\mu_{H} R_{H}(t)$ são os humanos que morrem, por outras razões, depois de recuperar-se da dengue.

Já a dinâmica na população de mosquitos, também com três equações, possui uma diferença importante. Os mosquitos permanecem infectados por todo o tempo após a sua infecção, assim, o compartimento de recuperados não existe aqui. O modelo é composto por compartimento de mosquitos suscetíveis, mosquitos latentes e mosquitos infectados.

A interpretação é similar à apresentada na dinâmica dos seres humanos, de forma que, $a c S_{M}(t) I_{H}(t)$ é o número de infecções diárias da população de mosquitos suscetíveis que pica humanos infectados, ou seja, mosquitos suscetíveis que transformam-se em infectados e portanto, subtraídos do compartimento de suscetíveis e somados ao compartimento de mosquitos infectados, $\mu_{M}\left(N_{M}(t)-\right.$ $\left.S_{M}(t)\right)$ é o total de novos mosquitos nascidos e o número de mosquitos suscetíveis que morrem sem portar o vírus da dengue, $\mu_{M} L_{M}(t)$ é o número de mosquitos latentes que morrem por dia e $\gamma_{M} L_{M}(t)$ são os mosquitos que deixam de ser latentes e se tornam infectantes, portanto, subtraídos do número de mosquitos latentes e adicionados ao compartimento de mosquitos infectados. Por fim, $\mu_{M} I_{M}(t)$ é o número de mosquitos infectantes que morrem.

\begin{tabular}{cc}
\hline Variável & Significado biológico \\
\hline $\mathrm{S}_{M}$ & População de mosquitos suscetíveis \\
$\mathrm{L}_{M}$ & População de mosquitos latentes \\
$\mathrm{I}_{M}$ & População de mosquitos infectados \\
\hline
\end{tabular}

Tabela 3 - Variáveis: Mosquitos

\subsection{Aproximação estocástica SI para o risco de dengue para os turistas}

Um processo estocástico (ou randômico) é um modelo de probabilidade usado para descrever fenômenos que evoluem ao longo do tempo ou espaço (ALdujaili, 2013; Lindsey, 2004) 
Suponhamos uma população humana fechada de tamanho N, e na ausência de riscos competitivos, o risco de infecção pode ser estocasticamente calculado por um modelo de dois estados, sem recuperação. Um modelo SI é aquele em que $S$ indivíduos são suscetíveis à infecção e $I$ são indivíduos que foram infectados e permanecem infectados por toda a vida.

Esta é uma aproximação à realidade da dengue e se justifica pelo fato de que os visitantes apresentam-se em número relativamente baixo em relação ao total da população local. Além disso, os turistas passam um período relativamente curto de tempo no local visitado.

Assumimos, por conseguinte, que os visitantes estão sujeitos à mesma força local de infecção, mas não contribuem para essa incidência. A consequência deste pressuposto é que podemos usar um modelo linear, o que simplifica o cálculo do risco de infecção.

Vamos começar por calcular a probabilidade de que $x$ indivíduos estejam no estado $S$ e $y$ indivíduos estejam no estado $I$ no tempo t $+\Delta$ t:

$$
P_{x, y}(t+\Delta t)=P_{x, y}(t)(1-\lambda x \Delta t)+P_{x+1, y-1} \lambda(x+1) \Delta t+o(\Delta t)
$$

Se $x+y=N$ e $0 \leq \mathrm{x} \leq \mathrm{N}-1$, temos:

$$
P_{x, y}(t+\Delta t)=P_{x, y}(t)(1-\lambda x \Delta t)+o(\Delta t)
$$

Se $x=N, y=0$ (ausência da doença)

$$
P_{x, y}(t+\Delta t)=0
$$

Consequentemente,

$$
\frac{d P_{x y}}{d t}=-\lambda x P_{x, y}(t)+\lambda(x+1) P_{x+1, y-1}
$$

se, $x+y=N, 0 \leq x \leq N-1$, e

$$
\frac{d P_{x y}}{d t}=-\lambda x P_{x, y}(t)
$$

se $\mathrm{x}=\mathrm{N}, \mathrm{y}=0$.

Para deixar o argumento mais fácil de compreender, seja $Q_{x}=P_{x, N-x} \mathrm{com}$ $0 \leq \mathrm{x} \leq \mathrm{N}$. Então:

$$
\frac{d Q_{x}}{d t}=-\lambda x Q_{x}+\lambda(x+1) Q_{x+1}
$$


se $0 \leq \mathrm{x} \leq \mathrm{N}-1$ e,

$$
\frac{d Q_{x}}{d t}=-\lambda x Q_{x}
$$

se $\mathrm{x}=\mathrm{N}$.

Na equação 3.4 o primeiro termo refere-se à probabilidade de que havia $x$ e $y$ indivíduos, no tempo $t$, nas condições $S$ e $I$, respectivamente, e que nenhum dos indivíduos suscetíveis x adquiriram a infecção no período. O segundo termo refere-se à probabilidade de que existam $(\mathrm{x}+1)$ e $(\mathrm{y}-1)$ indivíduos, no momento t, nas condições $S$ e $I$, respectivamente, e que um indivíduo suscetível adquira a infecção no período.

A expressão geral para a Função Geradora de Probabilidade (PGF), G (u, t) (Abate and Whitt, 1992), é dada por:

$$
\bar{G}(u, t)=\sum_{x=0}^{N} Q_{x}(t) u^{x}
$$

Notemos que

$$
\bar{G}(u, 0)=\sum_{x=0}^{N} Q_{x}(0) u^{x}=u^{N}
$$

Além disso,

$$
\begin{gathered}
\frac{d \bar{G}}{d t}=\sum_{x=0}^{N} \frac{d Q_{x}(t)}{d t} u^{x} \\
\frac{d \bar{G}}{d t}=-\lambda \sum_{x=0}^{N} x Q_{x} u^{x}+\lambda \sum_{x=0}^{N-1}(x+1) Q_{x+1} u^{x} \\
\frac{d \bar{G}}{d t}=-\lambda u \sum_{x=0}^{N} Q_{x} x u^{x-1}+\lambda \sum_{x=1}^{N} Q_{x} u^{x-1}
\end{gathered}
$$

(trocando o índice na segunda soma)

$$
\frac{d \bar{G}}{d t}=-\lambda u \frac{\partial}{\partial u}\left(\sum_{x=0}^{N} Q_{x} u^{x}\right)+\lambda \sum_{x=0}^{N} x Q_{x} u^{x-1}
$$

E agora, adicionando zero na segunda soma,

$$
\begin{gathered}
\frac{d \bar{G}}{d t}=-\lambda u \frac{\partial \bar{G}}{\partial u}+\lambda \frac{\partial}{\partial u}\left(\sum_{x=0}^{N} Q_{x} u^{x}\right) \\
\frac{d \bar{G}}{d t}=-\lambda u \frac{\partial \bar{G}}{\partial u}+\lambda \frac{\partial \bar{G}}{\partial u} \\
\frac{d \bar{G}}{d t}=\lambda(1-u) \frac{\partial \bar{G}}{\partial u}
\end{gathered}
$$

Com $\bar{G}(u, 0)=u^{N}$ : Têm-se uma equação diferencial auxiliar de Lagrange (da Silva, 1963)

$$
\frac{d t}{1}=\frac{-d u}{\lambda(1-u)}=\frac{d \bar{G}}{0}
$$


Temos duas soluções independentes:

A primeira é $\bar{G}=\kappa_{1}$ e a segunda é dada por:

$$
\begin{gathered}
\frac{d u}{d t}=-\lambda(1-u) \\
\int \frac{1}{u-1} d u=\int \lambda d t \\
\log _{e}(u-1)=\lambda t+C \\
u-1=\kappa_{2} e^{\lambda t} \\
\kappa_{2}=(u-1) e^{-\lambda t}
\end{gathered}
$$

Portanto, a solução geral é dada por

$$
\bar{G}(u, t)=f\left((u-1) e^{-\lambda t}\right)
$$

onde a função f pode ser encontrada a partir de

$$
\bar{G}(u, 0)=u^{N}=f(u-1)
$$

Assim, façamos $w=u-1$ e $u=w+1$, então $f(w)=(w+1)^{N}$. Consequentemente,

$$
\begin{aligned}
& \bar{G}(u, t)=\left(1+(u-1) e^{-\lambda t}\right)^{N} \\
& \bar{G}(u, t)=\left(1-e^{-\lambda t}+u e^{-\lambda t}\right)^{N}
\end{aligned}
$$

Esta é a PGF de uma distribuição binomial com parâmetros $\mathrm{N}$ e $p=e^{-\lambda t}$. Portanto, o número de suscetíveis segue uma distribuição binomial com parâmetros $\mathrm{N}$ e $p=e^{-\lambda t}$, e o número de indivíduos infectados segue uma distribuição binomial com parâmetros N e $p=p_{1}=1-e^{-\lambda t}$ (Greenhalgh, 2016). Daí, a média e a variância são obtidas, respectivamente, por:

$$
N_{p_{1}}=N\left(1-e^{-\lambda t}\right)
$$

e

$$
N_{p_{1}}\left(1-p_{1}\right)=N\left(e^{-\lambda t}\right)\left(1-e^{-\lambda t}\right)
$$

\subsubsection{Uma outra abordagem}

Uma alternativa para mostrar o mesmo resultado é apresentada a seguir:

Suponha que existam $N$ indivíduos suscetíveis no tempo $t=0$ sujeitos a uma força de infecção constante $\lambda$ dos quais $\mathrm{x}$ indivíduos permanecem suscetíveis no tempo t. 
A PGF é dada por:

$$
\begin{gathered}
\pi(u, t)=\left[1+(u-1) e^{-\lambda t}\right]^{N} \\
\pi(u, t)=\left[\left(1-e^{-\lambda t}\right)+u e^{-\lambda t}\right]^{N}
\end{gathered}
$$

conforme 3.6.

É possível ver claramente que o número de indivíduos infectados no momento $\mathrm{t}$ segue uma distribuição binomial com parâmetros $\mathrm{N}$ e $p=1-e^{-\lambda t}$ assim como cada indivíduo suscetível sofre independentemente uma força de infecção $\lambda$ (Greenhalgh, 2016).

A probabilidade de eles não serem infectados em $[0, \mathrm{t})$ é $e^{-\lambda t}$, então a probabilidade de que esses indivíduos sejam infectados em $[0, \mathrm{t})$ é $1-e^{-\lambda t}$. Portanto, o número de infectados em $[0, \mathrm{t})$ é dado pelos parâmetros $\mathrm{N}$ e $1-e^{-\lambda t}$. Dessa forma,

$$
\begin{gathered}
G(u, v, t)=\sum_{y=0}^{N} u^{N-y} v^{y} p(x=y) \\
G(u, v, t)=\sum_{y=0}^{N} u^{N-y} v^{y}\left(\begin{array}{c}
N \\
y
\end{array}\right) p^{y}(1-p)^{N-y} \\
G(u, v, t)=\sum_{y=0}^{N}\left(\begin{array}{c}
N \\
y
\end{array}\right)(p v)^{y}((1-p) u)^{N-y}
\end{gathered}
$$

Quando $p=1-e^{-\lambda t}$, têm-se:

$$
\begin{gathered}
G(u, v, t)=[(1-p) u+p v]^{N} \\
G(u, v, t)=\left[u e^{-\lambda t}+\left(1-e^{-\lambda t}\right) v\right]^{N} \\
G(u, v, t)=\left[(u-v) e^{-\lambda t}+v\right]^{N}
\end{gathered}
$$

conforme 3.6.

Agora, dada a validade da PGF, o número médio de indivíduos $y$, no tempo t, calculado tomando a primeira derivada parcial da PGF com respeito a $v$ para $\mathrm{u}, \mathrm{v}=1$ :

$$
\left.\frac{\partial G(u, v, t)}{\partial z}\right|_{u, v=1}=N\left[1-e^{-\lambda t}\right]
$$

Assim, conforme 3.7, a média do risco de infecção per capita, $\pi$ é dada por:

$$
\pi=\left[1-e^{-\lambda t}\right]
$$


A variância da distribuição de probabilidade para o número de indivíduos infectados, no tempo t, é dado por (Johnson et al., 2005):

$$
\sigma^{2}=\left.\frac{\partial^{2} G(u, v, t)}{\partial v^{2}}\right|_{u, v=1}+\left.\frac{\partial G(u, v, t)}{\partial v}\right|_{u, v=1}-\left[\left.\frac{\partial G(u, v, t)}{\partial v}\right|_{u, v=1}\right]^{2}
$$

que resulta em:

$$
\sigma^{2}=N e^{-\lambda t}\left[1-e^{-\lambda t}\right]
$$

conforme 3.8 .

\subsection{Determinando o risco}

Em um modelo, como o aqui descrito, em que excluem-se quaisquer riscos competitivos (isto é, não há recuperação do visitante infectado, não há morte antes de o visitante voltar para casa, e o visitante não volta para casa antes de se recuperar da infecção), a PGF (3.6) é a PGF de uma distribuição binomial (suscetíveis adquirem ou não a infecção) com $\mathrm{N}$ ensaios e probabilidade de sucesso $\pi$ dado por (3.13) e variância dada por (3.15).

A força de infecção da dengue, no entanto, não é constante no tempo e mostra uma oscilação com um pico no fim do verão, diminuindo depois disso. Portanto, para determinar o risco de dengue para os visitantes no período da Copa do Mundo da FIFA e durante os Jogos Olímpicos é necessário levar isso em conta, e a equação (3.13) agora se torna a equação (3.16), apresentada a seguir.

$$
\pi=\left[1-e^{-\int_{\omega}^{\omega+\Omega} \lambda(t) d t}\right]
$$

Notemos que na equação (3.16) assume-se que os turistas devem chegar no tempo $\omega$ e permanecer na cidade até o tempo $(\omega+\Omega)$.

A dinâmica da dengue é dada pelas equações (3.1 e 3.2), que é um modelo hospedeiro-vetor, em que a dinâmica epidemiológica da população humana é do tipo SIR (Suscetível - Infectado - Removido). No entanto, a escala de tempo em que ocorrem mudanças epidemiológicas é tipicamente muito longa quando comparado com o curto ciclo de vida do mosquito.

A probabilidade de que pelo menos 1 visitante desenvolva a doença é, portanto, dada pela equação (3.16). Dessa maneira o número de casos de dengue entre os turistas é novamente binomial com parâmetros $N$ e $p=\pi(\omega, \Omega)$.

Então, para finalmente determinar o risco a que os visitantes estarão submetidos, deve-se determinar a força de infecção $\lambda(t)$ da dengue. Portanto, 
reescrevendo as duas primeiras equações do sistema (3.1), obtemos:

$$
\left\{\begin{array}{l}
\frac{d S_{H}(t)}{d t}=-\lambda(t) S_{H}(t)-\mu_{H} S_{H}(t)+\alpha_{H} I_{H}(t) \\
\frac{d I_{H}(t)}{d t}=\lambda(t) S_{H}(t)-\left(\mu_{H}+\gamma_{H}+\alpha_{H}\right) I_{H}(t)
\end{array}\right.
$$

Neste sistema, a força de infecção $\lambda(t)=-a b \frac{I_{M}(t)}{N_{H}(t)}$ representa a taxa com que um único indivíduo suscetível no tempo $t$ se infecta e $\lambda(t) S_{H}(t)$ é portanto, a incidência per capita de novos casos de dengue por unidade de tempo. 



\section{Copa do Mundo da FIFA 2014}

\subsection{A competição}

A Copa do Mundo FIFA de 2014 foi uma competição composta por 32 seleções organizadas em 8 grupos (de A até H), com 4 equipes em cada grupo, e que seguem um calendário eliminatório dividido em 5 etapas:

- Primeira fase

- Oitavas de final

- Quartas de final

- Semifinais

- Finais

Em cada etapa metade das seleções foi eliminada até a etapa semifinal. Já a etapa final aconteceu com 4 equipes, onde duas disputaram o título e duas disputaram pela terceira colocação. Portanto, a primeira etapa continha 32 equipes e 48 partidas (6 partidas por grupo), a segunda fase continha 16 equipes e 8 partidas, e a terceira fase foi composta por 8 equipes e 4 partidas. As quarta e quinta etapas possuíam apenas 4 equipes que disputaram dois jogos. Duas equipes jogaram pela decisão da terceira posição na competição enquanto as outras duas fizeram a grande final pela disputa do título.

As equipes participantes desta edição contou com a participação das seguintes seleções nacionais: Alemanha, Argentina, Argélia, Austrália, Bélgica, BósniaHerzegovina, Brasil, Camarões, Colômbia, Coreia do Sul, Costa do Marfim, Costa Rica, Chile, Croácia, Espanha, Estados Unidos, Equador, França, Gana, Grécia, Holanda, Honduras, Inglaterra, Irã, Itália, Japão, México, Nigéria, Portugal, Rússia, Suíça e Uruguai.

Segundo o Ministério do Turismo do Brasil (Brasil, 2014a), esperava-se que até 600.000 turistas estrangeiros visitariam o Brasil para acompanhar os jogos da Copa do Mundo, realizada entre os dias 12 de Junho e 13 de Julho de 2014, em 12 cidades-sede: Belo Horizonte, Brasília, Cuiabá, Curitiba, Fortaleza, Manaus, Natal, Porto Alegre, Recife, Rio de Janeiro, Salvador e São Paulo. 
Conforme vimos no capítulo 3, equação 3.16, a determinação do risco é dependente da força de infecção e do tempo de exposição à ela. Assim, para a obtenção do risco de infecção sintomática da doença, além de determinar a força de infecção para cada cidade, foi preciso definir o tempo e o local em que os turistas permaneceriam durante os jogos. Para isso, elaborou-se o cronograma apresentado na seção 4.2 a seguir.

\subsection{Cronograma dos jogos}

Definiu-se que os turistas seguiriam suas equipes prediletas durante a Copa do Mundo e, caso essa equipe fosse eliminada da competição o turista também seria retirado do sistema, ou seja, ele volta para casa junto com sua equipe.

Devido à grande distância entre algumas cidades-sede dos jogos do Mundial (Porto Alegre e Manaus, por exemplo, distam entre si mais de 3 mil quilômetros em linha reta) e a combinação dos horários das partidas, com mais de um jogo por dia e alguns no mesmo horário, foi preciso definir ao viajante um roteiro de viagens e partidas, pois os fatos apresentados acima impediam que o turista frequentasse todos os jogos da competição. Assim, os cronogramas foram baseados em 32 possibilidades de agenda, de acordo com a tabela de jogos da Copa do Mundo da FIFA (FIFA, 2014).

O tempo de estadia do viajante em cada cidade é um fator importante na determinação do risco individual de infecção. Dessa maneira, assumiu-se que o comportamento dos turistas seria regido por função subjetiva da atratividade turística de cada cidade, ou seja, o turista sempre optaria por ficar mais tempo em cidades que aqui definimos serem mais turísticas, ou de maior apelo turístico, antes de seguir para a próxima cidade com sua equipe.

É importante ressaltar que a determinação de qual cidade é mais atrativa para os turistas não é uma tarefa fácil diante dos incontáveis cenários e da vasta atratividade encontrada em cada uma das 12 cidades-sede. Ainda assim, era preciso definir um roteiro e uma metodologia para a escolha do tempo de estadia em cada sede, e assim fez-se.

Para exemplificar o método suponha que o jogo 3 seria realizado em Fortaleza e o jogo seguinte em Brasília. Supomos aqui que o visitante estenderia ao máximo sua estadia em Fortaleza e partiria para Brasília apenas com um dia de antecedência para a próxima partida e após a partida permaneceria na cidade no mínimo mais um dia. Repetimos este raciocínio para todas as sequências de jogos. 
O resultado deste roteiro é apresentado na figura 5, onde a primeira coluna contém as 32 equipes, distribuídas em seus respectivos grupos. Por exemplo o grupo A, que contém 4 equipes: A1, A2, A3 e A4. As demais colunas referem-se aos dias de jogos e às cidades em que a partida ocorre.

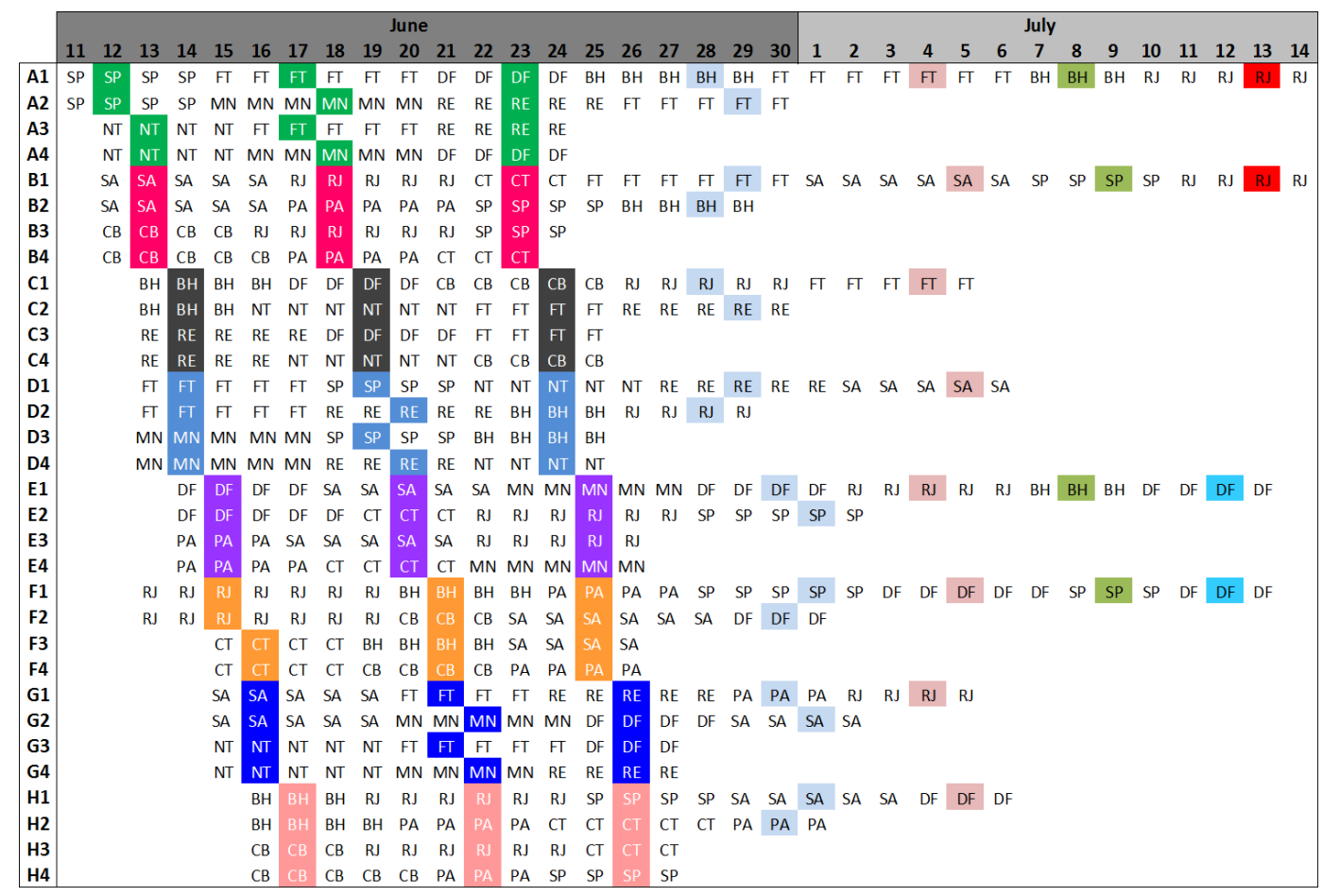

Figura 5 - Cronograma dos jogos

A cada nova fase, metade das equipes abandona a competição. As diferentes cores na figura 5 foram utilizadas apenas para facilitar a visualização de cada grupo e cada fase da competição.

Para exemplificar, considere o roteiro B3, presente no cronograma dos jogos (figura 5). O roteiro considera que o turista internacional desembarcaria em Cuiabá no dia 12 de Junho, assistiria à partida no dia 13 e permaneceria na cidade até o dia 15, partindo no dia 16 para o Rio de Janeiro. Ali, o turista assistiria à segunda partida da competição no dia 18 e permaneceria na cidade até o dia 21. No dia 22, o turista seguiria para São Paulo para acompanhar o terceiro jogo da competição no dia 23 permanecendo na cidade apenas mais um dia devido à eliminação de sua equipe predileta. Assim, no dia 25 de junho este turista já retornou à sua origem. No total este turista permaneceu 13 dias no Brasil e visitou 3 cidades Cuiabá onde esteve por 4 dias, Rio de Janeiro - 6 dias e São Paulo - 3 dias. 


\subsection{Determinação da força de infecção}

Conforme a equação 3.16, é preciso ter os valores da força de infecção para calcularmos o valor do risco de infecção. Assim, a partir do número de casos de dengue notificados por semana epidemiológica, obtidos com o Ministério da Saúde do Brasil, foram obtidas as forças de infecção para cada localidade e período definido.

Utilizou-se os dados das semanas epidemiológicas 23 até 28, entre os anos 2010 e 2013.

Ou seja, neste estudo o comportamento da dengue no início do ano foi ignorado e apenas o número de casos notificados de dengue durante as semanas epidemiológicas que contém o período correspondente ao evento foram utilizadas para determinar a força de infecção.

Assim, das 52 semanas epidemiológicas de cada ano (alguns anos possuem 53 semanas epidemiológicas), utilizou-se as notificações das semanas 23 a 28 (10 de junho até 15 de julho). Este período corresponde à época de baixa transmissão de dengue em todas as 12 cidades-sede dos jogos.

Definiu-se que o intervalo de dados a ser analisado seria aquele que apresentasse um comportamento compatível ao comportamento observado até a $14^{a}$ semana epidemiológica de 2014, ano da realização da Copa do Mundo. Assim, as evidências apontaram para os sorotipos DENV-1 e DENV-4 circulando no Brasil.

A suposição de que apenas estes dois sorotipos teriam influência no total de casos de dengue no país em 2014 foi confirmado após a achegada da semana 52 (figura 6).

Optou-se por iniciar a série de dados no ano de 2010, já que em 2009, apesar da forte presença do sorotipo DENV-1 a quantidade de casos de DENV-4 foi muito pequeno e além disso, neste ano, cerca de $40 \%$ dos casos notificados foram DENV-2 e DENV-3. O sorotipo DENV-4 apresentou apenas cerca de 1\% do total de casos daquele ano, enquanto DENV-1 resultou em $61 \%$ dos casos.

Embora em 2010 o porcentual de DENV-4 em relação aos outros sorotipos não tenha variado muito (passou de 1\% em 2009 para 3\% em 2010), o aumento do número de casos de DENV-4 foi de quase $30 \%$ de um ano para outro.

Por fim, a forte queda no porcentual do sorotipo 3, que passou a ter $2 \%$ do total de casos, seguida pelo aumento da presença do sorotipo 4 nos anos subsequentes sugere a existência de concorrência entre estes sorotipos. Portanto, como no início de 2014 não observou-se nenhum caso de DENV-3, definiu-se que 
a série de dados que melhor representaria o ano de 2014 deveria ser limitada aos anos de 2010 até 2013.

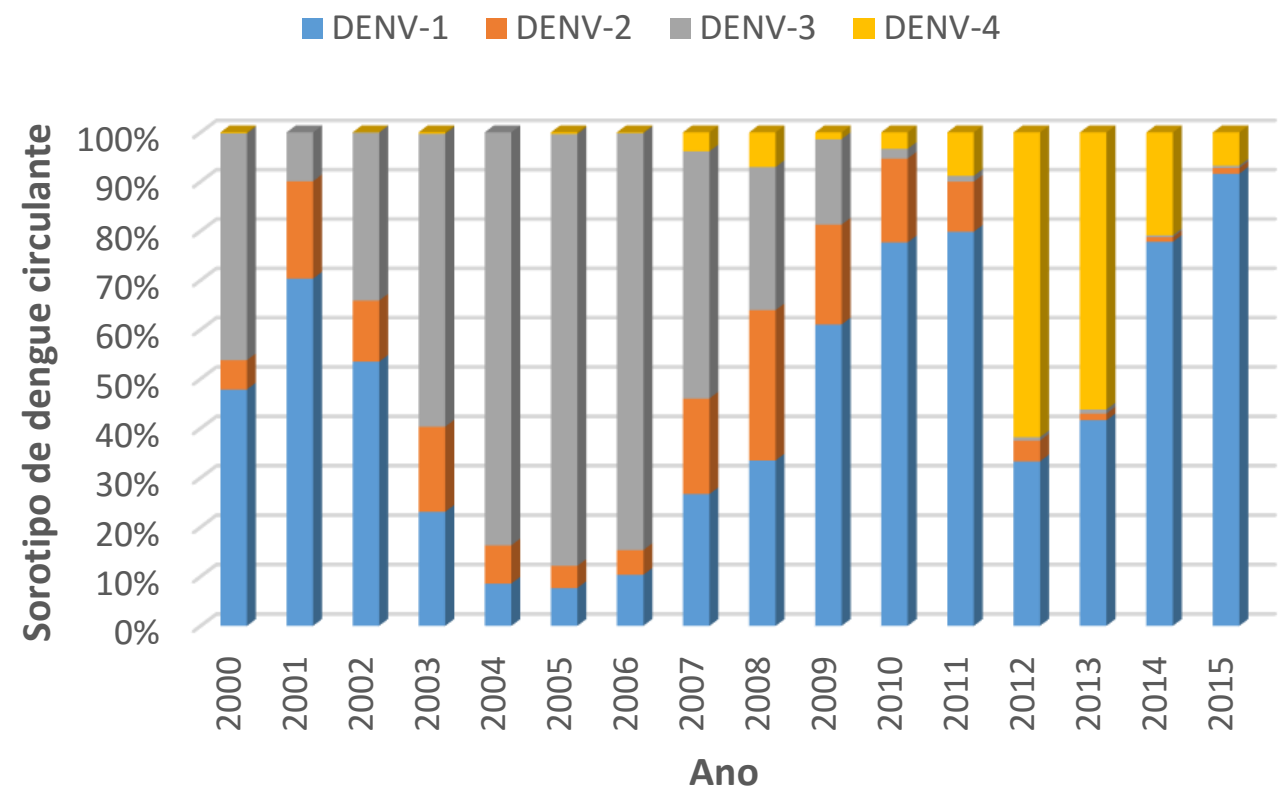

Figura 6 - Sorotipo da dengue circulante no Brasil por ano.

Considerou-se três cenários epidemiológicos distintos para os cálculos de $\lambda$ : o melhor cenário, o ano com a menor incidência de dengue nos meses de junho e julho dos anos 2010 até 2013; o pior cenário, o ano com a maior incidência de dengue no período homólogo; e o cenário médio, considerando a incidência média do período.

A figura 7 mostra o mapa do Brasil e as 12 cidades-sede da Copa do Mundo da FIFA e suas respectivas incidências médias de dengue entre os anos de 2010 e 2013, em cada cidade, durante a semana epidemiológica correspondente ao dia 11 de Junho (início da competição em 2014).

A base de dados, obtida com o Ministério da Saúde do Brasil ${ }^{1}$, contém o número de novas infecções por semana. Portanto, para que possamos determinar o risco de acordo com os cronogramas propostos é preciso desagregar a força de infecção semanal em dias, já que os turistas não ficariam na mesma cidade durante 7 dias seguidos.

Foram considerados apenas os casos sintomáticos de dengue já que as notificações de casos de dengue referem-se apenas aos casos sintomáticos.

$\overline{\text { http://dados.gov.br/dataset/taxa-de-incidencia-da-dengue }}$ 


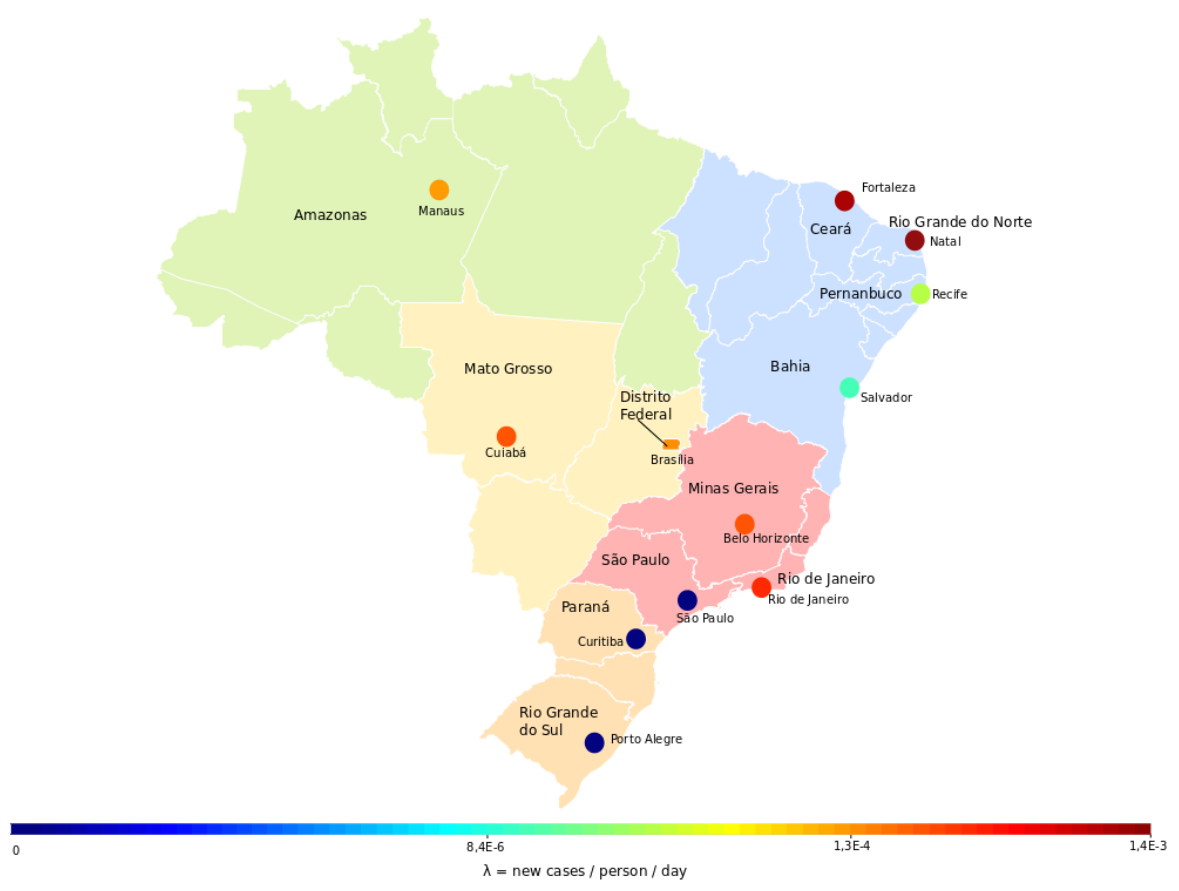

Figura 7 - Distribuição da força de infecção por cidade-sede.

Para desagregar a força de infecção semanal em dias, ao invés de utilizar o valor da força de infecção $(\lambda)$ obtida através dos ajustes da função exponencial pela incidência de dengue, calculada a partir dos casos notificados por semana, dividiu-se a força de infecção semanal por 7, obtendo-se a força de infecção diária média.

Para exemplificar e validar o método de desagregação, observemos a situação a seguir:

Foram agendados três jogos para a cidade de Natal para as semanas epidemiológicas 24, 25 e 26. Estas semanas começam nos dias 8, 15 e 22 de Junho. A fim de verificar a exatidão da operação de desagregação, aplicou-se a função exponencial contínua para obter as forças de infecção semanal e diária (figura 8) e integrou-se a função para o período dos jogos.

Os ajustes da figura 8, foram obtidos por equações exponenciais contínuas da forma $y=a e^{(b x)}$, e os valores dos parâmetros são apresentados na tabela 4 .

$$
\int_{t_{1}}^{t_{2}} \lambda(t) d t=a\left[\frac{-e^{\left(-b t_{2}\right)}+e^{\left(-b t_{1}\right)}}{b}\right]
$$

Dessa maneira, ao aplicar tais valores na equação 4.1 obtêm-se as forças de infecção (semanal e diária) para o mesmo período. Assim, a expectativa é de que os resultados sejam compatíveis. 


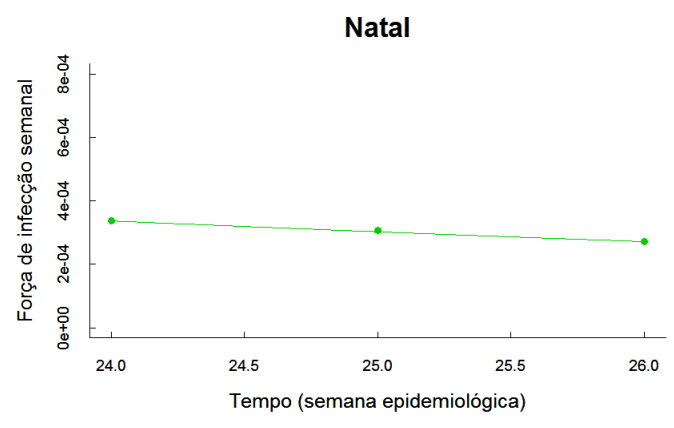

(a) Semanal

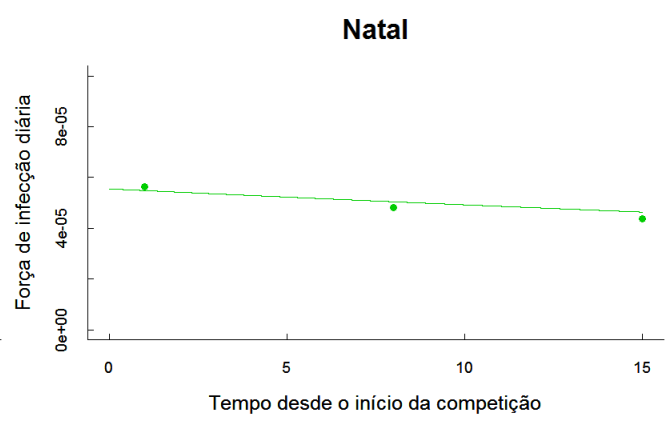

(b) Diário

Figura 8 - Desagregação da força de infecção

\begin{tabular}{lccc}
\hline$y=a e^{b x}$ & $\mathbf{a}$ & $\mathbf{b}$ & $R^{2}$ \\
\hline Semanal & $4.50^{*} 10^{-3}$ & -0.0108 & 0.9963 \\
Diário & $5.55^{*} 10^{-5}$ & -0.012 & 0.9813 \\
\hline
\end{tabular}

Tabela 4 - Ajuste exponencial e coeficiente de determinação $\left(R^{2}\right)$

Para a força de infecção semanal, temos:

$$
\begin{gathered}
\int_{24}^{26} \lambda_{\text {semanal }}(t) d t=4.5 * 10^{-3}\left[\frac{-e^{(-0.108 * 26)}+e^{(-0.108 * 24)}}{0.108}\right] \\
\int_{24}^{26} \lambda_{\text {semanal }}(t) d t=6.06 * 10^{-4}
\end{gathered}
$$

E, para a força de infecção diária:

$$
\begin{gathered}
\int_{1}^{13} \lambda_{\text {diária }}(t) d t=5.55 * 10^{-5}\left[\frac{-e^{(-0.012 * 13)}+e^{(0.012 * 1)}}{-9 * 10^{-7}}\right] \\
\int_{1}^{13} \lambda_{\text {diária }}(t) d t=6.13 * 10^{-4}
\end{gathered}
$$

Estes resultados sugerem que o método de desagregação utilizado é aceitável para este contexto, dado que os resultados obtidos variam apenas de 1.14\%. Assim, o registro semanal de notificações pode ser utilizado para a determinação da força de infecção diária em cada uma das 12 cidades.

\subsection{Ajustes}

Dados os casos notificados de dengue por semana em cada cidade-sede, obteve-se a incidência per capita de dengue, para cada ano estudado ao dividir o 
número de casos notificados pela população da respectiva cidade. O tamanho da população variou de acordo com a projeção do IBGE para cada ano.

Então, ajustou-se a incidência semanal, em cada cidade-sede, à função exponencial, logarítmica ou de potência de ordem n, obtendo-se desta forma a curva da força de infecção semanal.

Observa-se a seguir os resultados dos ajustes obtidos para cada cidade-sede e as respectivas funções utilizadas em cada caso:

\section{Belo Horizonte}

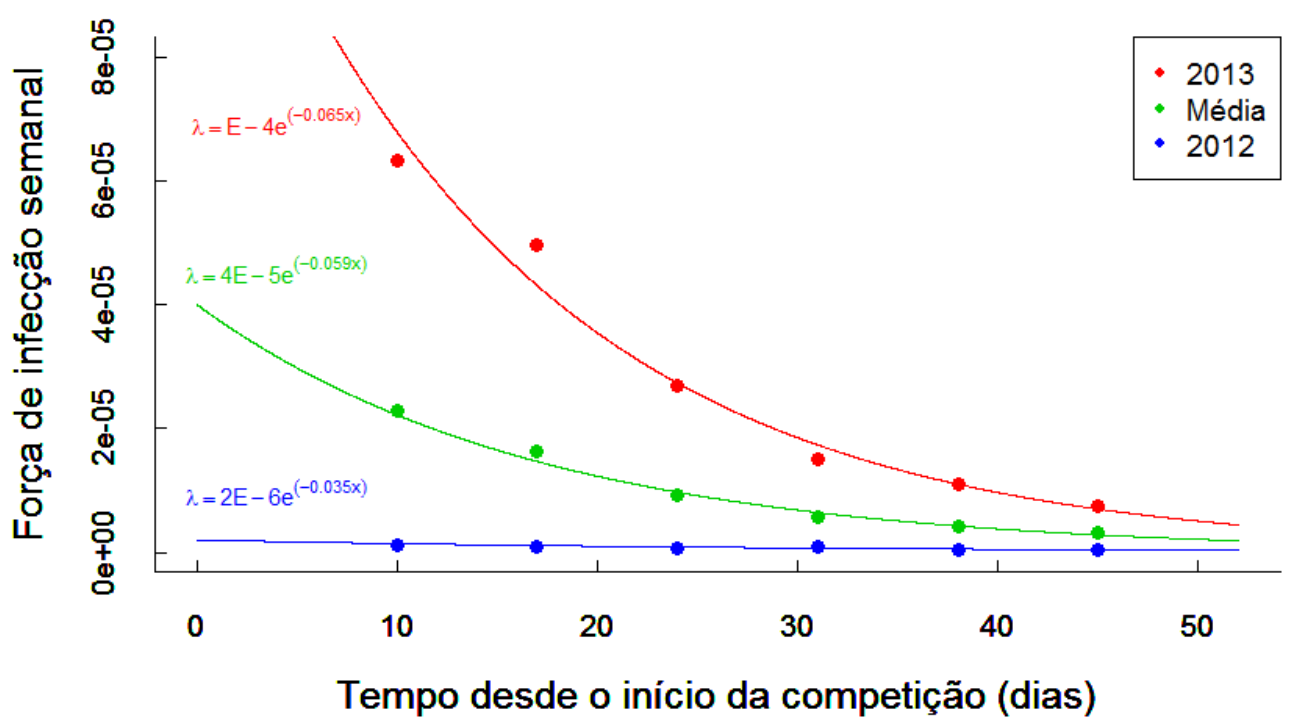

Figura 9 - Ajuste da força de infecção semanal - Belo Horizonte - $\mathrm{RMS}_{2012}=$ $2,05 x 10^{-7}, \quad \mathrm{R}^{2}{ }_{2012}=80,78 \%, A I C_{2012}=-13,55, R M S_{\text {Média }}=$ $7,76 \times 10^{-7}, \quad \mathrm{R}^{2}{ }_{\text {Média }}=98,93 \%, A I C_{\text {Média }}=-6,79, R M S_{2013}=$ $8,56 x 10^{-6}, \mathrm{R}^{2}{ }_{2013}=98,69 \%, A I C_{2013}=-4,60$ 


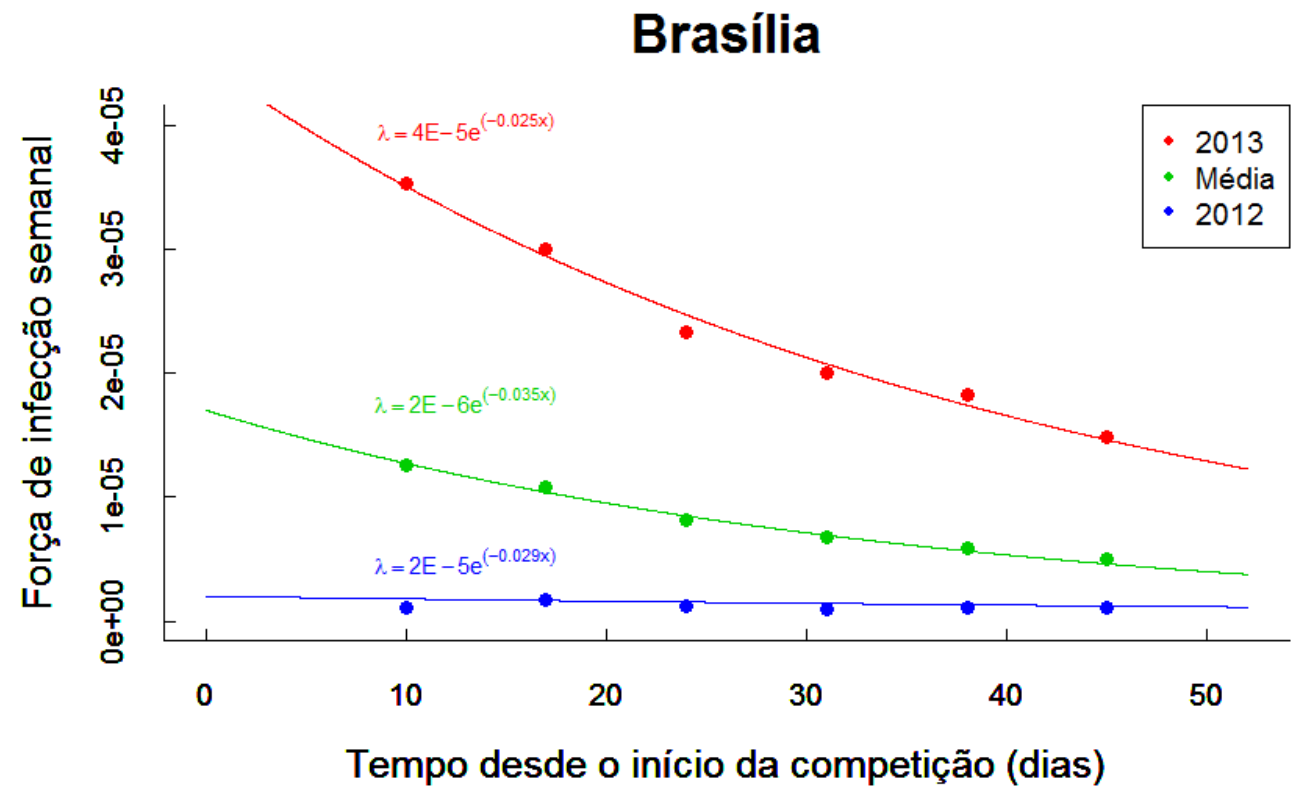

Figura 10 - Ajuste da força de infecção semanal - Brasília - $\mathrm{RMS}_{2012}=4,12 \times 10^{-07}$, $\mathrm{R}_{2012}^{2}=29,45 \%, A I C_{2012}=-13,13, R M S_{\text {Média }}=1,67 \times 10^{-6}$, $\mathrm{R}^{2}$ Média $=98,61 \%, A I C_{\text {Média }}=-8,99, R M S_{2013}=2,95 \times 10^{-6}$, $\mathrm{R}^{2}{ }_{2013}=987,76 \%, A I C_{2013}=-6,97$

\section{Cuiabá}

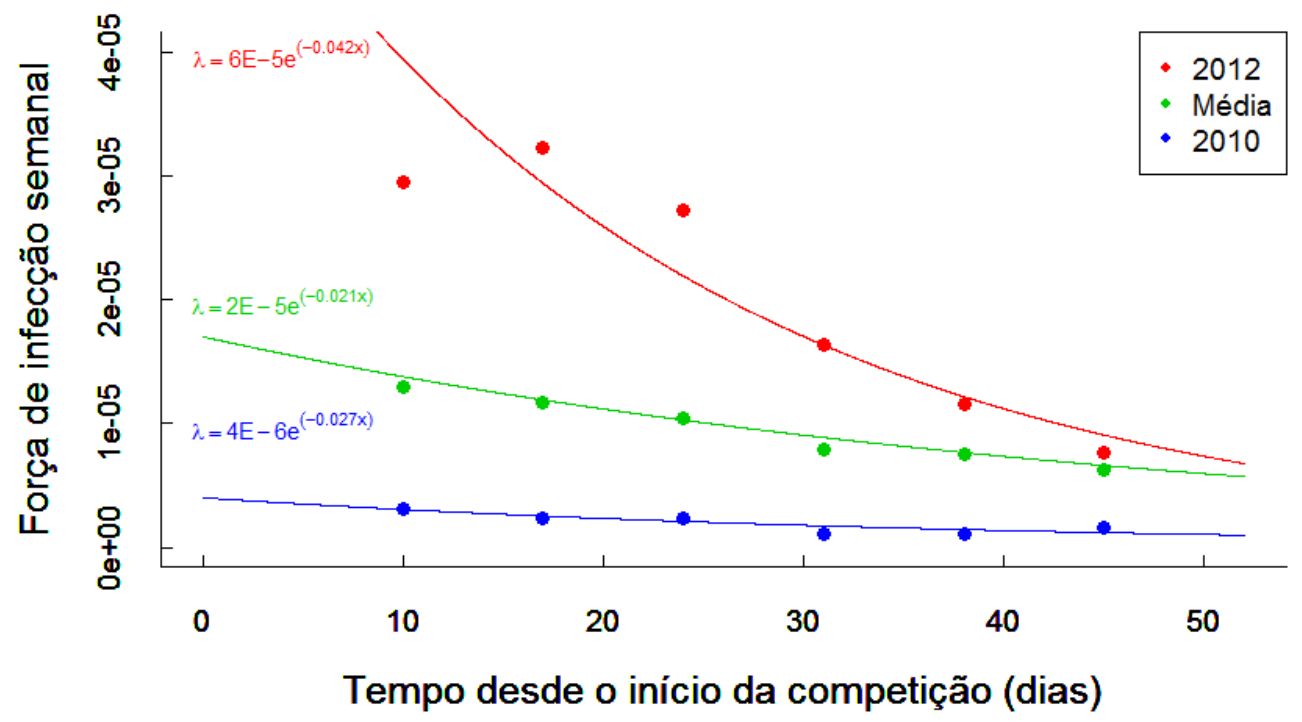

Figura 11 - Ajuste da força de infecção semanal - Cuiabá - $\mathrm{RMS}_{2011}=3,84 x 10^{-7}$, $\mathrm{R}^{2}{ }_{2011}=60,79 \%, A I C_{2011}=-11,56, R M S_{\text {Média }}=1,54 \times 10^{-6}$, $\mathrm{R}_{\text {Média }}=97,58 \%, A I C_{\text {Média }}=-8,88, R M S_{2012}=4,79 \times 10^{-6}$, $\mathrm{R}^{2}{ }_{2012}=90,29 \%, A I C_{2012}=-6,52$ 


\section{Curitiba}

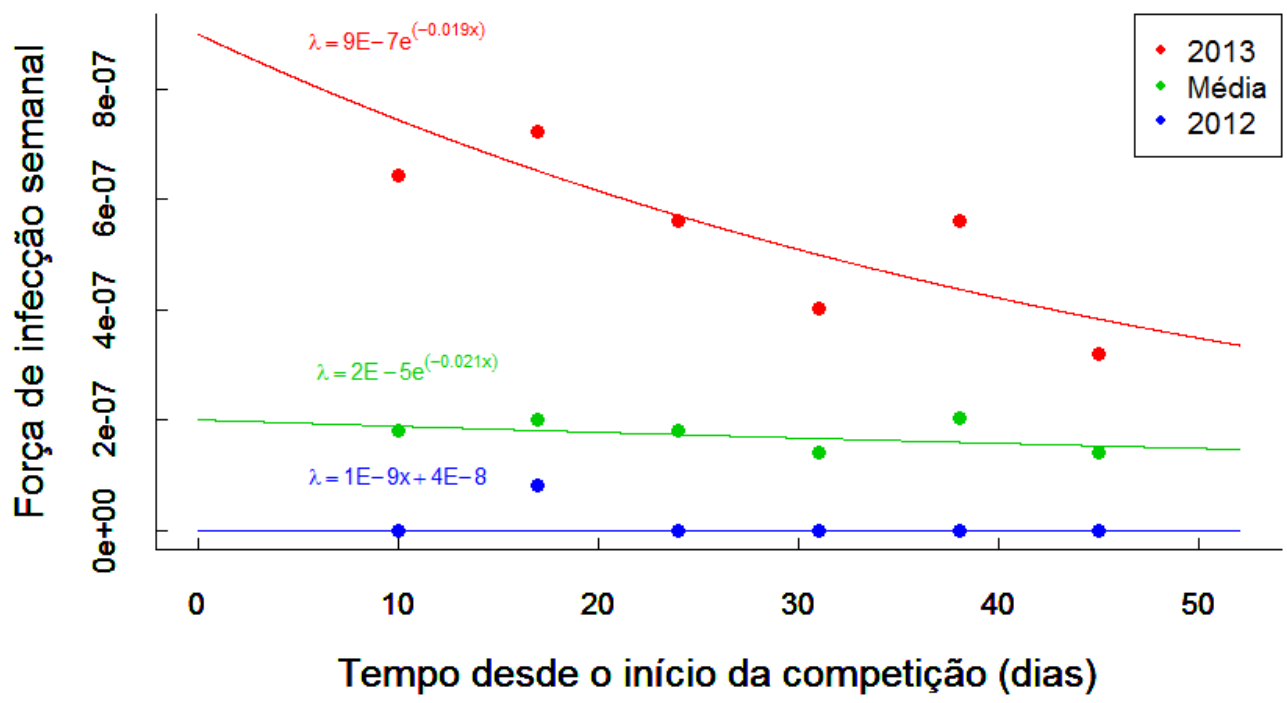

Figura 12 - Ajuste da força de infecção semanal - Curitiba $-\mathrm{RMS}_{2012}=2,76 \times 10^{-8}$, $\mathrm{R}_{2012}^{2}=15,43 \%, A I C_{2012}=-15,63, R M S_{\text {Média }}=2,26 x 10^{-8}$, $\mathrm{R}^{2}{ }_{\text {Média }}=23,35 \%, A I C_{\text {Média }}=-17,15, R M S_{2013} 8,61=x 10^{-8}$, $\mathrm{R}_{2013}^{2}=63,94 \%, A I C_{2013}=-14,61$

\section{Fortaleza}

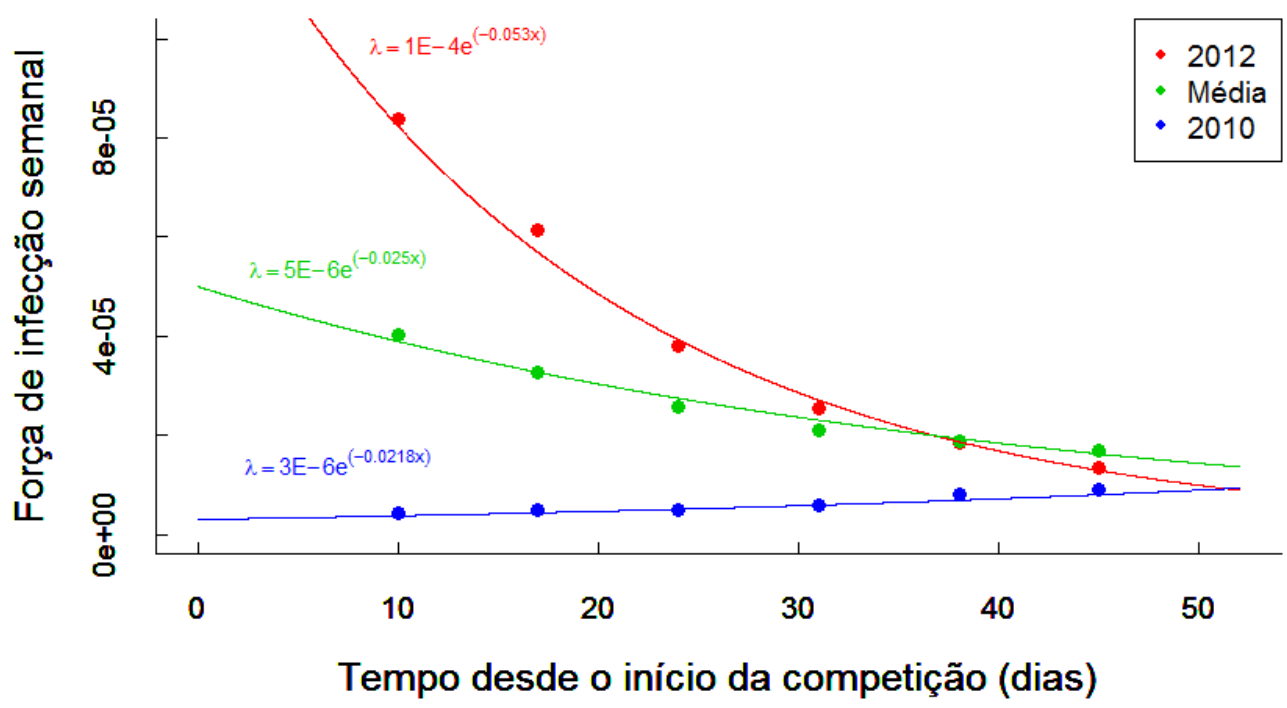

Figura 13 - Ajuste da força de infecção semanal - Fortaleza - $\mathrm{RMS}_{2010}=6,79 \times 10^{-7}$, $\mathrm{R}_{2010}{ }_{20}=94,55 \%, A I C_{2010}=-9,66, R M S_{\text {Média }}=1,22 \times 10^{-6}$, $\mathrm{R}_{M}^{2}{ }_{M e ́ d i a}=97,57 \%, A I C_{M e ́ d i a}=8,09, R M S_{2012}=1,44 x 10^{-5}, \mathrm{R}_{2012}^{2}=$ $99,49 \%, A I C_{2012}=0,64$ 


\section{Manaus}

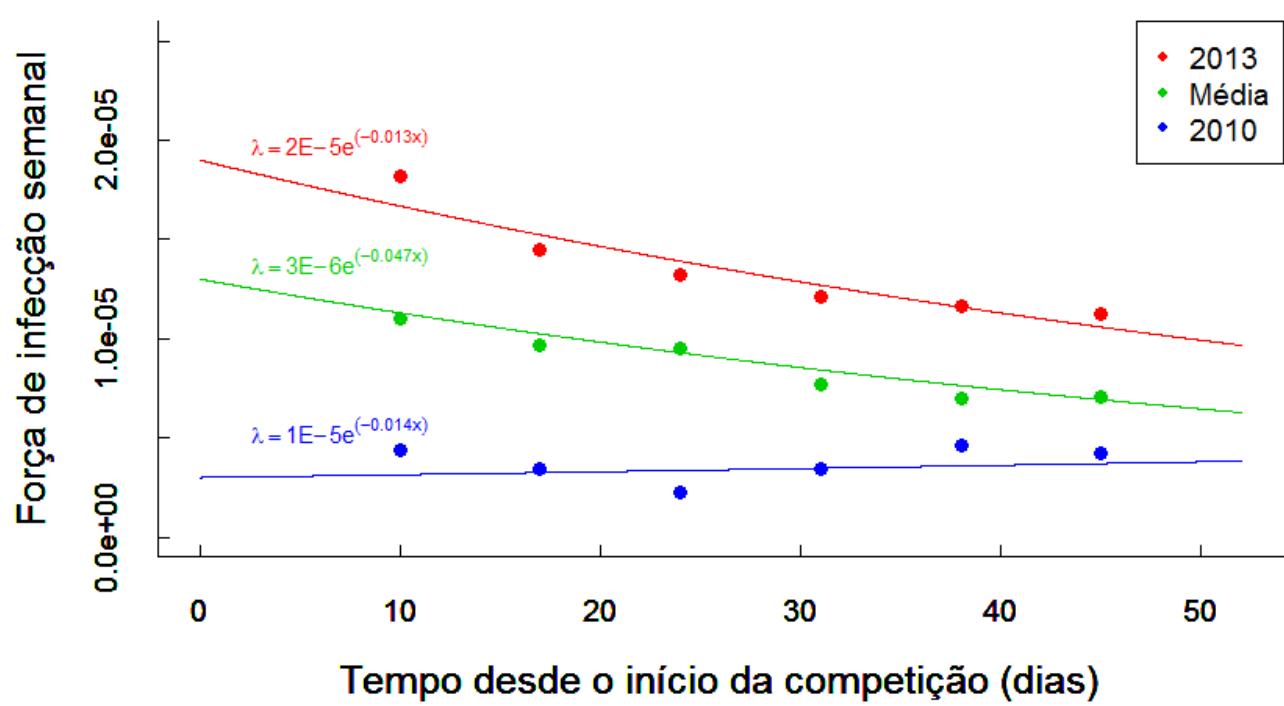

Figura 14 - Ajuste da força de infecção semanal - Manaus - $\mathrm{RMS}_{2010}=8,24 x 10^{-7}$, $\mathrm{R}_{2010}^{2}=5,17 \%, A I C_{2010}=-10,86, R M S_{M e ́ d i a}=1,82 \times 10^{-6}$, $\mathrm{R}^{2}{ }_{\text {Média }}=92,74 \%, A I C_{\text {Média }}=-9,27, R M S_{2013}=1,05 \times 10^{-6}$, $\mathrm{R}^{2}{ }_{2013} 88,17=\%, A I C_{2013}=-8,38$

\section{Natal}

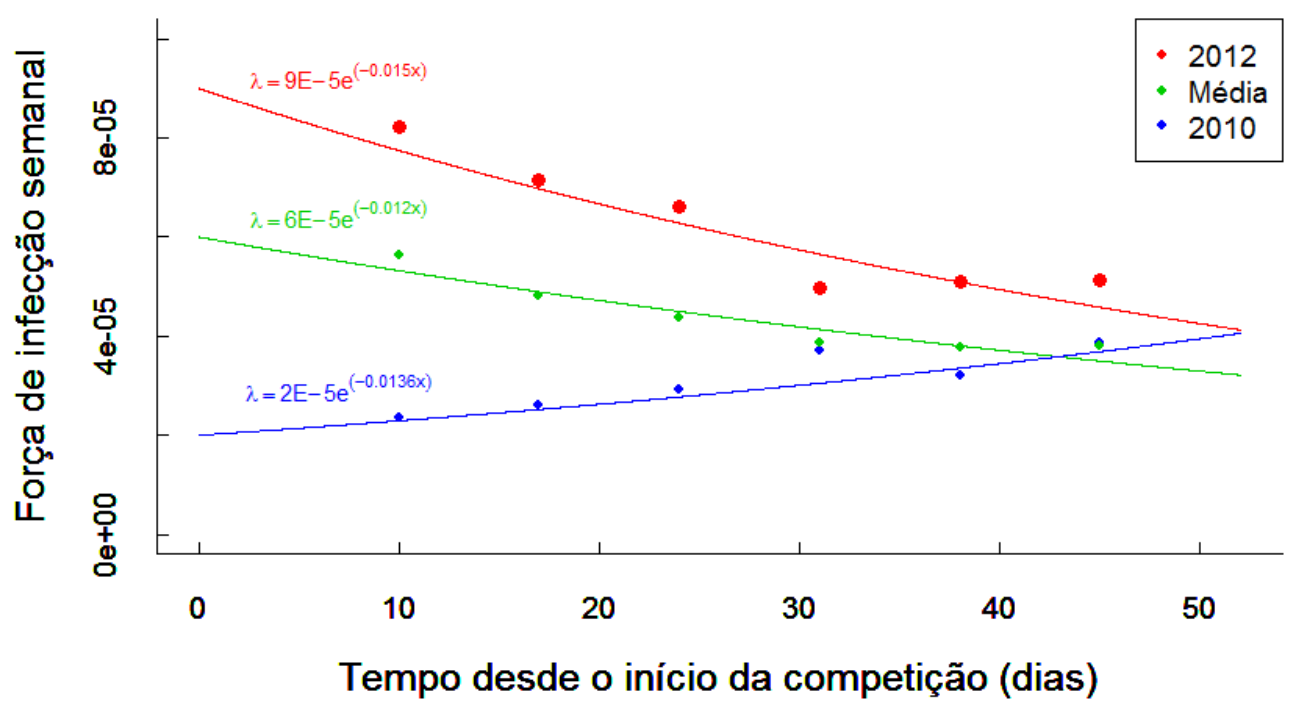

Figura 15 - Ajuste da força de infecção semanal - Natal - $\mathrm{RMS}_{2010}=8,24 x 10^{-7}$, $\mathrm{R}^{2}{ }_{2010}=5,17 \%, A I C_{2010}=-10,86, R M S_{\text {Média }}=1,82 \times 10^{-6}$, $\mathrm{R}^{2}{ }_{\text {Média }}=92,74 \%, A I C_{M e ́ d i a}=-9,27, R M S_{2013}=1,05 \times 10^{-6}$, $\mathrm{R}^{2}{ }_{2013}=88,17 \%, A I C_{2013}=-8,38$ 


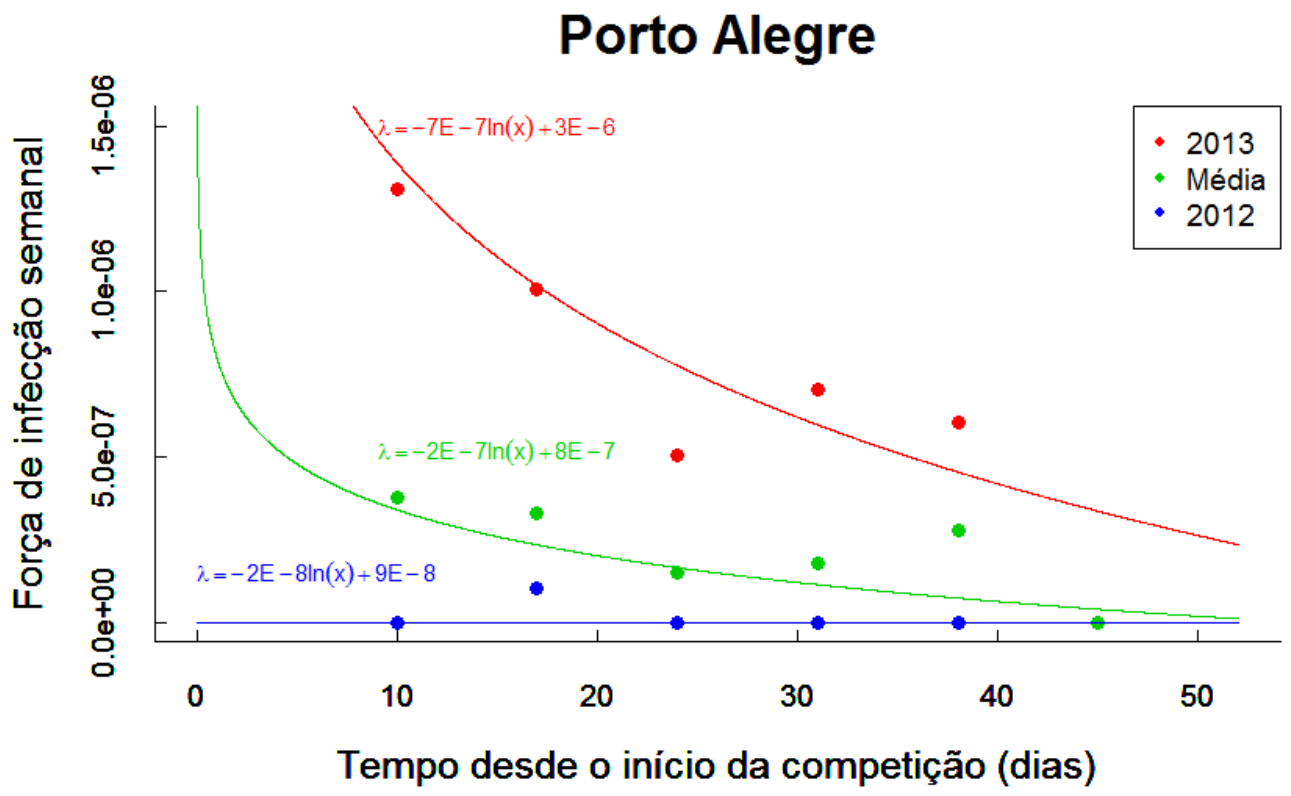

Figura 16 - Ajuste da força de infecção semanal - Porto Alegre - $\mathrm{RMS}_{2012}=$

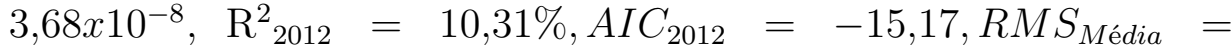
$9,83 x 10^{-8}, \mathrm{R}_{\text {Média }}=60,26 \%, A I C_{M e ́ d i a}=-15,06, R M S_{2013}=$ $1,95 \times 10^{-7}, \mathrm{R}^{2}{ }_{2013}=80,57 \%, A I C_{2013}=-12,68$

Recife

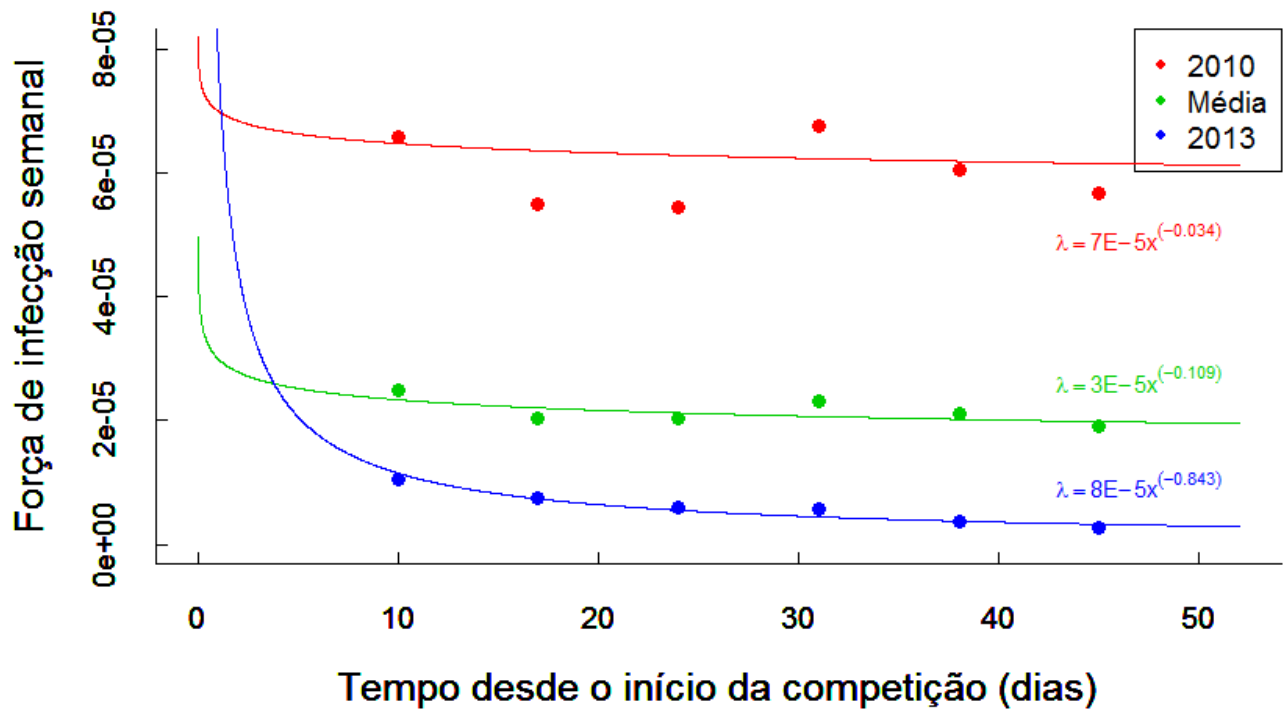

Figura 17 - Ajuste da força de infecção semanal - Recife - $\mathrm{RMS}_{2013}=7,30 \times 10^{-7}$, $\mathrm{R}_{2013}^{2}=90,01 \%, A I C_{2013}=-9,15, R_{M} S_{\text {Média }}=1,47 x 10^{-6}$, $\mathrm{R}_{\text {Média }}^{2}=40,40 \%, A I C_{M \text { édia }}=-7,61, R M S_{2010}=5,71 \times 10^{-6}$, $\mathrm{R}^{2} 2010=4,12 \%, A I C_{2010}=-5,55$ 


\section{Rio de Janeiro}

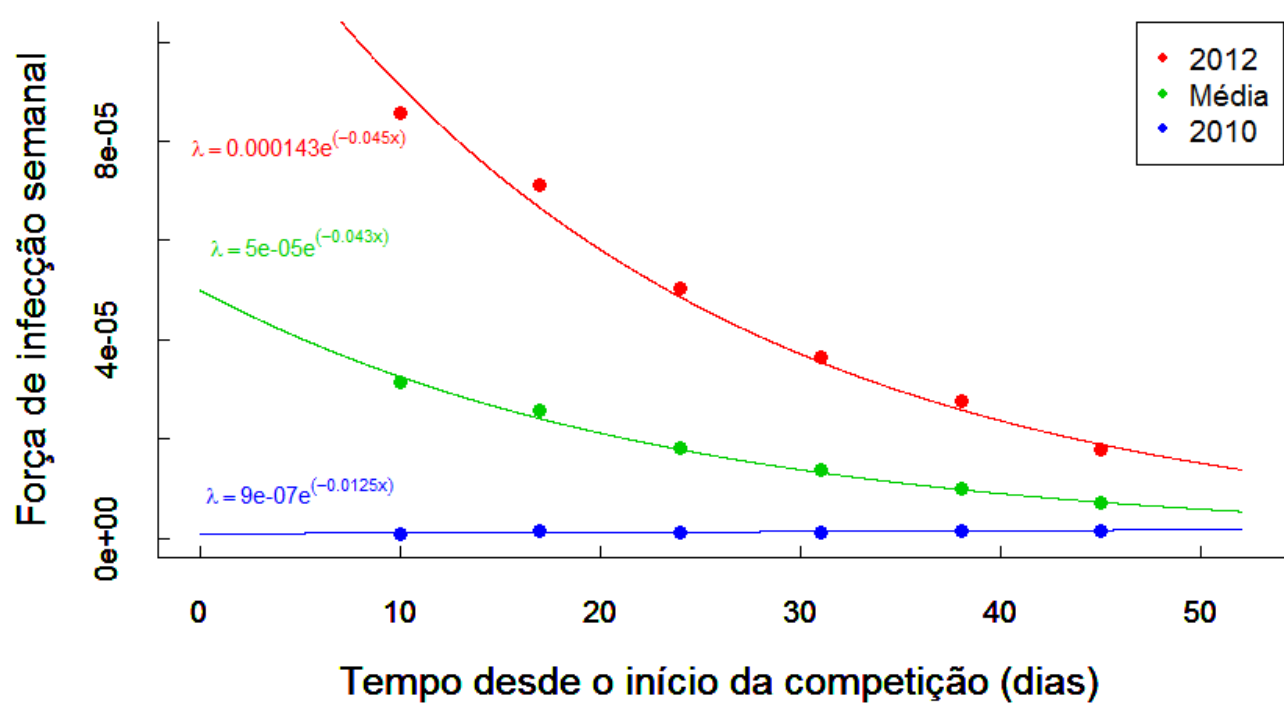

Figura 18 - Ajuste da força de infecção semanal - Rio de Janeiro - $\mathrm{RMS}_{2010}=$ $2,05 x 10^{-7}, \quad \mathrm{R}^{2}{ }_{2010}=43,84 \%, A I C_{2010}=-13,01, R M S_{\text {Média }}=$ $8,20 x 10^{-7}, \mathrm{R}_{\text {Média }}=99,66 \%, A I C_{M e ́ d i a}=-6,68, R M S_{2012}=$ $1,64 x 10^{-5}, \mathrm{R}^{2}{ }_{2012}=99,02 \%, A I C_{2012}=-4,64$

Salvador

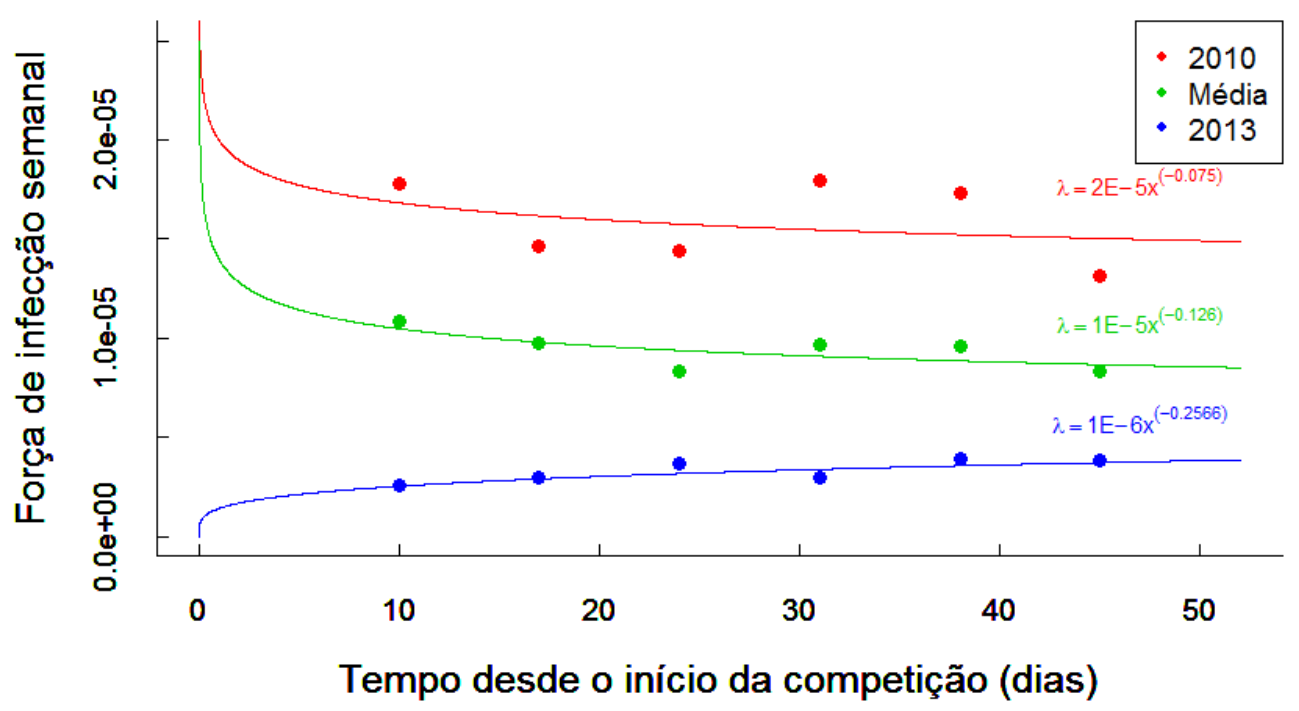

Figura 19 - Ajuste da força de infecção semanal - Salvador $-\mathrm{RMS}_{2013}=1,07 x 10^{-6}$, $\mathrm{R}^{2}{ }_{2013}=70,33 \%, A I C_{2013}=-11,24, R M S_{\text {Média }}=2,79 \times 10^{-6}$, $\mathrm{R}_{\text {Média }}=47,15 \%, A I C_{M e ́ d i a}=-9,25, R M S_{2010}=1,80 \times 10^{-6}$, $\mathrm{R}^{2}{ }_{2010}=10,01 \%, A I C_{2010}=-8,17$ 


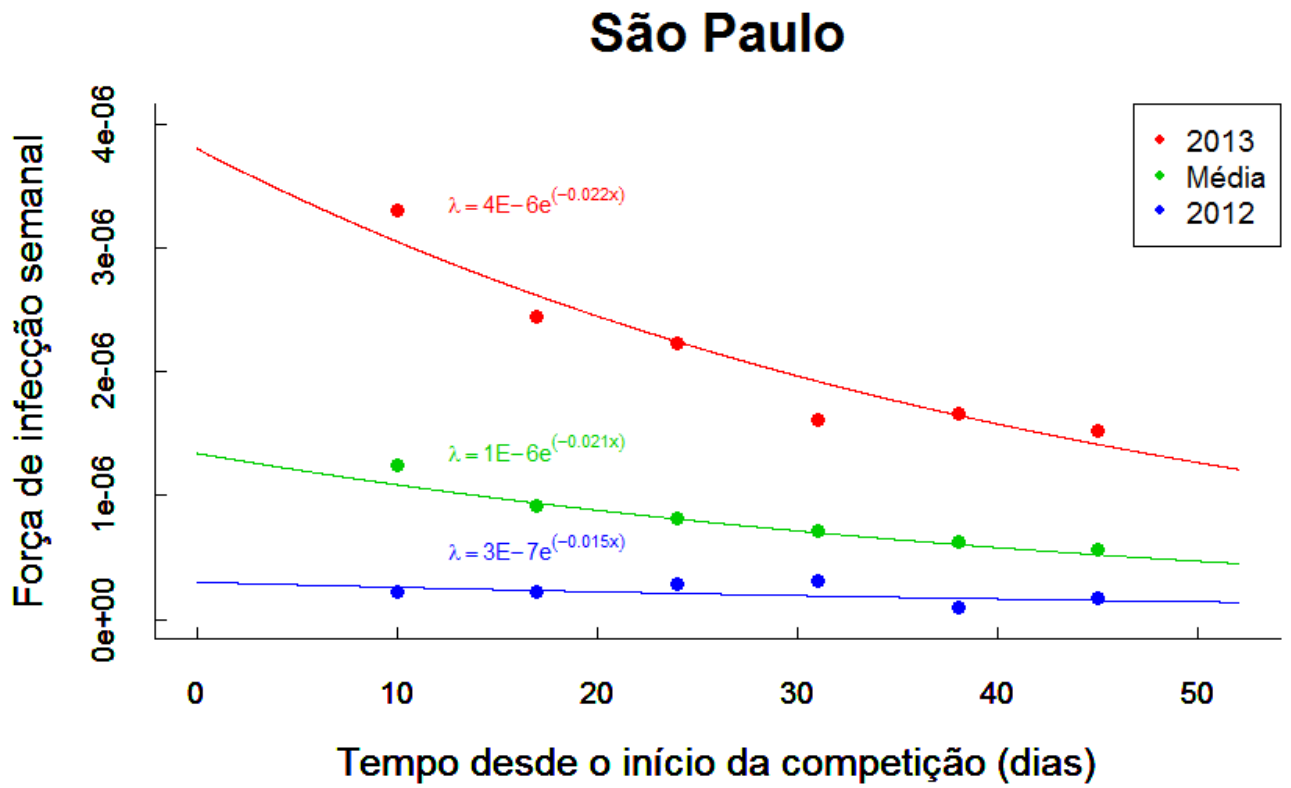

Figura 20 - Ajuste da força de infecção semanal - São Paulo - $\mathrm{RMS}_{2012}=6,20 \times 10^{-8}$, $\mathrm{R}_{2012}^{2}=21,88 \%, A I C_{2012}=-16,16$, RMS $_{\text {Média }}=2,59 \times 10^{-7}$, $\mathrm{R}^{2}{ }_{\text {Média }}=95,64 \%, A I C_{\text {Média }}=-13,69, R M S_{2013}=2,23 \times 10^{-7}$, $\mathrm{R}^{2}{ }_{2013}=89,88 \%, A I C_{2013}=-11,72$

A tabela 5 apresenta os parâmetros dos ajustes para cada cidade e o respectivo coeficiente de determinação $R^{2}$.

\begin{tabular}{|c|c|c|c|c|c|c|c|c|c|}
\hline \multirow[t]{2}{*}{ Cidade } & \multicolumn{3}{|c|}{ Maior } & \multicolumn{3}{|c|}{ Média } & \multicolumn{3}{|c|}{ Menor } \\
\hline & $\mathbf{a}$ & $\mathbf{b}$ & $R^{2}$ & $\mathbf{a}$ & b & $R^{2}$ & $\mathbf{a}$ & $\mathbf{b}$ & $R^{2}$ \\
\hline Belo Horizonte & $1.00 \mathrm{E}-04$ & $6.50 \mathrm{E}-02$ & 0.9869 & $4.00 \mathrm{E}-05$ & $5.90 \mathrm{E}-02$ & 0.9893 & $2.00 \mathrm{E}-06$ & 3.50E-02 & 0.8078 \\
\hline Brasília & $4.50 \mathrm{E}-05$ & $2.50 \mathrm{E}-02$ & 0.9776 & $2.00 \mathrm{E}-05$ & $2.90 \mathrm{E}-02$ & 0.9861 & $2.00 \mathrm{E}-06$ & $1.10 \mathrm{E}-02$ & 0.2945 \\
\hline Cuiabá & $6.00 \mathrm{E}-05$ & $4.20 \mathrm{E}-02$ & 0.9029 & $2.00 \mathrm{E}-05$ & $2.10 \mathrm{E}-02$ & 0.9758 & $4.00 \mathrm{E}-06$ & $2.70 \mathrm{E}-02$ & 0.6079 \\
\hline Curitiba $^{2}$ & $9.00 \mathrm{E}-07$ & $1.90 \mathrm{E}-02$ & 0.6394 & $2.00 \mathrm{E}-07$ & $6.00 \mathrm{E}-03$ & 0.2335 & $4.00 \mathrm{E}-08$ & 1.00E-09 & 0.1543 \\
\hline Fotaleza & $1.00 \mathrm{E}-04$ & $5.30 \mathrm{E}-02$ & 0.9949 & $5.00 \mathrm{E}-05$ & $2.50 \mathrm{E}-02$ & 0.9757 & $3.00 \mathrm{E}-06$ & $2.18 \mathrm{E}-02$ & 0.9455 \\
\hline Manaus & $2.00 \mathrm{E}-05$ & $1.30 \mathrm{E}-02$ & 0.8817 & $1.00 \mathrm{E}-05$ & $1.40 \mathrm{E}-02$ & 0.9274 & $3.00 \mathrm{E}-06$ & $4.70 \mathrm{E}-03$ & 0.0517 \\
\hline Natal & $9.00 \mathrm{E}-05$ & $1.50 \mathrm{E}-02$ & 0.8539 & $6.00 \mathrm{E}-05$ & $1.20 \mathrm{E}-02$ & 0.8792 & $2.00 \mathrm{E}-05$ & $1.36 \mathrm{E}-02$ & 0.8377 \\
\hline Porto Alegre $^{3}$ & $7.00 \mathrm{E}-07$ & $3.00 \mathrm{E}-06$ & 0.8057 & $2.00 \mathrm{E}-07$ & $8.00 \mathrm{E}-07$ & 0.6060 & $9.00 \mathrm{E}-08$ & $2.00 \mathrm{E}-08$ & 0.1031 \\
\hline Recife $^{4}$ & $7.00 \mathrm{E}-05$ & $3.40 \mathrm{E}-02$ & 0.0412 & $3.00 \mathrm{E}-05$ & $1.09 \mathrm{E}-01$ & 0.4040 & $8.00 \mathrm{E}-05$ & $8.43 \mathrm{E}-01$ & 0.9001 \\
\hline Rio de Janeiro & $1.43 \mathrm{E}-04$ & $4.50 \mathrm{E}-02$ & 0.9902 & $5.00 \mathrm{E}-05$ & $4.30 \mathrm{E}-02$ & 0.9966 & $9.00 \mathrm{E}-07$ & $1.25 \mathrm{E}-02$ & 0.4384 \\
\hline Salvador ${ }^{5}$ & $2.00 \mathrm{E}-05$ & $7.50 \mathrm{E}-02$ & 0.1001 & $1.00 \mathrm{E}-05$ & $1.26 \mathrm{E}-01$ & 0.4715 & $1.00 \mathrm{E}-06$ & $2.57 \mathrm{E}-01$ & 0.7033 \\
\hline São Paulo & 4.00E-06 & $2.20 \mathrm{E}-02$ & 0.8988 & $1.00 \mathrm{E}-06$ & $2.10 \mathrm{E}-02$ & 0.9564 & 3.00E-07 & $1.50 \mathrm{E}-02$ & 0.2188 \\
\hline
\end{tabular}

Tabela 5 - Parâmetros do ajuste da força de infecção semanal pela função exponencial.

2 Função linear para o ano de menor incidência

3 Função logarítmica

4 Função potência de ordem 2

5 Função potência de ordem 2 


\subsection{Risco de infecção}

Lembremos da equação do risco de infecção individual para infecção por dengue 3.16 apresentada no capítulo 3.

$$
\pi=\left[1-e^{-\int_{\omega}^{\omega+\Omega} \lambda(t) d t}\right]
$$

É fácil compreender que ao multiplicarmos o risco individual pelo número de turistas estrangeiros não imunes à dengue esperados em cada cidade, o resultado será o número de casos esperados de dengue em turistas para cada cidade. Assim, seja $\xi$ o número de turistas infectados durante a Copa do Mundo da FIFA, então:

$$
\xi_{i}=N_{i}\left[1-e^{-\int_{t_{1}}^{t_{2}} \lambda_{i}(t) d t}\right],(i=1 \ldots 12)
$$

Onde $N_{i}$ é o número de turistas estrangeiros no período entre $t_{1}$ e $t_{2} . N_{i}$ foi estimado a partir capacidade de cada estádio de futebol que receberiam as partidas.

Assumiu-se que 17\% da capacidade total dos estádios seriam ocupados por turistas internacionais, e suscetíveis à dengue.

Embora este valor possa parecer pequeno, ele foi obtido a partir da expectativa inicial do Ministério do turismo, que divulgou que o número de turistas estrangeiros esperados para a competição era de 600.000, de um total de 3,6 milhões de turistas (entre brasileiros e estrangeiros). Assim, a expectativa era de que apenas $17 \%$ do total de turistas fossem estrangeiros em cada partida da simulação. Além disso, como cada partida tem duas equipes, e portanto dois grupos de turistas, cada um seguindo o cronograma de sua equipe favorita, ajustou-se o número de turistas por partida, dividindo $N_{i}$ (total de turistas não imunes) por 2 ao estimar-se o número de casos de dengue por grupo.

\subsection{Resultados - Risco de dengue em turistas na Copa do Mundo}

Conforme vimos anteriormente, este estudo considerou três possíveis cenários epidemiológicos distintos (pior, média e melhor) para cada cronograma. Definido como pior o ano com a maior incidência de dengue no período entre 2010 e 2013 e melhor, o ano com a menor incidência de dengue para o período. O cenário médio refere-se à incidência média entre os anos de 2010 e 2013. 


\begin{tabular}{lccc}
\hline & $\begin{array}{c}\text { Capacidade do } \\
\text { estádio }\end{array}$ & $\begin{array}{c}\text { Turistas } \\
\text { estrangeiros }\end{array}$ & $\begin{array}{c}\text { Turistas por } \\
\text { partida }\end{array}$ \\
\hline Belo Horizonte & 62.254 & 10.583 & 5.292 \\
Brasília & 68.009 & 11.562 & 5.781 \\
Cuiabá & 42.968 & 7.305 & 3.652 \\
Curitiba & 41.456 & 7.048 & 3.524 \\
Fortaleza & 64.846 & 11.024 & 5.512 \\
Manaus & 42.374 & 7.204 & 3.602 \\
Natal & 42.086 & 7.155 & 3.577 \\
Porto Alegre & 48.849 & 8.304 & 4.152 \\
Recife & 44.248 & 7.522 & 3.761 \\
Rio de Janeiro & 76.804 & 13.057 & 6.528 \\
Salvador & 48.747 & 8.287 & 4.143 \\
São Paulo & 65.807 & 11.187 & 5.594 \\
\hline
\end{tabular}

Tabela 6 - Estádios e número de turistas estrangeiros esperados por partida

Assim, a partir da equação 4.2 e da expectativa do total de turistas não imunes à dengue previstos para cada cidade (tabela 6), obteve-se o número esperado de casos sintomáticos de dengue em turistas estrangeiros não imunes à dengue por cidade, durante a Copa do Mundo da FIFA, (tabela 7).

\begin{tabular}{lcc}
\hline \multicolumn{1}{c}{ Cidade } & $\begin{array}{c}\text { Número de Turistas } \\
\text { esperados }(\mathbf{n})\end{array}$ & $\begin{array}{c}\text { Casos de dengue esperados } \\
\mathbf{n}(\text { Melhor-Pior) }\end{array}$ \\
\hline Belo Horizonte & 36.788 & $0(0-9)$ \\
Brasília & 34.391 & $1(0-7)$ \\
Cuiabá & 20.740 & $0(0-4)$ \\
Curitiba & 34.782 & $0(0)$ \\
Fortaleza & 58.195 & $12(0-15)$ \\
Manaus & 26.252 & $0(0)$ \\
Natal & 44.952 & $8(0-8)$ \\
Porto Alegre & 35.343 & $0(0)$ \\
Recife & 37.693 & $0(0)$ \\
Rio de Janeiro & 101.910 & $11(0-30)$ \\
Salvador & 57.855 & $0(0)$ \\
São Paulo & 101.150 & $0(0)$ \\
\hline Total & 607.051 & $32(0-73)$ \\
\hline
\end{tabular}

Tabela 7 - Número de turistas internacionais e de casos sintomáticos de dengue esperados em cada cidade-sede

A tabela 8 apresenta o resultado mais importante deste estudo, o risco individual de infecção por dengue durante a Copa do Mundo da FIFA. Ele é o resultado mais importante pois, através dessa informação pode-se calcular o número 
de turistas que serão infectados. Assim, alterando o valor de $N_{i}$ obtemos o total de turistas infectados.

\begin{tabular}{|c|c|c|}
\hline $\begin{array}{l}\text { Agenda/ } \\
\text { Grupo }\end{array}$ & $\begin{array}{c}\text { Casos esperados de dengue } \\
n \text { (Melhor-Pior) }\end{array}$ & $\begin{array}{c}\text { Risco individual de } \\
\text { dengue (Melhor-Pior) }\end{array}$ \\
\hline $\mathrm{A} 1$ & $2(1-5)$ & $3.61(1.08-6.22) \times 10^{-4}$ \\
\hline $\mathrm{A} 2$ & $1(0-1)$ & $1.82(0.26-2.76) \times 10^{-4}$ \\
\hline $\mathrm{A} 3$ & $2(0-2)$ & $3.42(0.70-5.34) \times 10^{-4}$ \\
\hline $\mathrm{A} 4$ & $1(1-1)$ & $2.50(1.57-3.34) \times 10^{-4}$ \\
\hline B1 & $2(0-4)$ & $3.09(0.15-6.08) \times 10^{-4}$ \\
\hline $\mathrm{B} 2$ & $0(0-1)$ & $6.23(0.57-15.4) \times 10^{-5}$ \\
\hline B3 & $1(0-4)$ & $2.31(0.16-6.50) \times 10^{-4}$ \\
\hline B4 & $0(0-1)$ & $7.97(1.50-22.6) \times 10^{-5}$ \\
\hline $\mathrm{C} 1$ & $2(1-5)$ & $4.05(1.24-7.42) \times 10^{-4}$ \\
\hline $\mathrm{C} 2$ & $2(0-3)$ & $4.46(1.01-7.11) \times 10^{-4}$ \\
\hline $\mathrm{C} 3$ & $1(1-1)$ & $1.74(1.21-2.09) \times 10^{-4}$ \\
\hline $\mathrm{C} 4$ & $1(0-1)$ & $2.78(0.96-4.63) \times 10^{-4}$ \\
\hline D1 & $2(0-3)$ & $3.88(0.79-6.25) \times 10^{-4}$ \\
\hline D2 & $1(0-3)$ & $2.92(0.20-6.10) \times 10^{-4}$ \\
\hline D3 & $0(0-1)$ & $9.39(1.62-21.0) \times 10^{-5}$ \\
\hline D4 & $1(0-1)$ & $1.98(0.66-3.16) \times 10^{-4}$ \\
\hline E1 & $1(1-1)$ & $1.73(1.20-3.05) \times 10^{-4}$ \\
\hline $\mathrm{E} 2$ & $1(0-2)$ & $2.05(1.42-3.92) \times 10^{-4}$ \\
\hline E3 & $1(0-2)$ & $1.16(0.04-3.24) \times 10^{-4}$ \\
\hline E4 & $0(0)$ & $3.81(1.18-8.63) \times 10^{-5}$ \\
\hline F1 & $2(1-5)$ & $3.40(0.96-8.33) \times 10^{-4}$ \\
\hline $\mathrm{F} 2$ & $2(0-4)$ & $2.89(0.60-7.41) \times 10^{-4}$ \\
\hline F3 & $0(0-1)$ & $6.67(0.43-15.8) \times 10^{-5}$ \\
\hline F4 & $0(0)$ & $5.57(0.98-14.4) \times 10^{-5}$ \\
\hline G1 & $1(0-2)$ & $1.83(0.12-3.58) \times 10^{-4}$ \\
\hline $\mathrm{G} 2$ & $0(0)$ & $7.56(9.12-8.36) \times 10^{-5}$ \\
\hline G3 & $2(0-2)$ & $3.94(1.36-5.40) \times 10^{-4}$ \\
\hline G4 & $1(0-1)$ & $2.51(0.83-3.88) \times 10^{-4}$ \\
\hline $\mathrm{H} 1$ & $1(0-4)$ & $2.29(0.51-5.68) \times 10^{-4}$ \\
\hline $\mathrm{H} 2$ & $0(0-1)$ & $8.44(0.53-21.1) \times 10^{-5}$ \\
\hline H3 & $1(0-3)$ & $1.88(0.11-5.18) \times 10^{-4}$ \\
\hline $\mathrm{H} 4$ & $0(0-1)$ & $7.42(1.41-19.7) \times 10^{-5}$ \\
\hline
\end{tabular}

Tabela 8 - Número de casos sintomáticos de dengue esperados em turistas e risco de infecção sintomática individual, para cada cronograma

Estas estimativas resultam em um número esperado de casos de dengue de 32 pessoas infectadas e sintomáticos pela doença, entre os turistas estrangeiros, portanto, a incidência resultante é igual a 5,27 casos/100.000 turistas estrangeiros. Já no melhor cenário epidemiológico calculado, nenhum turista seria infectado durante o evento e no pior cenário, 73 pessoas seriam infectadas. Este risco se 
traduz em uma incidência de 12,02 casos por 100.000 turistas estrangeiros durante o período dos jogos (11 de Junho até 14 de Julho de 2014).

O risco individual varia de acordo com o cronograma (tabela 5) e com o cenário epidemiológico considerado, partindo de $3.61 . \times 10^{-6}$ no cenário mais conservador (E3) até $8.33 \times 10^{-4}$ no cenário mais agressivo (F1). Se observarmos as médias, os riscos variam de $3.81 \times 10^{-5}$ no melhor cenário (E4) até $4.46 \times 10^{-4}$ no pior cenário $(\mathrm{C} 2)$.

\subsection{Validando a previsão a partir das notificações de 2014}

Após o término do ano de 2014 obteve-se as notificações de dengue e repetiu-se o processo de determinação do risco.

A tabela 9 mostra o risco individual dos turistas para cada cronograma e o respectivo número de casos esperados de infecções.

Na sequência observa-se a tabela 10 que apresenta o resultado dos cálculos de risco para o número de casos notificados no Brasil em 2014 por cidade-sede onde pode-se constatar que o resultado observado, assim como esperado, é menor do que a previsão determinada neste estudo, já que o total de casos neste ano foi inferior à média de casos notificados entre 2010 e 2013. Ainda assim, o resultado da média de casos esperados em 2014 (tabela 8) está dentro do intervalo de confiança obtido com os dados de 2014.

Estas estimativas resultam em um número médio total de casos de dengue de 12 pessoas infectadas, e sintomáticos à doença, entre os turistas estrangeiros, com máximo de 41 infectados. Este risco se traduz em uma incidência de 2 casos por 100.000 turistas estrangeiros durante o período dos jogos. O risco individual varia de acordo com o cronograma, partindo de $5.30 \times 10^{-5}$ no melhor cronograma (E3) até $2.30 \times 10^{-4}$ no pior cronograma (C3). 


\begin{tabular}{ccc}
\hline $\begin{array}{c}\text { Agenda/ } \\
\text { Grupo }\end{array}$ & $\begin{array}{c}\text { Casos esperados de } \\
\text { dengue } \mathbf{n}(\mathbf{I C} 95 \%)\end{array}$ & $\begin{array}{c}\text { Risco individual } \\
\text { de dengue }(\mathrm{IC} 95 \%)\end{array}$ \\
\hline A1 & $2(1-3)$ & $1.78(1.47-5.03) \times 10^{-4}$ \\
A2 & $1(0-2)$ & $1.82(0.00-3.41) \times 10^{-4}$ \\
A3 & $1(0-1)$ & $1.97(0.00-3.26) \times 10^{-4}$ \\
A4 & $1(0-2)$ & $2.15(0.00-3.70) \times 10^{-4}$ \\
B1 & $1(0-1)$ & $1.20(0.15-2.55) \times 10^{-4}$ \\
B2 & $0(0-1)$ & $1.27(0.00-2.09) \times 10^{-4}$ \\
B3 & $0(0-1)$ & $1.38(0.00-2.15) \times 10^{-4}$ \\
B4 & $0(0-1)$ & $1.50(0.00-2.16) \times 10^{-4}$ \\
C1 & $2(0-3)$ & $2.03(0.85-4.91) \times 10^{-4}$ \\
C2 & $1(0-2)$ & $1.77(0.00-3.25) \times 10^{-4}$ \\
C3 & $1(0-2)$ & $2.30(0.00-4.37) \times 10^{-4}$ \\
C4 & $0(0-1)$ & $1.81(0.00-2.75) \times 10^{-4}$ \\
D1 & $1(0-2)$ & $1.75(0.05-3.56) \times 10^{-4}$ \\
D2 & $1(0-2)$ & $1.59(0.00-2.97) \times 10^{-4}$ \\
D3 & $0(0-1)$ & $1.60(0.00-2.56) \times 10^{-4}$ \\
D4 & $0(0-1)$ & $1.42(0.00-2.00) \times 10^{-4}$ \\
E1 & $1(0-2)$ & $1.38(0.46-3.22) \times 10^{-4}$ \\
E2 & $1(0-2)$ & $1.97(0.19-4.12) \times 10^{-4}$ \\
E3 & $0(0-0)$ & $5.30(0.00-6.38) \times 10^{-5}$ \\
E4 & $0(0-0)$ & $8.32(0.00-10.3) \times 10^{-5}$ \\
F1 & $1(0-2)$ & $1.23(0.30-2.77) \times 10^{-4}$ \\
F2 & $0(0-1)$ & $1.28(0.00-2.13) \times 10^{-4}$ \\
F3 & $0(0-1)$ & $1.13(0.00-1.56) \times 10^{-4}$ \\
F4 & $0(0-1)$ & $1.11(0.00-1.47) \times 10^{-4}$ \\
G1 & $0(0-1)$ & $1.13(0.00-1.92) \times 10^{-4}$ \\
G2 & $1(0-1)$ & $1.58(0.00-2.73) \times 10^{-4}$ \\
G3 & $1(0-2)$ & $2.19(0.00-4.04) \times 10^{-4}$ \\
G4 & $0(0-1)$ & $1.41(0.00-1.97) \times 10^{-4}$ \\
H1 & $1(0-1)$ & $1.20(0.00-2.22) \times 10^{-4}$ \\
H2 & $0(0-1)$ & $1.01(0.00-1.47) \times 10^{-4}$ \\
H3 & $0(0-1)$ & $1.01(0.00-1.37) \times 10^{-4}$ \\
H4 & $0(0-1)$ & $1.51(0.00-2.30) \times 10^{-4}$ \\
\hline & &
\end{tabular}

Tabela 9 - Número de casos sintomáticos de dengue esperados em turistas e risco de infecção sintomática individual, com dados de 2014 


\begin{tabular}{lcc}
\hline \multicolumn{1}{c}{ Cidade } & $\begin{array}{c}\text { Número de Turistas } \\
\text { esperados(n) }\end{array}$ & $\begin{array}{c}\text { Casos de dengue esperados } \\
\mathbf{n} \text { (Melhor-Pior) }\end{array}$ \\
\hline Belo Horizonte & 36.788 & $0(0-9)$ \\
Brasília & 34.391 & $7(0-3)$ \\
Cuiabá & 20.740 & $0(0-2)$ \\
Curitiba & 34.782 & $0(0)$ \\
Fortaleza & 58.195 & $5(0-11)$ \\
Manaus & 26.252 & $0(0-2)$ \\
Natal & 44.952 & $0(0-2)$ \\
Porto Alegre & 35.343 & $0(0)$ \\
Recife & 37.693 & $0(0-1)$ \\
Rio de Janeiro & 101.910 & $0(0-2)$ \\
Salvador & 57.855 & $0(0-1)$ \\
São Paulo & 101.150 & $0(0-3)$ \\
\hline Total & 607.051 & $12(0-41)$ \\
\hline
\end{tabular}

Tabela 10 - Número de turistas internacionais e de casos sintomáticos de dengue esperados em cada cidade-sede, com dados de 2014 


\section{Jogos Olímpicos de Verão - Rio 2016}

\subsection{Os Jogos Olímpicos Rio 2016}

Oficialmente Jogos da XXXI Olimpíada, os Jogos Olímpicos Rio 2016, foi a primeira edição dos jogos na América do Sul.

Um mega evento esportivo realizado entre 5 e 21 de Agosto de 2016, no Rio de Janeiro, onde mais de 10.000 atletas de 206 países disputaram 42 modalidades esportivas (Rio2016, 2016).

Assim como a Copa do Mundo, os Jogos Olímpicos tornaram o Brasil, em especial o Rio de Janeiro, o foco das atenções de todo o mundo e um destino certo para milhares de turistas, mesmo em meio às adversidades que o Brasil enfrentou durante os meses que antecederam aos jogos.

Durante o ano de 2016 o Brasil enfrentou uma profunda crise política, altos índices de violência (Cerqueira et al., 2016) e epidemias de 3 doenças (Dengue, Chikungunya e Zika) disseminadas pelo mesmo vetor, o Aedes aegypti, e um novo surto de H1N1 (Brasil, 2016a).

Assim, não havia como garantir o sucesso de bilheteria durante os Jogos, principalmente com turistas internacionais, tendo este cenário catastrófico em pleno curso. Porém, a expectativa oficial do Ministério do Turismo era de que o Rio de Janeiro receberia 500.000 turistas internacionais para acompanhar os Jogos Olímpicos (EBC, 2016).

Embora todos estes fatores sejam propaganda negativa ao evento, o Ministério do Turismo aumentou a expectativa inicial do número de turistas internacionais esperados de 400.000 para 500.000 visitantes após o Governo Federal mudar as regras de visto para entrada de turistas no país. Contudo, neste trabalho considerouse que o Rio de Janeiro teria recebido 400.000 turistas não imunes à dengue, pois este foi o número de turistas internacionais divulgado pelo Ministério do Turismo até 3 meses antes do início dos jogos.

O Rio de Janeiro, sede dos Jogos Olímpicos de verão de 2016, têm sido de grande importância para a epidemiologia da dengue no Brasil. Depois das apresentações DENV 1-4, em 1986, 1990, 2000 e 2011, respectivamente, a cidade sofreu surtos explosivos (Heringer et al., 2015).

Com o surgimento de novas doenças infecciosas no território brasileiro e o 
grande fluxo de turistas presentes no Brasil, a importância em prever o risco de infecção por dengue para turistas cresceu para o período olímpico em comparação à Copa do Mundo.

Este estudo propõe um modelo estocástico para o cálculo da probabilidade per capita de infecção por dengue para os visitantes do Rio de Janeiro em período compreendido entre as semanas epidemiológicas 31 e 33 do ano de 2016.

O modelo é baseado na força de infecção, calculada em média para toda a cidade e para cada ano desde o ano 2000 até 2015.

\subsection{Probabilidade de infecção per capita}

Tal como discutido no capítulo 3, o risco de infecção pode ser calculado estocasticamente por um modelo de dois estados, sem recuperação, $S I$ onde, $S$ são os indivíduos suscetíveis à infecção e $I$ são os indivíduos que adquiriram a infecção, e que permanecem infectados por toda a vida.

Embora a dengue permita que o infectado se recupere, esta aproximação à realidade se justifica pelo fato de que os visitantes permanecem na cidade um período relativamente curto, além de apresentarem-se em número baixo em relação à população local, de forma que apesar de os visitantes estarem sujeitos à força de infecção local, eles não contribuem para ela. Deste modo, a consequência deste pressuposto é que podemos usar o modelo linear, o que simplifica o cálculo do risco de infecção.

\subsubsection{População suscetível}

Para a determinação do risco de infecção, é essencial conhecer a população sujeito ao estudo o que, neste caso, significa determinar quem é suscetível à infecção e quem não é.

Claramente a população suscetível é aquela que nunca foi infectada, isso nos leva à pergunta: Quem já foi infectado?

Para responder a essa questão assumiu-se que todos os casos sintomáticos de dengue no Brasil são notificados e que, consequentemente, a base de dados do Ministério da Saúde (base SINAN) pode ser reproduzida pelo modelo desde que a o número de casos notificados seja igual a $\lambda(t) S_{H}(t)$, ou seja, SINAN $=\lambda(t) S_{H}(t)$.

Assim, é evidente que o número de suscetíveis varia ano a ano para a dengue, já que é uma doença endêmica e além disso, possui 4 diferentes sorotipos. Dessa 
maneira, para estimar o número de suscetíveis à dengue, no Rio de Janeiro, após cada epidemia, elaborou-se o método descrito a seguir:

A população total do Rio de Janeiro, em 2000, foi obtida a partir do censo demográfico de 2010 realizado pelo Instituto Brasileiro de Geografia e Estatística (IBGE) como 5.857.904 habitantes (IBGE, 2010). O próximo censo nacional foi realizado em 2015 e o número total de habitantes aumentou para 6.317.424 pessoas (IBGE, 2015).

Para a determinação do número de suscetíveis é necessário saber a população total em cada ano, dessa maneira obtivemos a população através da interpolação entre as quantidades dos dois anos. Depois de 2010, a população foi extrapolada a partir dos dois censos precedentes.

Para determinarmos as condições iniciais das equações 3.1 e 3.2 para o Rio de Janeiro, isto é, o número de suscetíveis em cada ano, projetou-se o número esperado de habitantes por ano (tabelas 11, 12 e 13) e subtraiu-se o número de casos de dengue registrado no ano anterior. Este método foi utilizado para os anos de 2000 até 2007, quando o sorotipo dominante no Rio de Janeiro foi o tipo (DENV-3). Para o ano de 2008 o tamanho total projetado da população foi utilizado por inteiro, porque um novo sorotipo (DENV-2) começou a circular naquele ano, para o qual todos os habitantes foram assumidos como suscetíveis. Para o ano de 2009 e 2010 realizou-se o mesmo procedimento de subtrair o número de casos registrados no ano anterior, já que o sorotipo 2 continuou a predominar ao longo deste período. Em 2011 os sorotipos 1 e 4 foram introduzidos e assumimos, para simular os anos de 2011 até 2015, a condição inicial de dobrar a população projetada para 2011 (havia 2 sorotipos circulando) e para 2012 até 2015 subtraiu-se os casos notificados nos anos anteriores.

Um aspecto importante a ser considerado, no entanto, é o número esperado de infecções por dengue que são assintomáticos, que recentemente tem sido mais debatido. A proporção assintomática/sintomática varia de 2 a 10 casos, de acordo com Bhatt et al. (2013); Chastel (2012), isto é, para cada caso sintomático existem outros 2 (e até 10) casos assintomáticos de dengue. Além disso, há evidências que sugerem que os indivíduos assintomáticos são igualmente ou mesmo mais transmissíveis aos mosquitos (Duong et al., 2015).

Em razão disso, neste estudo simulou-se cenários com diferentes proporções entre sintomáticos e assintomáticos com proporções sintomáticos/assintomáticos iguais a $1: 1,1: 2,1: 4,1: 6$ e 1:10.

As tabelas a seguir resumem os procedimentos descritos acima: 
So Sintomáticos

\begin{tabular}{ccccc}
\hline & Sorotipo & População & Número de casos notificados & $\mathbf{1 : 1}$ \\
\hline 2000 & 3 & $5,857,904$ & 4387 & $5,857,904$ \\
2001 & 3 & $5,860,374$ & 29607 & $5,855,987$ \\
2002 & 3 & $5,906,079$ & 152687 & $5,872,085$ \\
2003 & 3 & $5,951,784$ & 3781 & $5,765,103$ \\
2004 & 3 & $5,997,489$ & 2606 & $5,807,027$ \\
2005 & 3 & $6,043,194$ & 2874 & $5,850,126$ \\
2006 & 3 & $6,088,899$ & 16623 & $5,892,957$ \\
2007 & 3 & $6,093,472$ & 27340 & $5,880,907$ \\
2008 & 2 & $6,180,309$ & 130876 & $6,180,309$ \\
2009 & 2 & $6,226,014$ & 5269 & $6,095,138$ \\
2010 & 2 & $6,320,446$ & 5477 & $6,184,301$ \\
2011 & 1 e 4 & $6,317,424$ & 83357 & $12,634,848$ \\
2012 & 1 e 4 & $6,363,129$ & 70559 & $12,593,901$ \\
2013 & 1 e 4 & $6,408,834$ & 56077 & $12,613,371$ \\
2014 & 1 e 4 & $6,453,682$ & 17504 & $12,700,796$ \\
2015 & 1 e 4 & $6,500,244$ & & \\
\hline
\end{tabular}

Tabela 11 - Projeção população suscetível - Sintomáticos 1:1

Na tabela 11 a coluna 3 apresenta o tamanho projetado da população do Rio de Janeiro, em cada ano. A quarta coluna é o número de casos notificados (sintomáticos) e a quinta coluna é o número inicial de suscetíveis calculado subtraindo-se do total da população o número de casos relatados, considerando que não houve casos assintomáticos.

Nas tabelas 12 e 13 a quinta e sexta colunas apresentam a população suscetível à dengue segundo a relação sintomáticos/assintomáticos de 1:2 e 1:4 e de 1:6 e 1:10, respectivamente.

Por exemplo, para a relação de 1:1 do ano 2001, considerou-se a população total igual a população do ano 2000 menos o número de casos notificados naquele ano, já para a relação 1:2, fez-se a população de 2000, menos 2 vezes o número de casos notificados em 2000, e assim por diante para todos os índices considerados. 


\begin{tabular}{|c|c|c|c|c|c|}
\hline & \multirow[b]{2}{*}{ Sorotipo } & \multirow[b]{2}{*}{ População } & \multirow[b]{2}{*}{ Número de casos notificados } & \multicolumn{2}{|c|}{ S0 Assintomáticos } \\
\hline & & & & $1: 2$ & $1: 4$ \\
\hline 2000 & 3 & $5,857,904$ & 4387 & $5,857,904$ & $5,857,904$ \\
\hline 2001 & 3 & $5,860,374$ & 29607 & $5,851,600$ & $5,842,826$ \\
\hline 2002 & 3 & $5,906,079$ & 152687 & $5,838,091$ & $5,770,103$ \\
\hline 2003 & 3 & $5,951,784$ & 3781 & $5,578,422$ & $5,205,060$ \\
\hline 2004 & 3 & $5,997,489$ & 2606 & $5,616,565$ & $5,235,641$ \\
\hline 2005 & 3 & $6,043,194$ & 2874 & $5,657,058$ & $5,270,922$ \\
\hline 2006 & 3 & $6,088,899$ & 16623 & $5,697,015$ & $5,305,131$ \\
\hline 2007 & 3 & $6,093,472$ & 27340 & $5,668,342$ & $5,243,212$ \\
\hline 2008 & 2 & $6,180,309$ & 130876 & $6,180,309$ & $6,180,309$ \\
\hline 2009 & 2 & $6,226,014$ & 5269 & $5,964,262$ & $5,702,510$ \\
\hline 2010 & 2 & $6,320,446$ & 5477 & $6,048,156$ & $5,775,866$ \\
\hline 2011 & 1 e 4 & $6,317,424$ & 83357 & $12,634,848$ & $12,634,848$ \\
\hline 2012 & 1 e 4 & $6,363,129$ & 140559 & $12,559,544$ & $12,392,830$ \\
\hline 2013 & 1 e 4 & $6,408,834$ & 70077 & $12,369,836$ & $11,922,004$ \\
\hline 2014 & 1 e 4 & $6,453,682$ & 5699 & $12,319,378$ & $11,731,392$ \\
\hline 2015 & 1 e 4 & $6,500,244$ & 17504 & $12,401,104$ & $11,801,720$ \\
\hline
\end{tabular}

Tabela 12 - Projeção população suscetível - Assintomáticos 1:2 e 1:4

\begin{tabular}{cccccc}
\hline & & & & \multicolumn{2}{c}{ S0 Assintomáticos } \\
\hline & Sorotipo & População & Número de casos notificados & $\mathbf{1 : 6}$ & $\mathbf{1 : 1 0}$ \\
\hline 2000 & 3 & $5,857,904$ & 4387 & $5,857,904$ & $5,857,904$ \\
2001 & 3 & $5,860,374$ & 29607 & $5,834,052$ & $5,816,504$ \\
2002 & 3 & $5,906,079$ & 152687 & $5,702,115$ & $5,566,139$ \\
2003 & 3 & $5,951,784$ & 3781 & $4,831,698$ & $4,084,974$ \\
2004 & 3 & $5,997,489$ & 2606 & $4,854,717$ & $4,092,869$ \\
2005 & 3 & $6,043,194$ & 2874 & $4,884,786$ & $4,112,514$ \\
2006 & 3 & $6,088,899$ & 16623 & $4,913,247$ & $4,129,479$ \\
2007 & 3 & $6,093,472$ & 27340 & $4,818,082$ & $3,967,822$ \\
2008 & 2 & $6,180,309$ & 130876 & $6,180,309$ & $6,180,309$ \\
2009 & 2 & $6,226,014$ & 5269 & $5,440,758$ & $4,917,254$ \\
2010 & 2 & $6,320,446$ & 5477 & $5,503,576$ & $4,958,996$ \\
2011 & 1 e 4 & $6,317,424$ & 83357 & $12,634,848$ & $12,634,848$ \\
2012 & 1 e 4 & $6,363,129$ & 140559 & $12,226,116$ & $11,892,688$ \\
2013 & 1 e 4 & $6,408,834$ & 70077 & $11,474,172$ & $10,578,508$ \\
2014 & 1 e 4 & $6,453,682$ & 5699 & $11,143,406$ & $9,967,434$ \\
2015 & 1 e 4 & $6,500,244$ & 17504 & $11,202,336$ & $10,003,568$ \\
\hline
\end{tabular}

Tabela 13 - Projeção população suscetível - Assintomáticos 1:6 e 1:10

\subsection{Estimando a força de infecção da dengue no Rio de Ja- neiro}

Historicamente a força de infecção da dengue no Rio de Janeiro mostra um comportamento sazonal com início dos casos no início do mês de Janeiro, pico no final do mês de Abril e declínio após o mês de Abril. A figura 21 apresenta o total 
de casos acumulados por semana epidemiológica para o Rio de Janeiro entre os anos 2000 e 2015.

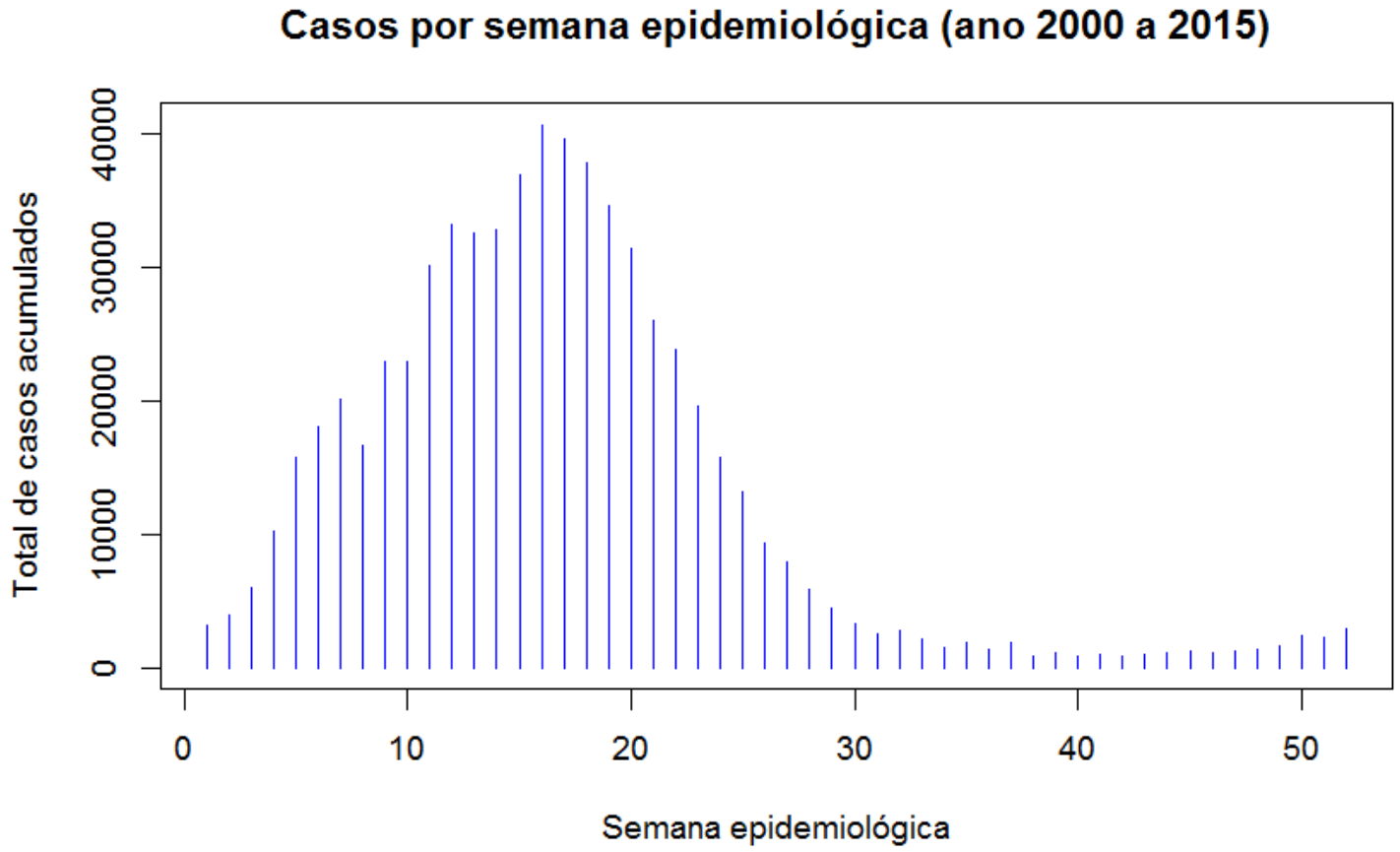

Figura 21 - Casos acumulados de dengue por semana epidemiológica - Rio de Janeiro

Ao considerar o número notificado de casos semanais relatados ao banco de dados do SINAN de 2000 até 2015, pôde-se calcular a força de infecção da dengue, dependente do tempo, para cada ano deste conjunto de dados.

Para estimar a força de infecção da dengue no Rio de Janeiro nos anos do histórico analisado, a força dependente do tempo de infecção, obtida através do ajuste das equações 3.17, que reproduzem os casos de dengue por semana, foi ajustada como uma função, conforme:

$$
\lambda(t)=c_{1} e^{\left[-\frac{\left(t-c_{2}\right)^{2}}{c_{3}}\right]} F(t)
$$

Na equação 5.1, $c_{1}$ é um parâmetro de escala que determina a incidência máxima, $c_{2}$ é o tempo em que a incidência máxima é alcançada, $c_{3}$ representa a largura da função de incidência dependente do tempo e $F(t)$ é uma função ad hoc, de forma logística, introduzida para melhorar o ajuste do modelo aos dados e definir o tempo inicial da infecção $c_{5}$, onde $F(t)$ é dada por:

$$
F(t)=\frac{1}{1+e^{\left[-c_{4}\left(t-c_{5}\right)\right]}}
$$


onde $c_{4}$ determina a taxa de variação da incidência.

Para obter o risco de dengue para os turistas ajustou-se os dados de incidência às funções 5.1 e 5.2 da força de infecção, conforme descrito no capítulo 3 , assumindo a variação das condições iniciais para o número de indivíduos suscetíveis, afim de se obter os parâmetros que, quando aplicados ao conjunto de equações 3.17, recupera a incidência dos novos casos relatados por semana no banco de dados do SINAN $(\lambda(t) S(t))$. Os resultados destes ajustes podem ser observados na próxima seção, figuras 22 a 53.

\subsection{Resultados - Risco de dengue em turistas nos Jogos Olím- picos 2016}

A seguir observa-se os ajustes do modelo aos casos notificados de dengue por ano, para a série 2000 até 2015 , destacando para cada ano o ajuste realizado para os casos sintomáticos (1:1).

As condições iniciais utilizadas em todos os ajustes foram: $S_{H}$ variou de acordo com as tabelas 11,12 e $13, I_{H}=1, R_{H}=0, \mu_{H}=3,4 \times 10^{-5} / \mathrm{dia}, \alpha=$ $1 \times 10^{-3} /$ dia e $\gamma=0,14 /$ dia (Massad et al., 2010). Os parâmetros $c_{1}, c_{2}, c_{3}, c_{4}$ e $c_{5}$ são ajustados pelo programa durante a busca da curva que reproduz a força de infecção.

Repetimos o processo de ajuste para as 5 proporções entre sintomáticos e assintomáticos (1:1, 1:2, 1:4, 1:6 e 1:10) para cada ano da série (2000 até 2015).

Os pontos em azul representam os casos de dengue por semana, no Rio de Janeiro, notificados ao Ministério da Saúde e a linha vermelha é o ajuste do modelo às notificações, ou seja, é a curva de incidência $\left(\lambda(t) S_{H}(t)\right)$ para os casos de dengue notificados obtidas pelo modelo 3.17.

Todos os ajustes foram realizados no software Berkeley Madonna (versão 8.3.23.0) e seguiu o método do guia de uso do software (Macey et al., 2009) reproduzido no apêndice. 


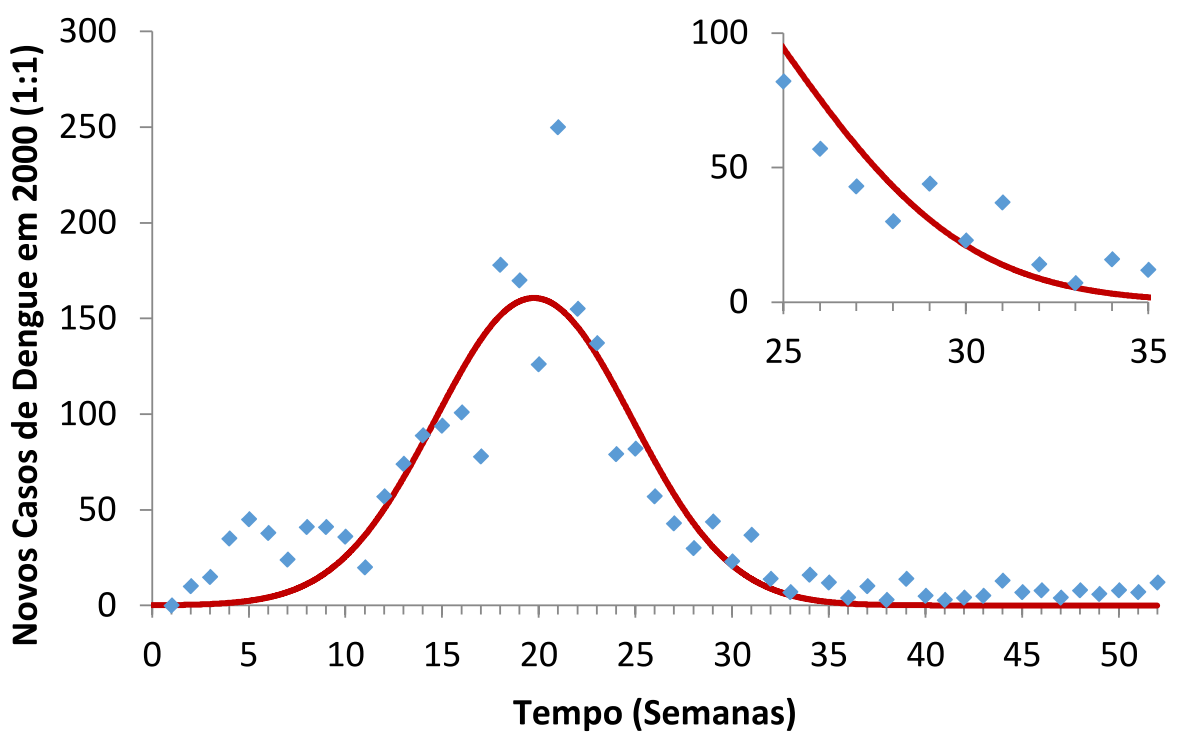

Figura 22 - Ajuste casos sintomáticos ano $2000-\mathrm{RMS}=22,18, \mathrm{R}^{2}=82,59 \%$, AIC $=150,69$

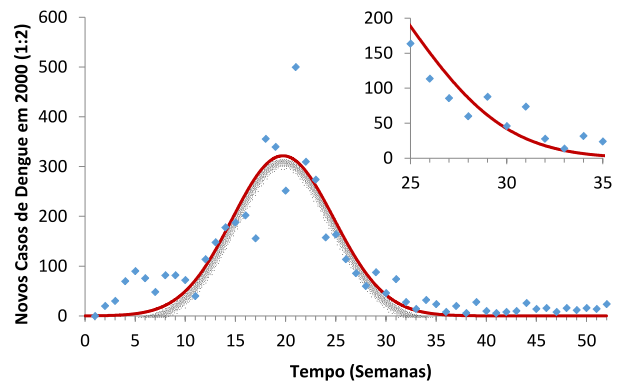

((a)) $1: 2$

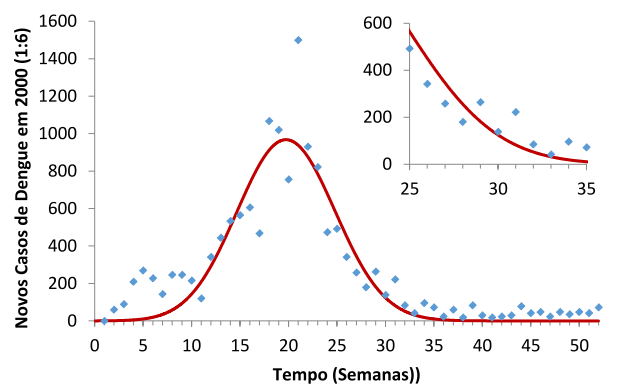

((c)) $1: 6$

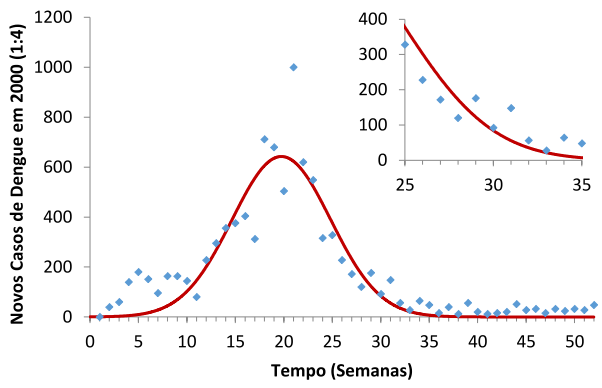

((b)) $1: 4$

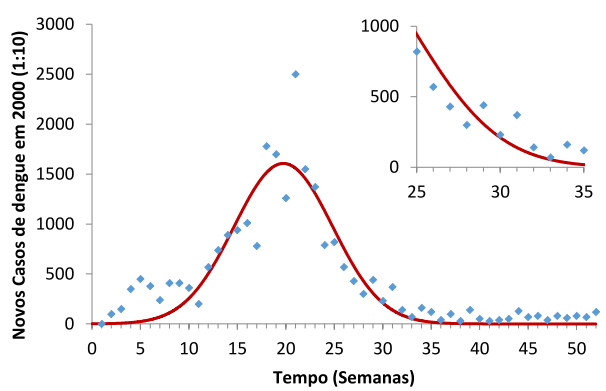

((d)) $1: 10$

Figura 23 - Ajuste casos assintomáticos, ano 2000 - ((a)) RMS $=44,47, \mathrm{R}^{2}=$ $82,67 \%, \mathrm{AIC}=152,07,((\mathrm{~b})) \mathrm{RMS}=88,72, \mathrm{R}^{2}=82,76 \%, \mathrm{AIC}=$ $153,45,((\mathrm{c})) \mathrm{RMS}=88,72, \mathrm{R}^{2}=82,76 \%, \mathrm{AIC}=153,45$ e $((\mathrm{d})) \mathrm{RMS}$ $=221,80, \mathrm{R}^{2}=82,76 \%, \mathrm{AIC}=155,28$ 


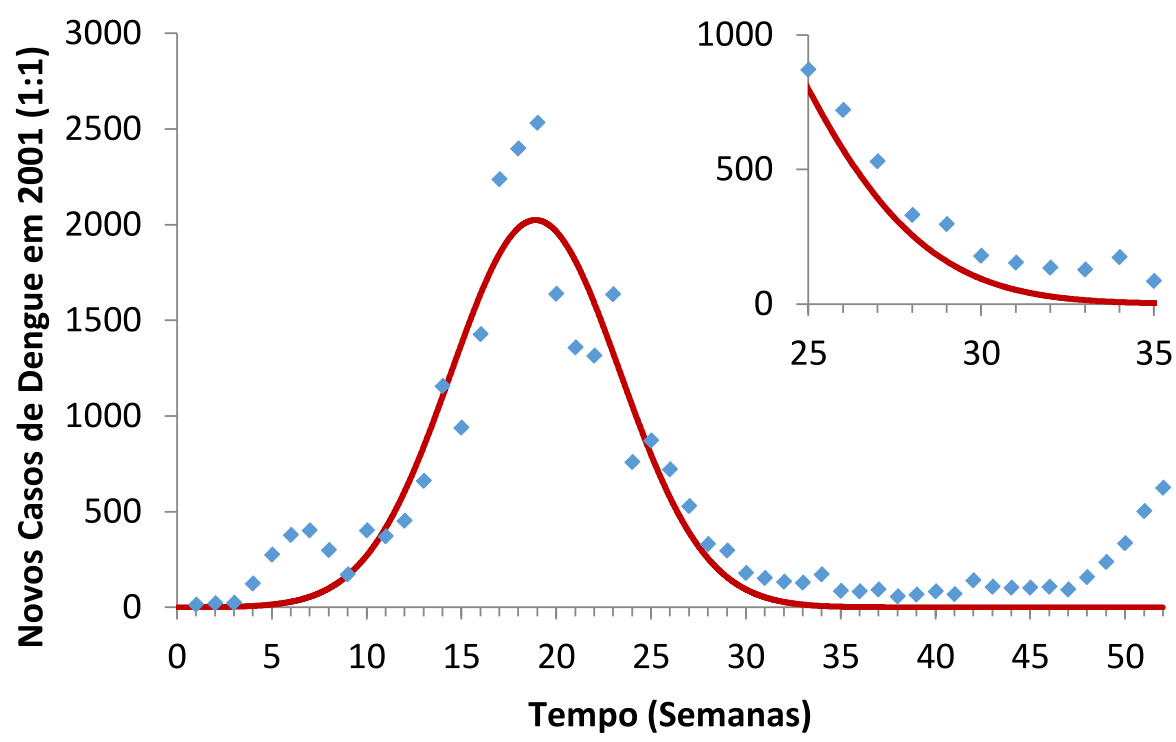

Figura 24 - Ajuste casos sintomáticos ano $2001-\mathrm{RMS}=237,22, \mathrm{R}^{2}=85,81 \%$, $\mathrm{AIC}=152,34$

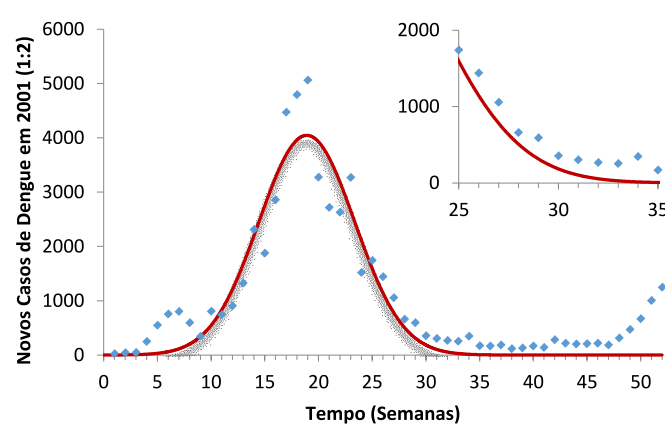

((a)) $1: 2$

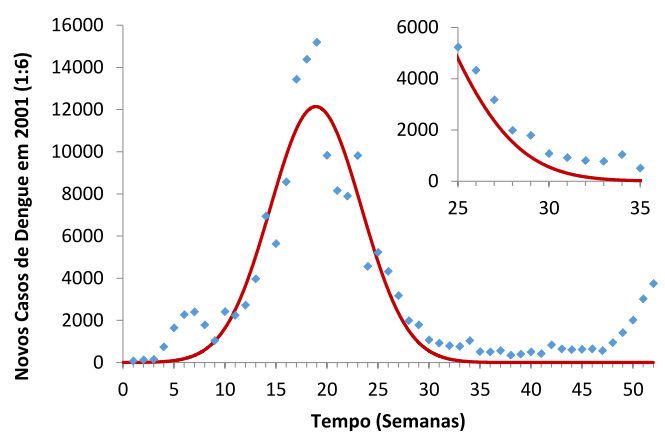

((c)) $1: 6$

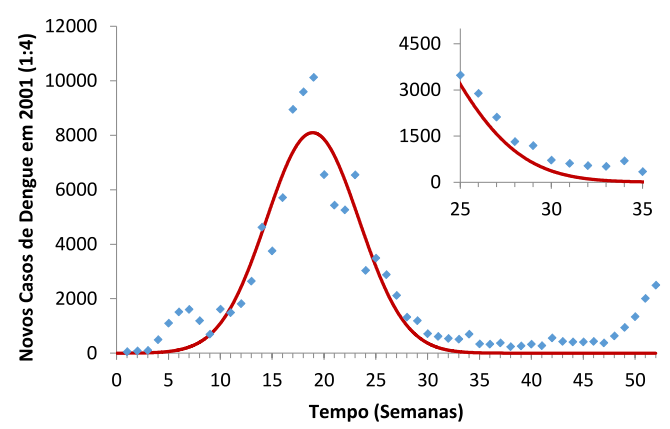

((b)) 1:4

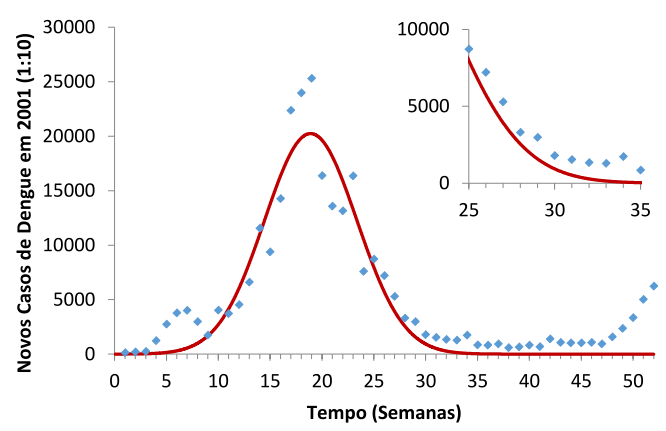

((d)) $1: 10$

Figura 25 - Ajuste casos assintomáticos ano 2001 - ((a)) RMS $=474,56, \mathrm{R}^{2}=$ $85,80 \%, \mathrm{AIC}=153,73,((\mathrm{~b})) \mathrm{RMS}=949,01, \mathrm{R}^{2}=85,81 \%, \mathrm{AIC}=$ $155,11,((\mathrm{c})) \mathrm{RMS}=1423,24, \mathrm{R}^{2}=85,81 \%, \mathrm{AIC}=155,92$ e $((\mathrm{d}))$ $\mathrm{RMS}=2371,24, \mathrm{R}^{2}=85,82 \%, \mathrm{AIC}=156,94$ 


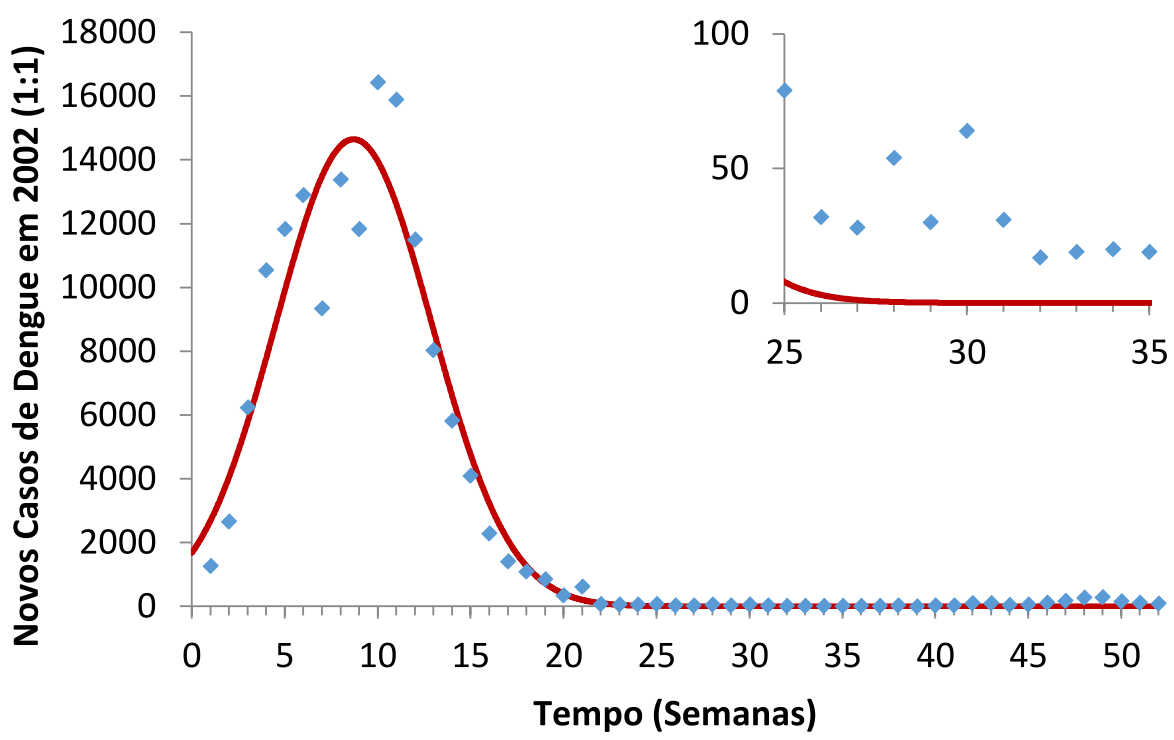

Figura 26 - Ajuste casos sintomáticos ano $2002-\mathrm{RMS}=1102,64, \mathrm{R}^{2}=94,80 \%$, $\mathrm{AIC}=162,86$

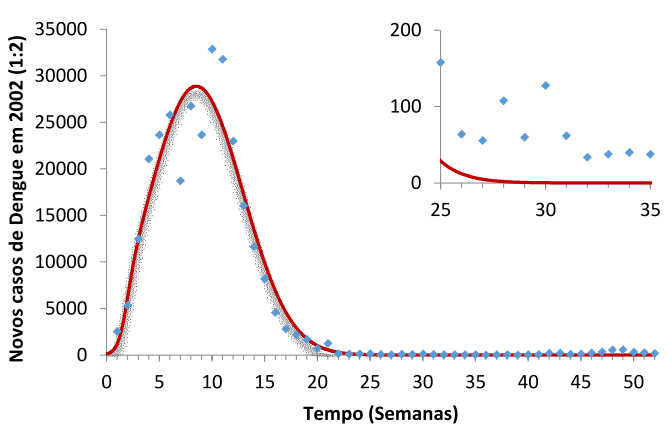

((a)) $1: 2$

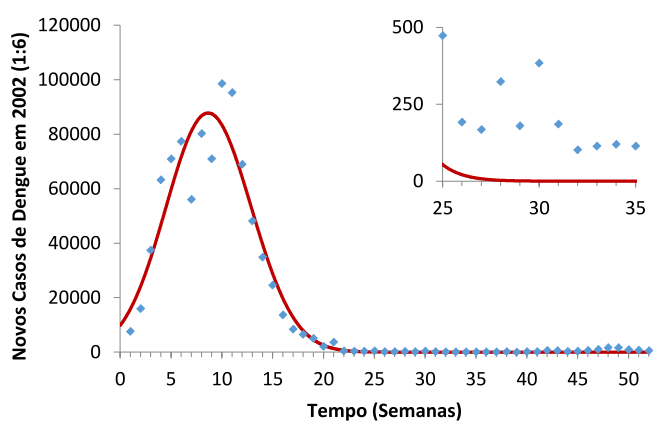

((c)) $1: 6$

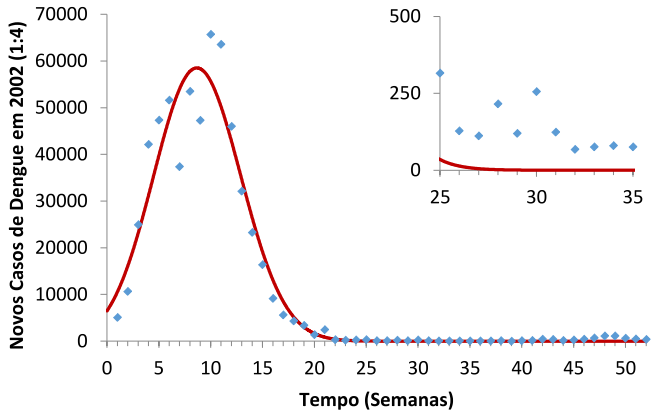

((b)) $1: 4$

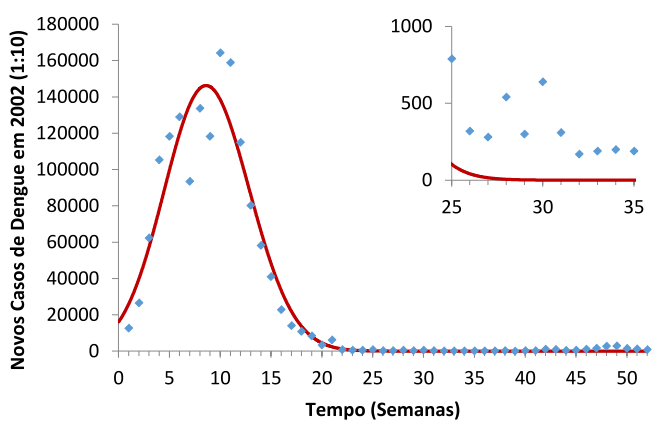

((d)) $1: 10$

Figura 27 - Ajuste casos assintomáticos ano 2002 - ((a)) RMS $=213,47, \mathrm{R}^{2}=$ $95,18 \%, \mathrm{AIC}=164,15,((\mathrm{~b})) \mathrm{RMS}=4425,40, \mathrm{R}^{2}=94,76 \%, \mathrm{AIC}=$ $165,67,((\mathrm{c})) \mathrm{RMS}=6597,03, \mathrm{R}^{2}=94,73 \%, \mathrm{AIC}=166,50$ e $((\mathrm{d}))$ $\mathrm{RMS}=11077,00, \mathrm{R}^{2}=94,65 \%, \mathrm{AIC}=167,57$ 


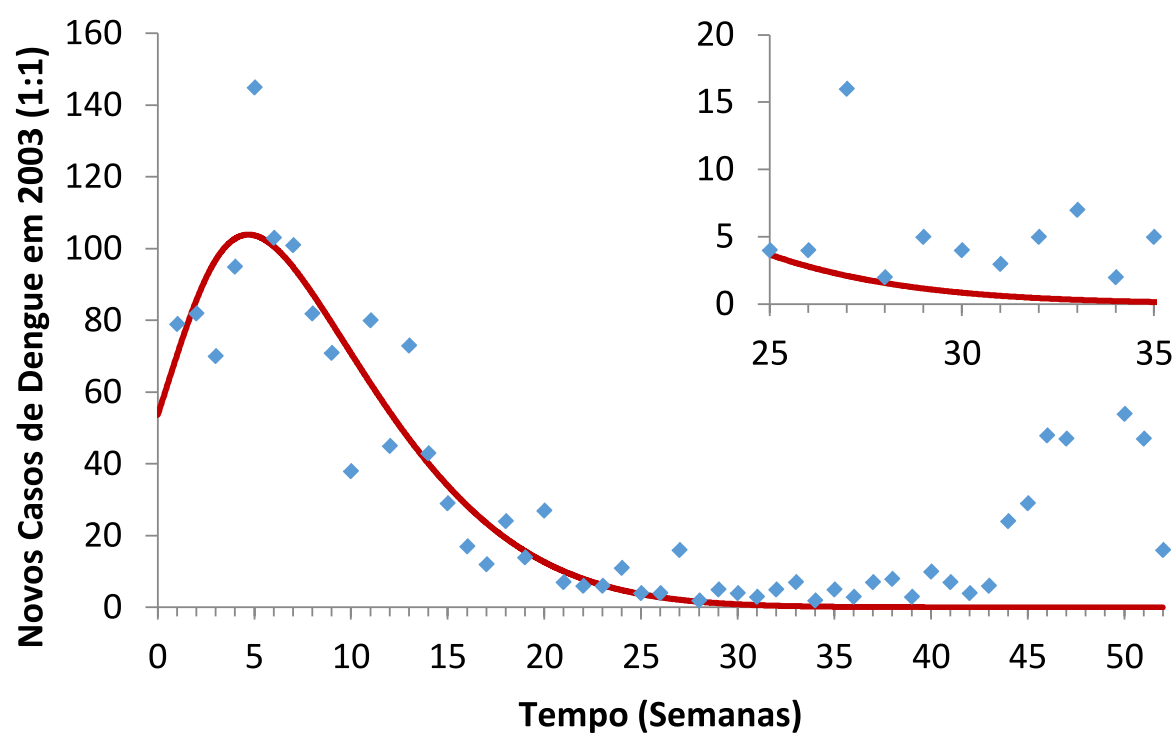

Figura 28 - Ajuste casos sintomáticos ano 2003 - RMS $=23,35, \mathrm{R}^{2}=54,87 \%$, AIC $=147,66$

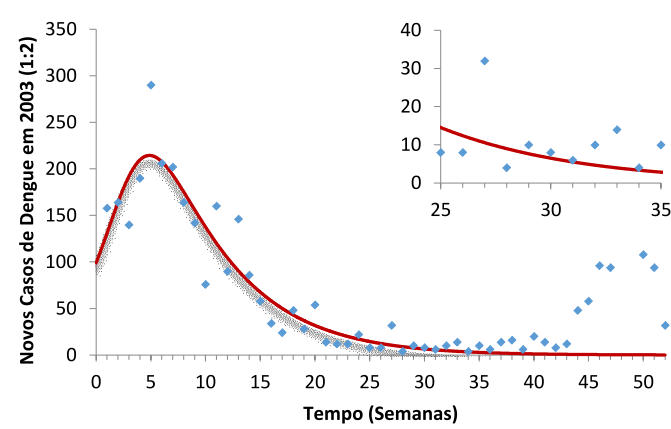

((a)) $1: 2$

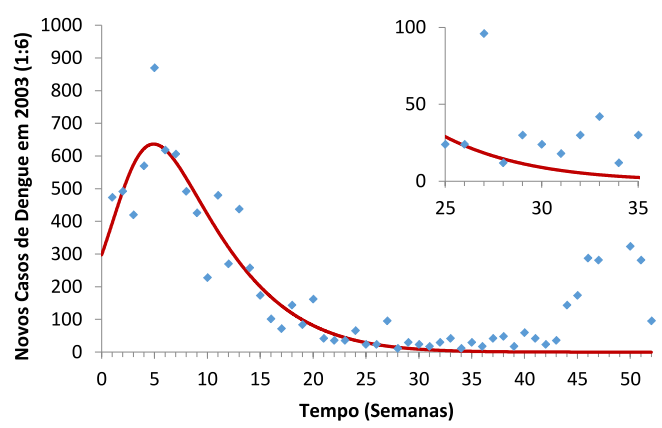

((c)) $1: 6$

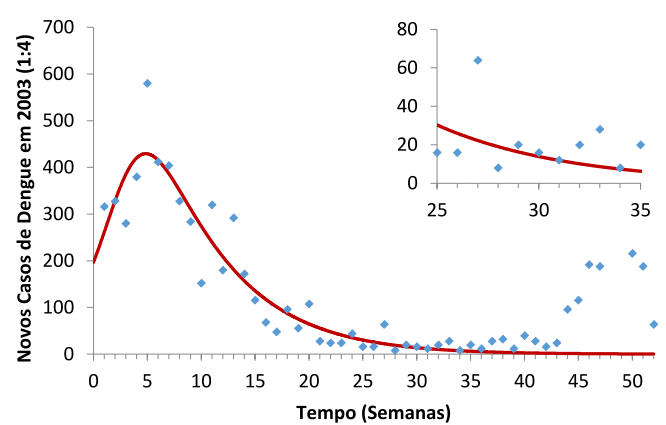

((b)) 1:4

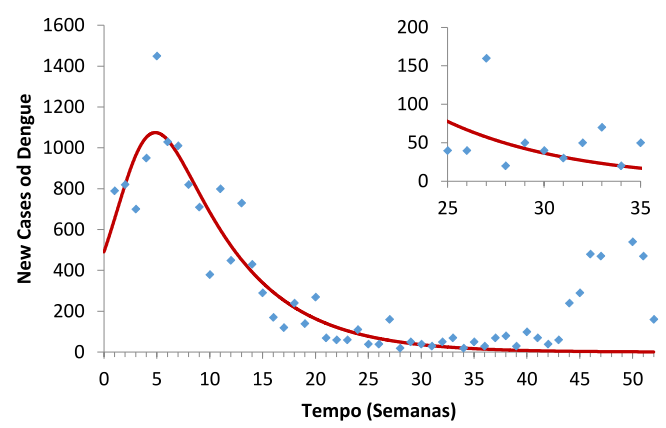

((d)) $1: 10$

Figura 29 - Ajuste casos assintomáticos ano $2003-((\mathrm{a})) \mathrm{RMS}=45,85, \mathrm{R}^{2}=$ $55,67 \%, \mathrm{AIC}=148,89,((\mathrm{~b})) \mathrm{RMS}=92,52, \mathrm{R}^{2}=55,71 \%, \mathrm{AIC}=$ $150,25,((\mathrm{c})) \mathrm{RMS}=138,24, \mathrm{R}^{2}=55,22 \%, \mathrm{AIC}=151,21$ e $((\mathrm{d})) \mathrm{RMS}$ $=228,94, \mathrm{R}^{2}=55,78 \%, \mathrm{AIC}=152,07$ 


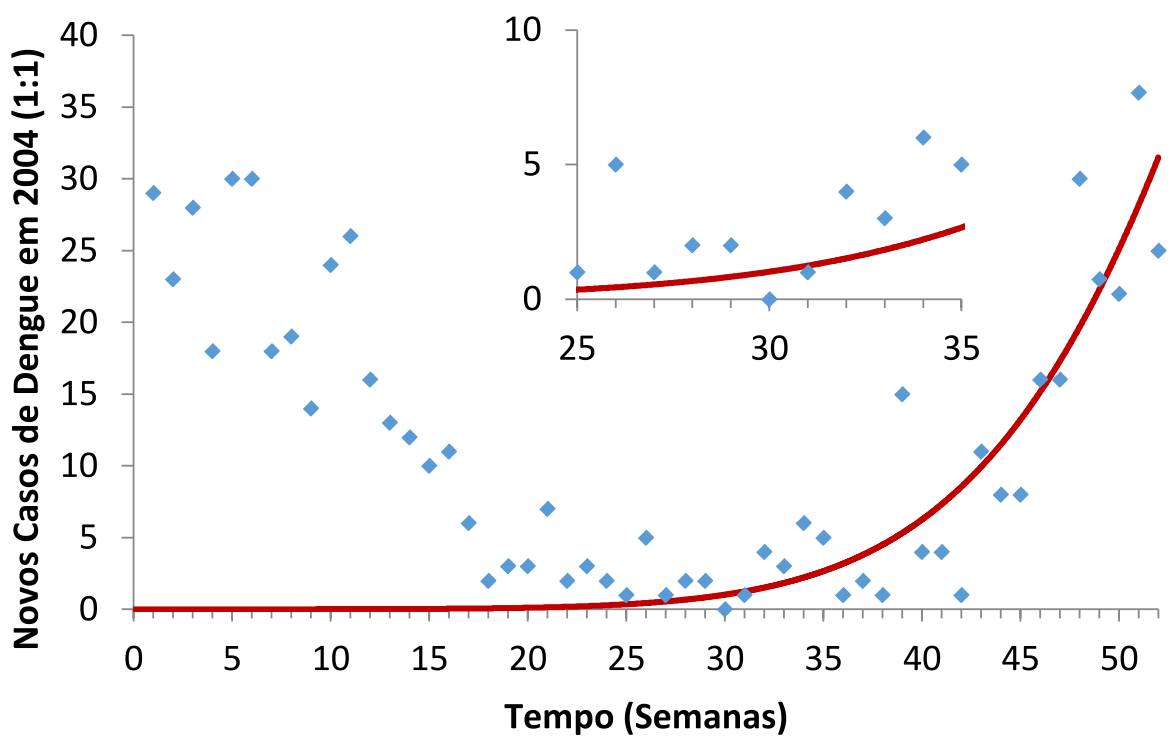

Figura 30 - Ajuste casos sintomáticos ano 2004 - RMS $=12,26, \mathrm{R}^{2}=46,40 \%$, AIC $=172,18$

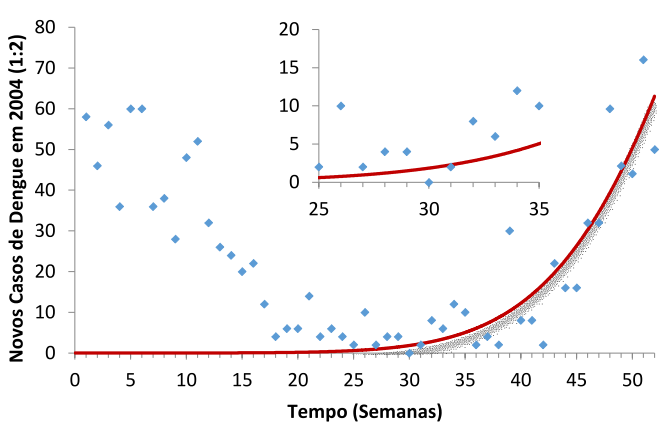

((a)) $1: 2$

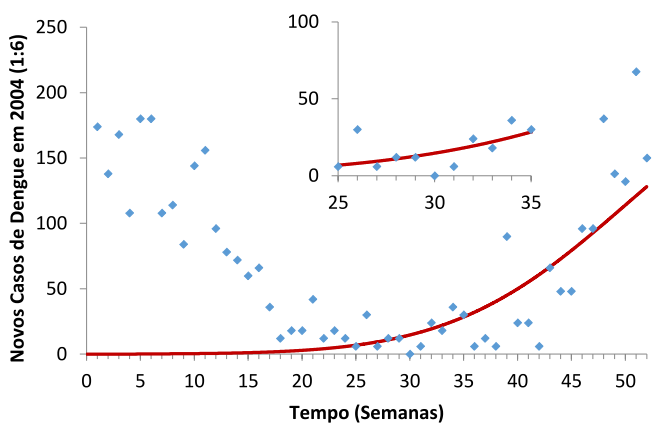

((c)) $1: 6$

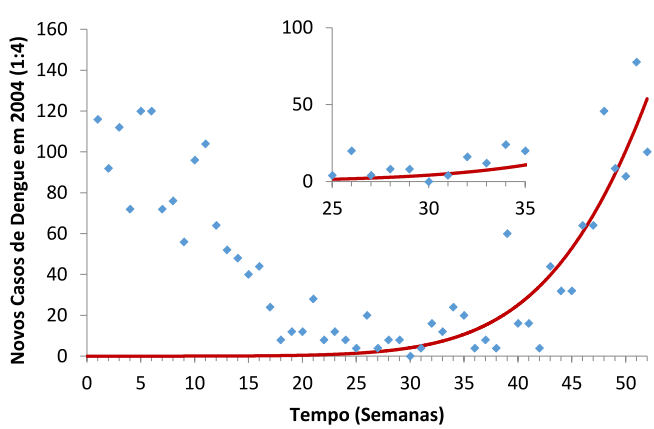

((b)) $1: 4$

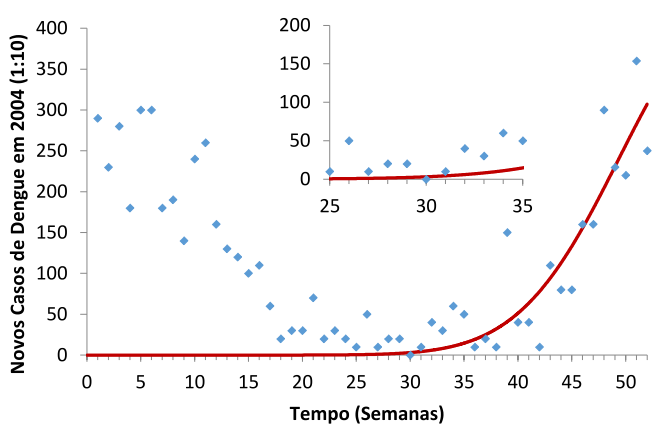

((d)) $1: 10$

Figura 31 - Ajuste casos assintomáticos ano 2004 - ((a)) RMS = 24,53, $\mathrm{R}^{2}=$ $46,46 \%, \mathrm{AIC}=173,60,((\mathrm{~b})) \mathrm{RMS}=49,04, \mathrm{R}^{2}=46,40 \%, \mathrm{AIC}=$ $174,94,((\mathrm{c})) \mathrm{RMS}=76,34, \mathrm{R}^{2}=51,21 \%, \mathrm{AIC}=199,83$ e $((\mathrm{d})) \mathrm{RMS}$ $=122,72, \mathrm{R}^{2}=46,67 \%, \mathrm{AIC}=176,99$ 


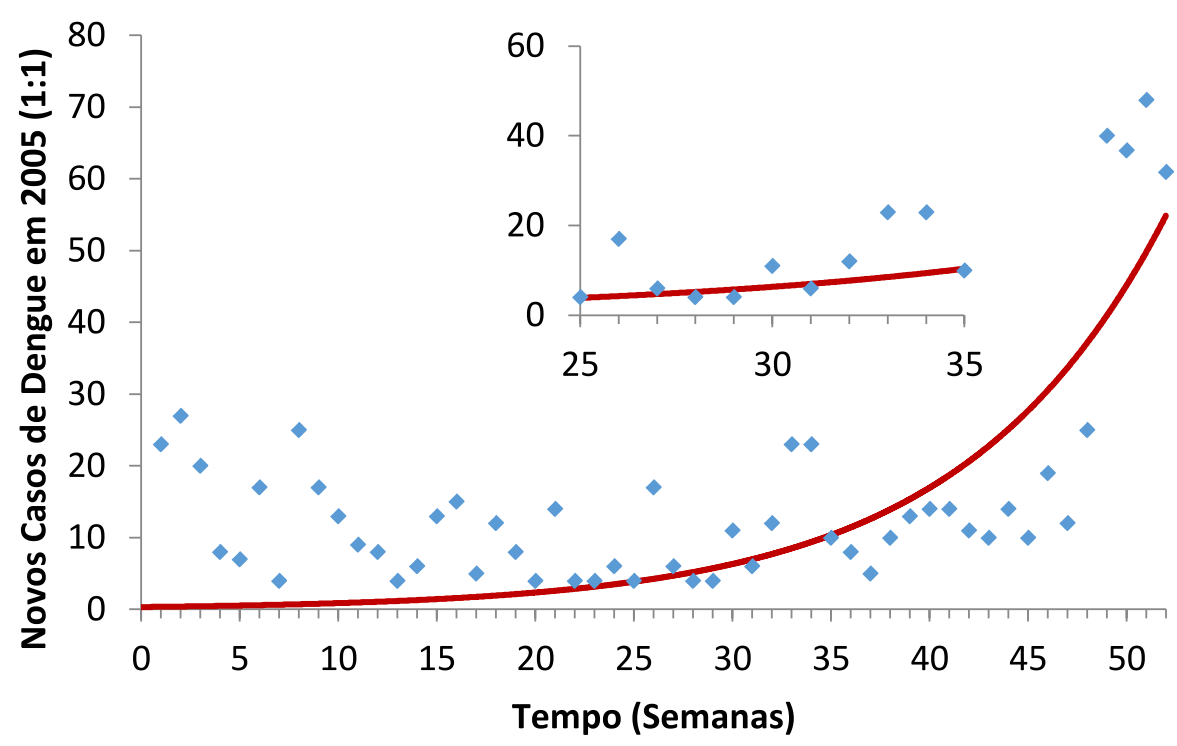

Figura 32 - Ajuste casos sintomáticos ano 2005 - RMS $=11,90, \mathrm{R}^{2}=45,87 \%$, AIC $=149,46$

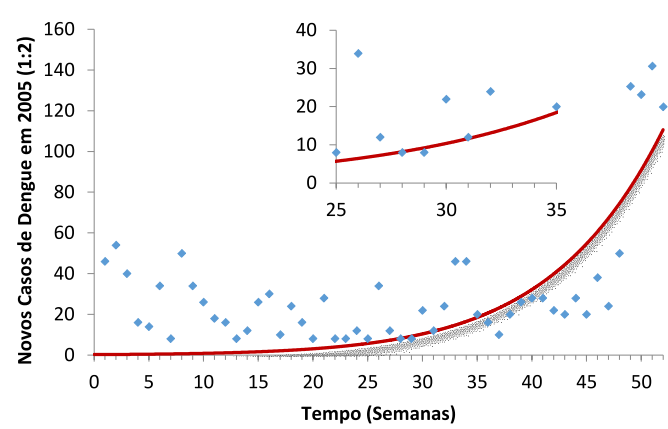

((a)) $1: 2$

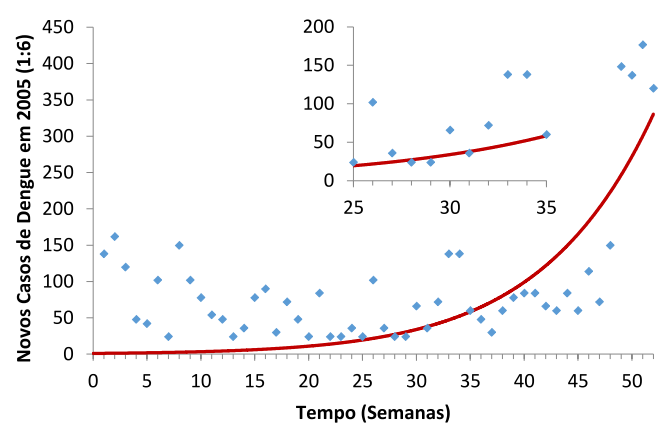

((c)) $1: 6$

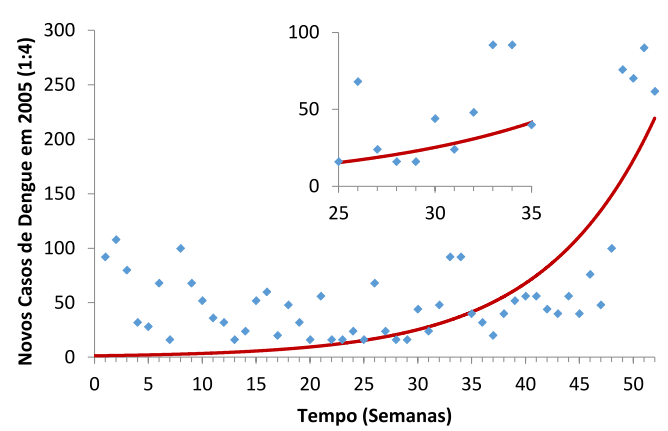

((b)) 1:4

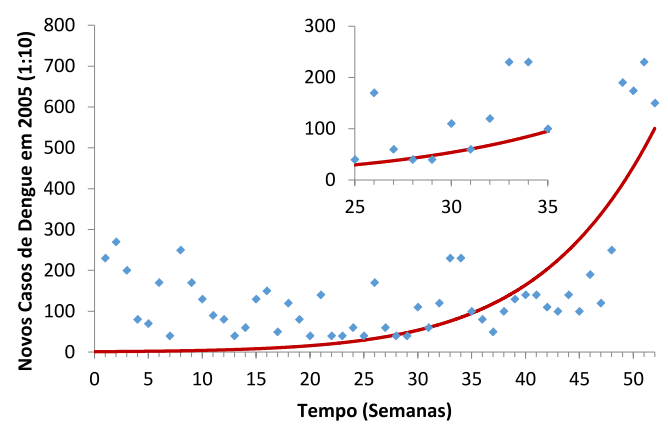

((d)) $1: 10$

Figura 33 - Ajuste casos assintomáticos ano 2005 - ((a)) RMS $=24,13, \mathrm{R}^{2}=$ $44,34 \%, \mathrm{AIC}=151,29,((\mathrm{~b})) \mathrm{RMS}=47,60, \mathrm{R}^{2}=45,83 \%, \mathrm{AIC}=$ $152,23,((\mathrm{c})) \mathrm{RMS}=72,08, \mathrm{R}^{2}=44,81 \%, \mathrm{AIC}=153,32$ e $((\mathrm{d})) \mathrm{RMS}$ $=120,96, \mathrm{R}^{2}=44,04 \%, \mathrm{AIC}=154,59$ 


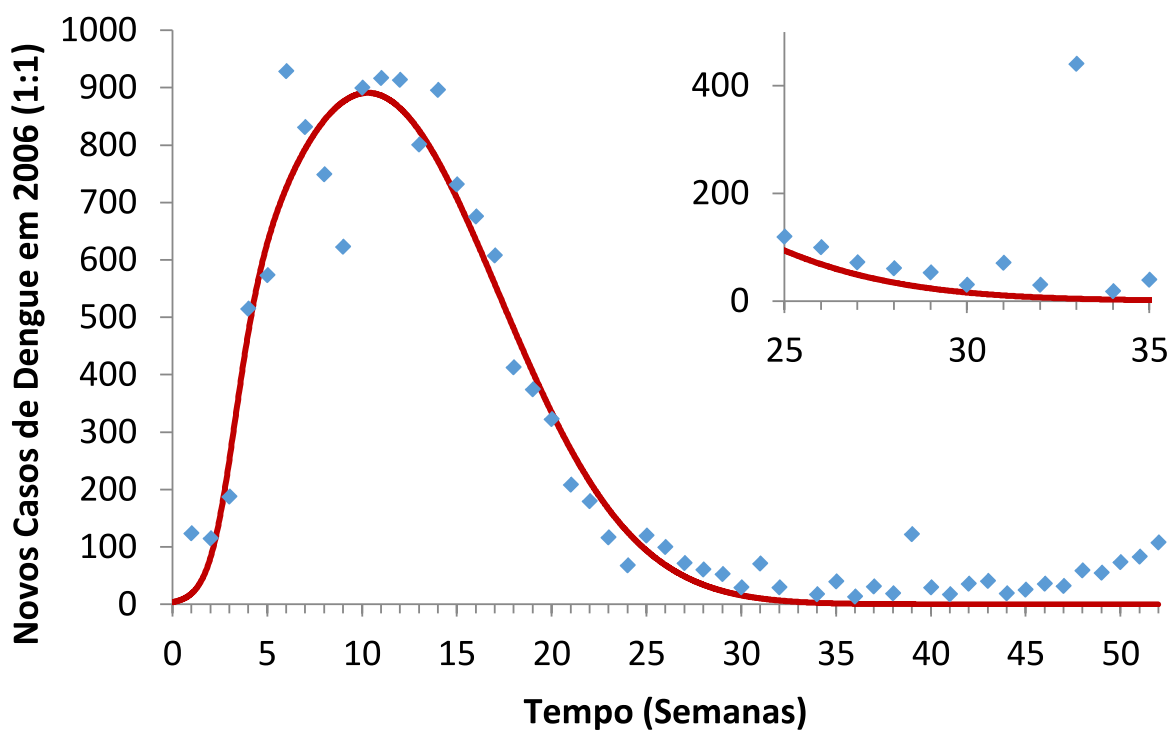

Figura 34 - Ajuste casos sintomáticos ano 2006 - RMS $=91,16, \mathrm{R}^{2}=91,61 \%$, AIC $=148,24$

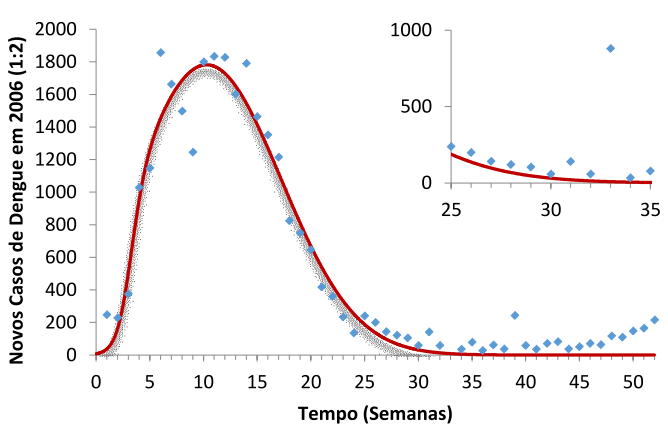

((a)) $1: 2$

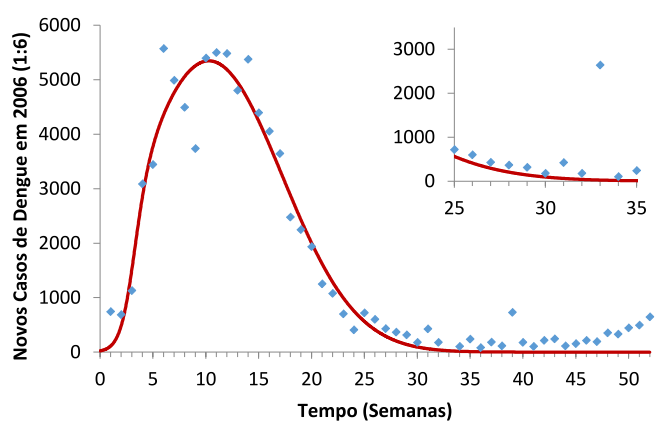

((c)) $1: 6$

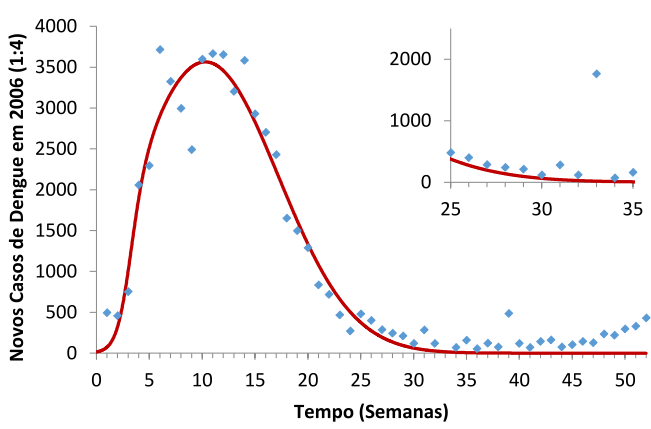

((b)) $1: 4$

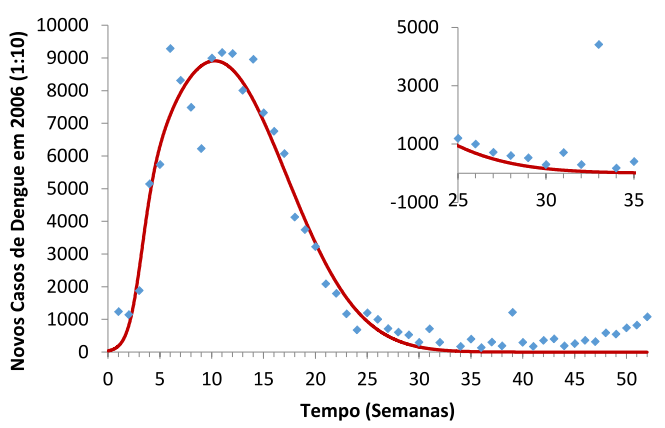

((d)) $1: 10$

Figura 35 - Ajuste casos assintomáticos ano 2006 - ((a)) RMS $=182,33, \mathrm{R}^{2}=$ $91,61 \%, \mathrm{AIC}=149,62,((\mathrm{~b})) \mathrm{RMS}=364,69, \mathrm{R}^{2}=91,61 \%, \mathrm{AIC}=$ $151,01,((\mathrm{c})) \mathrm{RMS}=541,90, \mathrm{R}^{2}=91,61 \%, \mathrm{AIC}=151,82$ e $((\mathrm{d})) \mathrm{RMS}$ $=903,40, \mathrm{R}^{2}=91,61 \%, \mathrm{AIC}=152,85$ 


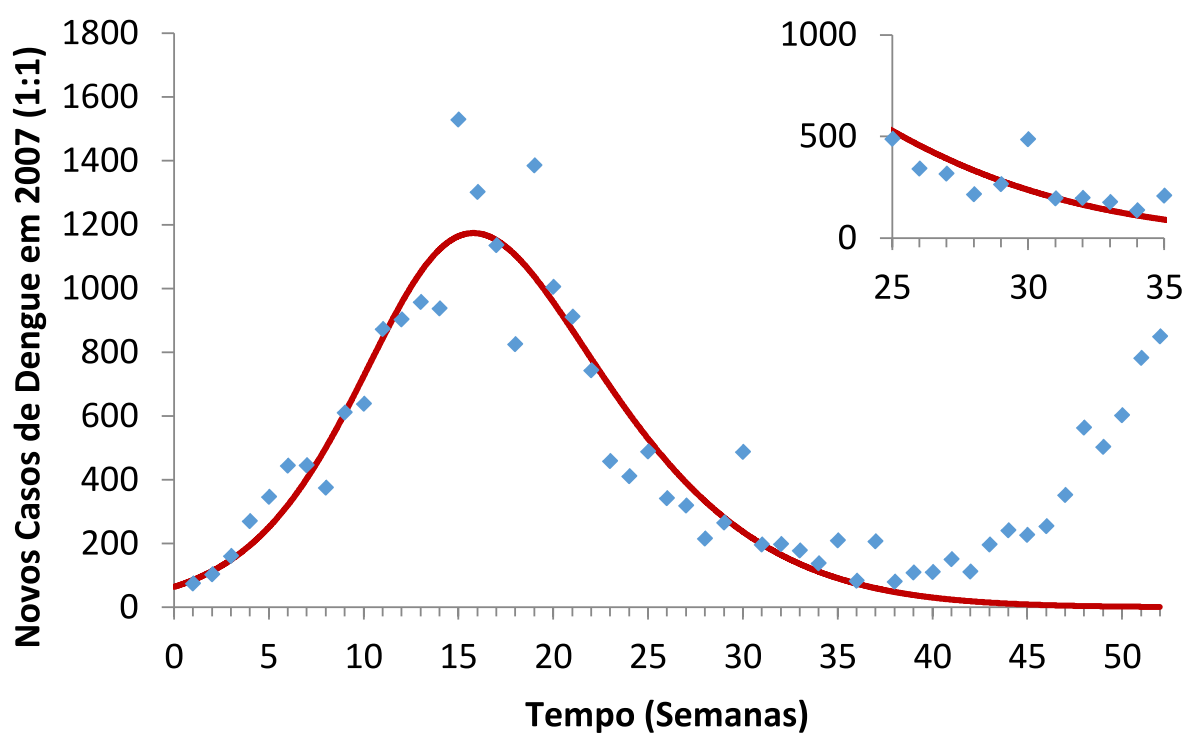

Figura 36 - Ajuste casos sintomáticos ano 2007 - RMS $=251,75, \mathrm{R}^{2}=52,99 \%$, $\mathrm{AIC}=141,23$

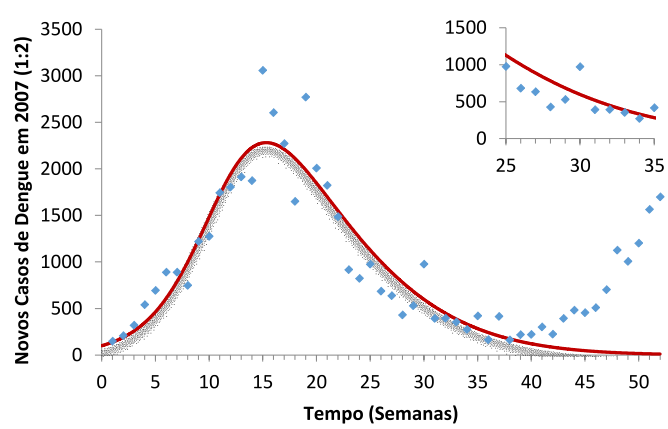

((a)) $1: 2$

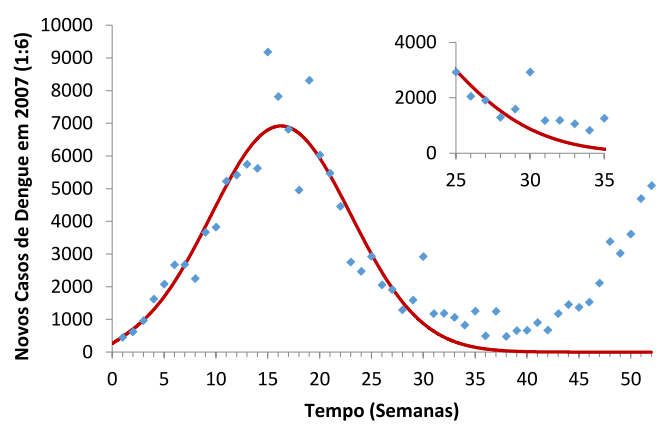

((c)) $1: 6$

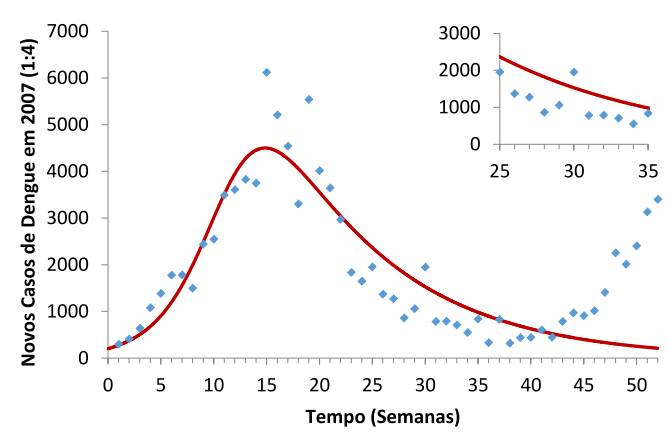

((b)) 1:4

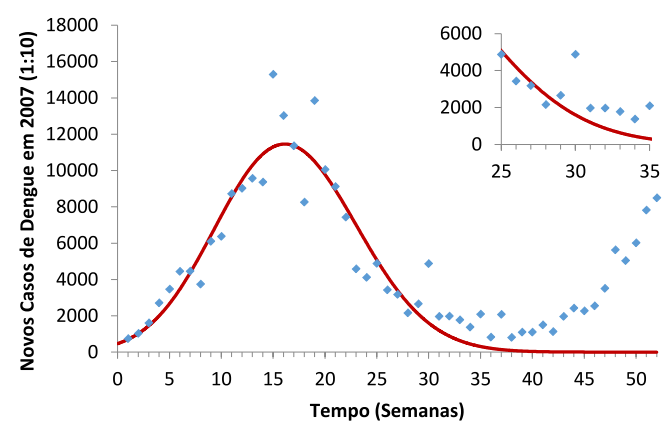

((d)) $1: 10$

Figura 37 - Ajuste casos assintomáticos ano 2007 - ((a)) RMS $=502,81, \mathrm{R}^{2}=$ $53,12 \%, \mathrm{AIC}=142,72,((\mathrm{~b})) \mathrm{RMS}=959,31, \mathrm{R}^{2}=57,34 \%, \mathrm{AIC}=$ $143,56,((\mathrm{c})) \mathrm{RMS}=1551,68, \mathrm{R}^{2}=50,39 \%, \mathrm{AIC}=145,03$ e $((\mathrm{d}))$ $\mathrm{RMS}=2583,02, \mathrm{R}^{2}=50,51 \%, \mathrm{AIC}=146,19$ 


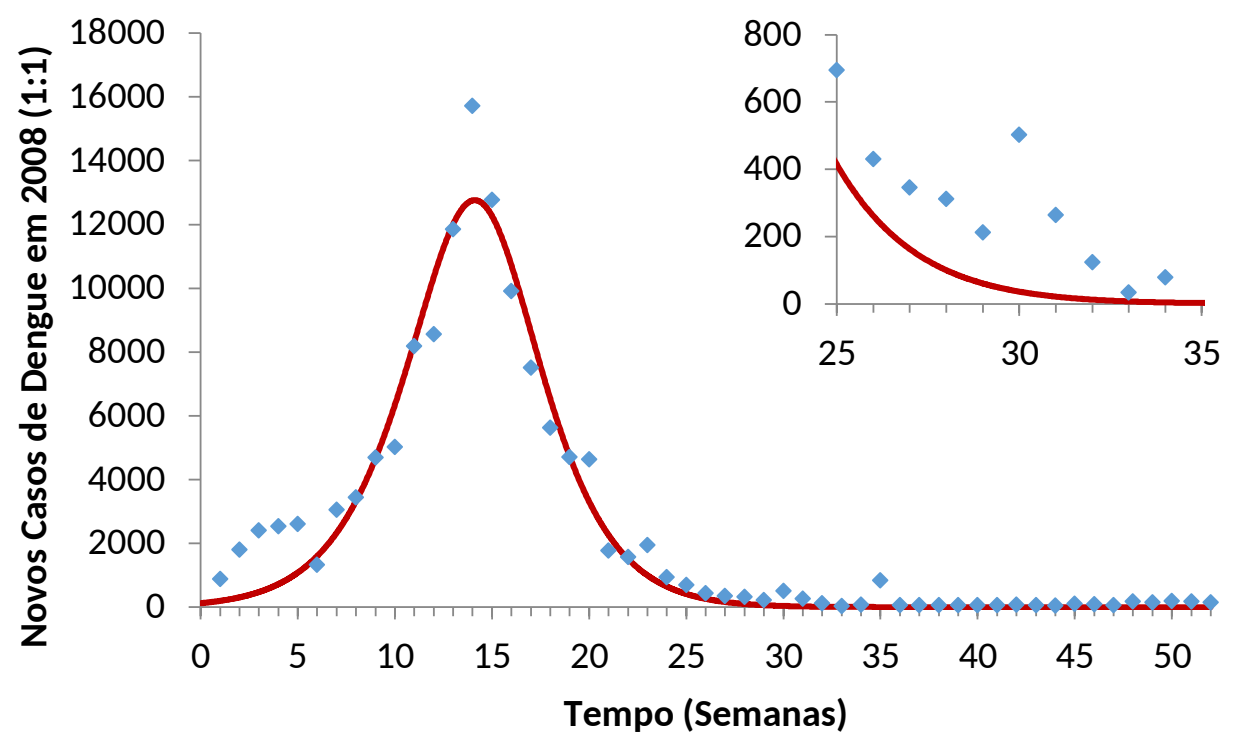

Figura 38 - Ajuste casos sintomáticos ano 2008 - RMS $=806,19, \mathrm{R}^{2}=95,22 \%$, $\mathrm{AIC}=159,68$

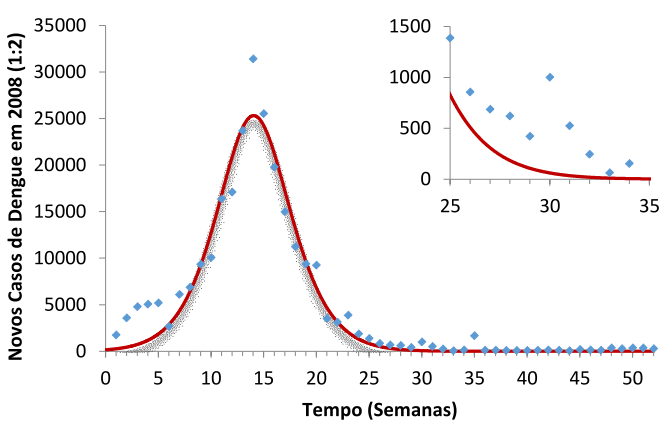

((a)) $1: 2$

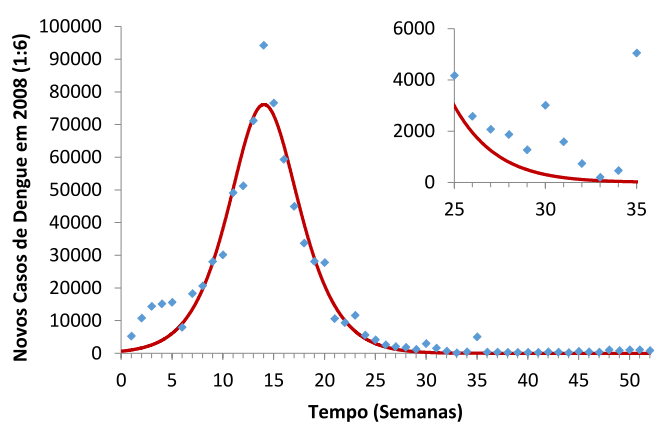

((c)) $1: 6$

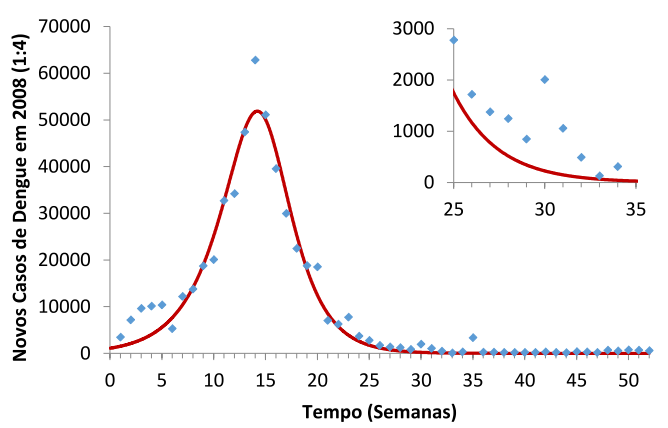

((b)) $1: 4$

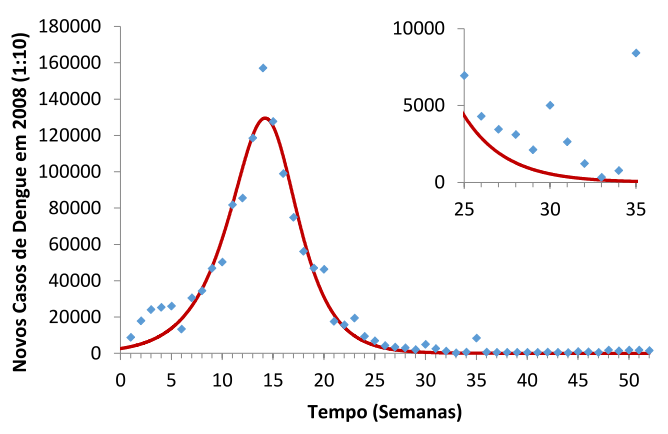

((d)) $1: 10$

Figura 39 - Ajuste casos assintomáticos ano 2008 - ((a)) RMS $=1681,39, \mathrm{R}^{2}=$ $94,80 \%, \mathrm{AIC}=161,22,((\mathrm{~b})) \mathrm{RMS}=2957,41, \mathrm{R}^{2}=95,98 \%, \mathrm{AIC}=$ $162,23,((\mathrm{c})) \mathrm{RMS}=5776,97, \mathrm{R}^{2}=93,05 \%, \mathrm{AIC}=163,80$ e $((\mathrm{d}))$ $\mathrm{RMS}=7370,80, \mathrm{R}^{2}=95,93 \%, \mathrm{AIC}=164,08$ 


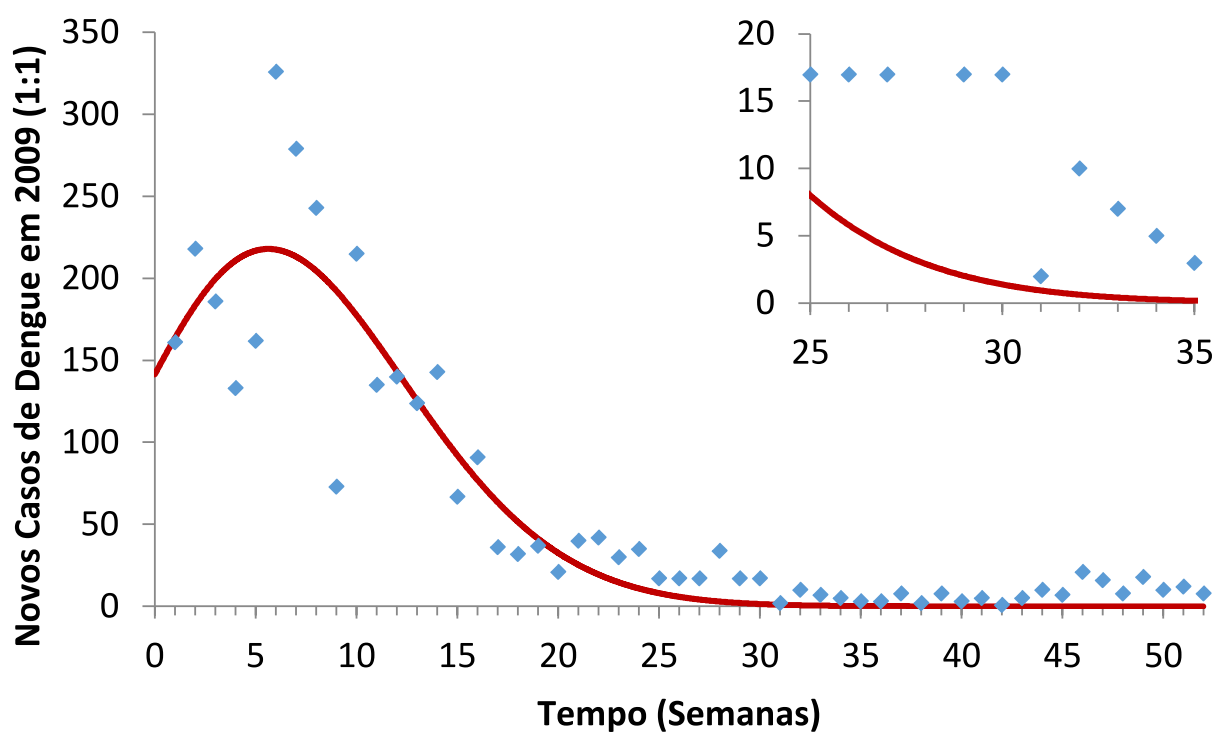

Figura 40 - Ajuste casos sintomáticos ano 2009 - RMS $=31,90, \mathrm{R}^{2}=84,57 \%$, AIC $=151,08$

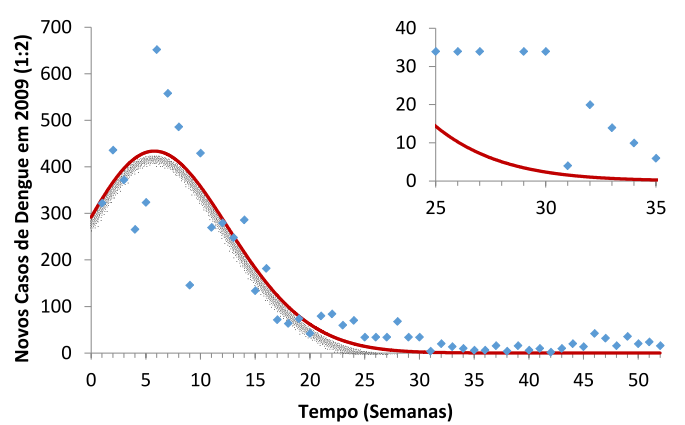

((a)) $1: 2$

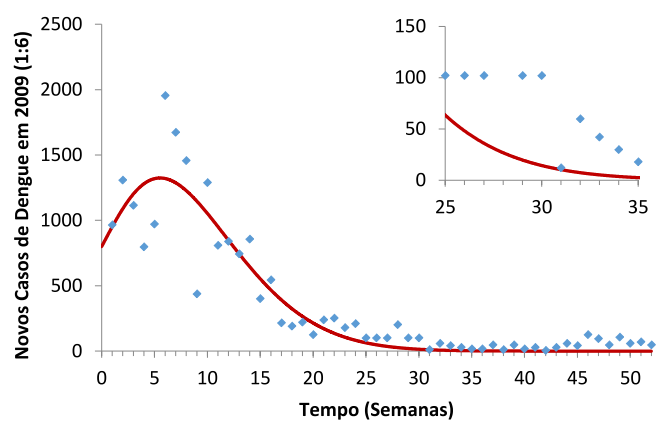

((c)) $1: 6$

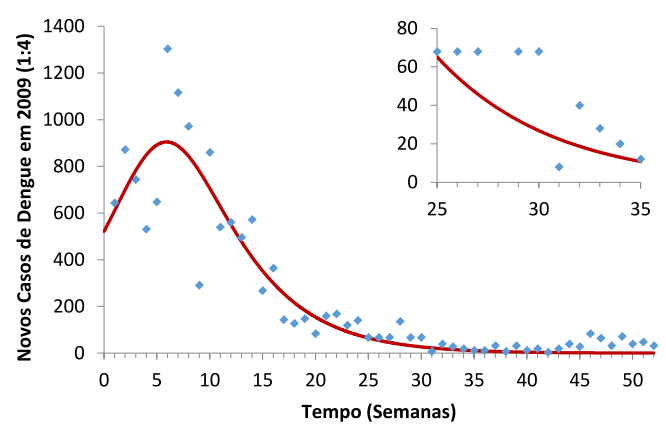

((b)) 1:4

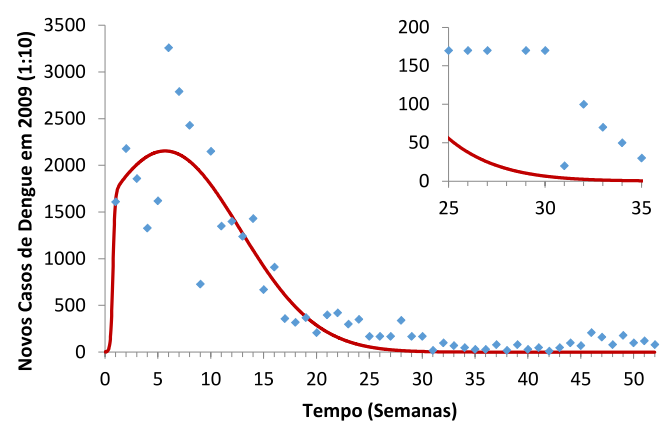

((d)) $1: 10$

Figura 41 - Ajuste casos assintomáticos ano 2009 - ((a)) RMS $=63,83, \mathrm{R}^{2}=$ $84,56 \%, \mathrm{AIC}=152,51,((\mathrm{~b})) \mathrm{RMS}=124,28, \mathrm{R}^{2}=84,36 \%, \mathrm{AIC}=$ $153,67,((\mathrm{c})) \mathrm{RMS}=188,73, \mathrm{R}^{2}=84,71 \%, \mathrm{AIC}=154,63$ e $((\mathrm{d})) \mathrm{RMS}$ $=318,15, \mathrm{R}^{2}=84,36 \%, \mathrm{AIC}=155,73$ 


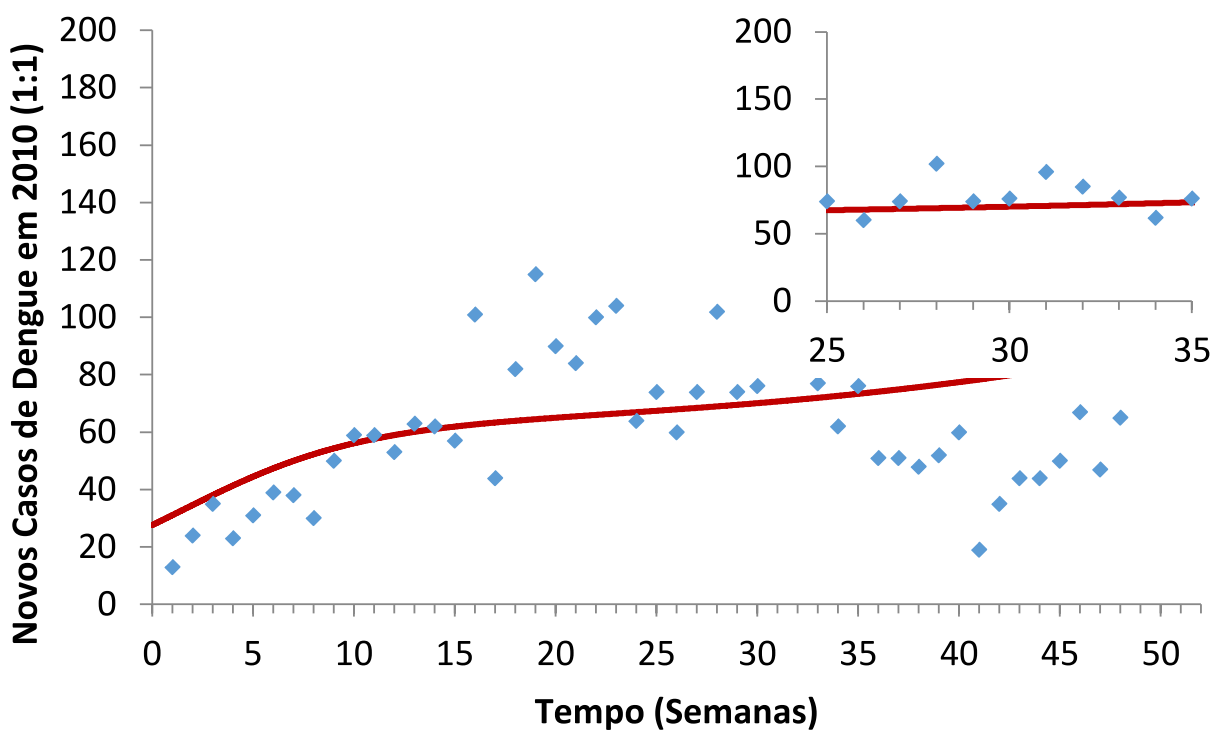

Figura 42 - Ajuste casos sintomáticos ano 2010 - RMS $=28,12, \mathrm{R}^{2}=25,76 \%$, AIC $=126,03$

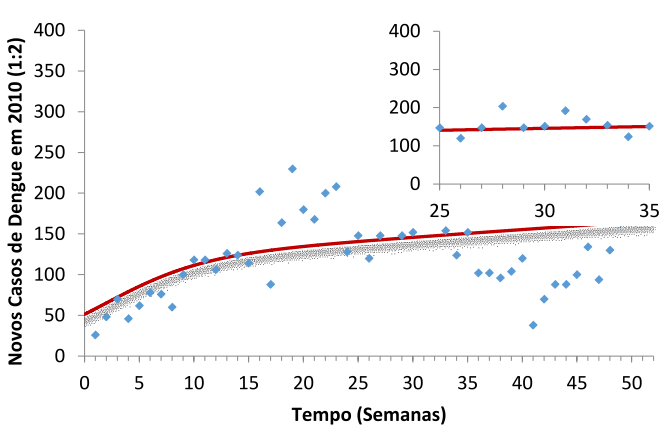

((a)) $1: 2$

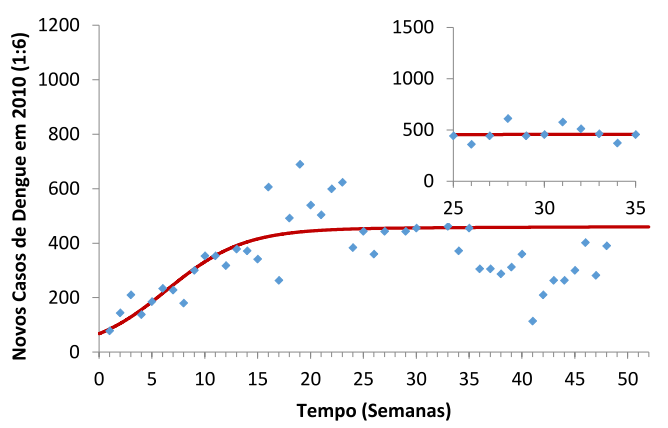

((c)) $1: 6$

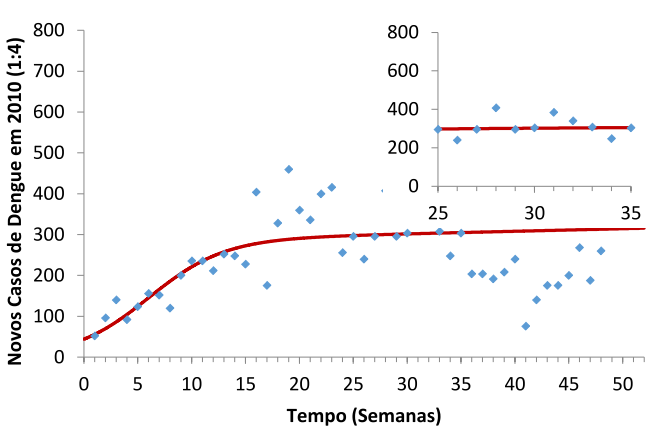

((b)) $1: 4$

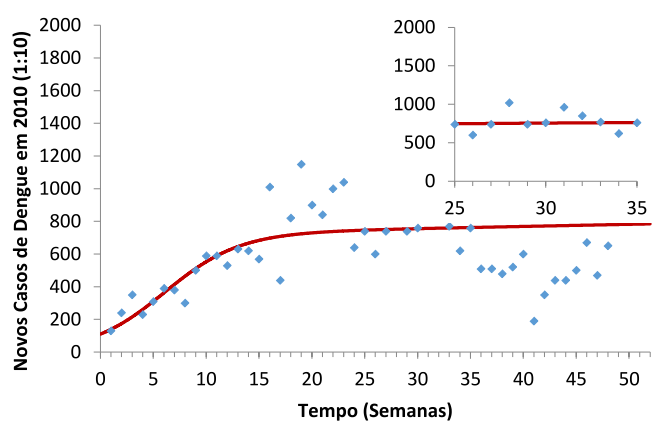

((d)) $1: 10$

Figura 43 - Ajuste casos assintomáticos ano 2010 - ((a)) RMS = 56,79, $\mathrm{R}^{2}=$ $24,29 \%, \mathrm{AIC}=127,47,((\mathrm{~b})) \mathrm{RMS}=111,45, \mathrm{R}^{2}=27,11 \%, \mathrm{AIC}=$ $128,78,((\mathrm{c})) \mathrm{RMS}=167,28, \mathrm{R}^{2}=27,02 \%, \mathrm{AIC}=129,59$ e $((\mathrm{d})) \mathrm{RMS}$ $=278,67, \mathrm{R}^{2}=27,09 \%, \mathrm{AIC}=130,61$ 


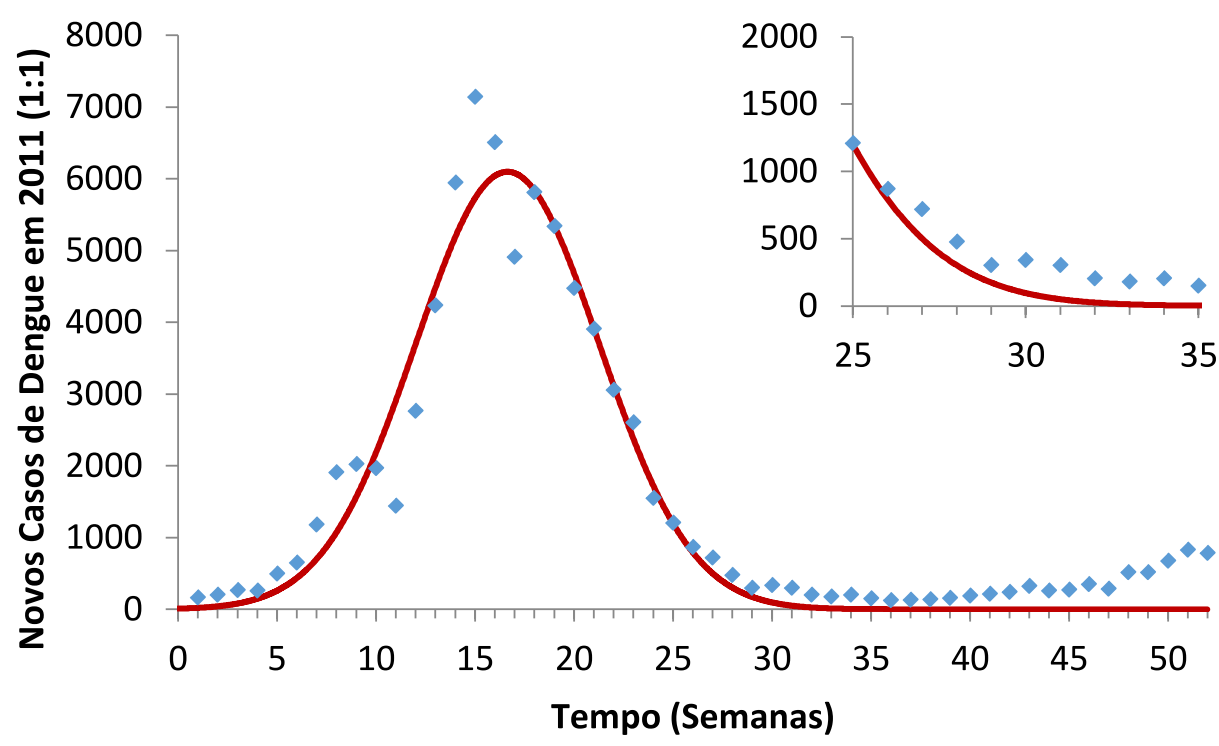

Figura 44 - Ajuste casos sintomáticos ano 2011 - RMS $=514,95, \mathrm{R}^{2}=92,78 \%$, $\mathrm{AIC}=157,18$

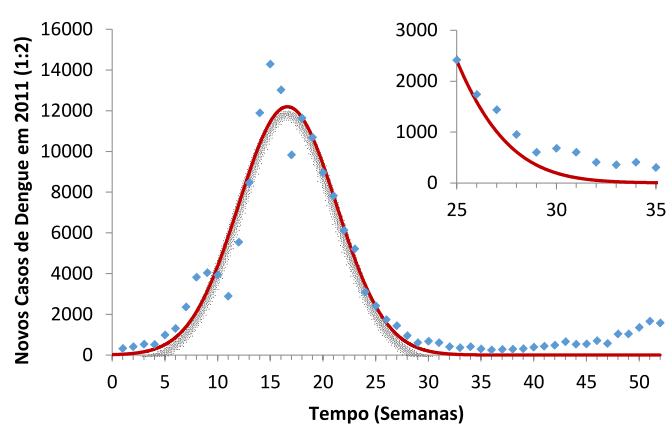

((a)) $1: 2$

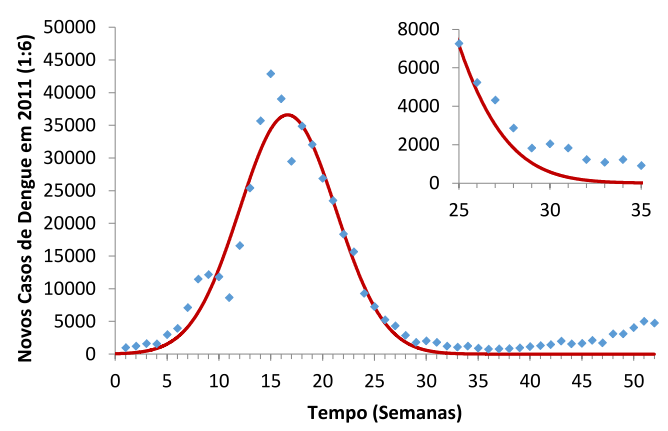

((c)) $1: 6$

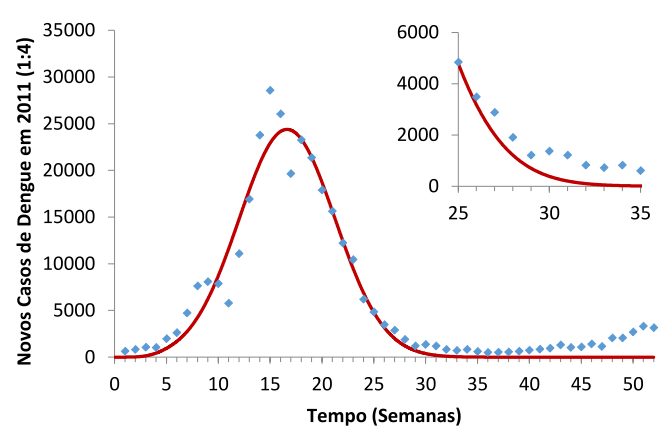

((b)) 1:4

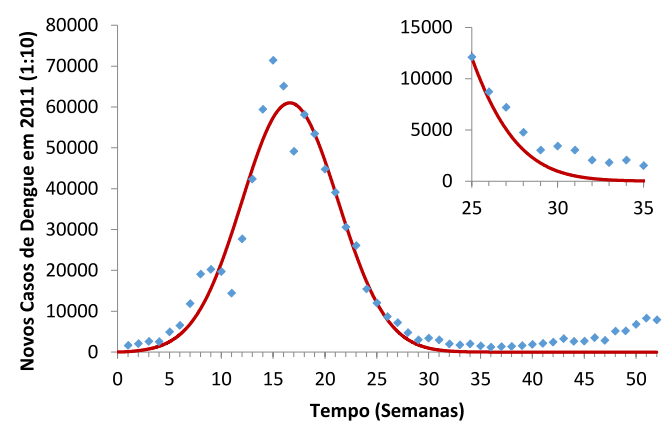

((d)) $1: 10$

Figura 45 - Ajuste casos assintomáticos ano 2011 - ((a)) RMS $=1029,78, \mathrm{R}^{2}=$ $92,78 \%, \mathrm{AIC}=158,56,((\mathrm{~b})) \mathrm{RMS}=2064,45, \mathrm{R}^{2}=92,74 \%, \mathrm{AIC}=$ 159,98, ((c)) RMS $=3088,76, \mathrm{R}^{2}=92,78 \%, \mathrm{AIC}=160,76$ e $((\mathrm{d}))$ $\mathrm{RMS}=5147,51, \mathrm{R}^{2}=92,78 \%, \mathrm{AIC}=161,78$ 


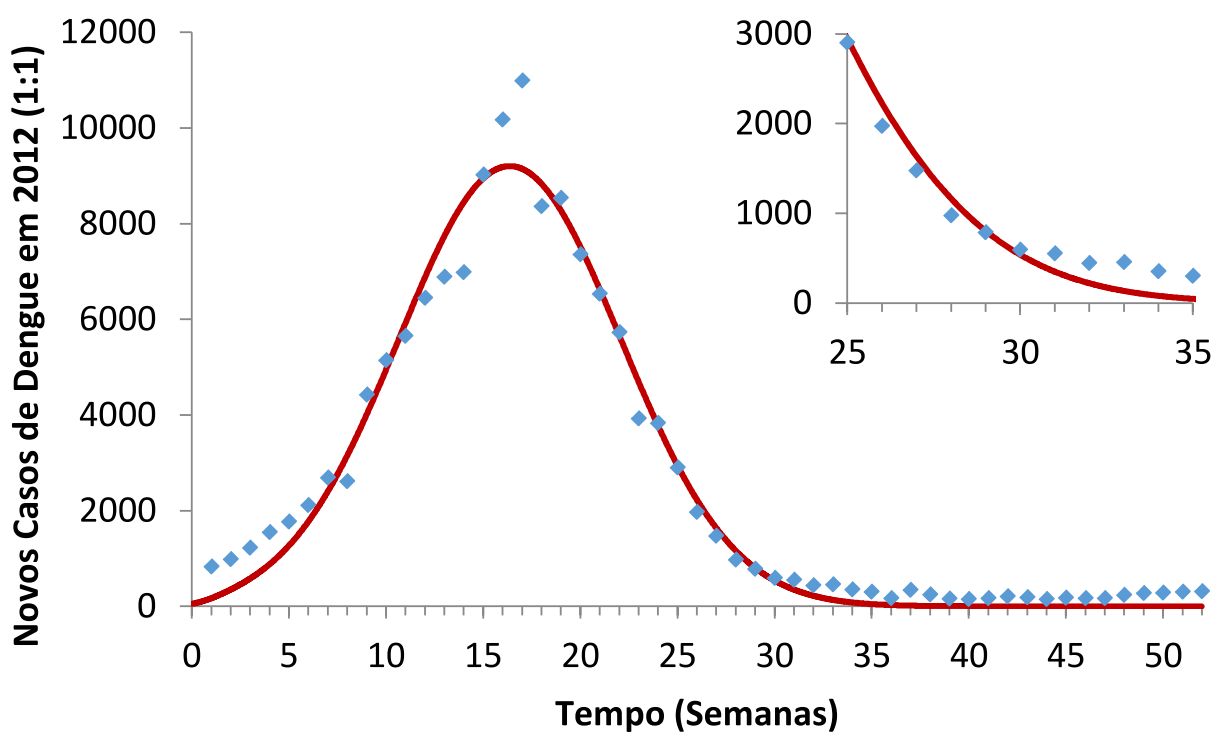

Figura 46 - Ajuste casos sintomáticos ano 2012 - RMS $=486,41, \mathrm{R}^{2}=97,51 \%$, $\mathrm{AIC}=152,87$

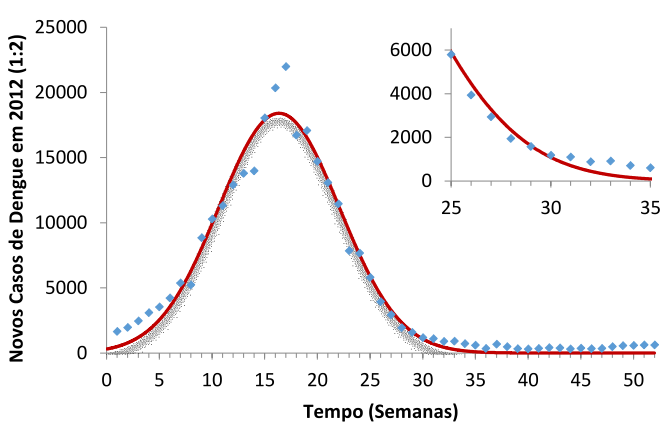

((a)) $1: 2$

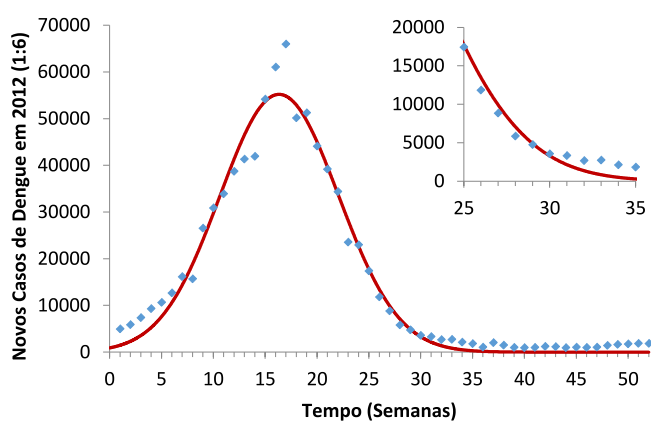

((c)) $1: 6$

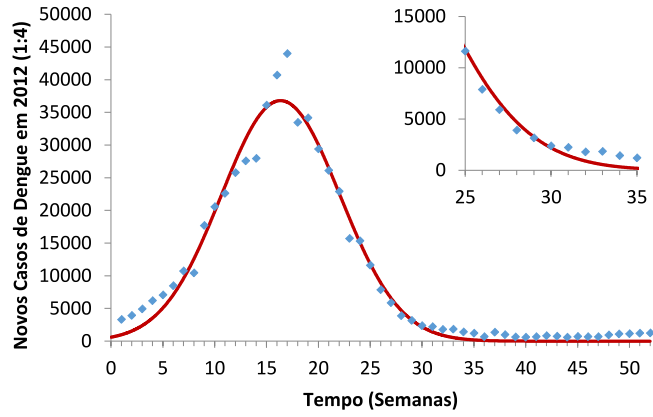

((b)) $1: 6$

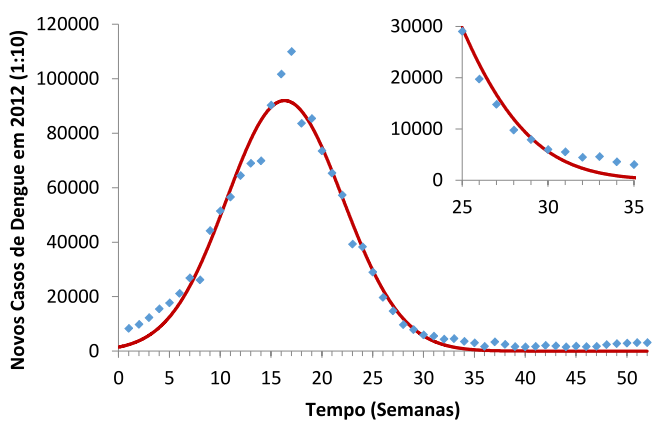

((d)) $1: 10$

Figura 47 - Ajuste casos assintomáticos ano 2012 - ((a)) RMS $=973,88, \mathrm{R}^{2}=$ $97,54 \%, \mathrm{AIC}=154,25,((\mathrm{~b})) \mathrm{RMS}=1952,13, \mathrm{R}^{2}=97,53 \%, \mathrm{AIC}=$ $155,64,((\mathrm{c})) \mathrm{RMS}=2935,06, \mathrm{R}^{2}=97,52 \%, \mathrm{AIC}=156,45$ e $((\mathrm{d}))$ $\mathrm{RMS}=4916,40, \mathrm{R}^{2}=97,50 \%, \mathrm{AIC}=157,48$ 


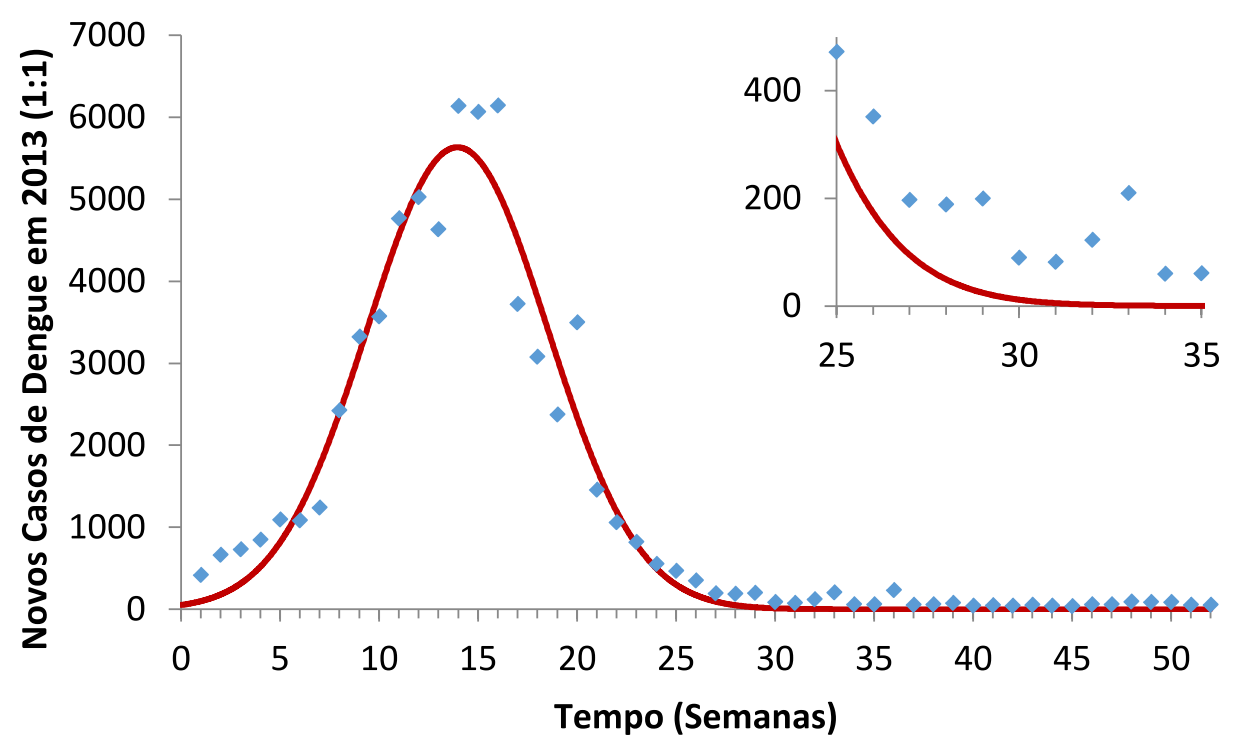

Figura 48 - Ajuste casos sintomáticos ano 2013 - RMS $=366,31, \mathrm{R}^{2}=96,00 \%$, $\mathrm{AIC}=156,62$

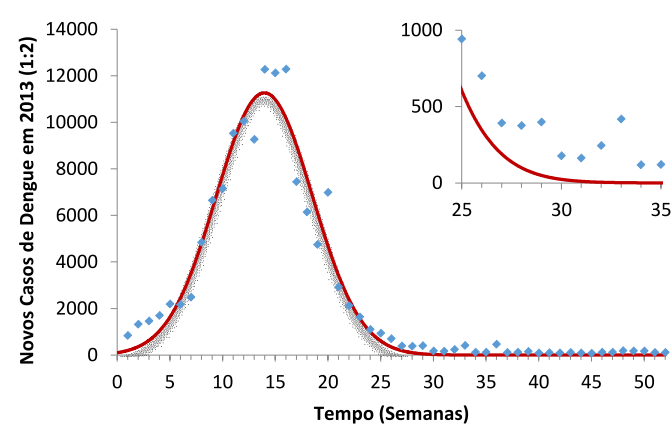

((a)) $1: 2$

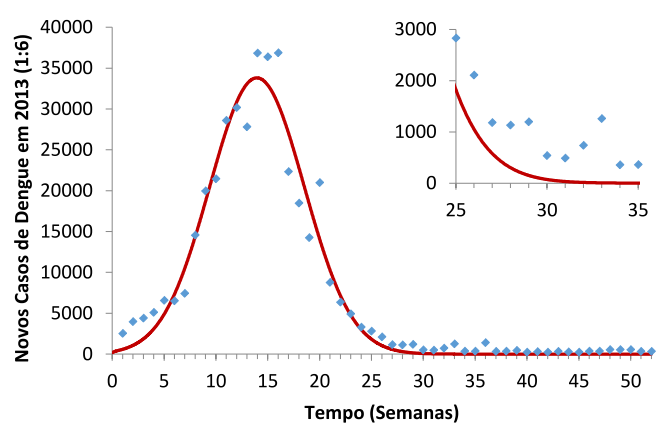

((c)) $1: 6$

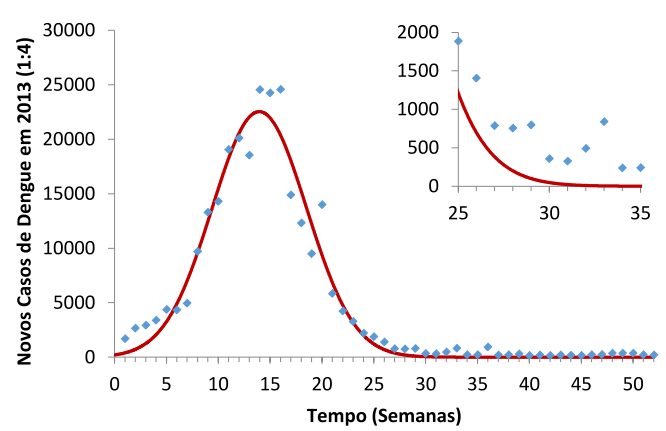

((b)) $1: 4$

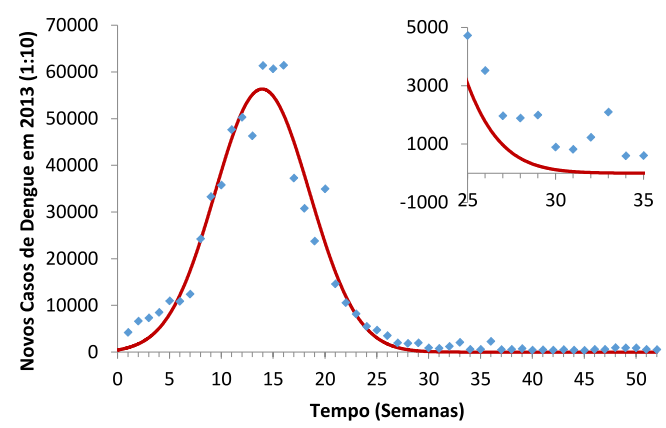

((d)) $1: 10$

Figura 49 - Ajuste casos assintomáticos ano 2013 - ((a)) RMS $=732,70, \mathrm{R}^{2}=$ $96,00 \%, \mathrm{AIC}=158,00,((\mathrm{~b})) \mathrm{RMS}=1465,62, \mathrm{R}^{2}=96,00 \%, \mathrm{AIC}=$ $159,40,((\mathrm{c})) \mathrm{RMS}=2198,87, \mathrm{R}^{2}=96,00 \%, \mathrm{AIC}=160,21$ e $((\mathrm{d}))$ $\mathrm{RMS}=3666,66, \mathrm{R}^{2}=95,99 \%, \mathrm{AIC}=161,23$ 


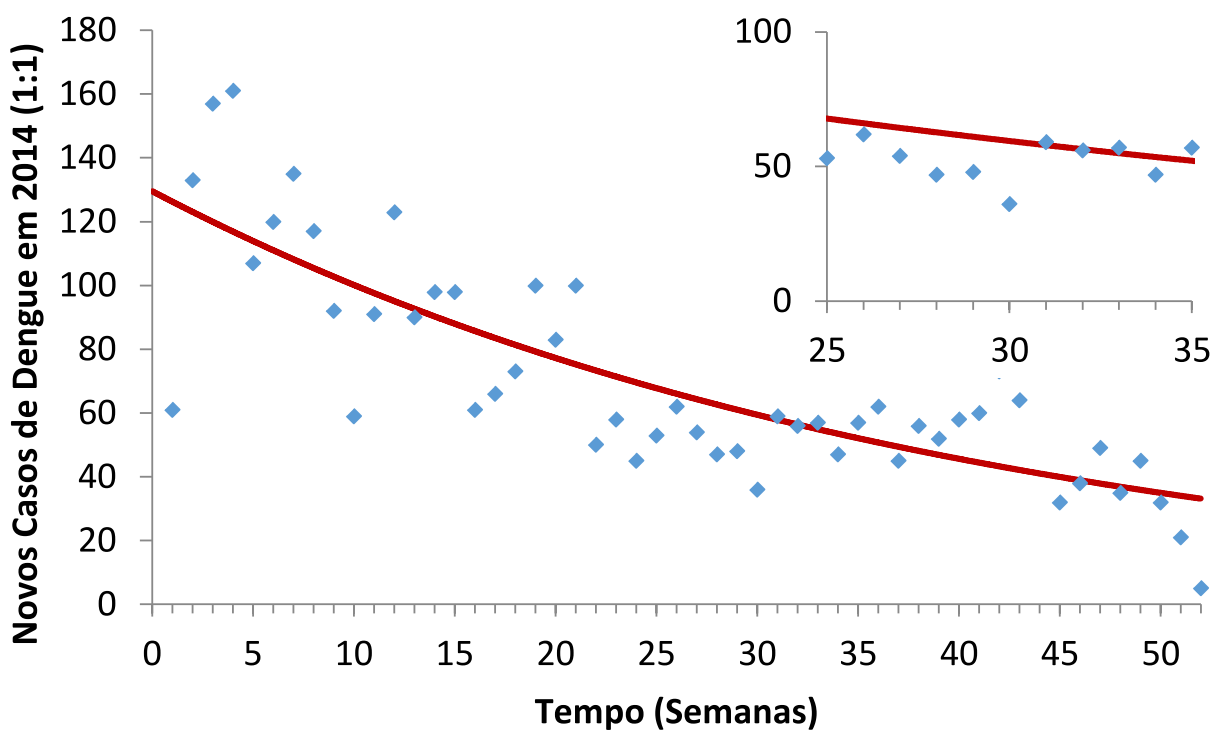

Figura 50 - Ajuste casos sintomáticos ano 2014 - RMS $=20,65, \mathrm{R}^{2}=61,68 \%$, AIC $=124,76$

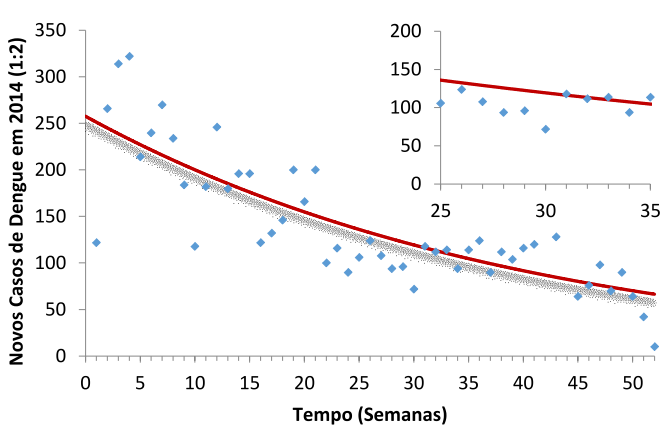

((a)) $1: 2$

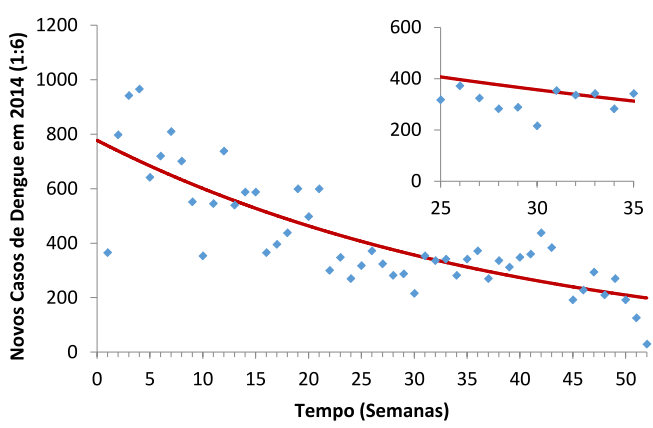

((c)) $1: 6$

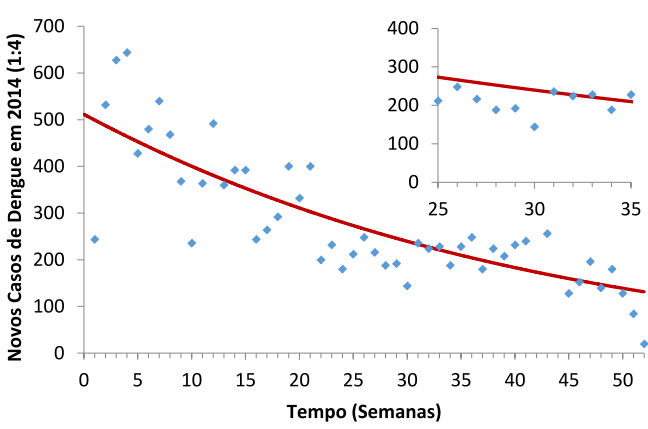

((b)) $1: 4$

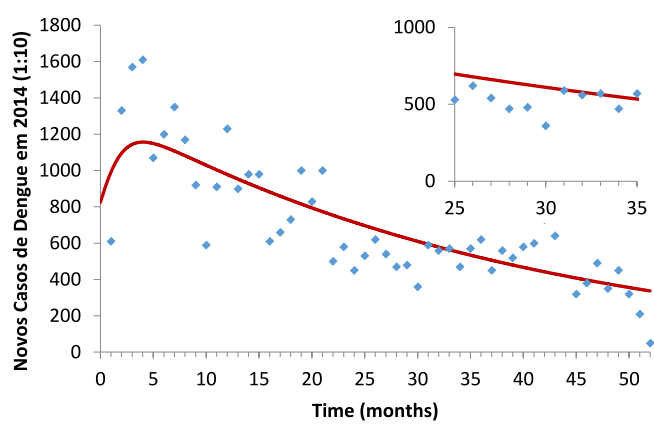

((d)) 1:10

Figura 51 - Ajuste casos assintomáticos ano 2014 - ((a)) RMS $=41,33, \mathrm{R}^{2}=$ $61,65 \%, \mathrm{AIC}=126,15,((\mathrm{~b})) \mathrm{RMS}=82,75, \mathrm{R}^{2}=61,52 \%, \mathrm{AIC}=$ $127,54,((\mathrm{c})) \mathrm{RMS}=123,92, \mathrm{R}^{2}=61,67 \%, \mathrm{AIC}=128,34$ e $((\mathrm{d})) \mathrm{RMS}$ $=199,77, \mathrm{R}^{2}=64,22 \%, \mathrm{AIC}=129,33$ 


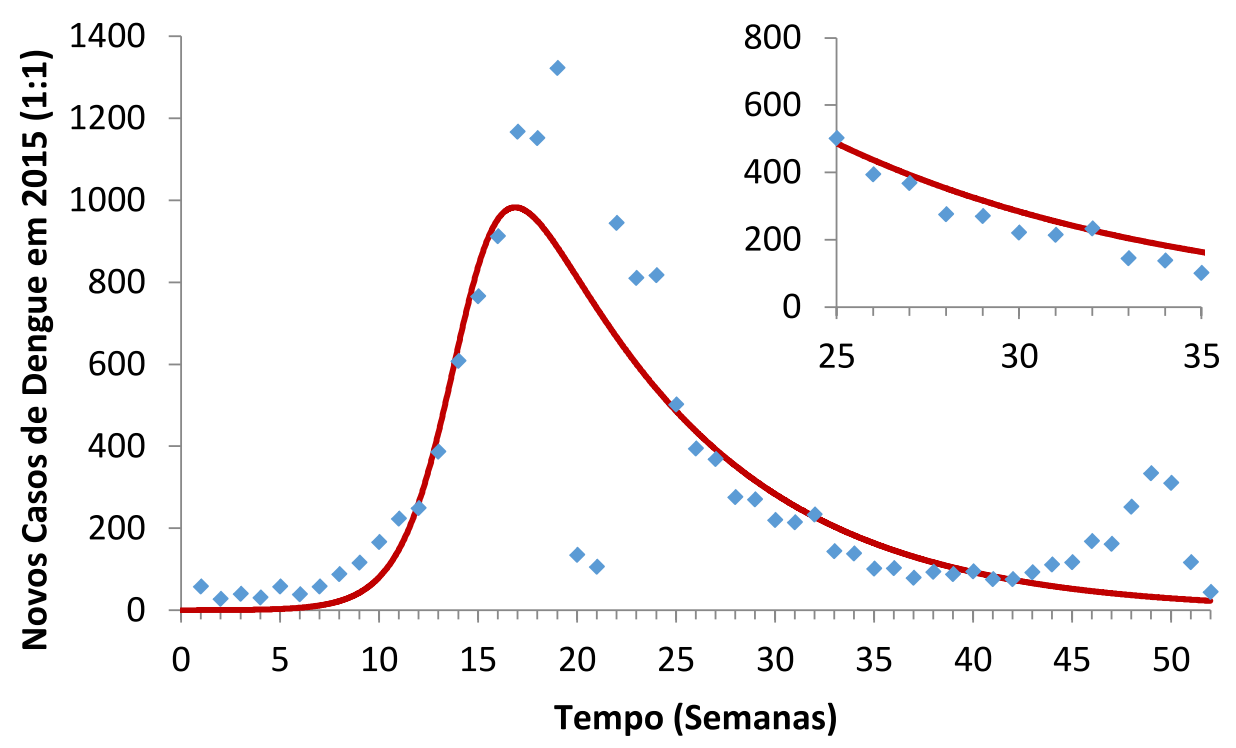

Figura 52 - Ajuste casos sintomáticos ano 2015 - RMS $=357,29, \mathrm{R}^{2}=69,91 \%$, $\mathrm{AIC}=151,76$

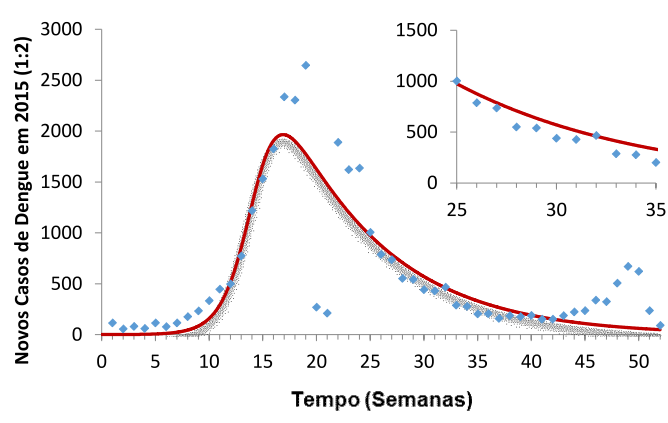

((a)) $1: 2$

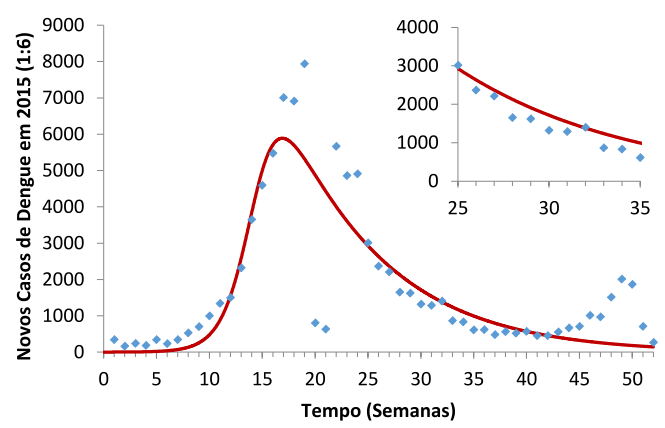

((c)) $1: 6$

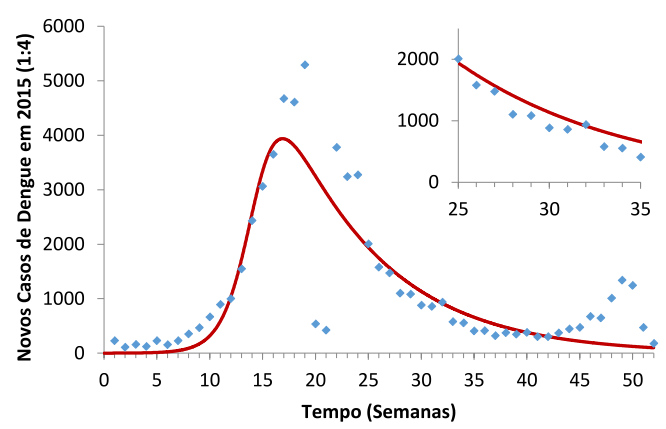

((b)) 1:4

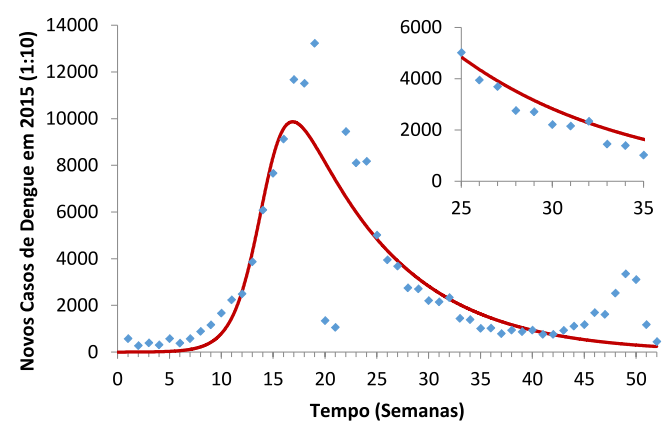

((d)) $1: 10$

Figura 53 - Ajuste casos assintomáticos ano 2015 - ((a)) RMS $=357.29, \mathrm{R}^{2}=$ $69,96 \%, \mathrm{AIC}=153,12,((\mathrm{~b})) \mathrm{RMS}=713.99, \mathrm{R}^{2}=70,01 \%, \mathrm{AIC}=$ $154,54,((\mathrm{c})) \mathrm{RMS}=1072.36, \mathrm{R}^{2}=69,93 \%, \mathrm{AIC}=155,34$ e $((\mathrm{d}))$ $\mathrm{RMS}=1785.51, \mathrm{R}^{2}=69,99 \%, \mathrm{AIC}=156,34$ 
Observa-se que em diversos anos o número de casos de dengue volta a subir perto das últimas semanas epidemiológicas (SE) do ano, como em 2001, por exemplo, quando após a SE 47 as notificações de dengue não pararam de subir até atingir o ápice na SE 10 do ano seguinte. Assim, o ressurgimento dos casos de dengue no final do ano epidemiológico são, na verdade, casos de um novo ciclo epidêmico.

Em alguns casos, este início prematuro da nova epidemia influenciou fortemente no resultado da força de infecção, como em 2007, por exemplo, quando após a SE 38, foram notificados mais de $20 \%$ dos casos daquele ano.

\subsection{Tabelas de resultados}

Os resultados apresentados aqui mostram o total de casos esperados para cada cenário simulado neste estudo, além do risco individual para um turista ser infectado por dengue durante sua estadia no Rio de Janeiro, no período dos Jogos Olímpicos em 2016.

\begin{tabular}{cccccc}
\hline \multicolumn{5}{c}{ Número de casos esperados (IC 95\%) } \\
\hline Ano & $\mathbf{1 : 1}$ & $\mathbf{1 : 2}$ & $\mathbf{1 : 4}$ & $\mathbf{1 : 6}$ & $\mathbf{1 : 1 0}$ \\
$\mathbf{2 0 0 0}$ & $1(1-2)$ & $3(2-3)$ & $5(4-6)$ & $8(6-9)$ & $13(11-15)$ \\
$\mathbf{2 0 0 1}$ & $4(3-5)$ & $8(7-10)$ & $17(15-19)$ & $25(23-28)$ & $44(40-47)$ \\
$\mathbf{2 0 0 2}$ & $0(0-0)$ & $0(0-0)$ & $0(0-0)$ & $0(0-0)$ & $0(0-0)$ \\
$\mathbf{2 0 0 3}$ & $0(0-0)$ & $1(0-1)$ & $2(1-2)$ & $1(0-1)$ & $5(4-7)$ \\
$\mathbf{2 0 0 4}$ & $0(0-0)$ & $0(0-1)$ & $1(0-2)$ & $3(2-4)$ & $1(1-2)$ \\
$\mathbf{2 0 0 5}$ & $1(1-2)$ & $2(1-3)$ & $5(4-6)$ & $7(6-9)$ & $14(11-16)$ \\
$\mathbf{2 0 0 6}$ & $1(0-1)$ & $2(1-3)$ & $4(3-5)$ & $7(6-9)$ & $14(12-17)$ \\
$\mathbf{2 0 0 7}$ & $23(21-26)$ & $66(62-71)$ & $206(198-214)$ & $82(77-87)$ & $195(186-204)$ \\
$\mathbf{2 0 0 8}$ & $2(1-2)$ & $3(2-4)$ & $14(13-16)$ & $18(16-20)$ & $41(37-44)$ \\
$\mathbf{2 0 0 9}$ & $0(0-0)$ & $0(0-0)$ & $3(2-4)$ & $1(1-2)$ & $0(0-1)$ \\
$\mathbf{2 0 1 0}$ & $10(8-11)$ & $20(18-23)$ & $43(40-47)$ & $69(64-73)$ & $127(121-133)$ \\
$\mathbf{2 0 1 1}$ & $2(1-2)$ & $4(3-4)$ & $7(6-8)$ & $11(10-12)$ & $19(18-21)$ \\
$\mathbf{2 0 1 2}$ & $15(14-16)$ & $31(29-33)$ & $65(62-68)$ & $102(98-105)$ & $187(182-192)$ \\
$\mathbf{2 0 1 3}$ & $0(0-0)$ & $0(0-1)$ & $1(0-1)$ & $1(1-2)$ & $2(2-3)$ \\
$\mathbf{2 0 1 4}$ & $4(3-4)$ & $8(7-9)$ & $16(15-18)$ & $25(23-27)$ & $48(45-51)$ \\
$\mathbf{2 0 1 5}$ & $15(14-16)$ & $31(29-33)$ & $64(62-67)$ & $103(99-107)$ & $191(185-196)$ \\
\hline
\end{tabular}

Tabela 14 - Número de casos esperados por cenário (sintomático/assintomático) 


\begin{tabular}{ccc}
\hline Ano & $\begin{array}{c}\text { Risco individual } \\
\text { Sintomático 1:1 }\end{array}$ & IC 95\% \\
\hline $\mathbf{2 0 0 0}$ & $3.21 \mathrm{E}-06$ & {$[1.73 \mathrm{E}-06,4.68 \mathrm{E}-06]$} \\
$\mathbf{2 0 0 1}$ & $1.05 \mathrm{E}-05$ & {$[7.87 \mathrm{E}-06,1.32 \mathrm{E}-05]$} \\
$\mathbf{2 0 0 2}$ & $1.40 \mathrm{E}-09$ & {$[0.00 \mathrm{E}+00,3.22 \mathrm{E}-08]$} \\
$\mathbf{2 0 0 3}$ & $1.58 \mathrm{E}-07$ & {$[0.00 \mathrm{E}+00,4.89 \mathrm{E}-07]$} \\
$\mathbf{2 0 0 4}$ & $5.42 \mathrm{E}-07$ & {$[0.00 \mathrm{E}+00,1.15 \mathrm{E}-06]$} \\
$\mathbf{2 0 0 5}$ & $2.75 \mathrm{E}-06$ & {$[1.37 \mathrm{E}-06,4.12 \mathrm{E}-06]$} \\
$\mathbf{2 0 0 6}$ & $2.39 \mathrm{E}-06$ & {$[1.12 \mathrm{E}-06,3.67 \mathrm{E}-06]$} \\
$\mathbf{2 0 0 7}$ & $5.84 \mathrm{E}-05$ & {$[5.21 \mathrm{E}-05,6.47 \mathrm{E}-05]$} \\
$\mathbf{2 0 0 8}$ & $4.44 \mathrm{E}-06$ & {$[2.75 \mathrm{E}-06,6.14 \mathrm{E}-06]$} \\
$\mathbf{2 0 0 9}$ & $2.15 \mathrm{E}-07$ & {$[0.00 \mathrm{E}+00,5.89 \mathrm{E}-07]$} \\
$\mathbf{2 0 1 0}$ & $2.39 \mathrm{E}-05$ & {$[1.99 \mathrm{E}-05,2.78 \mathrm{E}-05]$} \\
$\mathbf{2 0 1 1}$ & $4.45 \mathrm{E}-06$ & {$[3.27 \mathrm{E}-06,5.64 \mathrm{E}-06]$} \\
$\mathbf{2 0 1 2}$ & $3.75 \mathrm{E}-05$ & {$[3.41 \mathrm{E}-05,4.10 \mathrm{E}-05]$} \\
$\mathbf{2 0 1 3}$ & $4.18 \mathrm{E}-07$ & {$[5.46 \mathrm{E}-08,7.82 \mathrm{E}-07]$} \\
$\mathbf{2 0 1 4}$ & $9.25 \mathrm{E}-06$ & {$[7.54 \mathrm{E}-06,1.10 \mathrm{E}-05]$} \\
$\mathbf{2 0 1 5}$ & $3.72 \mathrm{E}-05$ & {$[3.38 \mathrm{E}-05,4.07 \mathrm{E}-05]$} \\
\hline
\end{tabular}

Tabela 15 - Risco Individual - Sintomáticos - Por cenário

\begin{tabular}{ccccc}
\hline Ano & Risco individual & CI 95\% & $\begin{array}{c}\text { Risco individual } \\
\mathbf{1 : 4}\end{array}$ & CI 95\% \\
\hline $\mathbf{2 0 0 0}$ & $6.49 \mathrm{E}-06$ & {$[4.39 \mathrm{E}-06,8.59 \mathrm{E}-06]$} & $1.29 \mathrm{E}-05$ & {$[9.90 \mathrm{E}-06,1.58 \mathrm{E}-05]$} \\
$\mathbf{2 0 0 1}$ & $2.07 \mathrm{E}-05$ & {$[1.70 \mathrm{E}-05,2.45 \mathrm{E}-05]$} & $4.18 \mathrm{E}-05$ & {$[3.65 \mathrm{E}-05,4.72 \mathrm{E}-05]$} \\
$\mathbf{2 0 0 2}$ & $1.06 \mathrm{E}-08$ & {$[0.00 \mathrm{E}+00,9.58 \mathrm{E}-08]$} & $7.50 \mathrm{E}-09$ & {$[0.00 \mathrm{E}+00,7.95 \mathrm{E}-08]$} \\
$\mathbf{2 0 0 3}$ & $1.74 \mathrm{E}-06$ & {$[6.24 \mathrm{E}-07,2.85 \mathrm{E}-06]$} & $4.04 \mathrm{E}-06$ & {$[2.28 \mathrm{E}-06,5.80 \mathrm{E}-06]$} \\
$\mathbf{2 0 0 4}$ & $1.04 \mathrm{E}-06$ & {$[1.79 \mathrm{E}-07,1.89 \mathrm{E}-06]$} & $2.42 \mathrm{E}-06$ & {$[1.06 \mathrm{E}-06,3.78 \mathrm{E}-06]$} \\
$\mathbf{2 0 0 5}$ & $4.80 \mathrm{E}-06$ & {$[2.96 \mathrm{E}-06,6.63 \mathrm{E}-06]$} & $1.21 \mathrm{E}-05$ & {$[9.08 \mathrm{E}-06,1.51 \mathrm{E}-05]$} \\
$\mathbf{2 0 0 6}$ & $4.97 \mathrm{E}-06$ & {$[3.10 \mathrm{E}-06,6.83 \mathrm{E}-06]$} & $1.07 \mathrm{E}-05$ & {$[7.90 \mathrm{E}-06,1.36 \mathrm{E}-05]$} \\
$\mathbf{2 0 0 7}$ & $1.66 \mathrm{E}-04$ & {$[1.55 \mathrm{E}-04,1.76 \mathrm{E}-04]$} & $5.14 \mathrm{E}-04$ & {$[4.94 \mathrm{E}-04,5.34 \mathrm{E}-04]$} \\
$\mathbf{2 0 0 8}$ & $6.98 \mathrm{E}-06$ & {$[4.86 \mathrm{E}-06,9.11 \mathrm{E}-06]$} & $3.62 \mathrm{E}-05$ & {$[3.14 \mathrm{E}-05,4.11 \mathrm{E}-05]$} \\
$\mathbf{2 0 0 9}$ & $3.63 \mathrm{E}-07$ & {$[0.00 \mathrm{E}+00,8.55 \mathrm{E}-07]$} & $6.83 \mathrm{E}-06$ & {$[4.65 \mathrm{E}-06,9.02 \mathrm{E}-06]$} \\
$\mathbf{2 0 1 0}$ & $5.05 \mathrm{E}-05$ & {$[4.48 \mathrm{E}-05,5.63 \mathrm{E}-05]$} & $1.09 \mathrm{E}-04$ & {$[1.00 \mathrm{E}-04,1.17 \mathrm{E}-04]$} \\
$\mathbf{2 0 1 1}$ & $9.21 \mathrm{E}-06$ & {$[7.50 \mathrm{E}-06,1.09 \mathrm{E}-05]$} & $1.82 \mathrm{E}-05$ & {$[1.58 \mathrm{E}-05,2.06 \mathrm{E}-05]$} \\
$\mathbf{2 0 1 2}$ & $7.72 \mathrm{E}-05$ & {$[7.22 \mathrm{E}-05,8.21 \mathrm{E}-05]$} & $1.62 \mathrm{E}-04$ & {$[1.54 \mathrm{E}-04,1.69 \mathrm{E}-04]$} \\
$\mathbf{2 0 1 3}$ & $8.59 \mathrm{E}-07$ & {$[3.33 \mathrm{E}-07,1.38 \mathrm{E}-06]$} & $1.82 \mathrm{E}-06$ & {$[1.04 \mathrm{E}-06,2.60 \mathrm{E}-06]$} \\
$\mathbf{2 0 1 4}$ & $1.90 \mathrm{E}-05$ & {$[1.65 \mathrm{E}-05,2.15 \mathrm{E}-05]$} & $4.01 \mathrm{E}-05$ & {$[3.64 \mathrm{E}-05,4.38 \mathrm{E}-05]$} \\
$\mathbf{2 0 1 5}$ & $7.70 \mathrm{E}-05$ & {$[7.20 \mathrm{E}-05,8.19 \mathrm{E}-05]$} & $1.61 \mathrm{E}-04$ & {$[1.54 \mathrm{E}-04,1.69 \mathrm{E}-04]$} \\
\hline
\end{tabular}

Tabela 16 - Risco individual - Assintomáticos (1:2 e 1:4) - Por cenário 


\begin{tabular}{ccccc}
\hline Ano & $\begin{array}{c}\text { Risco individual } \\
\mathbf{1 : 6}\end{array}$ & CI 95\% & $\begin{array}{c}\text { Risco individual } \\
\mathbf{1 : 1 0}\end{array}$ & CI 95\% \\
\hline $\mathbf{2 0 0 0}$ & $1.91 \mathrm{E}-05$ & {$[1.54 \mathrm{E}-05,2.27 \mathrm{E}-05]$} & $3.25 \mathrm{E}-05$ & {$[2.78 \mathrm{E}-05,3.72 \mathrm{E}-05]$} \\
$\mathbf{2 0 0 1}$ & $6.36 \mathrm{E}-05$ & {$[5.71 \mathrm{E}-05,7.02 \mathrm{E}-05]$} & $1.09 \mathrm{E}-04$ & {$[1.00 \mathrm{E}-04,1.18 \mathrm{E}-04]$} \\
$\mathbf{2 0 0 2}$ & $1.28 \mathrm{E}-08$ & {$[0.00 \mathrm{E}+00,1.07 \mathrm{E}-07]$} & $3.30 \mathrm{E}-08$ & {$[0.00 \mathrm{E}+00,1.87 \mathrm{E}-07]$} \\
$\mathbf{2 0 0 3}$ & $2.33 \mathrm{E}-06$ & {$[9.42 \mathrm{E}-07,3.71 \mathrm{E}-06]$} & $1.37 \mathrm{E}-05$ & {$[1.00 \mathrm{E}-05,1.73 \mathrm{E}-05]$} \\
$\mathbf{2 0 0 4}$ & $8.24 \mathrm{E}-06$ & {$[5.64 \mathrm{E}-06,1.08 \mathrm{E}-05]$} & $3.05 \mathrm{E}-06$ & {$[1.33 \mathrm{E}-06,4.78 \mathrm{E}-06]$} \\
$\mathbf{2 0 0 5}$ & $1.79 \mathrm{E}-05$ & {$[1.41 \mathrm{E}-05,2.17 \mathrm{E}-05]$} & $3.41 \mathrm{E}-05$ & {$[2.83 \mathrm{E}-05,3.98 \mathrm{E}-05]$} \\
$\mathbf{2 0 0 6}$ & $1.75 \mathrm{E}-05$ & {$[1.38 \mathrm{E}-05,2.13 \mathrm{E}-05]$} & $3.55 \mathrm{E}-05$ & {$[2.96 \mathrm{E}-05,4.14 \mathrm{E}-05]$} \\
$\mathbf{2 0 0 7}$ & $2.05 \mathrm{E}-04$ & {$[1.92 \mathrm{E}-04,2.18 \mathrm{E}-04]$} & $4.88 \mathrm{E}-04$ & {$[4.66 \mathrm{E}-04,5.11 \mathrm{E}-04]$} \\
$\mathbf{2 0 0 8}$ & $4.41 \mathrm{E}-05$ & {$[3.88 \mathrm{E}-05,4.94 \mathrm{E}-05]$} & $1.02 \mathrm{E}-04$ & {$[9.35 \mathrm{E}-05,1.10 \mathrm{E}-04]$} \\
$\mathbf{2 0 0 9}$ & $2.83 \mathrm{E}-06$ & {$[1.39 \mathrm{E}-06,4.27 \mathrm{E}-06]$} & $1.07 \mathrm{E}-06$ & {$[1.37 \mathrm{E}-07,2.00 \mathrm{E}-06]$} \\
$\mathbf{2 0 1 0}$ & $1.72 \mathrm{E}-04$ & {$[1.61 \mathrm{E}-04,1.83 \mathrm{E}-04]$} & $3.18 \mathrm{E}-04$ & {$[3.02 \mathrm{E}-04,3.33 \mathrm{E}-04]$} \\
$\mathbf{2 0 1 1}$ & $2.79 \mathrm{E}-05$ & {$[2.50 \mathrm{E}-05,3.09 \mathrm{E}-05]$} & $4.82 \mathrm{E}-05$ & {$[4.43 \mathrm{E}-05,5.21 \mathrm{E}-05]$} \\
$\mathbf{2 0 1 2}$ & $2.54 \mathrm{E}-04$ & {$[2.45 \mathrm{E}-04,2.63 \mathrm{E}-04]$} & $4.68 \mathrm{E}-04$ & {$[4.56 \mathrm{E}-04,4.81 \mathrm{E}-04]$} \\
$\mathbf{2 0 1 3}$ & $2.91 \mathrm{E}-06$ & {$[1.90 \mathrm{E}-06,3.91 \mathrm{E}-06]$} & $5.54 \mathrm{E}-06$ & {$[4.10 \mathrm{E}-06,6.99 \mathrm{E}-06]$} \\
$\mathbf{2 0 1 4}$ & $6.29 \mathrm{E}-05$ & {$[5.82 \mathrm{E}-05,6.76 \mathrm{E}-05]$} & $1.20 \mathrm{E}-04$ & {$[1.13 \mathrm{E}-04,1.27 \mathrm{E}-04]$} \\
$\mathbf{2 0 1 5}$ & $2.57 \mathrm{E}-04$ & {$[2.48 \mathrm{E}-04,2.67 \mathrm{E}-04]$} & $4.77 \mathrm{E}-04$ & {$[4.63 \mathrm{E}-04,4.90 \mathrm{E}-04]$} \\
\hline
\end{tabular}

Tabela 17 - Risco individual - Assintomáticos (1:6 e 1:10) - Por cenário

O pior risco individual de infecção por dengue obtido para um turista não imune foi de $5,84 \times 10^{-5}$ (IC $95 \%$ : $5,21 \times 10^{-5}-6,47 \times 10^{-5}$ ), na proporção $1: 1$. As

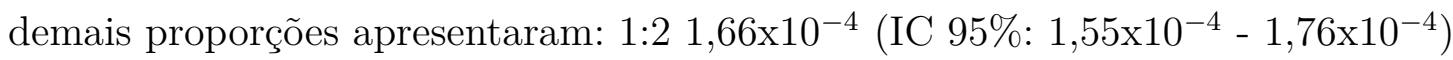

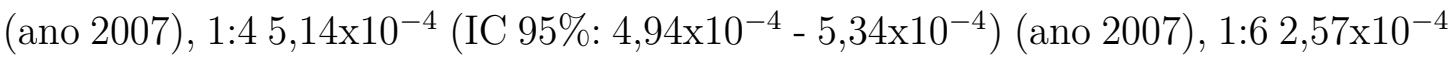

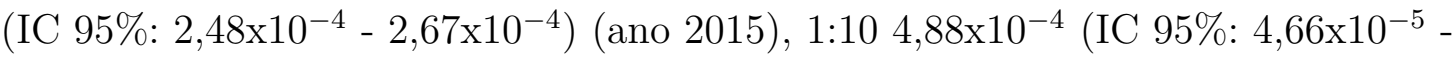
$5,11 \times 10^{-5}$ ) (ano 2007).

No melhor cenário epidemiológico calculado, nenhum turista seria infectado durante o evento e no pior cenário sintomático 23 (21-26) turistas não imunes seriam infectados. Ao considerar as subnotificações apresentadas na tabela 14, a previsão obtida foi, na relação 1:2 66 (62-71) casos, já na relação 1:4 obteve-se 206 (198-214) casos, na relação 1:6 foram 103 (99-107) casos e, por fim, a relação 1:10 resultou em 195 (186-204) casos de dengue em turistas não imunes. A incidência prevista no pior cenário, foi igual a 5,84 (sintomático) e 16,60, 51,40, 25,70 e 48,80 (assintomáticos 1:2, 1:4, 1:6 e 1:10, respectivamente) por 100.000 indivíduos. 


\section{Discussão}

Este trabalho tem como principal resultado o risco individual de infecção por dengue que o turista internacional não imune à dengue submeteu-se ao visitar o Brasil durante os grandes eventos sediados pelo país nos anos de 2014 e 2016, respectivamente, a Copa do Mundo da FIFA e os Jogos Olímpicos de Verão.

Um ponto fraco da previsão em epidemiologia é a dificuldade em estabelecer o limite em que o passado deve ser utilizado como um guia para o futuro (Woolhouse, 2011).

Existem diversos fatores imprevisíveis que geram incertezas em muitos níveis, ainda assim muitas decisões políticas (de saúde e econômicas) são tomadas a partir de surtos anteriores pelos governos responsáveis. Woolhouse (2011) propõe 4 cenários para a previsão, interpretados aqui para a dengue:

1. Nenhuma mudança. Os dados de entrada, os valores dos parâmetros, e o próprio modelo de surtos anteriores são válidos para serem aplicados à nova epidemia;

2. A mudança dos dados de entrada. Pode haver mudanças no tipo de dengue que circula no momento da previsão, ou nas condições climáticas que interferem diretamente na reprodução dos mosquitos, ou até mesmo na intensidade de transmissão da doença;

3. Mudar os valores dos parâmetros, tal como a força da infecção de dengue, determinada pela densidade de mosquitos infectados em relação aos hospedeiros humanos e a taxa de apreensão. Essas mudanças seriam difíceis de quantificar a priori, então os novos valores desses parâmetros podem ser estimados a partir de dados da epidemia anterior;

4. Mudar o modelo. A estrutura do modelo original ou as suposições do modelo são incorretas para a nova epidemia.

Estes fatores podem explicar a falta de precisão ou a incapacidade de prever com maior precisão o número de casos de dengue para a Copa do Mundo FIFA 2014, no Brasil, e a precisão para os Jogos Olímpicos não está imune aos mesmos fatores.

A precisão da previsão apresentada neste estudo depende muito da intensidade da transmissão, que por sua vez, depende de fatores como as condições 
climáticas, comportamento do hospedeiro e a mudança (ou manutenção) do sorotipo circulante / presente no ano dos eventos. Ainda que todas as condições fossem iguais ao pior ano da série, é plausível supor que a própria condição de rebeber os eventos motivasse os governos a aumentar a vigilância, intensificando as medidas de controle e combate aos vetores nas áreas que receberam as competições, possibilitando desta forma, a redução do risco de dengue.

A primeira parte deste trabalho trata do risco de infecção durante a Copa do Mundo. Dada a força de infecção diária da dengue, que foi obtida após a desagregação dos dados semanais, quando ajustada pela equação exponencial da forma $y=a e^{(b x)}$ (em alguns casos foi preciso utilizar funções lineares, logarítmicas ou de potência), apresentou excelentes resultados.

Durante as 5 semanas do mundial o risco individual para o turista não imune à dengue ser infectado variou de acordo com o cronograma de viagens seguido por cada turista. No cenário que utilizou a média de casos notificados entre 2010 e 2013 para a determinação do risco individual, o resultado obtido variou de $3,81 \times 10^{-5}$ a $4,46 \times 10^{-4}$ e, quando utilizados os dados dos anos de melhor e piores notificações entre 2010 e 2013, isto é, respectivamente, o menor número de casos e o maior número de casos, o risco obtido variou de $3,61 \times 10^{-6}$ no melhor cenário a $8,33 \times 10^{-4}$, no pior.

A partir dos riscos individuais e da expectativa do total de turistas presentes em cada cidade-sede, além do tempo em que cada turista permanece em cada cidade, calculado a partir da tabela de jogos da competição, obteve-se o número esperado de turistas infectados ao final da competição, por cidade.

Conforme apresentado na tabela 7, obteve-se o total de 32 casos de dengue no cenário médio entre os 607.051 turistas. Este resultado implica na incidência de 5 casos em 100.000 turistas. No pior cenário, o total foi de 73 casos esperados de dengue (12 casos em 100.000 turistas) e, no melhor cenário, a previsão resultou em 0 casos esperados.

As cidades que apresentam a previsão com o maior número de casos sintomáticos esperados de dengue foram Fortaleza e Rio de Janeiro, 12 (0-15) e 11 (0-30) casos, respectivamente. Isto ocorreu nestas cidades devido ao maior número de turistas e maior tempo de permanência em relação às outras cidades, conforme pode-se observar na tabela 7 e no cronograma de viagens apresentado na figura 5 .

Portanto, ao considerar o cenário com a média de casos notificados, a incidência esperada nestas cidades foi de 21 casos para 100.000 turistas em Fortaleza e 11 casos notificados em 100.000 turistas no Rio de Janeiro. As duas cidades 
somam quase $72 \%$ da expectativa do número de casos no cenário médio.

É importante destacar que a Copa do Mundo da FIFA começou no mês de Junho e terminou no mês de Julho, inverno brasileiro, que é um período de baixa na dinâmica de transmissão da dengue.

Embora inverno, a região nordeste brasileira continua a apresentar temperaturas elevadas neste período do ano. Isto permite aos mosquitos o prolongamento do ciclo reprodutivo, ainda que com menor intensidade de reprodução, mas suficiente para o prolongamento a dinâmica de infecção.

Após o fim do ano de 2014 e a consequente obtenção do número de infecções para aquele ano, afim de verificar a qualidade do método da determinação do risco aqui apresentado, isto é, verificar se é ou não representativo utilizar o histórico de casos notificados no passado para prever casos no futuro através da força de infecção ajustada para o período determinado, repetiu-se todo o processo de ajuste dos casos notificados à função exponencial para as notificações de dengue de 2014.

Assim como na previsão apresentada acima, o resultado deste novo ajuste depende da agenda seguida pelo turista, e variou de $5,30 \times 10^{-5}\left(0-6,38 \times 10^{-5}\right)$ a $2,30 \times 10^{-4}\left(0-4,37 \times 10^{-4}\right)$, correspondendo a $12(0-41)$ casos entre os 607.051 turistas internacionais considerados, isto é, 2 casos em 100.000 turistas estrangeiros não imunes à dengue.

Portanto, apesar de a previsão inicial apresentar variação no resultado do risco individual quando comparado ao risco calculado com os dados de 2014, variação esta que é diretamente relacionada aos cenários epidemiológicos dos anos estudados, o risco individual de infecção aqui determinado é compatível ao calculado com a base de 2014, já que o cenário médio possui a mesma ordem de grandeza do resultado obtido após a Copa do Mundo, de $3,81 \times 10^{-5}$ a $4,46 \times 10^{-4}$ contra $5,30 \times 10^{-5}$ a $2,30 \times 10^{-4}$.

Observa-se na tabela 18, que compara o número de casos de dengue notificados nas primeiras 14 semanas epidemiológicas de 2013 e 2014 nas 12 cidades-sede, que o número de casos notificados nas primeiras 14 semanas do ano de 2014 foi $83 \%$ menor do que em 2013. Muitos são os fatores que podem explicar esta observação, em particular, a enorme epidemia que ocorreu em 2013, com mais de 1,3 milhão de casos notificados em todo o Brasil, a maior epidemia da história até aquele ano, e que foi superada em 2015 quando o número de casos atingiu mais de 1,6 milhão de pessoas em todo o Brasil.

Outro motivo que pode ajudar a explicar a grande diferença entre o número de casos nas primeiras semanas epidemiológicas é a severa seca que atingiu o Brasil 


\begin{tabular}{lccc}
\hline Cidade-sede & $\mathbf{2 0 1 3}$ & $\mathbf{2 0 1 4}$ & Variação \\
\hline Cuiabá & 1945 & 177 & $-91 \%$ \\
Fortaleza & 3308 & 1168 & $-65 \%$ \\
Natal & 678 & 294 & $-57 \%$ \\
Recife & 65 & 73 & $12 \%$ \\
Salvador & 766 & 1362 & $78 \%$ \\
Manaus & 10321 & 1516 & $-85 \%$ \\
Rio de Janeiro & 41165 & 1278 & $-97 \%$ \\
Porto Alegre & 741 & 120 & $-84 \%$ \\
Curitiba & 553 & 177 & $-68 \%$ \\
São Paulo & 6945 & 7550 & $9 \%$ \\
Belo Horizonte & 74860 & 4849 & $-94 \%$ \\
Brasília & 5107 & 4532 & $-11 \%$ \\
\hline Total & 144867 & 25110 & $-83 \%$ \\
\hline
\end{tabular}

Tabela 18 - Casos de dengue até a $14^{a}$ semana epidemiológica

no verão de 2013/2014 (ONU, 2013; País, 2014). Fator este que fora relatado anteriormente no Brasil por Olívêr et al. (2014), ao observarem uma correlação negativa significativa entre casos de dengue e incêndios florestais. Fenômeno fortemente influenciado pela seca.

Além disso, o impacto gerado pelas medidas de controle de vetores, reforçadas após a grande epidemia de 2013, também é um potencial responsável pela baixa do número total de mosquitos.

Ao final do ano de 2014, obteve-se outro dado importante para a confirmação da qualidade do método utilizado neste trabalho e consequentemente do resultado aqui obtido. Segundo Aguiar et al. (2015), apenas 3 casos de dengue em turistas estrangeiros foram notificados durante a Copa do Mundo da FIFA, distribuídos entre 2 cidadãos dos Estados Unidos da América e 1 cidadão do Japão. Portanto, este resultado está dentro da expectativa deste estudo, isto é, o risco individual de infecção por dengue para os turistas durante as 5 semanas da competição foi tão baixo como o esperado. No entanto, há que se levar em conta as subnotificações, especialmente levando-se em consideração que há países em que a notificação da infecção por dengue não é obrigatória e/ou é deficiente.

Estudos prospectivos mostraram que viajantes podem apresentar alta porcentagem de casos de dengue assintomáticos (Wichmann and Jelinek, 2004). Dessa maneira, considerando a relação de casos sintomáticos e assintomáticos 1:10 (Chastel, 2012) para o cálculo do total de infecções ocorridas, os 3 casos de dengue em turistas infectados durante a Copa do Mundo passam a ser 30 casos, aproximando ainda mais o número de infectados à previsão deste trabalho, já que o total esperado de turistas infectados fora de 32 casos, variando entre 0 e 73 casos dependendo do 
cenário.

Segundo o Ministério do Turismo, em Junho de 2014, 1.018.876 turistas entraram no Brasil, entre imunes e não imunes à doença. Dada a notificação de 3 turistas infectados, têm-se a incidência de 0,29 casos de dengue em 100.000 turistas. O menor risco obtido neste estudo foi de $3,61 \times 10^{-6}$, portanto, menos de 4 casos em 1.000.000 de visitantes.

Uma importante premissa utilizada neste cálculo foi baseada na análise das 14 primeiras SE de 2014, onde houve apenas a incidência dos sorotipos DENV-1 e DENV-4. A partir daí, assumiu-se que durante todo o ano de 2014 os sorotipos presentes no país seriam apenas DENV-1 e DENV-4 e então, fez-se o recorte para o histórico de casos notificados entre 2010 e 2013.

A escolha do período de notificações limitado aos anos de 2010 a 2013, se deu após análise retroativa dos sorotipos circulantes por ano, desde o ano 2000. Ainda que, desde o ano 2000, em praticamente todos os anos, tenha havido casos de DENV-1 e DENV-4 em todo o Brasil, a presença dos sorotipos 2 e 3 foi intensa até 2009, ano em que a quantidade de casos de DENV-1 e DENV-4 supera a de DENV-2 e DENV-3. Naquele ano o sorotipo 1 tem quase $60 \%$ dos casos. No entanto, julgou-se que 2009 não deveria ser considerado na série por ainda apresentar muitos casos notificados de DENV-2 e DENV-3, o que não se repetiu a partir de 2010 até o início de 2014.

O mesmo argumento foi utilizado para excluir o ano 2000 do conjunto de dados, e em 2001, a falta de notificações de DENV-4 foi a responsável pela não utilização daquele conjunto de dados.

Felizmente 2014 foi um ano de baixa incidência de dengue em todas as cidades-sede. Ao fim do ano de 2014, dos casos confirmados de dengue em todo o Brasil (figura 54), 78\% dos casos foram DENV-1, 21\% DENV-4 e apenas $1 \%$ DENV-2. Apenas 4 dentre os 12 Estados participantes da competição apresentaram, além dos sorotipos 1 e 4, outros sorotipos de dengue: Bahia, Minas Gerais e São Paulo tiveram casos de DENV-2 e o Ceará apresentou casos de DENV-3, com respectivamente, $0,98 \%, 0,54 \%, 1,12 \%$ e $4,35 \%$ dos casos confirmados em cada cidade.

Assim, apesar do conjunto de dados utilizado para a determinação do risco de contaminação dos turistas por dengue durante a Copa do Mundo aparentar-se reduzido, a princípio, contendo apenas 4 anos da série histórica (2010 a 2013), entende-se que este é um intervalo representativo para o ano de 2014, já que os sorotipos presentes no Brasil em 2014 atendem a expectativa da hipótese inicial. 


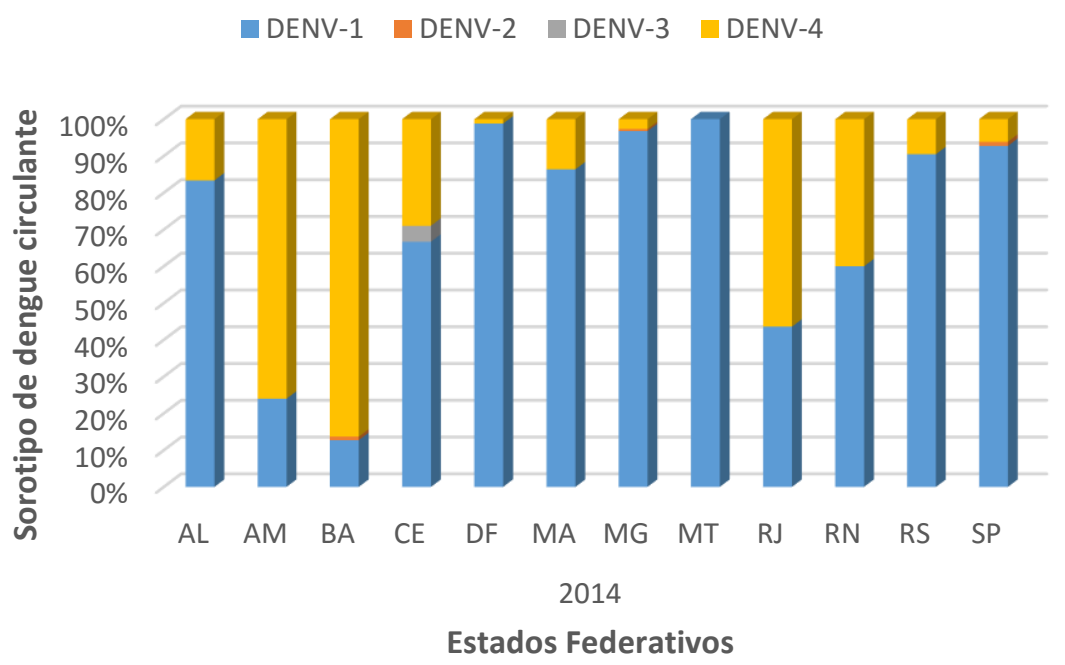

Figura 54 - Sorotipo da dengue circulante em 2014 nos Estados-sede dos jogos da Copa do Mundo FIFA

Outra premissa utilizada neste trabalho foi de que o turista submete-se, durante a Copa do Mundo FIFA, ao mesmo risco que um residente local. Os cálculos demonstrados fazem uma superestimativa ao deixar os turistas com o mesmo risco que os moradores locais. Contudo, o equilíbrio entre os riscos se dá devido à subnotificação dos casos notificados ao Ministério da Saúde, o que torna o cálculo do risco uma subestimação do risco real. Chastel (2012) e Bhatt et al. (2013) mostraram que a subnotificação, ou casos assintomáticos, pode ser um grande problema no controle da dengue.

Entretanto, há evidências de que os turistas são suscetíveis a um risco de infecção por dengue menor do que os moradores locais. Os dados do Ministério do Turismo do Brasil mostram que em 2008 houve apenas um único caso de dengue entre os 350 mil europeus que visitaram o Rio de Janeiro naquele ano (Brasil, 2009). Se dividirmos o total de casos pelo total de turistas obtemos o valor que corresponde a um risco individual de dengue para os turistas da ordem de $2 \times 10^{-6}$.

Ao compararmos este risco individual de dengue que os turistas europeus sofreram em 2008 com o risco de dengue para a população do Rio de Janeiro naquele ano, que foi de $2 \times 10^{-2}$, tem-se que os turistas europeus foram submetidos a um risco de dengue da ordem de $10^{4}$ menor do que a população local. Para o ano de 2010, o número de casos de dengue relatados em visitantes europeus no Rio de Janeiro foi de 3 casos entre os 370 mil turistas, correspondendo ao risco individual da ordem de $6 \times 10^{-6}$. Já para a população local, o risco individual foi de $5 \times 10^{-4}$, uma diferença de cerca de $1,2 \times 10^{-2}$. 
É verdade que não há como saber o tempo de permanência destes turistas europeus na cidade do Rio de Janeiro, nem mesmo em que época do ano eles foram infectados. Além disso, deve-se levar em consideração que o risco para o período da Copa do Mundo considera outras 11 cidades-sede além do Rio de Janeiro. Assim, a diferença entre os riscos dos anos 2008 e 2010 com os aqui calculados pode ser explicada pelo comportamento dos turistas e também devido à competição realizar-se fora do período de maior incidência de dengue.

As diferenças de infraestrutura, por exemplo, saneamento básico, nas cidades brasileiras entre os pontos turísticos e as áreas menos atrativas aos turistas, isto é, as periferias das cidades, também ajudam a explicar a diferença entre os riscos a que os turistas estão submetidos, já que quanto menor o cuidado com a infraestrutura, mais focos de procriação do mosquito podem aparecer, aumentando o risco de contaminação.

Para exemplificar essa diferença podemos comparar o IDHM (Índice de Desenvolvimento Humano Municipal) de dois bairros do Rio de Janeiro. Leblon e Cidade de Deus estão distantes cerca de $23 \mathrm{~km}$. O IDHM evidencia o enorme contraste entre as duas regiões, enquanto o Leblon possui um índice compatível aos países primeiro mundo, com IDHM de 0,944, o Complexo do Alemão tem IDHM de 0,656, compatível aos países com IDH médio (das Nações Unidas para o Desenvolvimento, 2013).

Existe uma diferença entre os valores publicados no artigo "Risk of symptomatic dengue for foreign visitors to the 2014 FIFA World Cup in Brasil" (Massad et al., 2014b) e os aqui apresentados. Tal diferença está relacionada à atualização da base de dados obtida junto ao Ministério da Saúde do Brasil e ao ajuste no método de contabilização dos casos previstos neste estudo. Inicialmente a contagem dos casos previstos de dengue se deu pela soma de todos os valores obtidos a cada etapa/cidade visitada pelo turista. No entanto, entende-se aqui que cada período do cronograma é individual e não está relacionado ao roteiro futuro.

Por exemplo, o risco de infecção em Brasília não está relacionado ao risco em Fortaleza, assim o número total de infectados em uma cidade não pode ser composto pelo número de infectados na outra cidade. Então, se a previsão para o número de casos de dengue para um período em Brasília for igual a 0,4 casos, entende-se que o número de casos a ser somado ao final deve ser 0 e não 0,4. Deste modo, se na próxima cidade, neste exemplo Fortaleza, a previsão for de 2,3 casos, o número de casos esperados que deve ser somado ao total de casos acumulados é igual a 2, de forma que, ao somarmos os valores sem e com os arredondamentos teremos resultados distintos. Sem o arredondamento prévio tem-se $(0,4+2,3=$ 
$2,7)$, portanto previsão de 3 casos de dengue, já utilizando o arredondamento prévio, teremos $(0+2=2)$ e então, previsão de 2 casos.

Isto explica porque na previsão anterior, publicada por Massad et al. (2014b), apresentou-se valores distintos dos aqui explicitados. Dessa forma, o resultado publicado, onde previu-se 33 (3-54) casos, foi corrigido para 32 (0-73) casos de dengue em turistas não imunes.

Assim como para a Copa do Mundo, a proposta principal para o período dos Jogos Olímpicos foi de determinar o risco individual de um turista ser infectado por dengue. A diferença principal entre os dois estudos está no método de determinação da força de infecção em cada um dos eventos.

No primeiro caso, ajustou-se apenas os casos notificados nas semanas epidemiológicas respectivas ao evento entre os anos 2010 e 2013 à função exponencial (funções lineares, logarítmicas ou de potência também foram utilizadas), obtendo-se a força de infecção diária para, então, finalmente determinar-se o risco a partir dos parâmetros do ajuste aplicados à equação 4.1 .

Já no caso dos Jogos Olímpicos, por não existir a necessidade de trabalhar com a força de infecção diária, exigida no caso da Copa do Mundo, pois o turista não permaneceria todos os dias do evento na mesma cidade, o ajuste da força de infecção foi dado pelo modelo matemático, ao reproduzir a quantidade de casos notificados por semana epidemiológica, para cada ano do histórico da dengue na cidade do Rio de Janeiro, entre 2000 e 2015.

Para descrever a propagação da dengue entre a população local utilizou-se se do modelo SIR e uma aproximação estocástica, assumindo estrutura SI, foi aplicada para estimar o risco individual de dengue para os viajantes.

A força de infecção durante as 3 semanas dos Jogos Olímpicos foi calculada assumindo a função apresentada na seção 5.3 (equação 5.1), que fora ajustada para reproduzir os dados notificados apresentados no SINAN - Sistema de Informação de Agravos de Notificação, de forma a obedecer as equações do modelo proposto.

Se a dinâmica da incidência de dengue durante o período olímpico for igual àquela apresentada em qualquer um dos anos estudados neste trabalho (de 2000 até 2015), o risco individual para os viajantes durante o evento será igual àquele apresentado na tabela 15 (secção 5.5).

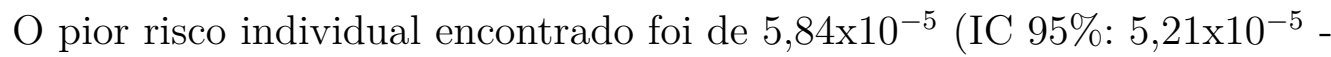
$\left.6,47 \times 10^{-5}\right)$. Supondo que 400.000 turistas suscetíveis permaneceriam no Rio de Janeiro durante todo o período dos Jogos Olímpicos, a multiplicação do risco individual pelo número de turistas resulta em 23 (21-26) casos de dengue. 
Este é o resultado da reprodução dos casos sintomáticos de 2007, ou seja, se durante o mês de Agosto de 2016 a força de infecção $(\lambda)$ da dengue fosse igual àquela de 2007, o risco individual de infecção do turista, durante os jogos, seria de

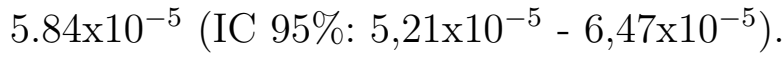

Seguindo o mesmo raciocínio, o menor risco individual obtido foi de $1.4 \times 10^{-9}$ (IC 95\%: $0-3.22 \times 10^{-8}$ ) (correspondendo ao ano 2002), que resulta em 0 casos sintomáticos entre os 400.000 visitantes suscetíveis considerados.

Levando-se em consideração os casos assintomáticos, ao contrário da expectativa inicial, o pior risco não aparece para a proporção 1:10, mas sim na proporção

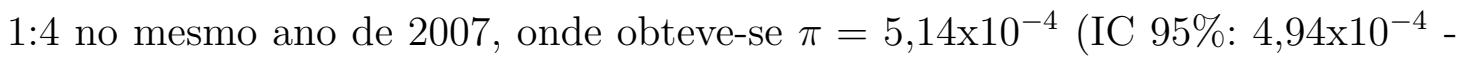
$\left.5,34 \times 10^{-4}\right)$, resultando em 206 casos esperados de dengue.

Analisando os ajustes obtidos para os dados de 2007, vê-se claramente a diferença entre os ajustes de todas as proporções de sintomáticos e assintomáticos, quando comparadas à relação 1:4 (figura ((b))). Para os 5 ajustes realizados com os dados de 2007, a relação 1:4 foi quem encontrou maior dificuldade até obter o melhor ajuste que obedecesse ao modelo e à tolerância determinada. O número de iterações executadas até a obtenção do melhor ajuste que obedecesse às condições determinadas para cada relação de casos sintomáticos e assintomáticos foi igual a 974 iterações (1:1), 986 iterações (1:2), 11.706 iterações (1:4), 317 iterações (1:6) e, por fim, 915 iterações (1:10).

Assim, as relações sintomáticos/assintomáticos 1:2, 1:4, 1:6 e 1:10 resultaram para o risco individual máximo, respectivamente, em 1,66x10 ${ }^{-4}$ (IC 95\%: $\left.1,55 \times 10^{-4}-1,76 \times 10^{-4}\right)($ ano 2007$), 5,14 \times 10^{-4}\left(\right.$ IC $\left.95 \%: 4,94 \times 10^{-4}-5,34 \times 10^{-4}\right)$ (ano

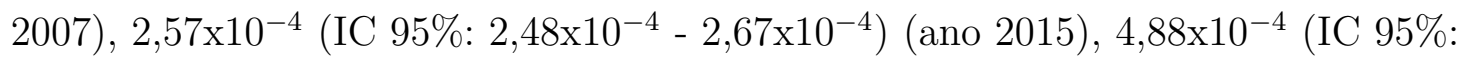
$\left.4,66 \times 10^{-5}-5,11 \times 10^{-5}\right)($ ano 2007$)$.

O resultado do pior risco individual $\left(5.84 \times 10^{-5}\right)$ pode ser traduzido em uma incidência de 5,84 casos em 100.000 visitantes. No pior risco global, isto é, levando-se em consideração as subnotificações, a incidência encontrada é de 51,40 casos em 100.000 visitantes.

A relação entre o total de casos notificados por ano e o risco de infecção para um período específico, como se vê, não é direta. Apesar de o pior ano da dengue no Rio de Janeiro ter acontecido em 2002, o mês de Agosto daquele ano apresentou uma força de infecção extremamente baixa, resultando em riscos individuais muito baixos em todos os cenários estudados (da ordem de $10^{-7}$ no pior caso), traduzindose em 0 casos entre os 400.000 visitantes. Assim, pode-se afirmar que, para a determinação do risco da forma que buscamos aqui, ou seja, para um período 
específico do ano, o comportamento da dinâmica da dengue durante o ano tem maior importância do que a soma total de casos notificados em todo o ano, pois, é a intensidade da força de infecção quem determina a intensidade do risco de infecção, e não a quantidade de casos ocorridos durante todo o ano epidêmico. Em outras palavras, é a distribuição dos casos durante o ano quem influenciará a intensidade da força de infecção e consequentemente o risco.

A figura 55 auxilia na comparação entre o volume de casos por ano no Rio de Janeiro e mostra que apesar de os anos de 2002 e 2008 apresentarem os maiores picos no número de casos, estes foram concentrados durante a temporada de verão, com o pico em Março e começo de Abril, respectivamente.

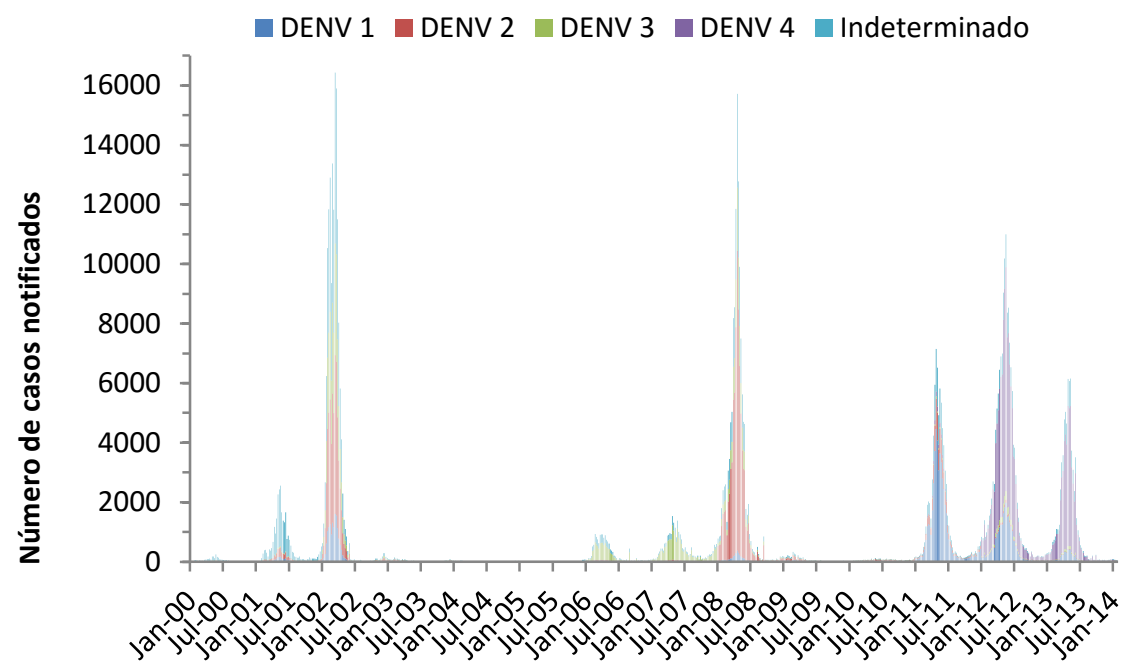

Figura 55 - Número de casos de dengue reportados no Rio de Janeiro entre 2000 e Julho de 2014

Embora o ano de 2007 tenha apresentado poucos casos em relação aos anos de 2002 e 2012, a força de infecção durante as semanas 31 e 33 naquele ano foi superior aos outros anos, resultando em um risco de infecção muito maior.

Os anos de 2004, 2005 e 2010 são excepcionais para o Rio de Janeiro, pois nestes anos a distribuição dos casos notificados por semana não teve seu pico entre as primeiras semanas do ano, mas apenas na penúltima SE, forçando a descaracterização da curva epidêmica nestes anos. Assim, embora os totais de casos notificados nestes 3 anos estejam entre os menores para toda a série estudada, o comportamento da curva é refletido no cálculo da força de infecção para o mês de Agosto, que apresenta nesses três episódios a tendência de crescimento do número de casos.

Outro caso que merece destaque é o ajuste da reprodução dos casos de 2015. 
Mais uma vez, apesar do total de casos ser baixo (17.504 casos sintomáticos), o comportamento da dengue foi atípico, pois apresentou o pico do número de casos notificados apenas na SE 17, 3 semanas mais tarde que média da série, alongando assim o período epidêmico.

Dependendo do número de casos que se observa dentro de um ano epidemiológico, a chegada de um ciclo epidêmico prematuro, pode ser substancial e interferir no ajuste da incidência, como por exemplo, em 2007, quando nas últimas 14 semanas do ano foram notificados $20,30 \%$ dos casos daquele ano. Dessa forma, a curva da incidência é mais larga o que resultou, para aquele ano, o maior risco dentre todos os anos estudados.

Ao analisar o ajuste de 2004 observa-se que os casos, na verdade, começam a crescer ainda em 2003 e entram em 2004 já com aceleração negativa, resultando em baixíssimos riscos em 2004.

Em 2005 a distribuição dos casos permanece estacionária com poucos casos por semana, até que nas últimas semanas epidemiológicas se dá o início da epidemia de 2006. Embora 2005 tenha somado pouquíssimos casos, a influência da epidemia do ano seguinte, é responsável pelo aumento da força de infecção calculada para aquele ano.

Já em 2010 não houve aumento substancial no número de casos durante o verão e as notificações não cederam durante o inverno e, ainda que lentamente, a curva da incidência cresce com o tempo, sendo assim, responsável pelo 4 o maior risco individual obtido neste estudo $\left(\pi=2,39 \times 10^{-5}\left(\mathrm{IC} 95 \% 1,99 \times 10^{-5}-2,78 \times 10^{-5}\right)\right)$.

Os anos em que, se reproduzidas as condições durante os Jogos Olímpicos do Rio de Janeiro, resultam em maiores riscos para os turistas são os anos de 2007, 2010, 2012 e 2015, com incidência variando de 2 casos entre 100.000 visitantes (2010), até 6 casos por 100.000 visitantes (2007).

Embora 2002 tenha apresentado uma forte epidemia com mais de 150 mil casos notificados em todo o ano, o risco calculado para essa dinâmica é o menor da série estudada. Naquele ano, o maior número de casos notificados (16.435) foi durante a SE 10, 4 semanas mais cedo do que a média entre os anos analisados. Além disso, após poucas semanas, as notificações estagnaram-se sem apresentar nenhuma variação capaz de aumentar a força de infecção e, consequentemente, incapaz de gerar risco considerável.

A epidemia de 2008, que apresentou o $3^{\circ}$ maior número de casos da série estudada com 128.868 casos, tem seu início no ano de 2007. Na epidemia de 2007, embora a curva de incidência tenha apresentado a esperada queda nas notificações 
com a aproximação do inverno, as notificações não cessaram e logo voltaram a subir semana após semana até atingir o pico na semana 14 de 2008.

É evidente que para que existam novas infecções é preciso que haja mosquitos. Se imediatamente após o fim do inverno (SE 35) o número de notificações começa a subir, é concebível determinar que a densidade de mosquitos permaneceu alta durante o inverno, favorecendo o rápido e o precoce crescimento no número de novos casos de dengue.

Este comportamento pode ser explicado pela variação da temperatura e o volume de chuvas em 2007. Considerando que, das condições climáticas necessárias para a sobrevivência dos mosquitos $A$. aegypti, a temperatura mais favorável para o seu desenvolvimento está entre $25^{\circ} \mathrm{C}$ e $30^{\circ} \mathrm{C}$, diminuindo-se a atividade para temperaturas mais baixas. Este dado pode nos ajudar a entender por que o risco obtido através da reprodução dos casos de 2007 é superior aos outros anos, mesmo 2007 não tendo apresentado um grande número de infectados.

As temperaturas máxima média, média e mínimas média, em 2007, foram: $26^{\circ} \mathrm{C}, 21^{\circ} \mathrm{C}, 17^{\circ} \mathrm{C}$ (Julho) e $27^{\circ} \mathrm{C}, 22^{\circ} \mathrm{C}, 18^{\circ} \mathrm{C}$ (Agosto) (The Weather Company, 2016), a média histórica é de $24,5^{\circ} \mathrm{C}, 20,6^{\circ} \mathrm{C}, 16,7^{\circ} \mathrm{C}$ (Julho) e $25,5^{\circ} \mathrm{C}, 21,8^{\circ} \mathrm{C}$, $18,9^{\circ} \mathrm{C}$ (Agosto) (data, 2016). Portanto, em Julho de 2007 as temperaturas mínima média e média foram $2,3^{\circ} \mathrm{C}$ e $0,4^{\circ} \mathrm{C}$ mais altas, respectivamente, do que na média histórica. Já em Agosto daquele ano as temperaturas mínima média, média e máxima média superaram a média histórica em $2^{\circ} \mathrm{C}, 1^{\circ} \mathrm{C}$ e $2^{\circ} \mathrm{C}$, respectivamente.

Conforme dito na introdução deste trabalho, o acréscimo de 1 a $2^{\circ} \mathrm{C}$ na temperatura do planeta pode aumentar a população de risco em várias centenas de milhões de pessoas (Guzmán and Kouri, 2002). Dessa maneira, podemos inferir que o inverno mais quente pode ser o responsável pelo maior risco de contaminação em 2007 pois a elevada temperatura para o período pode ter resultado em uma maior densidade de mosquitos e, consequentemente, maior intensidade de transmissão naquele ano.

Outra informação relevante é a precipitação em cada período. Dos anos com maior notificação de dengue no mês de Agosto, 2012 aparece com 1.462 casos, seguido por 2011 (1.050 casos) e 2015 (594 casos), enquanto em 2007 apenas 835 casos foram notificados. Nestes anos o volume de chuva foi, respectivamente, $37 \%$, $53 \%$ e $74 \%$ menor do que em 2007.

Se compararmos o volume de chuvas no mês de Julho, entre os anos com maiores notificações de dengue em Agosto, devemos incluir na lista acima os anos de 2002 e 2008, que por sua vez foram $58 \%$ e $56 \%$ mais secos do que 2007 , 
respectivamente.

As informações sobre o histórico do volume de chuvas no Rio de Janeiro foram obtidas no Sistema Alerta Rio, da Prefeitura do Rio de Janeiro (do Rio de Janeiro, 2016).

\begin{tabular}{|c|c|c|c|c|c|c|c|c|c|c|c|c|}
\hline & Jan & $\mathrm{Fev}$ & Mar & Abr & Mai & Jun & Jul & Ago & Set & Out & Nov & Dez \\
\hline 2000 & 160.7 & 136.9 & 97.4 & 34.7 & 35.2 & 10.9 & 68.7 & 78.3 & 132.9 & 52.8 & 124.5 & 141.0 \\
\hline 2001 & 62.7 & 58.8 & 120.2 & 46.4 & 99.2 & 56.7 & 94.2 & 8.9 & 43.4 & 79.7 & 97.6 & 275.9 \\
\hline 2002 & 69.8 & 154.0 & 49.6 & 26.2 & 123.1 & 62.0 & 30.0 & 27.3 & 115.9 & 42.6 & 163.3 & 167.9 \\
\hline 2003 & 339.9 & 6.8 & 249.2 & 86.7 & 64.2 & 19.2 & 5.3 & 163.7 & 85.8 & 193.7 & 212.4 & 100.8 \\
\hline 2004 & 163.2 & 159.3 & 63.7 & 148.2 & 78.0 & 38.3 & 167.2 & 24.8 & 27.8 & 70.9 & 164.1 & 123.9 \\
\hline 2005 & 196.4 & 83.0 & 189.1 & 173.2 & 84.3 & 36.9 & 112.4 & 17.7 & 178.5 & 56.8 & 154.9 & 182.3 \\
\hline 2006 & 222.0 & 132.5 & 100.2 & 93.0 & 125.9 & 80.2 & 37.5 & 56.0 & 121.5 & 115.5 & 163.2 & 104.1 \\
\hline 2007 & 108.2 & 113.2 & 19.2 & 82.7 & 127.8 & 50.8 & 71.0 & 22.8 & 19.3 & 173.0 & 162.7 & 217.1 \\
\hline 2008 & 161.0 & 142.5 & 204.4 & 140.2 & 63.5 & 61.5 & 31.0 & 78.5 & 103.1 & 80.9 & 158.7 & 133.7 \\
\hline 2009 & 206.3 & 112.4 & 109.2 & 149.9 & 59.2 & 68.2 & 95.5 & 42.2 & 106.6 & 167.7 & 116.2 & 371.4 \\
\hline 2010 & 175.4 & 95.0 & 361.3 & 361.3 & 62.1 & 56.1 & 113.5 & 28.3 & 45.7 & 167.2 & 114.5 & 205.9 \\
\hline 2011 & 98.7 & 35.8 & 116.5 & 149.8 & 114.5 & 35.4 & 33.2 & 36.5 & 31.2 & 117.8 & 82.8 & 175.8 \\
\hline 2012 & 179.5 & 30.8 & 91.0 & 96.6 & 99.3 & 128.3 & 44.8 & 15.5 & 105.0 & 63.0 & 90.0 & 44.1 \\
\hline 2013 & 346.8 & 93.6 & 220.1 & 89.9 & 104.9 & 48.9 & 112.9 & 18.8 & 73.0 & 73.4 & 143.0 & 206.8 \\
\hline 2014 & 65.1 & 39.6 & 107.9 & 123.4 & 56.0 & 68.0 & 107.7 & 45.0 & 32.1 & 25.5 & 57.4 & 67.5 \\
\hline 2015 & 90.1 & 121.5 & 138.2 & 94.4 & 48.4 & 93.2 & 18.6 & 6.6 & 96.6 & 32.7 & 179.0 & 84.9 \\
\hline
\end{tabular}

Tabela 19 - Precipitação no Município do Rio de Janeiro, em milímetros

Se compararmos a precipitação total entre Julho e Agosto de 2007 e os anos que apresentaram maior número de casos notificados, apenas em 2008 choveu mais (volume de chuva 17\% maior), enquanto em 2002, 2011, 2012 e 2015 choveu, respectivamente, $39 \%, 26 \%, 36 \%$ e $73 \%$ menos do que em 2007 .

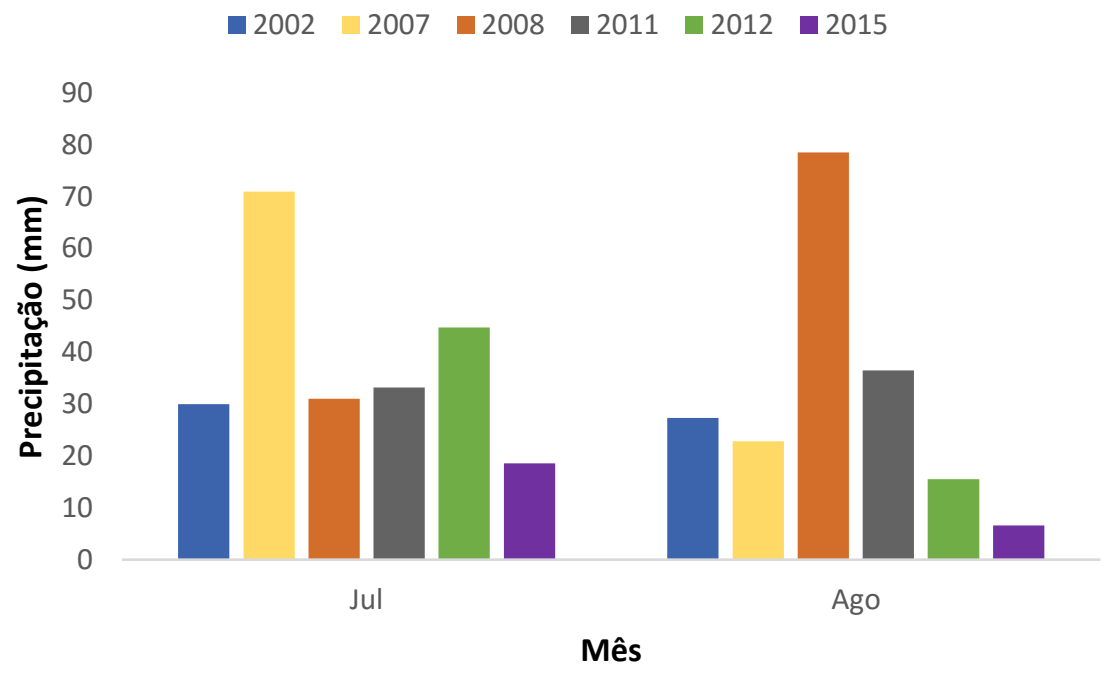

Figura 56 - Precipitação em Julho e Agosto - Rio de Janeiro

Estes fatores podem ser a razão de o risco individual de infecção por dengue para os turistas, ao reproduzir-se a dinâmica de 2007, ser tão elevado frente aos demais anos estudados. E quando dimensionado este risco individual aos 400.000 
visitantes não imunes, obtém-se os 23 casos de dengue em visitantes durante os Jogos Olímpicos, conforme tabela 14.

O modelo utilizado baseia-se em várias premissas, e assim como para o estudo da Copa do Mundo, assume que os visitantes estão sujeitos à mesma força de infecção que os moradores locais e, também assume que os visitantes estão em número baixo em relação à população local. Além disso, o modelo também assume que os visitantes permanecem no Rio de Janeiro por um período relativamente curto e, portanto, não contribuem para a força local de infecção. Por fim, o modelo assume que não há risco competitivo para os viajantes, como voltar para casa antes de adquirir a infecção.

De forma geral, tanto no estudo para a Copa do Mundo quanto para os Jogos Olímpicos, o principal resultado obtido aqui foi o risco individual de um turista não imune adquirir a infecção causada pela dengue e, através deste resultado qualquer turista poderia decidir sobre sua participação ou não nos eventos.

O risco individual permite que se calcule o número total de turistas infectados, desde que tenha-se conhecimento prévio sobre o total de turistas não imunes que estariam presentes no Brasil (no caso da Copa do Mundo) e no Rio de Janeiro, durante os Jogos Olímpicos.

Como já dito, para se determinar o total de turistas que serão infectados assumiu-se neste trabalho que todos os turistas que aqui chegarem não são imunes à doença. Portanto, o valor obtido é um limite superior para o número médio de casos esperados/infecções.

No que diz respeito aos visitantes de países endêmicos imunes à dengue, observa-se:

1. Os indivíduos devem ser provenientes de Sudeste da Ásia, África ou América do Sul, que são as regiões endêmicas de dengue;

2. A julgar pelo número de visitantes que frequentaram a Copa do Mundo FIFA 2014, dos 471.000 visitantes estrangeiros no Rio de Janeiro (Brasil, 2016b), cerca de $40 \%$ veio da América do Sul. O restante veio tanto da Europa ou América do Norte. Africanos e Asiáticos do Sudeste eram uma pequena minoria, em alguns casos, apenas representados pelos próprios atletas.

Levando-se estes pontos em consideração, o número de casos esperados/infecções obtidos neste estudo poderia ser cortado pela metade. 
Infelizmente, todos os quatro sorotipos de dengue estão circulando nos países da América do Sul e a proporção de indivíduos que são imunes é desconhecida.

No que tange à comparação entre os riscos aqui determinados e os encontrados na literatura, tem-se:

Barcellos and Lowe (2014), relatam uma notável diferença entre as incidências de dengue no verão e no inverno e determinam que durante a Copa do Mundo as cidades de Porto Alegre, Curitiba e São Paulo apresentariam baixa transmissão da dengue devido à região em que essas cidades estão localizadas, enquanto Fortaleza, Natal, Recife, Salvador e Cuiabá, embora apresentem decaimento nas taxas de transmissão durante o inverno, são cidades em que os mosquitos permanecem ativos. Já no Rio de Janeiro, Manaus, Brasília e Belo Horizonte, apesar de estarem presentes em uma área de permanente transmissão, elas apresentariam um risco mais baixo durante a temporada da competição de 2014.

Barcellos and Lowe (2014), ao citar o risco encontrado por este trabalho disse: "considerando as condições climáticas e demográficas específicas em que a Copa do Mundo vai ocorrer, apenas uma pequena fração de casos são esperados entre os visitantes".

Lowe et al. (2014) previram que as cidades-sede localizadas no nordeste brasileiro teriam alta probabilidade de epidemia de dengue durante a Copa do Mundo. As maiores probabilidades foram encontradas para Recife $\left(p_{\text {high }}=19 \%\right)$, Fortaleza $\left(p_{\text {high }}=46 \%\right)$ e Natal $\left(p_{\text {high }}=48 \%\right)$, enquanto Salvador, apresentou probabilidade mais baixa e foi classificada como risco médio.

Embora haja uma sensível diferença entre o propósito da publicação de Lowe et al. (2014) e o resultado deste trabalho, sendo que o primeiro busca determinar a probabilidade de que houvesse uma epidemia de dengue durante o mundial, enquanto o segundo determina o risco de infecção individual do turista, ao comparar os resultados, dado que se a probabilidade de epidemia for alta, entende-se que o risco individual também é alto, há convergência apenas quanto ao risco em Fortaleza e Natal, embora entenda-se que a magnitude dos riscos aqui encontrados sejam muito menores do que o encontrado por Lowe et al. (2014).

Conforme a expectativa inicial desta pesquisa, Wilson and Chen (2014) relatam que o risco de infecção por dengue durante a Copa do Mundo no Brasil e durante os Jogos Olímpicos seria baixo, porém não utiliza de nenhum modelo preditivo, apenas conclui o baixo risco pois estes eventos acontecem fora do pico de transmissão.

Já Hay (2013) determinou que o durante a Copa do Mundo o nordeste 
brasileiro apresentaria alto risco epidêmico. No entanto, após o fim de 2014, pôde-se confirmar que as previsões de alto risco para a dengue durante a competição daquele ano estavam erradas.

Outros trabalhos também relataram o risco de dengue para turistas em diversas regiões, tanto para períodos de curta duração quanto para longos períodos.

Embora as condições entre Singapura e Brasil, como por exemplo a área total, a população e o IDH (0,912 e 0,755, respectivamente), sejam bastante distintas, os dois países são endêmicos para a dengue. Massad and Wilder-Smith (2009), ao determinarem o risco de dengue para turistas em Singapura através da modelagem matemática, encontraram riscos que variaram de $1,44 \times 10^{-4}$ a $2,18 \times 10^{-3}$, na baixa temporada de infecção, para um mês de estadia no país.

Singapura recebeu 15,1 milhões de turistas em 2014 (Tourism, 2015). Se o risco de dengue para turistas em Singapura, em 2014, repetir aquele da década passada, mesmo que grande parte destes turistas sejam imunes à dengue, o total de turistas infectados capazes de exportar a dengue para seu país é maior do que o número de turistas que seriam infectados no Brasil durante as competições aqui estudadas, dado que o volume de turistas que visitaram Singapura é muito maior do que o total de visitantes que o Brasil recebeu durante as duas competições esportivas e, claro, dado que o risco individual de um turista infectar-se no Brasil durante a Copa do Mundo (maior risco igual a $7,42 \times 10^{-4}$ ) e durante os Jogos

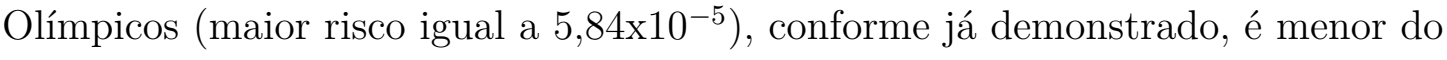
que aquele calculado para Singapura, no caso da Olimpíada, e de mesma ordem de grandeza no caso da Copa do Mundo.

Cobelens et al. (2002) estudou uma cohort de turistas holandeses com destino à regiões tropicais e subtropicais com duração média de 1 mês, e a partir do cálculo retroativo determinou que a incidência de dengue entre os viajantes foi igual a 29,08 casos/1.000 turistas. Já Baaten et al. (2011), em um estudo prospectivo, também com turistas holandeses, determinou que a incidência de dengue entre os turistas em viagem à áreas endêmicas (Ásia, África, América do Sul e Central e Caribe) foi de 11,6 casos/1.000 turistas.

Um terceiro estudo prospectivo com turistas israelenses que viajaram à Ásia, América do Sul e África, por um período de 3 a 6 meses resultou na incidência de 67,30 casos/1.000 turistas. No entanto, a atividade cruzada entre o teste IgG e a vacinação contra febre amarela e outras infecções por flavivírus podem ter superestimado este resultado (Potasman et al., 1999; Ratnam et al., 2013).

Ratnam et al. (2012), ao estudar uma cohort de turistas australianos que 
viajaram à Ásia por um período médio de curta duração, determinou que o risco de infecção que os turistas foram submetidos foi de 62,02 casos/1.000 turistas.

Nestes 4 estudos, as incidências obtidas foram de 22,68 a 131,60 vezes maiores do que a maior incidência aqui obtida, isto é, no pior resultado obtido para os Jogos Olímpicos, que foi igual a 51,40 casos em 100.000 turistas (sintomáticos/assintomáticos 1:4 ano 2007). Essa enorme diferença de incidência, por certo, está relacionada ao curto período em que os eventos aconteceram no Brasil e intimamente ligados ao período de baixa da dengue durante esses eventos, já que eles foram realizados durante o fim do outono e início do inverno brasileiro.

Massad et al. (2013), utilizando modelagem matemática, obtiveram que o risco de infecção na Tailândia durante a baixa temporada para turistas não imunes à dengue, era de $3,53 \times 10^{-6}$ para 4 semanas de estadia, e $2,02 \times 10^{-6}$ para 3 semanas de estadia. A Copa do Mundo teve duração de 5 semanas, e o risco individual variou da ordem de $10^{-6}$ até $10^{-4}$. No caso das Olimpíadas (3 semanas) ele variou da ordem de $10^{-5}$ a $10^{-9}$. Assim, guardadas as devidas proporções entre as condições encontradas em cada uma das regiões, observa-se que há um denominador comum entre as grandezas acima.

Na véspera dos Jogos Olímpicos o Brasil sofreu uma preocupante epidemia causada pelo vírus da Zika. Até a semana epidemiológica 27, isto é, mês de Julho de 2016, foram confirmados 78.421 casos de Zika em todo o Brasil, dos 174.003 casos notificados até então. O Estado do Rio de Janeiro contabilizou 46.022 casos notificados de Zika vírus, incidência de 278,1/100.000 habitantes. A segunda maior incidência até aquele momento em todo o Brasil, atrás apenas do Mato Grosso (610,8 casos/100.000 hab.) e Bahia (315,8 casos/100.000 hab.) (Brasil, 2016c).

No mesmo período a incidência de dengue no Estado do Rio de Janeiro era de 434,7 casos/100.000 habitantes (Brasil, 2016c).

Embora a taxa de mortalidade causada pela Zika seja aparentemente inferior à mortalidade da dengue, os potenciais agravos da febre do Zika provocaram um grande receio da sociedade quanto ao risco de infecção dos turistas durante os Jogos Olímpicos do Rio de Janeiro.

OMS, CDC e pesquisadores de diversas regiões do mundo manifestaram-se em cartas abertas (Attaran et al., 2016a), artigos científicos e noticiários, acerca dos riscos de turistas visitarem o Rio de Janeiro (Attaran, 2016; CDC, 2016; Codeço et al., 2016; Grills, 2016; Grubaugh and Andersen, 2016; Massad et al., 2016a,b; McConnell et al., 2016).

Após extensa discussão acerca do risco, onde muitos desses artigos utilizaram 
nossos resultados para argumentar a favor da manutenção dos Jogos e contra o risco alto de infecção por Zika, a posição oficial da OMS foi de apoiar a execução dos Jogos no Rio de Janeiro por entender que o risco seria baixo (BBC, 2016).

O mesmo método de determinação de risco de infecção por dengue para turistas apresentado neste estudo pode ser utilizado para a determinação do risco de infecção por Zika.

Ao comparar a probabilidade de o mosquito Aedes picar um turista durante o Carnaval de 2016, com a probabilidade de fazê-lo durante as Olimpíadas, concluiu-se a partir da equação de determinação do risco aqui apresentada (equação 3.16), que o risco de infecção do turista por Zika seria baixo, com incidência de 1,8/1.000.000 turistas (Burattini et al., 2016). Esta incidência é 97\% menor do que o maior risco sintomático de dengue para turistas apresentado neste trabalho.

Em ambos os casos aqui analisados neste estudo, conforme já evidenciado, o risco do turista é considerado como o mesmo dos moradores locais. Assim, se compararmos o risco de infecção individual a dados de violência urbana, poderemos compreender melhor a dimensão deste risco e, além disso, compreender melhor o cenário a que o turista estaria submetido ao visitar o Brasil durante os dois eventos de massa.

O Anuário Brasileiro de Segurança Pública - 2016 (de Segurança Pública, 2016) relata que durante o ano de 2015 a cada 9 minutos uma pessoa foi morta violentamente (assassinada) no Brasil. Além disso, 1 mulher foi estuprada a cada 11 minutos e 1 pessoa foi assassinada pela polícia a cada 3 horas. Considerando que, o número de estupros depende diretamente das denúncias de violência, estes dados são subnotificados, já que as pesquisas mostram que apenas $10 \%$ das mulheres violentadas denunciam a violência sofrida, segundo Senado (2016).

Nos piores cenários deste estudo obtivemos os seguintes resultados: previsão de 73 casos de dengue entre os turistas durante os 34 dias de Copa do Mundo e 195 casos de dengue durante os 17 dias de Jogos Olímpicos. Isto resulta em 1 novo caso de dengue em turistas a cada 12 horas durante a Copa do Mundo e menos de 1 caso a cada 2 horas durante os Jogos Olímpicos. Portanto, se durante a Copa do Mundo a epidemia de dengue fosse tal que igual à pior previsão deste estudo, ainda assim, os turistas estariam sujeitos a um risco 75 vezes menor de ser infectado por dengue, quando comparado ao risco de morte violenta, 61 vezes menor do que o risco de uma mulher ser estuprada e 4 vezes menor do que ser morto por um policial. Se considerarmos as subnotificações dos casos de estupro, a relação entre os riscos salta de 61 vezes menor para 610 vezes menor. 
Já, se compararmos estes mesmos dados aos resultados para o período dos Jogos Olímpicos, o risco de ser infectado por dengue foi 14 vezes menor do que sofrer morte violenta, 11 vezes menor do que sofrer estupro (114 vezes menor se considerarmos as subnotificações) e apenas neste caso, 1,3 vezes maior do que o risco de ser assassinado por um policial (em serviço ou fora de serviço).

Outro dado da violência urbana importante para ilustrar estas comparações é o referente ao levantamento do número de "balas perdidas" em todo o Brasil. Porém, não existe no Brasil a tipificação penal de "bala perdida". Assim, os casos são investigados pela polícia civil como homicídios e lesão corporal dolosa e, dessa maneira, é difícil obter o real valor para este dado. No entanto, o Gabinete das Nações Unidas para os Assuntos de Desarmamento (UNLIREC - em inglês United Nations Office for Disarment Affairs), após o levantamento do número de casos divulgados em meios de comunicação, divulgou que entre 2014 e 2015, no período de um ano, 197 pessoas foram vítimas de "bala perdida", sendo 98 mortes e 115 feridos.

Isso significa que a cada 2 dias uma pessoa é alvejada acidentalmente em todo o Brasil (Unidas, 2016), resultando em um risco 4 vezes inferior ao risco de um turista ser infectado por dengue durante a Copa do Mundo e 21 vezes menor do que ser infectado durante os Jogos Olímpicos.

No entanto, estas comparações estão relacionando mortes devido à violência urbana (exceto no caso de estupros) com o risco de infecção. Se considerarmos então os dados de 2015, que apresentou um recorde histórico no total de casos de dengue, com 1.649.008 casos notificados e 863 mortes, obtemos que o índice de mortalidade daquele ano foi igual a 0,05\%. Agora, ao comparar os mesmos dados de violência apresentados acima com o risco de infeção por dengue multiplicado pelo índice de mortalidade obtido, temos que o risco de ser infectado por dengue durante a Copa do Mundo e morrer devido à doença é 145.776 vezes menor do que sofrer morte violenta no Brasil, 119.271 vezes menor do que sofrer estupro (1.192.710 vezes menor se considerarmos as subnotificações dos estupros), 7.289 vezes menor do que ser assassinado pela polícia, e 245 vezes menor do que ser vítima fatal de bala perdida. Já, em comparação aos dados do período Olímpico, o risco de morrer devido a dengue é 27.286 vezes menor do que sofrer morte violenta no Brasil, 22.325 vezes menor do que sofrer estupro (223.251 vezes menor se considerarmos as subnotificações dos estupros), 1.364 vezes menor do que ser assassinado pela polícia e 46 vezes menor do que ser vítima fatal de bala perdida.

É importante ressaltar que tais comparações foram realizadas afim de ilustrar a dimensão dos riscos a que os turistas estariam submetidos durante a baixa temporada 
de dengue frente aos dados de violência urbana no Brasil, e que os cálculos da frequência dos dados de violência urbana são médias no tempo e no espaço. Embora utilizados aqui em comparação direta a um período específico do ano, não são dados homogêneos, ou seja, a violência urbana não é igual em todo o Brasil, tampouco é a mesma em cada bairro das cidades, nem é distribuída igualmente no tempo. No entanto, dada a premissa de que o viajante estaria sujeito ao mesmo risco de infecção por dengue durante os jogos que um morador local, optou-se por comparar tais situações para evidenciar o tamanho do risco de sofrer violência que experimenta o morador local (o mesmo a que o turista estaria submetido), contra o risco de ser infectado por dengue.

Estes dados não diminuem a importância da determinação do risco individual de um turista não imune ser infectado por dengue. No entanto, evidenciam a urgência não apenas da necessidade do controle e da eliminação dos mosquitos, para a erradicação da doença, mas também chamam atenção para os demais problemas de violência urbana encontrados no Brasil.

O governo brasileiro gasta bilhões de reais em ações de combate ao mosquito, prevenção e tratamento dos doentes, porque deve de fato fazê-lo (Martelli et al., 2015). Entretanto, as comparações apresentadas acima evidenciam não apenas a necessidade de investimento contra a dengue (e contra o vetor, responsável pela transmissão de outras enfermidades além da dengue) como também a carência existente no combate do Estado à diminuição da violência urbana, sem promovê-la ao mesmo tempo, que acomete um número muito maior de pessoas do que a dengue.

Assim, embora a preocupação da comunidade internacional ter-se voltado ao risco de infecção por doenças infecciosas, tal como dengue e zika vírus, fica evidente que o risco de infecção por dengue não deveria ser um motivo de preocupação para os turistas, ao menos durante o período de baixa temporada da dengue.

Ao estimar o número de infecções por dengue em visitantes internacionais no Brasil, este trabalho também ajuda a prever o risco de importação de dengue para países não endêmicos após o retorno dos turistas aos seus países. Os viajantes contribuem para a disseminação da dengue em todo o mundo que, por exemplo, levou ao surto de dengue na Europa em 2012, na Ilha da Madeira em Portugal (Wilder-Smith et al., 2014) e possivelmente trouxe para o Brasil a doença do vírus da Zika.

Nos últimos anos a dengue reapareceu nas Ilhas Galápagos, no Havaí, na Ilha de Páscoa e em Buenos Aires. Também há relatos de dengue na Flórida e no sudeste da França. A presença de mosquitos Aedes albopictus e Aedes aegypti na Europa, associada ao aumento das viagens e da introdução de agentes patogênicos, 
constitui um risco de transmissão da doença (Guzman and Harris, 2015).

Faria et al. (2016) estima que o vírus da Zika foi introduzido no Brasil entre Maio a Dezembro de 2013. Neste período, como preparação para a Copa do Mundo, o Brasil sediou a Copa das Confederações e teria recebido cerca de 20 mil turistas estrangeiros (da Copa, 2013).

Embora ainda não se saiba quem foi o vetor do vírus que o trouxe para o Brasil, é provável que o vírus tenha entrado no país através de um viajante da região da Polinésia Francesa, já que o Taiti participou da competição em Junho de 2013. Desde então, milhares de pessoas foram infectadas e um número crescente de implicações devido ao Zika tem sido confirmadas (microcefalia, síndrome de Guillain-Barré) (WHO, 2016b).

Assim, a determinação prévia de risco de infecção por dengue proposta neste trabalho pode ser utilizada pelos órgãos de vigilância para evitar tanto o aparecimento de novos surtos em território nacional, como também, e não menos importante, ajudar diminuir a exportação da doença através de turistas aqui infectados, tanto ao provocar atitudes de combate ao mosquito transmissor promovidas pela sociedade e principalmente pelas órgãos governamentais responsáveis pela prevenção da dengue, quanto, até mesmo, influenciar na decisão dos turistas em vir, ou não, ao Brasil.

A conclusão de baixo risco individual para turistas resulta não apenas em um baixo número de infectados mas também em um baixíssimo risco de que estes turistas importem a doença aos seus países de origem.

Neste contexto, tendo em vista que a Febre Chikungunya e o vírus da Zika provavelmente chegaram ao Brasil, durante durante a Copa das Confederações (2013) e a Copa do Mundo da FIFA 2014 (Arbex et al., 2016; Faria et al., 2016), pode-se afirmar que o impacto da chegada dessas doenças para a saúde pública brasileira foi muito maior do que o risco de infecção a que os turistas submeteram-se durante as semanas de visita ao país, já que desde então o Brasil tem apresentado epidemias dessas doenças.

Apenas em 2016, até a SE 37, foram notificados 236.287 casos prováveis de febre de chikungunya com 116.287 casos confirmados e 120 óbitos, e 200.465 casos prováveis de febre pelo vírus Zika em todo o país, com 109.596 casos confirmados e 3 óbitos (Brasil, 2016d). Das complicações causadas pelo zika vírus, até 26 de novembro de 2016, foram notificados 10.342 casos. Desses, 3.121 (30,2\%) casos permanecem em investigação, 2.211 foram confirmados para microcefalia e/ou alteração do sistema nervoso central sugestivos de infecção congênita e 5.010 
descartados (Brasil, 2016e).

Deve-se observar, que a luta contra a dengue não pode limitar-se à caça aos mosquitos. O Brasil tem sofrido por epidemias de dengue, cada vez maiores, há mais de trinta anos. E embora as medidas de controle do mosquito vetor sejam amplamente conhecidas, o modelo de urbanização encontrado nas grandes cidades favorece à perpetuação do mosquito, completamente adaptado às cidades.

O sucesso do controle da dengue através da vacinação ainda é incerto. A vacina tetravalente denominada Dengvaxia (Sanofi Pasteur), recentemente aprovada pela Anvisa (Agência Nacional de Vigilância Sanitária), é recomendada apenas para indivíduos entre 9 e 45 anos de idade que vivam em regiões endêmicas, todavia, a baixa eficiência contra o sorotipo 2 pode causar um aumento no número de casos de dengue hemorrágica.

Ainda que a vacina ajude com o controle e diminuição do número de casos de dengue, ela não será capaz de eliminar a dengue no país em curto prazo, já que a taxa de sucesso desta vacina ainda não é suficientemente alta, variando de $30 \%$ a $70 \%$ de sucesso entre os 4 sorotipos. Halstead and Aguiar (2016) concluíram que os turistas devam evitar tomar a vacina, já que quando aplicada em indivíduos não imunes a nenhum sorotipo da dengue, o resultado foi ruim. Em testes realizados, a proporção de pacientes admitidos em hospitais com sintomas de dengue grave foi 5 vezes maior do que o controle por placebo.

Ao determinar que o poder público e a sociedade negligenciam as medidas de controle do vetor, estudos preditivos podem ajudar a evidenciar a urgência da necessidade de ações de combate antes mesmo do surgimento dos primeiros casos.

O modelo de urbanização adotado pelas cidades mostra-se caótico. Temse cidades enormes com pouquíssimas áreas verdes e com inúmeras construções que transformam as cidades em regiões insalubres, muitas vezes sem coleta de lixo eficiente, com rede de esgoto e fornecimento de água precários. Todos estes fatores estão intimamente ligados à adaptação do mosquito vetor às cidades, e por conseguinte, às recorrentes epidemias de dengue, e mais recentemente às epidemias de Chikungunya e Zika.

Assim sendo, enquanto o modelo de urbanização não sofrer uma profunda alteração, as condições de insalubridade das grandes cidades não forem corrigidas, e as vacinas apresentarem resultados insatisfatórios, o combate entre humanos e mosquitos apresentará sempre o mesmo vencedor e, consequentemente, as doenças transmitidas por ele persistirão.

Neste sentido, cada vez mais, fica evidente a necessidade da aplicação de 
novas tecnologias no combate à propagação de doenças e a modelagem matemática é uma ferramenta extremamente poderosa que tem enorme potencial para isto, auxiliando-nos na construção dos métodos de prevenção de epidemias e daí contribuindo no combate à disseminação das doenças. 



\section{Conclusão}

O primeiro método apresentado neste trabalho foi eficiente em prever o número de turistas que seriam infectados durante o mundial no Brasil. A análise das notificações por dengue das primeiras 14 semanas de 2014 foram importantes para a determinação do recorte dos dados que seriam analisados e assim foram essenciais para o sucesso an determinação do risco durante a Copa do Mundo de 2014.

O método de desagregação da força de infecção semanal para diária, mostrouse eficaz e possibilitou, então, a determinação do risco individual de acordo com o cronograma aqui apresentado e até mesmo, de acordo com o roteiro que cada turista desejasse fazer.

Conforme proposta deste trabalho, é possível utilizar a modelagem matemática para determinar o risco de infecção por doenças transmitidas por vetores e, neste sentido, utilizou-se com sucesso um modelo baseado no modelo clássico de infecções transmitidas por vetores de Ross-Macdonald (Macdonald, 1952) e, de acordo com os objetivos propostos, conclui-se:

- A reprodução da dinâmica de casos de dengue nas 12 cidades-sede da Copa do Mundo e dos Jogos Olímpicos do Rio foram executadas e os ajustes obtidos apresentam grande qualidade. Nos casos em que a incidência de dengue é pequena a qualidade do ajuste diminui.

- Obtivemos, a partir da aproximação estocástica proposta, que o risco individual de infecção por dengue para turistas não imunes durante a Copa do Mundo da FIFA variou de acordo com o cenário estudado. No cenário que utilizou a média de casos notificados entre 2010 e 2013 para a determinação do risco individual, o resultado obtido variou de $3,81 \times 10^{-5}$ a $4,46 \times 10^{-4}$, já quando utilizados os dados dos anos de melhor e piores notificações entre 2010 e 2013, isto é, respectivamente, o menor número de casos e o maior número de casos, o risco obtido variou de $3,61 \times 10^{-6}$ no melhor cenário a $8,33 \times 10^{-4}$, no pior.

- O risco individual resultou, de acordo com o cronograma apresentado, em 32 casos de dengue em turistas internacionais para o cenário médio, entre os 607.051 turistas. Este resultado implica na incidência de 5 casos em 100.000 turistas. No pior cenário, o total de casos encontrado foi de 73 casos de 
dengue (12 casos em 100.000 turistas) e, no melhor cenário, a previsão foi de 0 casos notificados.

- Mostramos neste trabalho que o ano de 2014 sofreu uma incidência de dengue particularmente baixa e, quando aplicamos ao modelo as notificações de incidência de dengue em 2014, obtivemos que o total de casos esperados para os mesmos 607.051 turistas foi 12 (0-41), sendo o risco individual para o turista compatível, em ordem de grandeza, ao risco inicialmente obtido neste estudo: A previsão do risco médio variou de $3,81 \times 10^{-5}$ a $4,46 \times 10^{-4}$ contra $5,30 \times 10^{-5}$ a $2,30 \times 10^{-4}$, calculados a partir dos dados de incidência de 2014 .

- As diferentes proporções entre casos de dengue sintomáticos e casos assintomáticos foram utilizadas com sucesso para reproduzirmos as dinâmicas da dengue na cidade do Rio de Janeiro entre os anos 2000 e 2015 e utilizamos as proporções 1:1, 1:2, 1:4, 1:6 e 1:10.

- A reprodução da dinâmica da dengue permitiu o cálculo do risco individual. Se as condições do ano de 2007 (ano que apresentou o pior risco individual) fossem repetidas em 2016, o pior risco individual de um turista não imune ser infectado por dengue durante os Jogos Olímpicos obtido foi de $5,84 \times 10^{-5}$ (IC

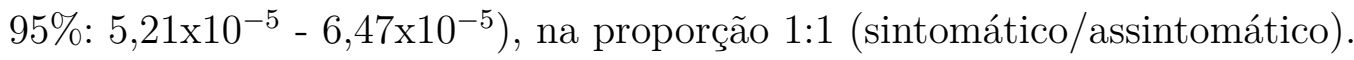
As demais proporções apresentaram os seguintes piores riscos: 1:2 1,66x10-4

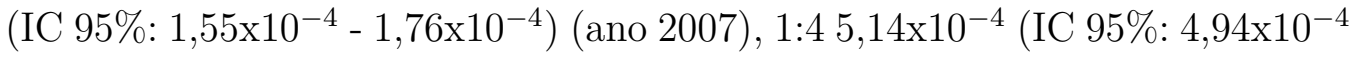

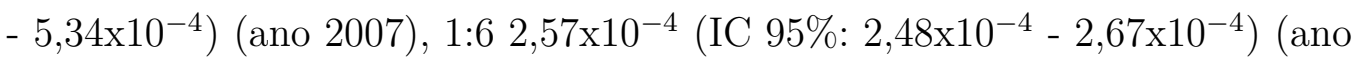

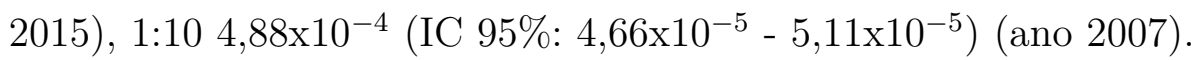

- Supondo que 400.000 turistas suscetíveis permaneceriam no Rio de Janeiro durante todo o período dos Jogos Olímpicos, o pior risco individual resultou, considerando apenas os casos notificados, em 23 (21-26) casos de dengue. No entanto, ao considerar as subnotificações temos que a previsão obtida foi, na relação 1:2 66 (62-71) casos, já na relação 1:4 obteve-se 206 (198-214) casos, na relação 1:6 foram 103 (99-107) casos e, por fim, a relação 1:10 resultou em 195 (186-204) casos de dengue em turistas não imunes. A incidência prevista no pior cenário, foi igual a 5,84 (sintomático) e 16,60, 51,40, 25,70 e 48,80 (assintomáticos 1:2, 1:4, 1:6 e 1:10, respectivamente) por 100.000 indivíduos. 


\section{Referências}

Bhatt S, Gething PW, Brady OJ, Messina JP, Farlow AW, Moyes CL, et al. The global distribution and burden of dengue. Nature. 2013;496(7446):504-507.

WHO. Dengue and severe dengue; 2015. [Online; acessado em Abril de 2015]. Available from: http://www. who.int/mediacentre/factsheets/fs117/en/.

Farmer P. Social inequalities and emerging infectious diseases. Emerging infectious diseases. 1996;2(4):259.

Guzmán MG, Kouri G. Dengue: an update. The Lancet infectious diseases. 2002;2(1):33-42.

Wilder-Smith A, Schwartz E. Dengue in travelers. New England journal of medicine. 2005;353(9):924-932.

de Almeida Pereira ATP. Patologia Infecciosa de Importação: Do passado ao presente. 2013;.

Sánchez-Albornoz N. El indio en el Alto Perú a fines del siglo XVII. Seminario de Historia Rural Andina; 1973.

da Cunha MC. Índios no Brasil-História, direitos e cidadania. Editora Companhia das Letras; 2013.

Dobyns HF. An appraisal of techniques with a new hemispheric estimate. Current Anthropology. 1966;p. 395-416.

Thornton R. American Indian holocaust and survival: A population history since 1492. vol. 186. University of Oklahoma Press; 1987.

Ribeiro D. O povo brasileiro: a formação e o sentido do Brasil. Global Editora e Distribuidora Ltda; 2015.

Town C. Encyclopaedia Britannica. Encyclopaedia Britannica Online Academic Edition, Encyclopædia Britannica Inc., 2016; 2015. Available from: https://www.britannica.com/topic/history-of-Europe/ The-emergence-of-modern-Europe-1500-1648.

Massad E, Coutinho F, Burattini M, Lopez L. The Eyam plague revisited: did the village isolation change transmission from fleas to pulmonary? Medical hypotheses. 2004;63(5):911-915. 
Benedictow OJ. The Black Death, 1346-1353: the complete history. Boydell \& Brewer; 2004.

CDC. "Black Death"or the Great Plague; 2015. Available from: https://www.cdc. gov/plague/history/.

Lopez LF, Amaku M, Coutinho FAB, Quam M, Burattini MN, Struchiner CJ, et al. Modeling importations and exportations of infectious diseases via travelers. Bulletin of mathematical biology. 2016;78(2):185-209.

Wilder-Smith A, Freedman DO. Confronting the new challenge in travel medicine: SARS. Journal of travel medicine. 2003;10(5):257-258.

WHO. Ebola Situation Reports; 2016. Available from: http://apps.who.int/ ebola/ebola-situation-reports.

Castro CFd, Simões DCM, Delamarque EV, Pepe VLE. Mass gatherings, disasters and public health. Ciência \& Saúde Coletiva. 2014;19(9):3717-3730.

Organization WH, et al. Communicable disease alert and response for mass gatherings. In: Technical Workshop. Geneva, Switzerland; 2008. p. 29-30.

Stannard DE. Disease, human migration, and history. The Cambridge world history of human disease Cambridge University Press, Cambridge. 1993;p. 35-42.

Wilder-Smith A, Quam M, Sessions O, Rocklov J, Liu-Helmersson J, Franco L, et al. The 2012 dengue outbreak in Madeira: exploring the origins. Euro Surveill. $2014 ; 19(8): 20718$.

Brady OJ, Gething PW, Bhatt S, Messina JP, Brownstein JS, Hoen AG, et al. Refining the global spatial limits of dengue virus transmission by evidence-based consensus. PLoS Negl Trop Dis. 2012;6(8):e1760.

Attaran A, Caplan A, Gaffney C, Igel L. Open letter to World Health Organisation re Olympics and Zika virus. Update. 2016;27:0.

Burattini M, COUTINHO F, Lopez L, Ximenes R, Quam M, Wilder-Smith A, et al. Potential exposure to Zika virus for foreign tourists during the 2016 Carnival and Olympic Games in Rio de Janeiro, Brazil. Epidemiology and infection. 2016;144(09):1904-1906.

Codeço C, Villela D, Gomes MF, Bastos L, Cruz O, Struchiner C, et al. Zika is not a reason for missing the Olympic Games in Rio de Janeiro: response to the open letter of Dr Attaran and colleagues to Dr Margaret Chan, Director-General, 
WHO, on the Zika threat to the Olympic and Paralympic Games. Memórias do Instituto Oswaldo Cruz. 2016;111(6):414-415.

Massad E, Wilder-Smith A, Ximenes R, Amaku M, Lopez LF, Coutinho FAB, et al. Risk of symptomatic dengue for foreign visitors to the 2014 FIFA World Cup in Brazil. Memórias do Instituto Oswaldo Cruz. 2014;(109):394-397.

Ximenes R, Amaku M, Lopez LF, Coutinho FAB, Burattini MN, Greenhalgh D, et al. The risk of dengue for non-immune foreign visitors to the 2016 summer olympic games in Rio de Janeiro, Brazil. BMC infectious diseases. 2016;16(1):1.

Massad E, Coutinho FAB, Wilder-Smith A. Is Zika a substantial risk for visitors to the Rio de Janeiro Olympic Games? The Lancet. 2016;388(10039):25.

Massad E, Coutinho FAB, Wilder-Smith A. The olympically mismeasured risk of Zika virus in Rio de Janeiro-Authors' reply. The Lancet. 2016;388(10045):658659.

Grubaugh ND, Andersen KG. Navigating the Zika panic [version 1; referees: awaiting peer. 2016;

Massad E, Burattini MN, Ximenes R, Amaku M, Wilder-Smith A. Dengue outlook for the World Cup in Brazil. The Lancet infectious diseases. 2014;14(7):552-553.

McConnell J, de Ambrogi M, Cleghorn S, Sekkides O. Zika virus and the 2016 Olympic Games-Editors' reply. The Lancet Infectious Diseases. 2016;16(9):10031004.

The LID. Zika virus at the games: is it safe? The Lancet Infectious diseases. 2016;

Attaran A. Zika virus and the 2016 Olympic Games. The Lancet Infectious Diseases. 2016;16(9):1001-1003.

Attaran A, Caplan A, Igel L. The olympically mismeasured risk of Zika virus in Rio de Janeiro. The Lancet. 2016;388(10045):657-658.

Hay S. Football fever could be a dose of dengue. Nature. 2013;503:439.

Lowe R, Barcellos C, Coelho CA, Bailey TC, Coelho GE, Graham R, et al. Dengue outlook for the World Cup in Brazil: an early warning model framework driven by real-time seasonal climate forecasts. The Lancet infectious diseases. 2014;14(7):619-626.

Macdonald G. The analysis of equilibrium in malaria. Tropical diseases bulletin. 1952;49(9):813-829. 
WHO. Dengue: guidelines for diagnosis, treatment, prevention and control. World Health Organization; 2009. World Health Organization and Special Programme for Research and Training in Tropical Diseases and World Health Organization. Department of Control of Neglected Tropical Diseases and World Health Organization. Epidemic and Pandemic Alert.

WHO. Dengue control; 2015. [Online; acessado em Abril de 2015]. Available from: www. who.int/denguecontrol/en.

CDC. Centers for Disease Control and Prevention - Dengue; 2013. [Online; acessado em Abril de 2015]. Available from: www.cdc.gov/Dengue.

Brasil. Casos de Dengue. Brasil, Grandes Regiões e Unidades Federadas, 1990 a 2014*; 2015. Available from: http://portalsaude.saude.gov.br/images/ pdf/2015/julho/29/Dengue-at---2014.pdf.

Brasil. Ministério da Saúde: Óbitos por Dengue. Brasil, Grandes Regiões e Unidades Federadas, 1990 a 2014*; 2015. [Online; acessado em Julho de 2015]. Available from: http://portalsaude.saude.gov.br/images/pdf/2015/julho/29/ --bitos-at---2014.pdf.

Coura JR. Dinâmica das doenças infecciosas e parasitárias. Guanabara Koogan; 2005.

Brasil. Diagnóstico rápido nos municípios para vigilância entomológica do Aedes aegypti no Brasil - LIRa: metodologia para avaliação dos índices de Breteau e predial. da Saúde M, editor. Brasília: Ministério da Saúde / Secretaria de Vigilância em Saúde / Diretoria Técnica de Gestão; 2005. Available from: http://www.dengue.pr.gov.br/arquivos/File/profissionais/ manual_dengue_liraa2.pdf.

Brasil. Guia de Vigilância Epidemiológica. da Saúde M, editor. Brasília: Ministério da Saúde / Secretaria de Vigilância em Saúde; 2005. Available from: http://portal.anvisa.gov.br/wps/wcm/connect/ 3463ca004745920f9a61de3fbc4c6735/Guia_Vig_Epid_novo2.pdf?MOD= A JPERES.

Brasil. Programa Nacional de Controle da Dengue: amparo legal à execução das ações de campo - imóveis fechados, abandonados ou com acesso não permitido pelo morador.. vol. 2. da Saúde M, editor. Brasília: Ministério da Saúde / Secretaria de Vigilância em Saúde; 2006. Available from: http://bvsms.saude. gov.br/bvs/politicas/programa_nacional_controle_dengue.pdf. 
Nations U. World population prospects; 2016. Available from: https://esa.un . org/unpd/wpp/DataQuery/.

SANOFI. http://www.sanofi.com.br/l/br/pt/layout.jsp?scat=9FCE2927-0080414C-AC8E-D3C95165CCDB. Consultado em 2014. 2007;

Brasil. Ministério da Saúde: Informações técnicas; 2013. [Online; acessado em Janeiro de 2013]. Available from: http://portalsaude.saude.gov.br/index . php/informacoes-tecnicas-dengue.

Wichmann O, Jelinek T. Dengue in travelers: a review. Journal of travel medicine. 2004;11(3):161-170.

WHO. Dengue/dengue haemorrhagic fever; 2012. [Online; acessado em Junho de 2012]. Available from: http://www.who.int/csr/disease/dengue/en/.

Chan M, Johansson MA. The incubation periods of dengue viruses. PloS one. 2012;7(11):e50972.

CDC. Epidemiology; 2010. [Online; acessado em Setembro de 2016]. Available from: http://www.cdc.gov/dengue/epidemiology/.

Massad E, Forattini OP. Modelling the temperature sensitivity of some physiological parameters of epidemiologic significance. Ecosystem Health. 1998;4(2):119-129.

Ferreira C, Yang H. Estudo da Transmissão da Dengue entre os Indivíduos em Interação com a População de Mosquitos Aedes aegypti. Trends in Applied and Computational Mathematics. 2003;4(3):323-332.

WHO. Investing to overcome the global impact of neglected tropical diseases: third WHO report on neglected diseases 2015. World Health Organization; 2015. World Health Organization and others.

McMichael AJ. The urban environment and health in a world of increasing globalization: issues for developing countries. Bulletin of the World Health Organization. 2000;78(9):1117-1126.

education N. Dengue viruses; 2014. [Online; acessado em Março de 2014]. Available from: http://www.nature.com/scitable/topicpage/ dengue-viruses-22400925.

Fried JR, Gibbons RV, Kalayanarooj S, Thomas SJ, Srikiatkhachorn A, Yoon IK, et al. Serotype-specific differences in the risk of dengue hemorrhagic fever: an analysis of data collected in Bangkok, Thailand from 1994 to 2006. PLoS Negl Trop Dis. 2010;4(3):e617. 
education N. What is dengue fever; 2014. [Online; acessado em Janeiro de 2015]. Available from: http://www.nature.com/scitable/topicpage/ what-is-dengue-fever-22399100.

Henchal EA, Putnak JR. The dengue viruses. Clinical microbiology reviews. 1990;3(4):376-396.

Siler JF, Hall MW, Hitchens AP, et al. Dengue: its history, epidemiology, mechanism of transmission, etiology, clinical manifestations, immunity, and prevention. Philipp J Sci. 1926;29(1-2):1-304.

CDC. Etymologia dengue; 2006. [Emerg Infect Dis [serial on the Internet]; acessado em Abril de 2015]. Available from: http://dx.doi.org/10.3201/eid1206. ET1206.

Rigau-Pérez JG. The early use of break-bone fever (Quebranta huesos, 1771) and dengue (1801) in Spanish. The American journal of tropical medicine and hygiene. 1998;59(2):272-274.

Grandelle R. Oswaldo Cruz, o homem que venceu o Aedes; 2016. Available from: http://oglobo.globo.com/sociedade/historia/ oswaldo-cruz-homem-que-venceu-aedes-18226566.

Cruz IO. O mosquito Aedes aegypti faz parte da história e vem se espalhando pelo mundo desde o período das colonizações;. [Online; acessado em Abril de 2016]. Available from: http://www.ioc.fiocruz.br/dengue/textos/ longatraje.html.

Cruz IO. Dengue vírus e vetor; 2013. [Online; acessado em Agosto 2013]. Available from: http://www.ioc.fiocruz.br/dengue/textos/sobreovirus.html.

Brasil. Ministério da Saúde: Descrição da Doença; 2014. [Online; acessado em Junho de 2014]. Available from: http://portalsaude.saude.gov.br/index. $\mathrm{php} /$ descricao-da-doenca-dengue.

Brasil ON. Incidência da Dengue no Brasil: dados alarmantes; 2015. Available from: https://www.organicsnewsbrasil.com.br/bem-estar/saude/ aedes-aegypti/incidencia-da-dengue-no-brasil-dados-alarmantes/.

Brasil. Guia de Vigilância Epidemiológica. da Saúde M, editor. Brasília: Ministério da Saúde / Secretaria de Vigilância em Saúde; 2010. Available from: http://www.epi.uff.br/wp-content/uploads/2013/10/Guia-de-Vigil\% C3\%A2ncia-Epidemiol\%C3\%B3gica-\%E2\%80\%93-7\%C2\%AAedi $\%$ C3\%A7\%C3\% A3o-2010.pdf. 
Brasil. Ministério da Saúde: Febre Chikungunya; 2015. [Online; acessado em Janeiro de 2015]. Available from: http://portalsaude.saude.gov.br/index . php/links-de-interesse/1073-chikungunya/14718-sinais-e-sintomas.

WHO. Dengue control; 2015. [Online; acessado em Setembro de 2016]. Available from: http://www.paho.org/hq/index.php?option=com_content\&view= article\&id=9183\%3A2015-preguntas-frecuentes-virus-fiebre-zika\& catid=3986\%3Azika-virus-infection\&Itemid=41711\&lang=en.

Brasil. Perguntas e Respostas; 2016. [Online; acessado em Novembro de 2016]. Available from: http://portalsaude.saude.gov.br/index.php/ perguntas-e-respostas-dengue-2.

Cruz IO. IOC / Fiocruz identifica a presença de Zika vírus em dois casos de microcefalia; 2015. [Online; acessado em Novembro de 2016]. Available from: http://portal.fiocruz.br/pt-br/content/ iocfiocruz-identifica-presenca-de-zika-virus-em-dois-casos-de-microcefalia.

Villamil-Gómez WE, González-Camargo O, Rodriguez-Ayubi J, Zapata-Serpa D, Rodriguez-Morales AJ. Dengue, chikungunya and Zika co-infection in a patient from Colombia. Journal of infection and public health. 2016;

Villamil-Gómez WE, Rodríguez-Morales AJ, Uribe-García AM, GonzálezArismendy E, Castellanos JE, Calvo EP, et al. Zika, dengue, and chikungunya co-infection in a pregnant woman from Colombia. International Journal of Infectious Diseases. 2016;51:135-138.

Meyer WJ. Concepts of mathematical modeling. Courier Corporation; 2012.

Amaku M, Azevedo F, Burattini M, Coutinho F, Lopez L, Massad E. Interpretations and pitfalls in modelling vector-transmitted infections. Epidemiology and infection. 2015;143(09):1803-1815.

AL-dujaili MAA. The Role of Leadership in Knowledge Engineering Systems and Neural Networks to Establish E-Government. CHEMICAL ENGINEERING. $2013 ; 35$.

Lindsey JK. Statistical analysis of stochastic processes in time. vol. 14. Cambridge University Press; 2004.

Abate J, Whitt W. Numerical inversion of probability generating functions. Operations Research Letters. 1992;12(4):245-251.

da Silva PN. Equaçoes Diferenciais Ordinárias; 1963. 
Greenhalgh D. Função geradora de probabilidade; 2016. Notas de aula.

Johnson NL, Kemp AW, Kotz S. Univariate Discrete Distributions, Set. vol. 444. John Wiley \& Sons; 2005.

Brasil. Portal da Copa; 2014. Ministério do Turismo do Brasil. Available from: http://www . copa2014.gov.br/pt-br/tags/turistas-estrangeiros.

FIFA. 2014 FIFA World Cup Brazil - Match Schedule; 2014. Available from: http://resources.fifa.com/mm/document/tournament/competition/ 01/52/99/91/2014fwc_matchschedule_wgroups_22042014_en_neutral.pdf.

Rio2016. Jogos Olímpicos Rio 2016; 2016. Available from: https://www.rio2016. $\mathrm{com} /$.

Cerqueira D, Ferreira H, Lima RSd, Bueno S, Hanashiro O, Batista F, et al. Atlas da Violência 2016. 2016;

Brasil. Informe Epidemiológico - Influenza: Monitoramento até a Semana Epidemiológica 25 de 2016; 2016. Secretaria de Vigilância em Saúde - Ministério da Saúde. Available from: http://portalsaude.saude.gov.br/images/pdf/ 2016/julho/06/informe-epidemiologico-influenza-se25-2016.pdf.

EBC. Agencia Brasil de Notícias - EBC; 2016. Available from: http:// agenciabrasil.ebc.com.br/.

Heringer M, Nogueira RMR, de Filippis AMB, Lima MR, Faria NR, Nunes PC, et al. Impact of the emergence and re-emergence of different dengue viruses' serotypes in Rio de Janeiro, Brazil, 2010 to 2012. Transactions of The Royal Society of Tropical Medicine and Hygiene. 2015;p. trv006.

IBGE. Censo Demográfico 2010; 2010. [Online; acessado em Janeiro 2014]. Available from: www.ibge.gov.br/home/estatistica/populacao/censo2010/.

IBGE. Estimativas populacionais para os municípios e para as Unidades da Federação brasileiros em 01.07.2015; 2015. [Online; acessado em Janeiro de 2016]. Available from: http://www.ibge.gov.br/home/estatistica/ populacao/estimativa2015/.

Chastel C. Eventual role of asymptomatic cases of dengue for the introduction and spread of dengue viruses in non-endemic regions. Front physiol. 2012;3:70.

Duong V, Lambrechts L, Paul RE, Ly S, Lay RS, Long KC, et al. Asymptomatic humans transmit dengue virus to mosquitoes. Proceedings of the National Academy of Sciences. 2015;112(47):14688-14693. 
Massad E, Coutinho F, Burattini M, Amaku M. Estimation of R0 from the initial phase of an outbreak of a vector-borne infection. Tropical Medicine \& International Health. 2010;15(1):120-126.

Macey R, Oster G, Zahley T. Berkeley Madonna User's Guide. Berkely, CA: University of California. 2009;

Woolhouse M. How to make predictions about future infectious disease risks. Philosophical Transactions of the Royal Society of London B: Biological Sciences. 2011;366(1573):2045-2054.

País E. Seca recorde pode afetar abastecimento de água de São Paulo até outubro; 2014. [Online; acessado em Fevereiro de 2014]. Available from: http://brasil. elpais.com/brasil/2014/02/11/politica/1392156791_436377.html.

ONU. Pior seca dos últimos 50 anos no nordeste brasileiro confirma estatísticas da ONU sobre escassez; 2013. [Online; acessado em Novembro de 2016]. Available from: https://nacoesunidas.org.

Olívêr L, Burattini MN, Coelho G, Struchiner C, Massad E. A negative correlation between dengue and bushfires in Brazil. J Environ Health. 2014;76:66-67.

Aguiar M, Coelho GE, Rocha F, Mateus L, Pessanha JEM, Stollenwerk N. Dengue transmission during the 2014 FIFA World Cup in Brazil. The Lancet Infectious Diseases. 2015;15(7):765-766.

Brasil; 2009. Ministério do Turismo do Brasil. Available from: http://www. dadosefatos.turismo.gov.br/dadosefatos/home.html.

das Nações Unidas para o Desenvolvimento P. Atlas do Desenvolvimento Humano no Brasil; 2013. Available from: http://www. atlasbrasil org.br/2013/pt/.

The Weather Company L. Wheather Underground; 2016. [Online; acessado em Agosto de 2016]. Available from: https://www . wunderground.com.

data C. CLIMATE-DATA.ORG; 2016. [Online; acessado em Agosto de 2016]. Available from: http://en.climate-data.org/location/853/.

do Rio de Janeiro P. Sistema Alerta Rio da Prefeitura do Rio de Janeiro; 2016. [Online; acessado em Agosto de 2016]. Available from: http://alertario.rio. rj.gov. br/.

Brasil. http://www.brasil.gov.br/turismo/2014/07/copa-trouxe-886-mil-turistas-emovimentou-r-4-4-bilhoes. Consultado em. 2016;. 
Barcellos C, Lowe R. Dengue and the world football cup: a matter of timing. PLoS Negl Trop Dis. 2014;8(7):e3022.

Wilson ME, Chen LH. Health risks among travelers to Brazil: implications for the 2014 FIFA World Cup and 2016 Olympic Games. Travel medicine and infectious disease. 2014;12(3):205-207.

Massad E, Wilder-Smith A. Risk estimates of dengue in travelers to dengue endemic areas using mathematical models. Journal of travel medicine. 2009;16(3):191-193.

Tourism S. Annual Report on Tourism Statistics 2014. Singapore Tourism; 2015. [Online; acessado em Agosto de 2016]. Available from: https://www.stb.gov . $\mathrm{sg} /$ statistics-and-market-insights/marketstatistics/stb\%20tourism\% 20statistics_fa\%20as\%20of\%2002262016\%20(lowres\%20res). pdf.

Cobelens FG, Groen J, Osterhaus AD, Leentvaar-Kuipers A, Wertheim-van Dillen PM, Kager PA. Incidence and risk factors of probable dengue virus infection among Dutch travellers to Asia. Tropical Medicine \& International Health. 2002;7(4):331-338.

Baaten G, Sonder G, Zaaijer HL, van Gool T, Kint JA, van den Hoek A. Travelrelated dengue virus infection, the Netherlands, 2006-2007. Emerg Infect Dis. 2011;17(5):821-828.

Potasman I, Srugo I, Schwartz E. Dengue seroconversion among Israeli travelers to tropical countries. Emerging infectious diseases. 1999;5(6):824.

Ratnam I, Leder K, Black J, Torresi J. Dengue fever and international travel. Journal of travel medicine. 2013;20(6):384-393.

Ratnam I, Black J, Leder K, Biggs BA, Matchett E, Padiglione A, et al. Incidence and seroprevalence of dengue virus infections in Australian travellers to Asia. European journal of clinical microbiology \& infectious diseases. 2012;31(6):12031210.

Massad E, Rocklov J, Wilder-Smith A. Dengue infections in non-immune travellers to Thailand. Epidemiology and infection. 2013;141(02):412-417.

Brasil. Boletim Epidemiológico. da Saúde M, editor. Brasília: Ministério da Saúde / Secretaria de Vigilância em Saúde; 2016. Available from: http://portalsaude. saude.gov. br/images/pdf/2016/agosto/09/2016-026.pdf. 
Grills A. Projected Zika virus importation and subsequent ongoing transmission after travel to the 2016 Olympic and Paralympic Games - country-specific assessment, July 2016. MMWR Morbidity and Mortality Weekly Report. 2016;65.

CDC. Projected Zika Virus Importation and Subsequent Ongoing Transmission after Travel to the 2016 Olympic and Paralympic Games - Country-Specific Assessment, July 2016; 2016. [Online; acessado em Agosto de 2016]. Available from: http://www.cdc.gov/mmwr/volumes/65/wr/mm6528e1.htm.

BBC. Zika crisis: WHO rejects 'move Rio Olympics' call; 2016. [Online; acessado em Agosto de 2016]. Available from: http://www.bbc.co.uk/news/ world-latin-america-36401150.

de Segurança Pública AB. Fórum Brasileiro de Segurança Pública. Fórum Brasileiro de Segurança Pública; 2016. Available from: http://www . forumseguranca.org .

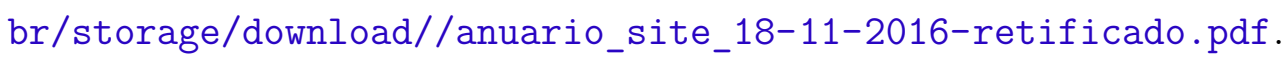

Senado A. A cada 11 minutos, uma mulher é estuprada no Brasil, alerta Simone Tebet; $2016 . \quad$ Available from: http://www12. senado.leg. br/noticias/materias/2016/05/30/ a-cada-11-minutos-uma-mulher-e-estuprada-no-brasil-alerta-simone-tebet.

Unidas N. Balas Perdidas II: Análisis de Casos de Balas Perdidas Reportados en Medios de Comunicación en América Latina y el Caribe; 2016. Available from: http://www.unlirec.org/Documents/Balas_Perdidas.pdf.

Martelli CMT, Junior JBS, Parente MPPD, Zara ALdSA, Oliveira CS, Braga C, et al. Economic Impact of Dengue: Multicenter Study across Four Brazilian Regions. PLoS Negl Trop Dis. 2015;9(9):e0004042.

Guzman MG, Harris E. Dengue. The Lancet. 2015;385(9966):453-465.

Faria NR, da Silva Azevedo RdS, Kraemer MU, Souza R, Cunha MS, Hill SC, et al. Zika virus in the Americas: Early epidemiological and genetic findings. Science. 2016;352(6283):345-349.

da Copa P. Copa das Confederações movimentou 230 mil turistas brasileiros; 2013. Available from: http://www.copa2014.gov.br/pt-br/noticia/ copa-das-confederacoes-movimentou-230-mil-turistas-brasileiros.

WHO. Zika virus and complications; 2016. Available from: http://www. who.int/ emergencies/zika-virus/en/. 
Arbex AK, Bizarro VR, Paletti MT, Brandt OJ, de Jesus ALC, Werner I, et al. Zika Virus Controversies: Epidemics as a Legacy of Mega Events? Health. 2016;8(07):711.

Brasil. Boletim Epidemiológico. da Saúde M, editor. Brasília: Ministério da Saúde / Secretaria de Vigilância em Saúde; 2016. Available from: http://portalsaude.saude.gov.br/images/pdf/2016/outubro/ 18/2016-029-Dengue-publicacao-n-34.pdf.

Brasil. Informe Epidemiológico 54 - MONITORAMENTO DOS CASOS DE MICROCEFALIA NO BRASIL. da Saúde: CENTRO DE OPERAÇÕES DE EMERGÊNCIAS EM SAÚDE PÚBLICA SOBRE MICROCEFALIAS M, editor. Brasília: Ministério da Saúde; 2016. Available from: http://combateaedes.saude.gov.br/images/boletins-epidemiologicos/ informe_microcefalia_epidemiologico54.pdf.

Halstead SB, Aguiar M. Dengue vaccine and the 2016 Olympics. 2016;

Ribeiro AF, Tengan C, Sato HK, Spinola R, Mascheretti M, França ACC, et al. A public health risk assessment for yellow fever vaccination: a model exemplified by an outbreak in the state of São Paulo, Brazil. Memórias do Instituto Oswaldo Cruz. 2015;(AHEAD):00-00.

Britton T. Stochastic epidemic models: a survey. Mathematical biosciences. 2010;225(1):24-35.

Ferguson NM, Donnelly CA, Anderson RM. Transmission dynamics and epidemiology of dengue: insights from age-stratified sero-prevalence surveys. Philosophical Transactions of the Royal Society of London B: Biological Sciences. 1999;354(1384):757-768.

Capeding MR, Tran NH, Hadinegoro SRS, Ismail HIHM, Chotpitayasunondh T, Chua MN, et al. Clinical efficacy and safety of a novel tetravalent dengue vaccine in healthy children in Asia: a phase 3, randomised, observer-masked, placebo-controlled trial. The Lancet. 2014;384(9951):1358-1365.

Pessanha JEM, Caiaffa WT, Cecilio AB, Iani FCdM, Araujo SC, Nascimento JC, et al. Cocirculation of two dengue virus serotypes in individual and pooled samples of Aedes aegypti and Aedes albopictus larvae. Revista da Sociedade Brasileira de Medicina Tropical. 2011;44(1):103-105. 


\section{Doutorado sanduíche - SWE}

\section{Impacto da vacinação tetravalente no total de casos e na mor- biletalidade para municípios do Estado de São Paulo}

Em paralelo à determinação do risco de dengue para turistas apresentado nesta tese, trabalhamos para determinar qual seria o impacto da vacina contra a dengue em uma dada população baseado no estudo de Ribeiro et al. (2015) sobre Febre Amarela.

As variáveis analisadas foram: Número esperado de mortes, risco per capita de morte devido à dengue, número total de dias de incidência de dengue, número total de casos esperados de dengue, número total de dias de infeç̧ão secundária, número total de casos secundários esperados de dengue, custo total estimado de mortes devido a dengue, custo total estimado por dia de infecção por dengue, custo total estimado dos casos de infecção por dengue, custo total estimado por dia de infecção secundária por dengue, custo total estimado por caso de infecção secundária por dengue.

Iniciamos o estudo pela cidade de São Paulo e pretendemos, posteriormente, aplicar a mesma metodologia à outras cidades do Estado de São Paulo.

A vacina utilizada neste estudo é a única vacina contra a dengue aprovada pela Anvisa até o momento, a vacina tetravalente denominada Dengvaxia, fabricada pela Sanofi Pasteur. Sua eficácia varia de acordo com o sorotipo (DENV-1 $=50.0 \%$, DENV-2 $=35.0 \%$, DENV-3=78.4\%, DENV-4=75.3\%).

Para o estudo do impacto dessa vacina na população, utilizou-se um modelo matemático baseado no modelo de infecção de Ross-Macdonald (Macdonald, 1952), um modelo matemático de transmissão de agentes patogênicos transmitidos por mosquitos, e considerou-se possível a existência de dois sorotipos do vírus da dengue circulantes simultaneamente, bem como a co-infecção por mosquitos e seres humanos com ambos os sorotipos. 
O modelo trabalha com a iteração dos sorotipos dois a dois, isto é, os cenários consideram apenas dois sorotipos circulantes por vez. Esta decisão foi tomada em virtude da elevada complexidade da elaboração de um modelo contendo os 4 sorotipos. Contudo, entende-se que a elaboração de modelos simplificados auxiliam na construção de modelos mais completos e assim, pretende-se, no futuro, utilizar este modelo aqui apresentado para a construção de um modelo geral, que envolva os 4 sorotipos da dengue.

\section{Modelo de transmissão}

$$
\begin{aligned}
\frac{d H_{s s}}{d t} & =-a b_{1} \frac{M_{i}^{1} H_{s s}}{N_{h}}-a b_{2} \frac{M_{i}^{2} H_{s s}}{N_{h}}-a\left(b_{1}+b_{2}-b_{12}\right) \frac{M_{i}^{12} H_{s s}}{N_{h}} \\
& -\nu_{h}\left(\alpha_{1}+\alpha_{2}-\alpha_{1} \alpha_{2}\right) H s s+\left((1-p)+p\left(1-\alpha_{1}\right)\left(1-\alpha_{2}\right)\right) \Lambda-\mu_{h} H_{s s}
\end{aligned}
$$

$$
\frac{d H_{i s}}{d t}=a b_{1} \frac{M_{i}^{1} H_{s s}}{N_{h}}-a b_{2} \frac{M_{i}^{2} H_{i s}}{N_{h}}+a b_{1}\left(1-b_{2}\right) \frac{M_{i}^{12} H_{s s}}{N_{h}}-\left(\gamma_{1}+\mu_{h}+\alpha_{h}^{1}\right) H_{i s}
$$

$$
\frac{d H_{s i}}{d t}=a b_{2} \frac{M_{i}^{2} H_{s s}}{N_{h}}-a b_{1} \frac{M_{i}^{1} H_{s i}}{N_{h}}+a b_{2}\left(1-b_{1}\right) \frac{M_{i}^{12} H_{s s}}{N_{h}}-\left(\gamma_{2}+\mu_{h}+\alpha_{h}^{2}\right) H_{s i}
$$

$$
\frac{d H_{i i}}{d t}=a b_{1} b_{2} \frac{M_{i}^{12} H_{s s}}{N_{h}}+a b_{1} \frac{M_{i}^{1} H_{s i}}{N_{h}}+a b_{2} \frac{M_{i}^{2} H_{i s}}{N_{h}}-\left(\gamma_{h}^{12}+\mu_{h}+\alpha_{h}^{12}\right) H_{i i}
$$

$$
\begin{array}{r}
\frac{d H_{r s}}{d t}=-\mu_{h} H_{r s}+p \alpha_{1}\left(1-\alpha_{2}\right) \Lambda+\nu_{h} \alpha_{1}\left(1-\alpha_{2}\right) H_{s s}+\gamma_{h}^{1} H_{i s} \\
-a b_{2} \frac{M_{i}^{2} H_{r s}}{N_{h}}-a b_{2} \frac{M_{i}^{12} H_{r s}}{N_{h}} \\
\begin{aligned}
\frac{d H_{s r}}{d t}=-\mu_{h} H_{s r}+p \alpha_{2}\left(1-\alpha_{1}\right) \Lambda+\nu_{h} \alpha_{2}\left(1-\alpha_{1}\right) H_{s s} & +\gamma_{h}^{2} H_{s i} \\
& -a b_{1} \frac{M_{i}^{1} H_{s r}}{N_{h}}-a b_{1} \frac{M_{i}^{12} H_{s r}}{N_{h}}
\end{aligned}
\end{array}
$$




$$
\begin{gathered}
\frac{d H_{r r}}{d t}=-\mu_{h} H_{r r}+p \alpha_{1} \alpha_{2} \Lambda+\nu_{h} \alpha_{1} \alpha_{2} H s s+\gamma_{h}^{1} H_{i r}+\gamma_{h}^{2} H_{r i} \\
\frac{d H_{r i}}{d t}=\gamma_{h}^{1} H_{i i}-\left(\mu_{h}+\gamma_{h}^{2}+\alpha_{h}^{21}\right) H_{r i}+a b_{2} \frac{M_{i}^{2} H_{r s}}{N_{h}}+a b_{2} \frac{M_{i}^{12} H_{r s}}{N_{h}} \\
\frac{d H_{i r}}{d t}=\gamma_{h}^{2} H_{i i}-\left(\mu_{h}+\gamma_{h}^{1}+\alpha_{h}^{12}\right) H_{i r}+a b_{1} \frac{M_{i}^{1} H_{s r}}{N_{h}}+a b_{1} \frac{M_{i}^{12} H_{s r}}{N_{h}} \\
\frac{d M_{s}}{d t}=-c_{1} a \frac{M_{s} H_{i s}}{N_{h}}-c_{2} a \frac{M_{s} H_{s i}}{N_{h}}-\left(c_{1}+c_{2}-c_{1} c_{2}\right) a \frac{M_{s} H_{i i}}{N_{h}}-c_{1} a \frac{M_{s} H_{i r}}{N_{h}} \\
-c_{2} a \frac{M_{s} H_{r i}}{N_{h}+\mu_{m}\left(M_{i}^{1}+M_{i}^{2}+M_{i}^{12}+M_{l}^{1}+M_{l}^{2}+M_{l}^{12}\right)} \\
\left.\frac{d M_{l}^{1}}{d t}=a\left\{\begin{array}{c}
M_{s} \\
c_{h}\left(H_{i s}+H_{i r}\right)+\left(1-c_{2}\right) c_{1} \frac{M_{s} H_{i i}}{N_{h}}
\end{array}\right]\right\}-\mu_{m} M_{l}^{1} \\
-c_{1} e^{-\mu_{m} \tau}\left[\begin{array}{c}
M_{s}(t-\tau)\left(H_{i s}(t-\tau)+H_{i r}(t-\tau)\right) \\
N_{h}(t-\tau) \\
-\left(1-c_{2}\right) c_{1} e^{-\mu_{m} \tau}\left[\frac{M_{s}(t-\tau) H_{i i}(t-\tau)}{N_{h}(t-\tau)}\right]
\end{array}\right.
\end{gathered}
$$

$$
\begin{aligned}
\frac{d M_{l}^{2}}{d t}=a\left\{c _ { 2 } \frac { M _ { s } } { N _ { h } } \left(H_{s i}+\right.\right. & \left.H_{r i}\right)+\left(1-c_{1}\right) c_{2} \frac{M_{s} H_{i i}}{N_{h}} \\
-c_{2} e^{-\mu_{m} \tau} & {\left[\frac{M_{s}(t-\tau)\left(H_{s i}(t-\tau)+H_{r i}(t-\tau)\right)}{N_{h}(t-\tau)}\right] } \\
& \left.-\left(1-c_{1}\right) c_{2} e^{-\mu_{m} \tau} \frac{M_{s}(t-\tau) H_{i i}(t-\tau)}{N_{h}(t-\tau)}\right\}-\mu_{m} M_{l}^{2}
\end{aligned}
$$

$$
\begin{aligned}
\frac{d M_{l}^{12}}{d t}= & a\left\{c_{1} c_{2} \frac{M_{s} H_{i i}}{N_{h}}+c_{2}\left[\frac{M_{i}^{1}\left(H_{s i}+H_{i i}+H_{r i}\right)}{N_{h}}\right]\right. \\
& +c_{1} \frac{M_{i}^{2}\left(H_{i s}+H_{i i}+H_{i r}\right)}{N_{h}}-c_{1} c_{2} e^{-\mu_{m} \tau} \frac{M_{s}(t-\tau) H_{i i}(t-\tau)}{N_{h}(t-\tau)} \\
& -c_{2} e^{-\mu_{m} \tau}\left[\frac{M_{i}^{1}(t-\tau)\left(H_{s i}(t-\tau)+H_{i i}(t-\tau)+H_{r i}(t-\tau)\right)}{N_{h}(t-\tau)}\right] \\
- & \left.c_{1} e^{-\mu_{m} \tau} \frac{M_{i}^{2}(t-\tau)\left(H_{i s}(t-\tau)+H_{i i}(t-\tau)+H_{i r}(t-\tau)\right)}{N_{h}(t-\tau)}\right\}-\mu_{m} M_{l}^{12}
\end{aligned}
$$




$$
\begin{aligned}
& \frac{d M_{i}^{1}}{d t}=-\mu_{v} M_{i}^{1}+a c_{1}\left\{e^{-\mu_{m} \tau}\left[\frac{M_{s}(t-\tau)\left(H_{i s}(t-\tau)+H_{i r}(t-\tau)\right)}{N_{h}(t-\tau)}\right]\right\} \\
& +e^{-\mu_{m} \tau} a\left(c_{1}\left(1-c_{2}\right)\left[\frac{M_{s}(t-\tau) H_{i i}(t-\tau)}{N_{h}(t-\tau)}\right]\right. \\
& -a c_{2}\left[\frac{M_{i}^{1}\left(H_{s i}+H_{i i}+H_{r i}\right)}{N_{h}}\right] \\
& \frac{d M_{i}^{2}}{d t}=-\mu_{v} M_{i}^{2}+a c_{2}\left\{e^{-\mu_{m} \tau}\left[\frac{M_{s}(t-\tau)\left(H_{s i}(t-\tau)+H_{r i}(t-\tau)\right)}{N_{h}(t-\tau)}\right]\right\} \\
& +e^{-\mu_{m} \tau} a\left(c_{2}\left(1-c_{1}\right)\left[\frac{M_{s}(t-\tau) H_{i i}(t-\tau)}{N_{h}(t-\tau)}\right]\right. \\
& -a c_{1}\left[\frac{M_{i}^{2}\left(H_{i s}+H_{i i}+H_{i r}\right)}{N_{h}}\right] \\
& \frac{d M_{i}^{12}}{d t}=-\mu_{v} M_{i}^{12}+a c_{2}\left\{e^{-\mu_{m} \tau}\left[\frac{M_{i}^{1}(t-\tau)\left(H_{s i}(t-\tau)+H_{i i}(t-\tau)+H_{r i}(t-\tau)\right)}{N_{h}(t-\tau)}\right]\right\} \\
& +e^{-\mu_{m} \tau} a\left(c_{2} c_{1}\right)\left[\frac{M_{s}(t-\tau) H_{i i}(t-\tau)}{N_{h}(t-\tau)}\right] \\
& +a c_{1} e^{-\mu_{m} \tau}\left[\frac{M_{i}^{2}(t-\tau)\left(H_{i s}(t-\tau)+H_{i i}(t-\tau)+H_{i r}(t-\tau)\right)}{N_{h}(t-\tau)}\right]
\end{aligned}
$$

Onde,

$$
N_{h}=H_{s s}+H_{r s}+H_{s r}+H_{r r}+H_{i s}+H_{s i}+H_{i i}+H_{r i}+H_{i r}
$$

e,

$$
\Lambda=\mu_{h} N_{h}+\alpha_{h}^{1} H_{i s}+\alpha_{h}^{2} H_{s i}+\alpha_{h}^{12} H_{i i}+\alpha_{h}^{21} H_{r i}+\alpha_{h}^{12} H_{i r}
$$

Estimativa do risco de epidemia de dengue após um longo tempo de campanha de vacinação

Suponhamos que não tenha havido nenhum caso da doença há muito tempo e que os recém nascidos recebem a vacina contra a dengue há um longo prazo. A 
teoria da epidemia prediz que o risco de um surto de um sorotipo específico é dado por (Britton, 2010):

$$
r=1-\frac{1}{R_{0} S}
$$

Onde S é a proporção da população total que é suscetível a cada sorotipo.

Para os valores $R_{0}$ utilizamos aqueles obtidos por (Ferguson et al., 1999) em um modelo estirpes independentes, conforme assumido neste trabalho.

Assim, o número total de mortes esperado devido a dengue é dado por:

$$
\pi=\sum_{x \in[A, B, C]} r_{x} \int_{0}^{\infty}\left(\alpha_{h}^{1} H_{i s}+\alpha_{h}^{2} H_{s i}+\alpha_{h}^{12} H_{i i}+\alpha_{h}^{21} H_{r i}+\alpha_{h}^{12} H_{i r}\right) d t
$$

O risco per capita de mortes devido a dengue é:

$$
\beta=\sum_{x \in[A, B, C]} r_{x} \int_{0}^{\infty} \frac{\alpha_{h}^{1} H_{i s}+\alpha_{h}^{2} H_{s i}+\alpha_{h}^{12} H_{i i}+\alpha_{h}^{21} H_{r i}+\alpha_{h}^{12} H_{i r}}{N_{h}} d t
$$

O número total de dias de incidência de dengue esperado é:

$$
\xi=\sum_{x \in[A, B, C]} r_{x} \int_{0}^{\infty}\left(H_{i s}+H_{s i}+H_{i i}+H_{i r}+H_{r i}\right) d t
$$

O número total de casos de dengue esperado é dado por:

$$
\begin{array}{r}
\xi_{1}=\sum_{x \in[A, B, C]} r_{x} \int_{0}^{\infty}\left[a b_{1} \frac{M_{i}^{1} H_{s s}}{N_{h}}+a b_{1}\left(1-b_{2}\right) \frac{M_{i}^{12} H_{s s}}{N_{h}}+a b_{2} \frac{M_{i}^{2} H_{s s}}{N_{h}}\right. \\
+a b_{2}\left(1-b_{1}\right) \frac{M_{i}^{12} H_{s s}}{N_{h}}+a b_{1} b_{2} \frac{M_{i}^{12} H_{s s}}{N_{h}}+a b_{1} \frac{M_{i}^{1} H_{s i}}{N_{h}}+a b_{2} \frac{M_{i}^{2} H_{i s}}{N_{h}} \\
\left.+a b_{2} \frac{M_{i}^{2} H_{r s}}{N_{h}}+a b_{2} \frac{M_{i}^{12} H_{r s}}{N_{h}}+a b_{1} \frac{M_{i}^{1} H_{s r}}{N_{h}}+a b_{1} \frac{M_{i}^{12} H_{s r}}{N_{h}}\right] d t
\end{array}
$$

Da mesma forma, o número total de dias de infecção secundária esperado é:

$$
\psi=\sum_{x \in[A, B, C]} r_{x} \int_{0}^{\infty}\left(H_{i r}+H_{r i}\right) d t
$$

E o número total esperado de casos secundários de dengue é:

$$
\psi_{1}=r_{x} \int_{0}^{\infty}\left[a b_{2} \frac{M_{i}^{2} H_{r s}}{N_{h}}+a b_{2} \frac{M_{i}^{12} H_{r s}}{N_{h}}+a b_{1} \frac{M_{i}^{1} H_{s r}}{N_{h}}+a b_{1} \frac{M_{i}^{12} H_{s r}}{N_{h}}\right] d t
$$


O custo de vacinação total esperado é dado por:

$$
\Phi=\kappa_{1} p N_{h}(0)+\sum_{x \in[A, B, C]} r_{x} \kappa_{1} \int_{0}^{\infty} \nu_{h} H_{s s} d t+\sum_{x \in[A, B, C]} r_{x} \kappa_{2} \theta d t
$$

Onde $\theta$ pode ser dado pelos seguintes termos:

I - $\pi$ quando $\kappa_{2}$ é o custo total estimado de mortes devido a dengue;

II - $\xi$ quando $\kappa_{2}$ é o custo total estimado por dia de infecção por dengue;

III - $\xi_{1}$ quando $\kappa_{2}$ é o custo total estimado dos casos de infecção por dengue;

IV - $\psi$ quando $\kappa_{2}$ é o custo total estimado por dia de infecção secundária por dengue;

$\mathrm{V}-\psi_{1}$ quando $\kappa_{2}$ é o custo total estimado por caso de infecção secundária por dengue.

A seguir são descritos os compartimentos e parâmetros utilizados no modelo:

$M_{s}$ - Número de mosquitos suscetíveis

$M_{i}^{1}$ - Número de mosquitos infectados pelo sorotipo A

$M_{i}^{2}$ - Número de mosquitos infectados pelo sorotipo B

$M_{i}^{12}$ - Número de mosquitos infectados por ambos sorotipos

$H_{s s}$ - Número de humanos suscetíveis a ambos sorotipos, não vacinados ou vacinados sem sucesso para ambos os sorotipos

$H_{i s}$ - Humanos infectados pelo sorotipo A e suscetíveis ao sorotipo B

$H_{s i}$ - Humanos infectados pelo sorotipo B e suscetíveis ao sorotipo A

Hii - Humanos infectados por ambos sorotipos

$H_{r s}$ - Humanos recuperados da infecção pelo sorotipo A / Vacinação bem sucedida contra o sorotipo A e suscetível ao sorotipo B

$H_{s r}$ - Humanos suscetíveis ao sorotipo A e recuperados da infecção pelo sorotipo B / Vacinação bem sucedida contra o sorotipo B

$H_{r r}$ - Humanos recuperados de infecções contra ambos sorotipos/ vacinação bem sucedida contra ambos sorotipos

$H_{r i}$ - Humanos recuperados ou vacinados com sucesso contra o sorotipo A e infectados pelo sorotipo B 
$H_{i r}$ - Humanos infectados pelo sorotipo $\mathrm{A}$ e recuperados ou vacinados com sucesso contra o sorotipo B

$N_{h}$ - Tamanho total da população de humanos

$a$ - Taxa diária de picadas dos mosquitos

$b_{1}$ - Probabilidade de transmissão da dengue por picada de mosquitos infectados pelo sorotipo A para humanos suscetíveis

$b_{2}$ - Probabilidade de transmissão da dengue por picada de mosquitos infectados pelo sorotipo B para humanos suscetíveis

$b_{12}$ - Probabilidade de transmissão da dengue pela picada de mosquitos infectados por ambos sorotipos $\left(b_{12}=b_{1} * b_{2}\right)$

$c_{1}$ - Probabilidade de transmissão para os mosquitos do sorotipo A por picada em humanos infectados

$c_{2}$ - Probabilidade de transmissão para os mosquitos do sorotipo B por picada em humanos infectados

$\mu_{m}$ - Taxa diária de mortalidade dos mosquitos

$\tau$ - Período de latência - Tempo de atraso, no mosquito, para que o vírus se torne infeccioso

$\nu_{h}$ - Taxa contínua de vacinação per capita de humanos suscetíveis

$\alpha_{1}$ - Probabilidade de que a vacina seja bem sucedida contra o sorotipo A

$\alpha_{2}$ - Probabilidade de que a vacina seja bem sucedida contra o sorotipo B

$p$ - Proporção de recém nascidos vacinados

$\gamma_{h}^{1}$ - Taxa diária per capita de recuperação dos infectados pelo sorotipo A

$\gamma_{h}^{2}$ - Taxa diária per capita de recuperação dos infectados pelo sorotipo B

$\gamma_{h}^{12}$ - Taxa diária per capita de recuperação dos infectados por ambos sorotipos

$\alpha_{h}^{1}$ - Taxa diária de mortalidade causada pelo sorotipo A

$\alpha_{h}^{2}$ - Taxa diária de mortalidade causada pelo sorotipo B

$\alpha_{h}^{12}$ - Taxa diária de mortalidade de indivíduos infectados por ambos soroti-

pos

$\mu_{h}$ - Taxa diária de mortalidade natural per capita

$\Lambda$ - Taxa diária de mortalidade $=$ taxa diária de natalidade 
$r_{1}$ - Probabilidade de uma nova epidemia causada pelo sorotipo A

$r_{2}$ - Probabilidade de uma nova epidemia causada pelo sorotipo B

$r_{12}$ - Probabilidade de uma nova epidemia causada pelos sorotipos A e B

Os valores assumidos para os parâmetros foram: $\mathrm{a}=1, b_{1}=0.8, b_{2}=0.8$, $b_{12}=b_{1} * b_{2}, c_{1}=0.5, c_{2}=0.5, c_{12}=c_{1}+c_{2}-c_{1} c_{2}, M_{i}^{1}=0, M_{i} 2=0, M_{i}^{12}=0, \gamma_{h}^{1}=0.143$, $\gamma_{h}^{2}=0.143, \gamma_{h}^{12}=\gamma_{h}^{1}+\gamma_{h}^{2}, \alpha_{h}^{1}=0.001, \alpha_{h}^{2}=0.001, \alpha_{h}^{12}=0.001, \alpha_{h}^{21}=0.143, \mu_{h}=0.000035$, $\mu_{v}=0.263, \mathrm{~m}=1.5, \tau=7$ e $\mathrm{Ms}=\mathrm{m}^{*} N_{h}$.

A população inicial de recuperados e de suscetíveis, além de variarem de acordo com a região estudada, foram definidas como funções da proporção de recém nascidos vacinados $(p)$, onde:

$$
\begin{gathered}
H_{r r}(0)=N_{h}(0) p \alpha_{1} \alpha_{2} \\
H_{r s}(0)=N_{h}(0) p \alpha_{1}\left(1-\alpha_{2}\right) \\
H_{s r}(0)=N_{h}(0) p\left(1-\alpha_{1}\right) \alpha_{2} \\
H_{s s}(0)=N_{h}(0) p\left(1-\alpha_{1}\right)\left(1-\alpha_{2}\right)+(1-p) N_{h}(0)
\end{gathered}
$$

A população inicial de humanos infectados varia de acordo com 3 cenários, conforme:

- Cenário (condições iniciais) 1: $H_{i s}=1, H_{s i}=0$ e $H_{i i}=0$

- Cenário (condições iniciais) 2: $H_{i s}=0, H_{s i}=1$ e $H_{i i}=0$

- Cenário (condições iniciais) 3: $H_{i s}=0, H_{s i}=0$ e $H_{i i}=1$

Neste trabalho consideramos que todas as pessoas vacinadas recebem todas as doses da vacina. De acordo com Capeding et al. (2014), a eficiência da vacina, após a aplicação das três doses, varia de acordo com o sorotipo e as taxas de eficácia da vacina, de acordo com o sorotipo, são: DENV-1 $=50.0 \%$, DENV-2 $=35.0 \%$, DENV-3=78.4\%, DENV-4=75.3\%.

Neste modelo consideramos, conforme Pessanha et al. (2011), que o mosquito pode portar dois sorotipos distintos da dengue ao mesmo tempo e trabalhamos com a iteração dois a dois entre os 4 sorotipos da dengue. Ou seja, para cada cenário considerou-se que apenas dois sorotipos, no máximo, circulam ao mesmo tempo nas cidades. 
Essa suposição é, em primeira instância, devido a enorme dificuldade em modelar um sistema com os 4 sorotipos circulando simultaneamente.

A figura 57 mostra o histórico da dengue no Estado de São Paulo entre os anos 2000 e 2014. Observa-se que, embora exista a ocorrência dos 4 sorotipos em um mesmo ano, o número absoluto de casos de um terceiro (e quarto) sorotipos é sempre pequeno em relação aos outros dois sorotipos.

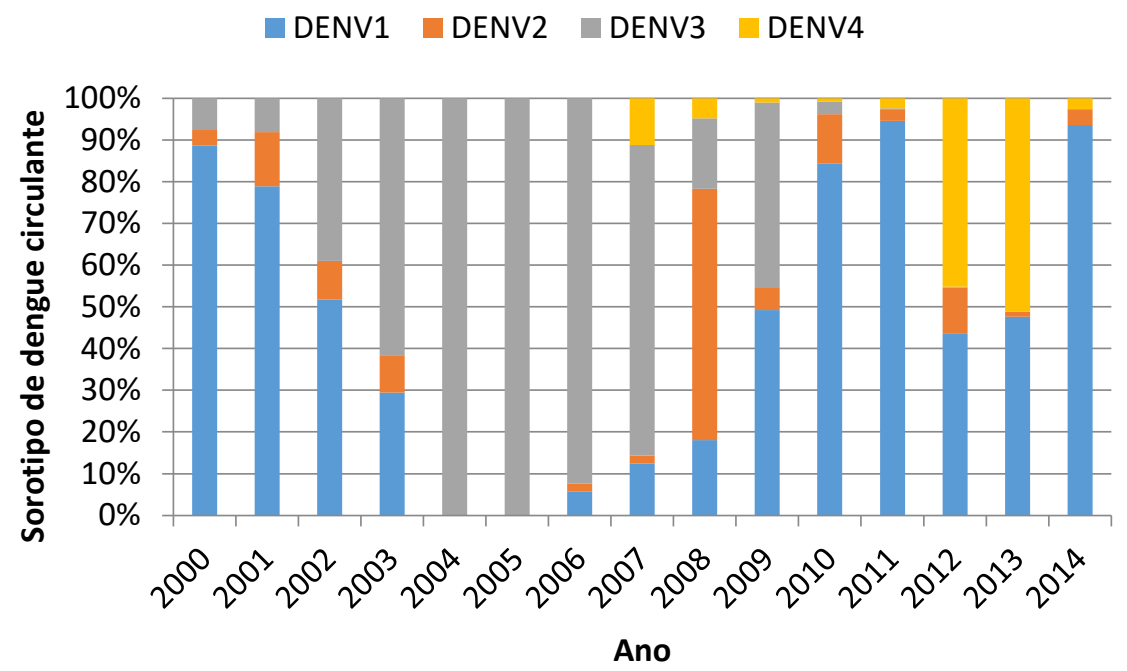

Figura 57 - Sorotipo da dengue circulante no Brasil por ano.

\section{Resultados preliminares}

\section{Humanos infectados}

O comportamento da população de humanos infectados após o aparecimento da doença em seguida a um longo período de vacinação é apresentado a seguir para três cenários que diferem-se nas condições iniciais. Para exemplificar, apresentamos a seguir evolução da população infectada no cenário com os sorotipos DENV1 e DENV2.

Observa-se que o número de infectados por ambos sorotipos simultaneamente é baixo e que o número de pessoas infectadas pelo DENV-2 e suscetível ao DENV-1 é ligeiramente superior ao número de pessoas infectadas pelo DENV-1 e suscetíveis ao DENV-2. Isso acontece porque a probabilidade de que a vacina seja bem sucedida contra o sorotipo 2 (35\%) é menor do que a probabilidade de sucesso contra o sorotipo $1(50 \%)$. 

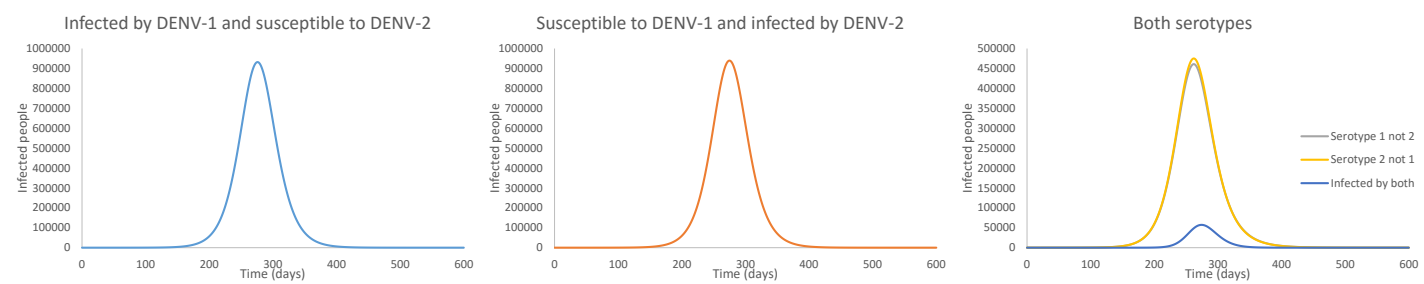

((a)) Infectado DENV1 e ((b)) Suscetível DENV1 e ((c)) Infectado por ambos suscetível DENV2 infectado DENV2 sorotipos

Figura 58 - Dinâmica da população de humanos infectados - Condições iniciais: ((a)) $H_{i s}=1, H_{s i}=0$ e $H_{i i}=0,((\mathrm{~b})) H_{i s}=0, H_{s i}=1$ e $H_{i i}=0 \mathrm{e}$ ((c)) $H_{i s}=0, H_{s i}=0$ e $H_{i i}=1$

As figuras 59((a)) e 59((b)) apresentam o número esperado de mortes em função da variação de $\nu$ (para diferentes valores de p) e p (para diferentes valores de $\nu$, respectivamente.

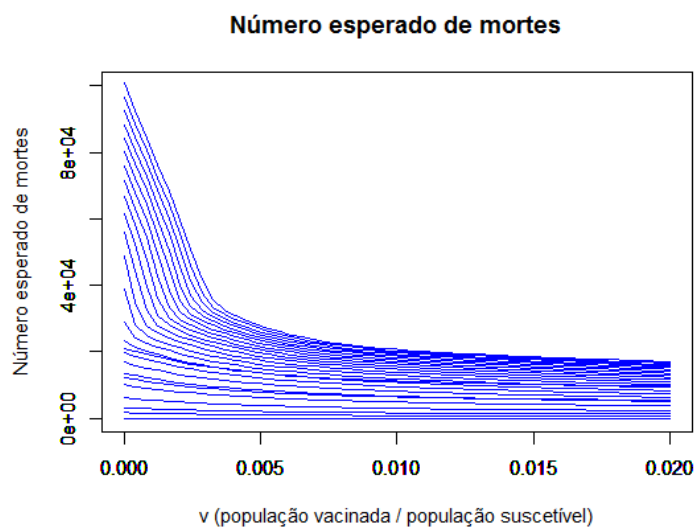

$((\mathrm{a}))$

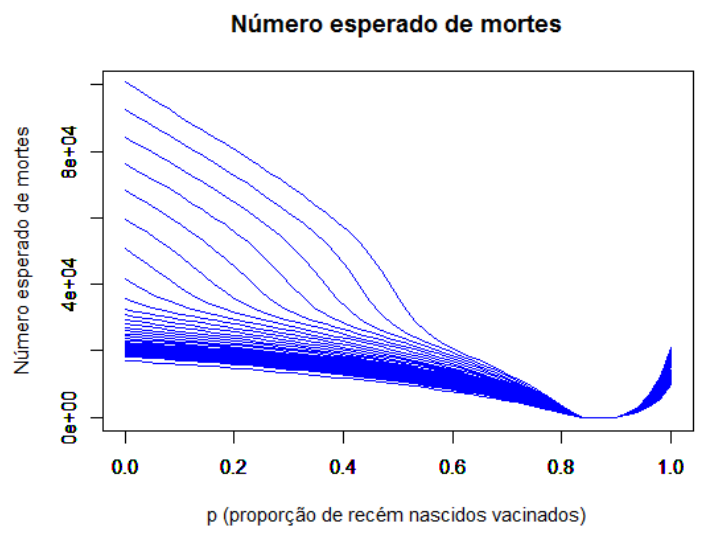

$((\mathrm{b}))$

Figura 59 - Número total de mortes devido à dengue (DENV2-DENV3) versus: ((a)) $\nu_{h}$ e $((\mathrm{b})) p$

A figura 60 é a compilação das imagens anteriores e possibilita uma melhor compreensão da influência da variação simultânea de p e $\nu$ na varável escolhida.

Os arranjos que contém os sorotipos 2 e 3, e 2 e 4 apresentaram, até o momento, os resultados mais interessantes. Para valores altos de $\mathrm{p}$ (isto é, $\mathrm{p}$ próximo a 0,8 ) o sistema volta a apresentar crescimento das variáveis analisadas (excluindo-se os custos).

A combinação DENV3 e DENV4 foi quem apresentou como resultado os menores valores para todas as variáveis estudadas, o que já era esperado pois a eficiência da vacina tetravalente para estes sorotipos é grande. Também destacam-se 


\section{Número esperado de mortes sorotipos 2 e 3}

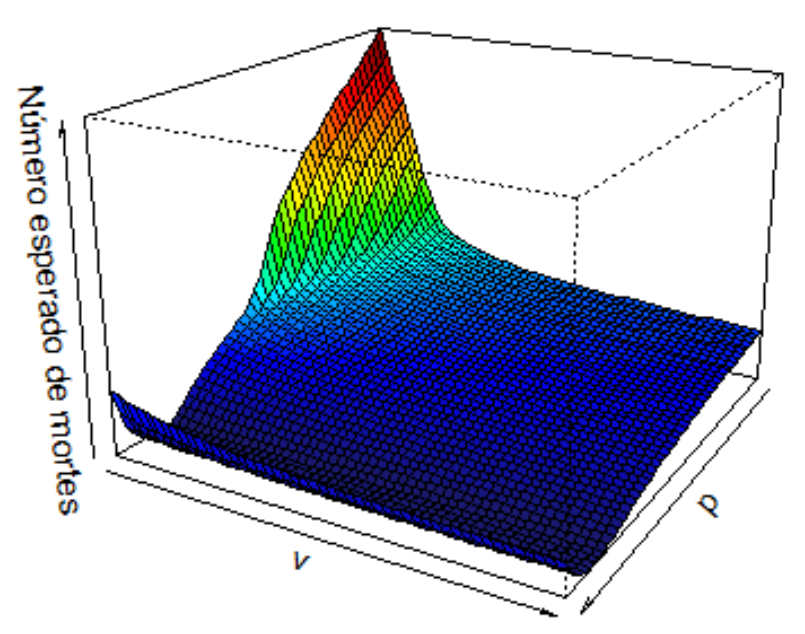

Figura 60 - Número total de mortes devido à dengue - DENV2-DENV3 - 3D

as turbulências na dinâmica causadas pela interação entre a baixa eficiência da vacina para o sorotipo 2 e a altas eficiências para os sorotipos 3 e 4 .

O modelo com valores de p e $\nu$ iguais a zero, isto é, não há um programa de vacinação vigente. Assim, ao analisar a figura 60, por exemplo, deve-se observar que quanto menor o valor de p e de $\nu$, maior é o número esperado para o total de mortes devido à dengue. Assim sendo, excluindo-se os gráficos referentes aos custos estimados, o valor de máximo para todas as variáveis é sempre no ponto correspondente a $\mathrm{p}=0$ e $\nu=0$, ou seja, quando não há nenhum programa de vacinação.

Embora o comportamento esperado para essas variáveis fosse o decaimento conforme p e $\nu$ aumentam, em alguns casos isso não acontece indefinidamente, como pode-se observar na figura 60 que expõe o comportamento do número total esperado de mortes na presença dos sorotipos DENV2 e DENV3 onde, após aparentemente apresentar equilíbrio, volta a aumentar a previsão do valor da variável com o aumento do valor de p. Esse mesmo comportamento foi observado para as variáveis: Número esperado de mortes, risco per capita de morte devido à dengue, número total de dias de incidência de dengue, número total de casos esperados de dengue, número total de dias de infecção secundária, e número total de casos secundários esperados de dengue (figuras 62, 68, 70, 64, 66) e também repetiu-se para o conjunto DENV2-DENV4. 
O menor valor obtido para o total de mortes esperado no arranjo DENV1DENV2 tem $\mathrm{p}=1$ e $\nu=0.02$, resultando em 28 mortes. Para os demais arranjos o mínimo encontra-se no mesmo ponto $(\mathrm{p}=1$ e $\nu=0.02)$ mas o valor final é menor do que 1, portanto, zero mortes. No entanto este resultado ainda deve ser melhor analisado.

A seguir, pode-se observar os resultados obtidos para as demais variáveis, na presença dos sorotipos 2 e 3 .

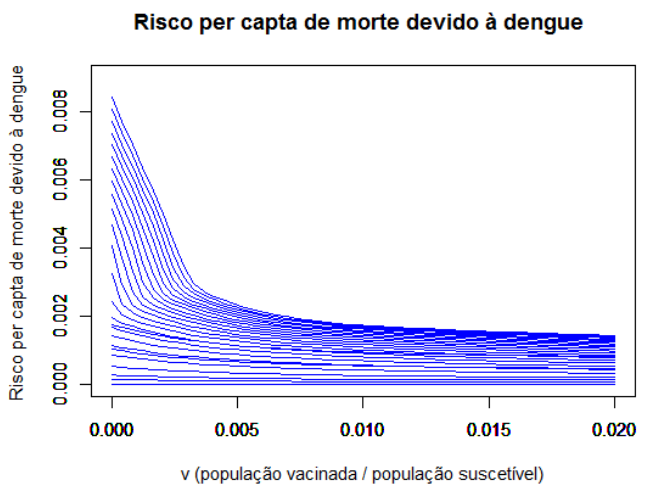

$((\mathrm{a}))$

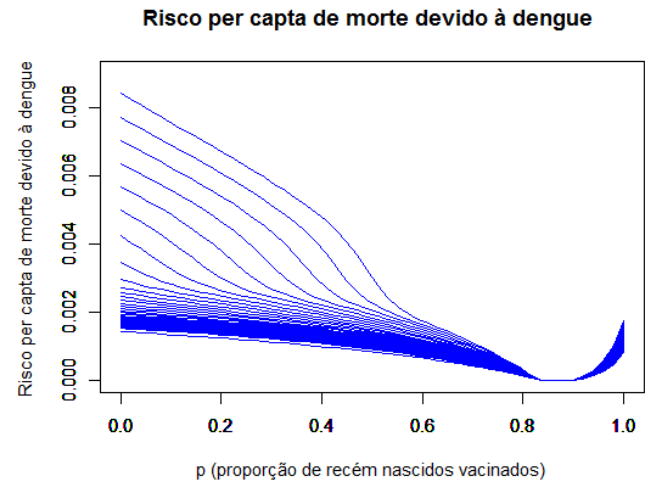

$((\mathrm{b}))$

Figura 61 - Risco per capita de mortes devido à dengue (DENV2-DENV3) versus: ((a)) $\nu_{h}$ e $((\mathrm{b})) p$

\section{Risco per capta de morte devido à dengue sorotipos 2 e 3}

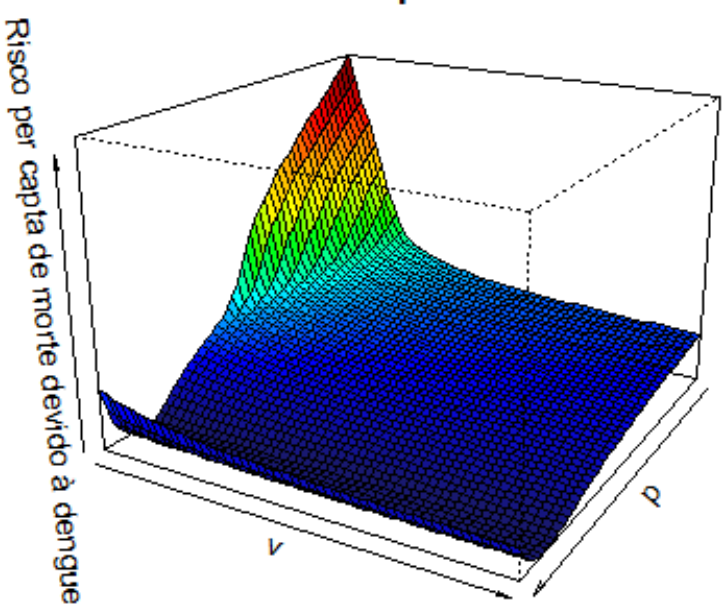

Figura 62 - Risco per capita de mortes devido à dengue - DENV2-DENV3 - 3D 


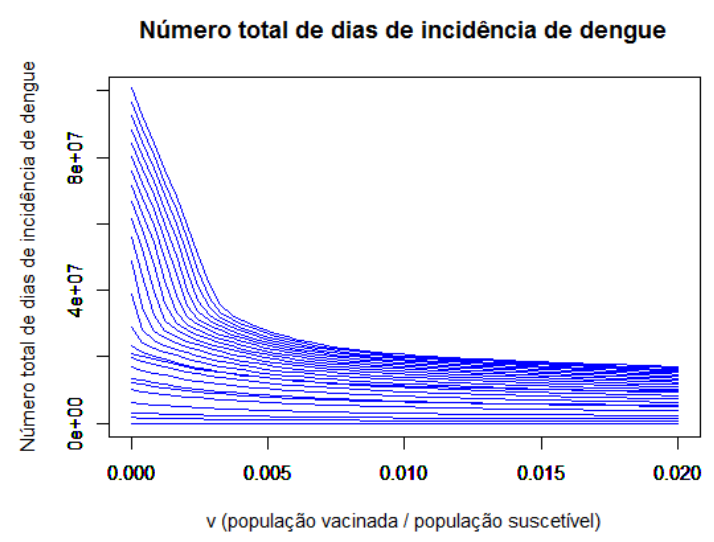

$((\mathrm{a}))$

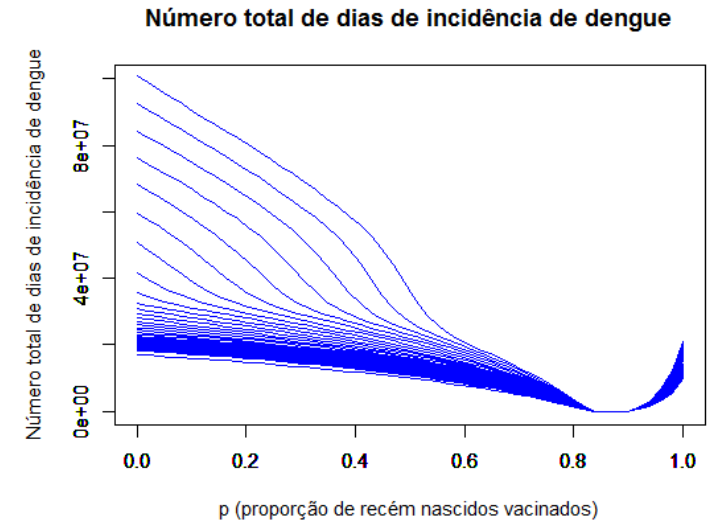

$((\mathrm{b}))$

Figura 63 - Número total esperado de dias de incidência de dengue (DENV2DENV3) versus: ((a)) $\nu_{h}$ e $((\mathrm{b})) p$

\section{Número total de dias de incidência de dengue sorotipos 2 e 3}

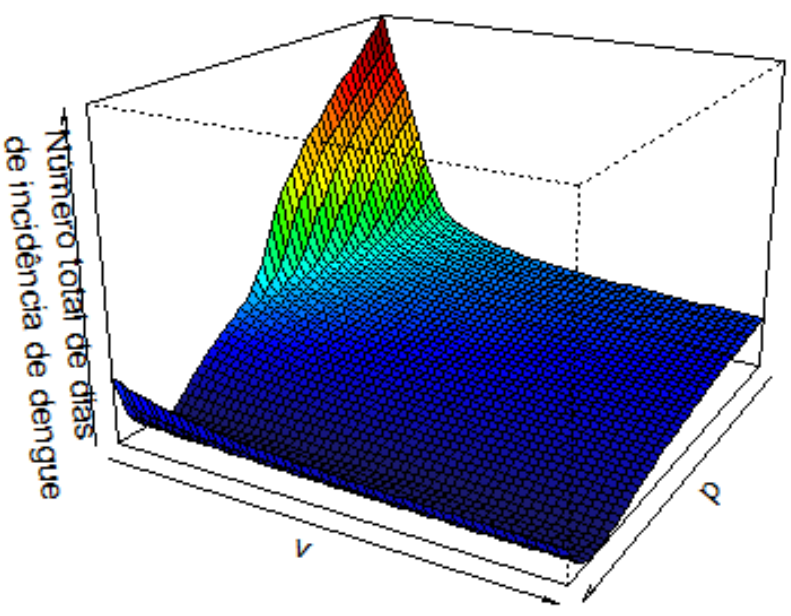

Figura 64 - Número total esperado de dias de incidência de dengue - DENV2DENV3 - 3D 


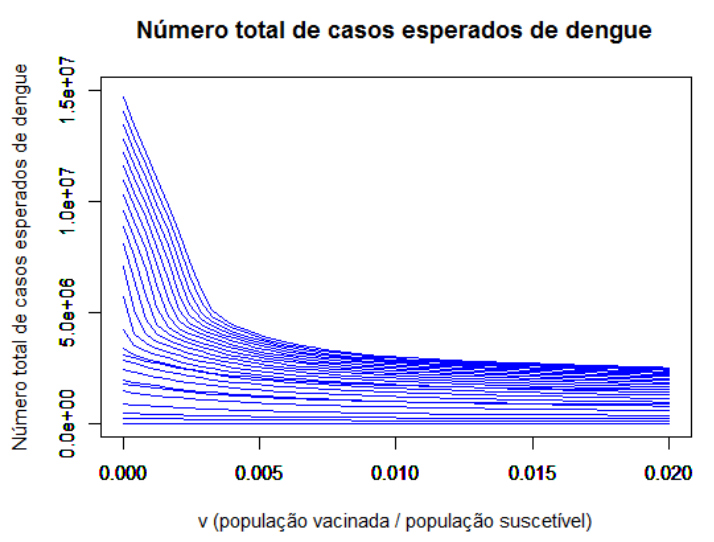

$((\mathrm{a}))$

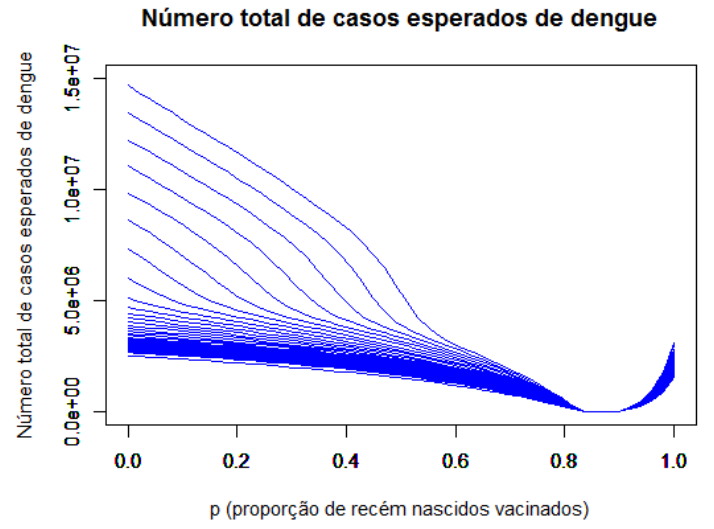

$((\mathrm{b}))$

Figura 65 - Número total esperado de casos de dengue (DENV2-DENV3) versus: ((a)) $\nu_{h}$ e ((b)) $p$

\section{Número total de casos esperados de dengue sorotipos 2 e 3}

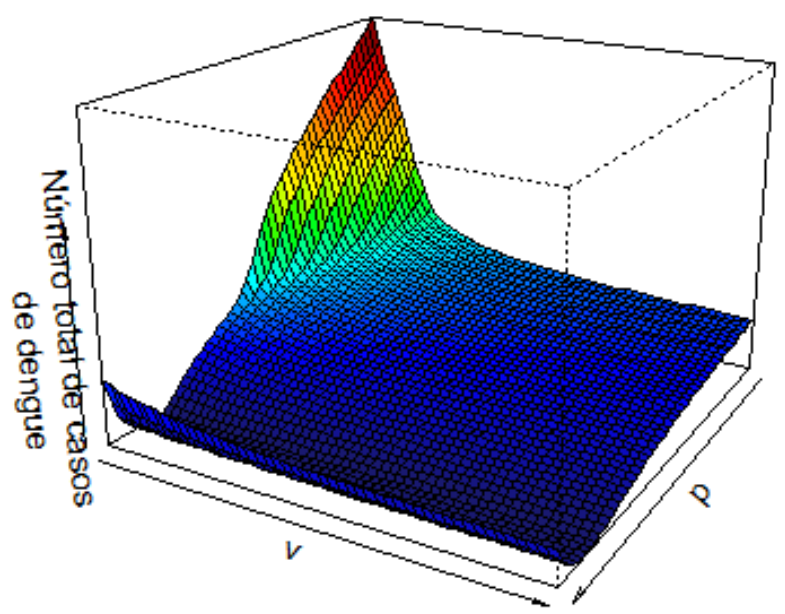

Figura 66 - Número total esperado de casos de dengue - DENV2-DENV3 - 3D 


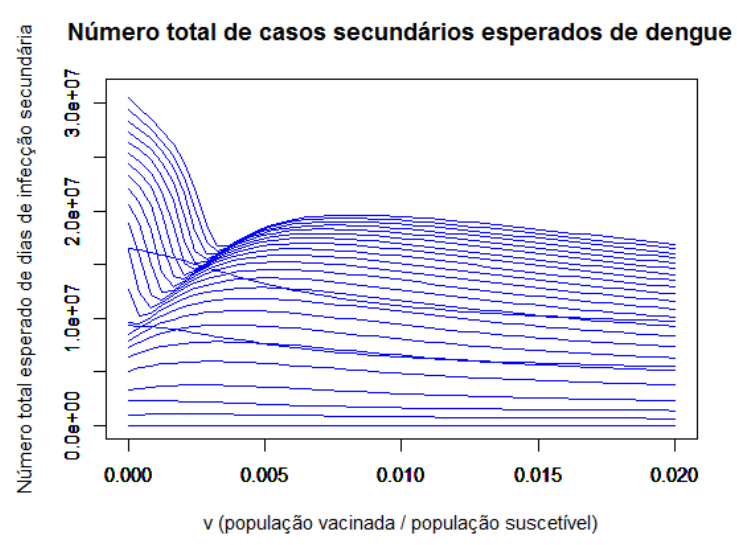

$((\mathrm{a}))$

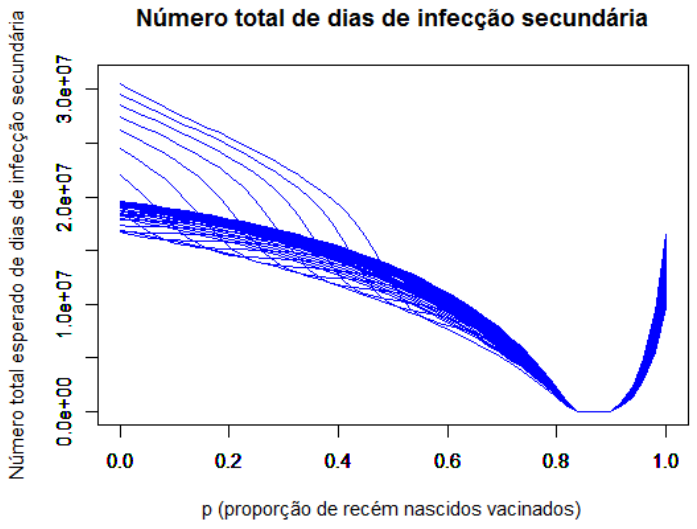

$((\mathrm{b}))$

Figura 67 - Número total de dias de infecção secundária esperado (DENV2DENV3) versus: ((a)) $\nu_{h}$ e ((b)) $p$

\section{Número total esperado de dias de infecção secundária sorotipos 2 e 3}

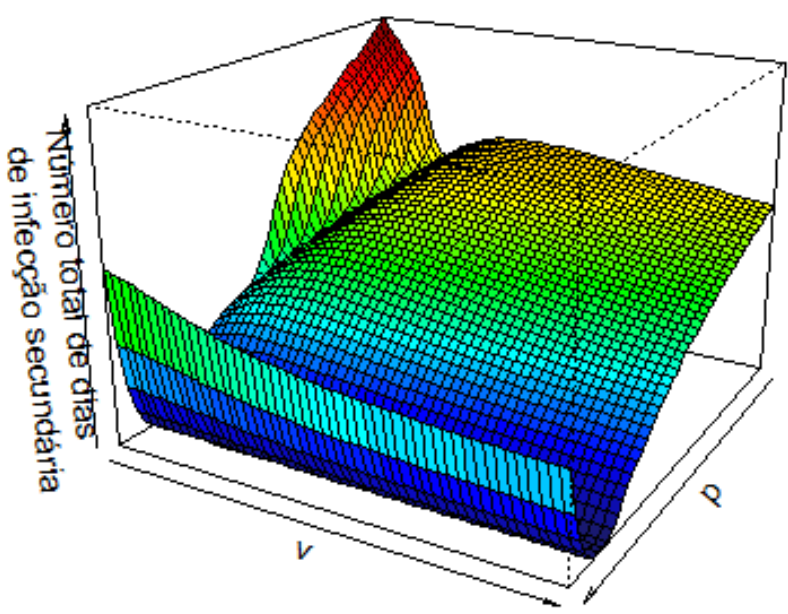

Figura 68 - Número total de dias de infecção secundária esperado - DENV2DENV3 - 3D 


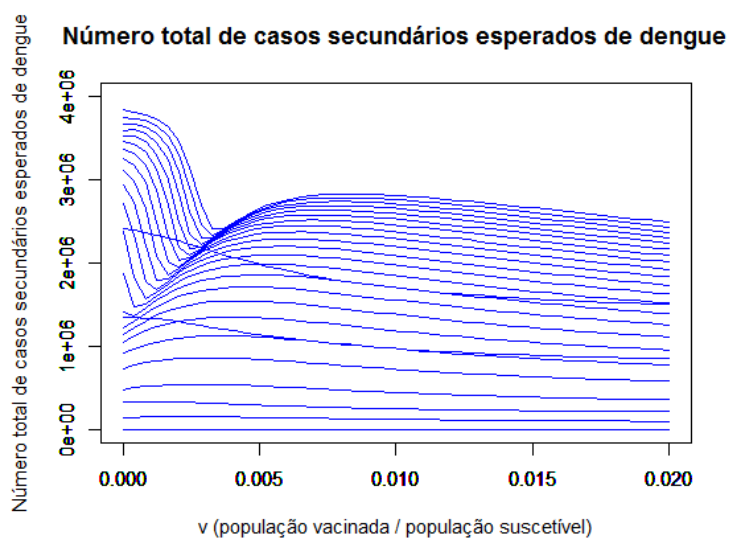

$((\mathrm{a}))$

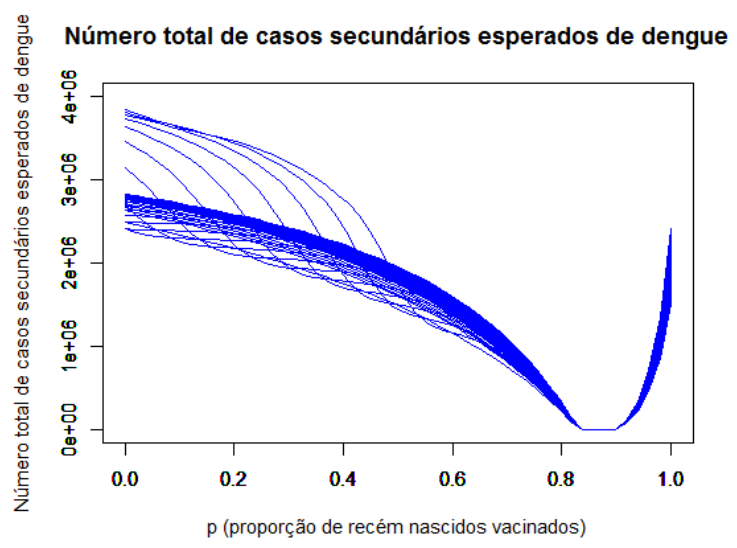

$((\mathrm{b}))$

Figura 69 - Número total esperado de casos secundários de dengue (DENV2DENV3) versus: ((a)) $\nu_{h}$ e $((\mathrm{b})) p$

\section{Número total de casos secundários esperados de dengue sorotipos 2 e 3}

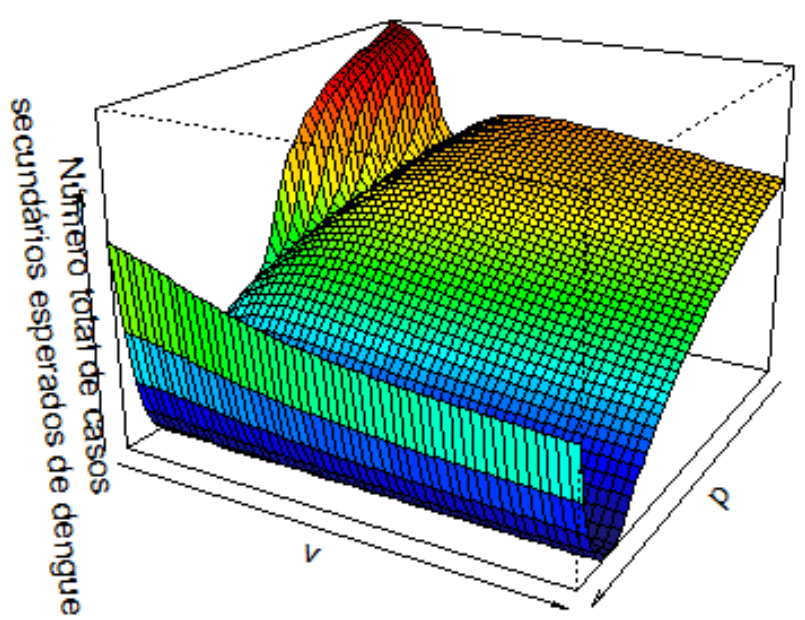

Figura 70 - Número total esperado de casos secundários de dengue - DENV2DENV3 - 3D 


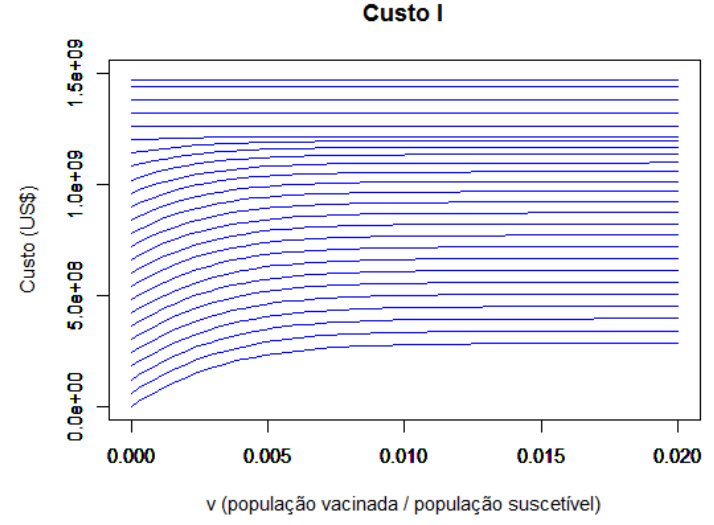

((a))

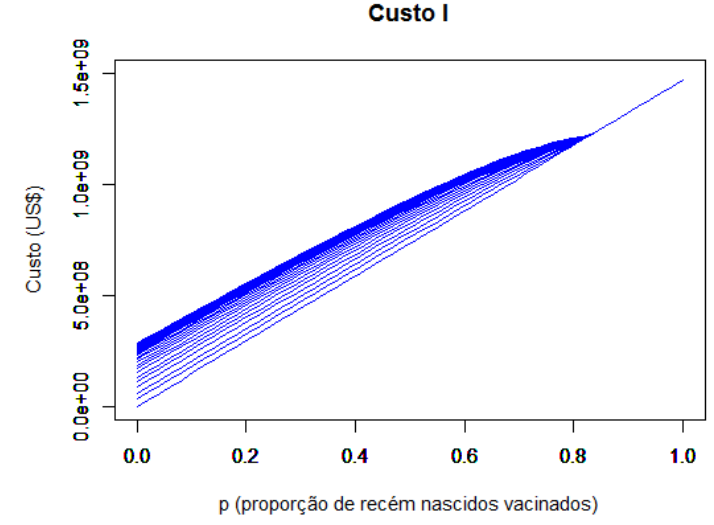

((b))

Figura 71 - Custo econômico 1 (DENV2-DENV3) versus: ((a)) $\nu_{h}$ e ((b)) $p$

\section{Custo esperado da vacinação por morte devido à dengue sorotipos 2 e 3}

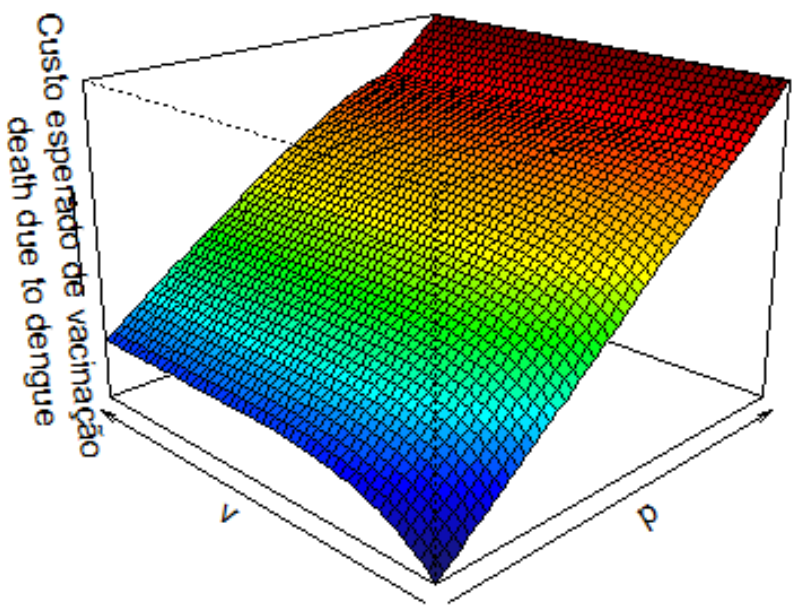

Figura 72 - Custo econômico 1 - DENV2-DENV3 - 3D 


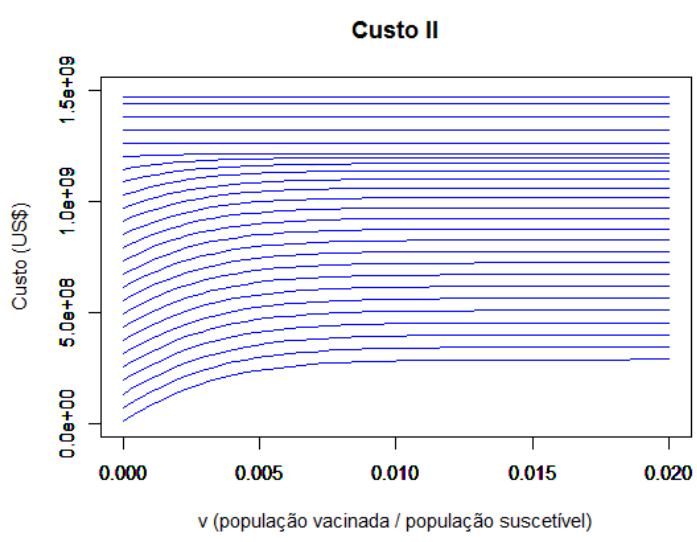

$((\mathrm{a}))$

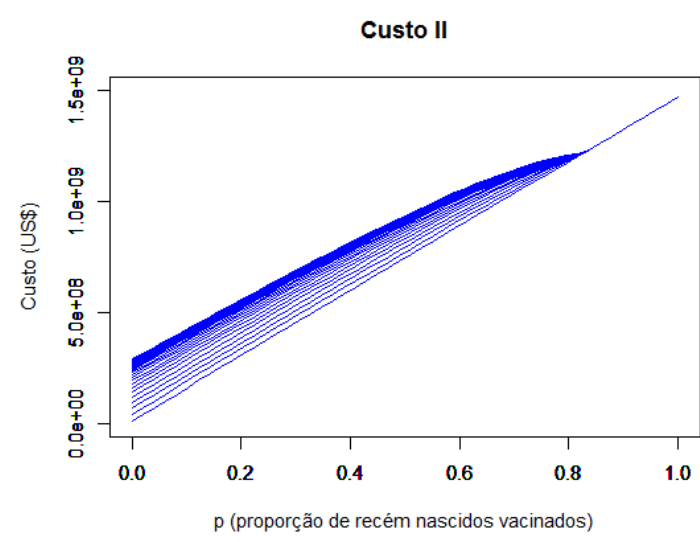

$((\mathrm{b}))$

Figura 73 - Custo econômico 2 (DENV2-DENV3) versus: ((a)) $\nu_{h}$ e ((b)) $p$

\section{Custo esperado da vacinação por dia de infecção por dengue sorotipos 2 e 3}

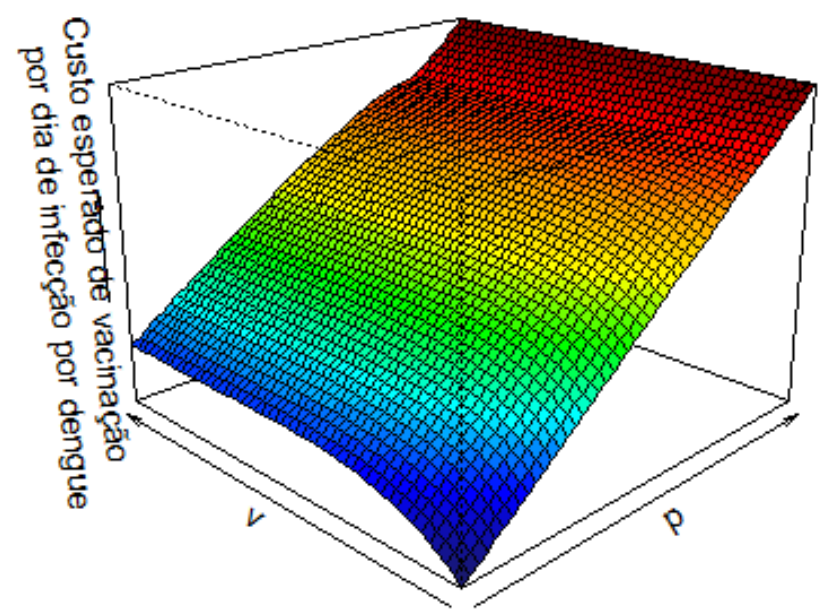

Figura 74 - Custo econômico 2 - DENV2-DENV3 - 3D 


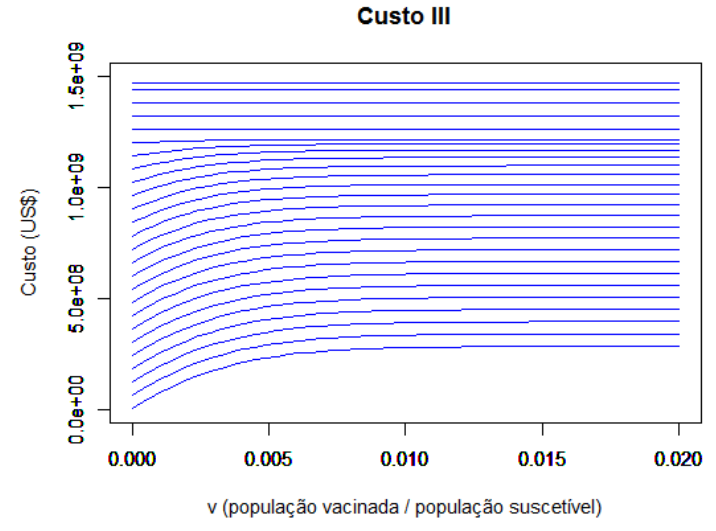

((a))

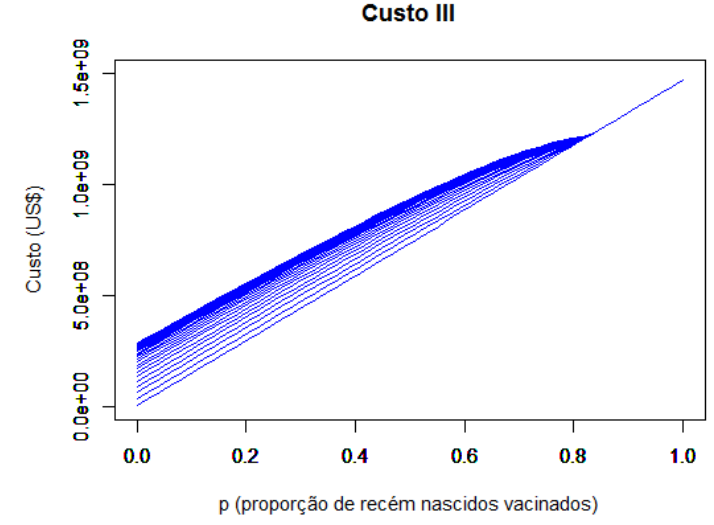

((b))

Figura 75 - Custo econômico 3 (DENV2-DENV3) versus: $((\mathrm{a})) \nu_{h}$ e ((b)) $p$

\section{Custo de vacinação esperado por caso de dengue sorotipos 2 e 3}

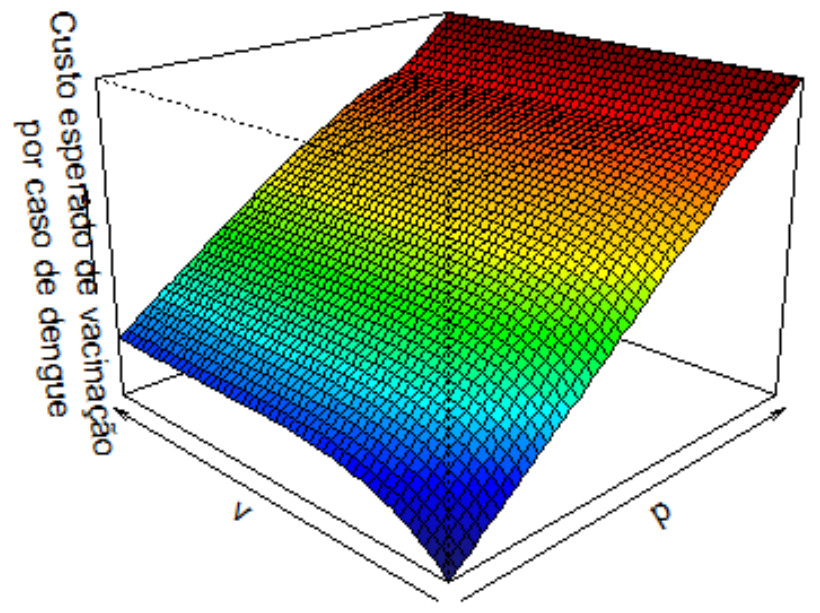

Figura 76 - Custo econômico 3 - DENV2-DENV3 - 3D 


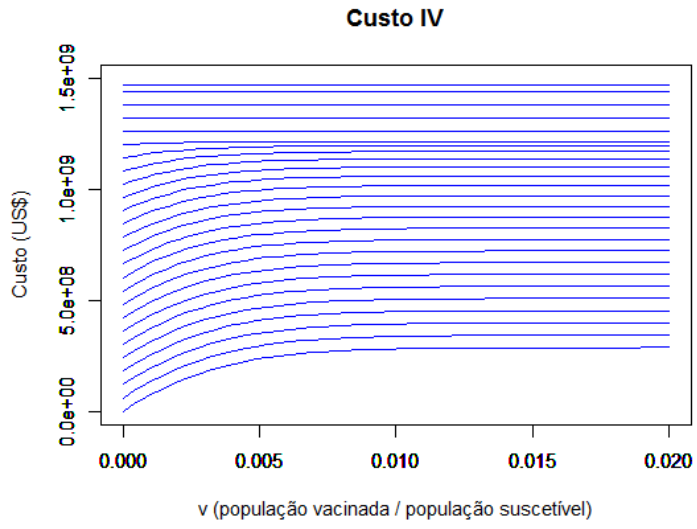

((a))

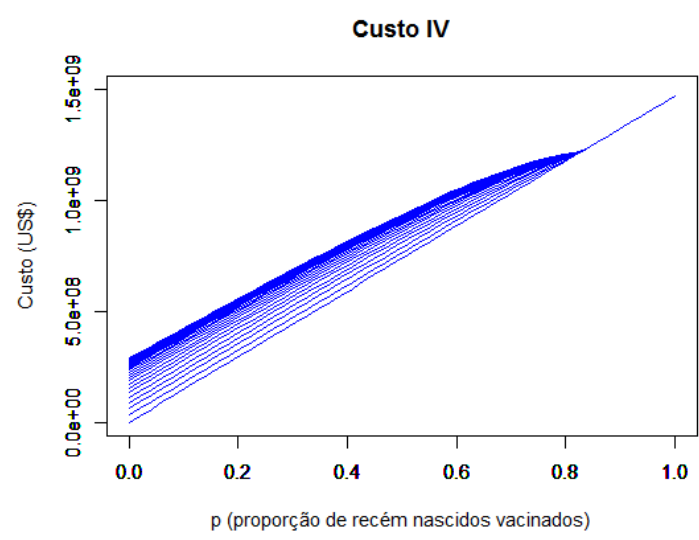

((b))

Figura 77 - Custo econômico 4 (DENV2-DENV3) versus: ((a)) $\nu_{h}$ e ((b)) $p$

\section{Custo esperado de vacinação por dia de infecção secundária de dengue sorotipos 2 e 3}

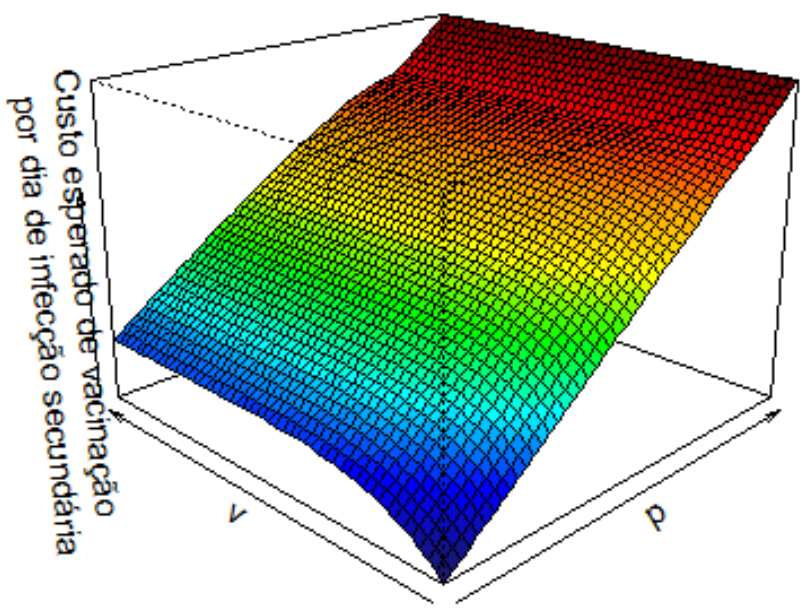

Figura 78 - Custo econômico 4 - DENV2-DENV3 - 3D 


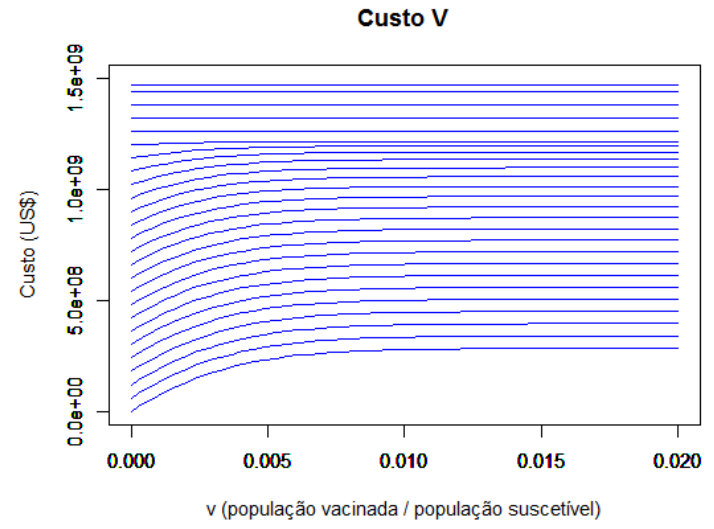

((a))

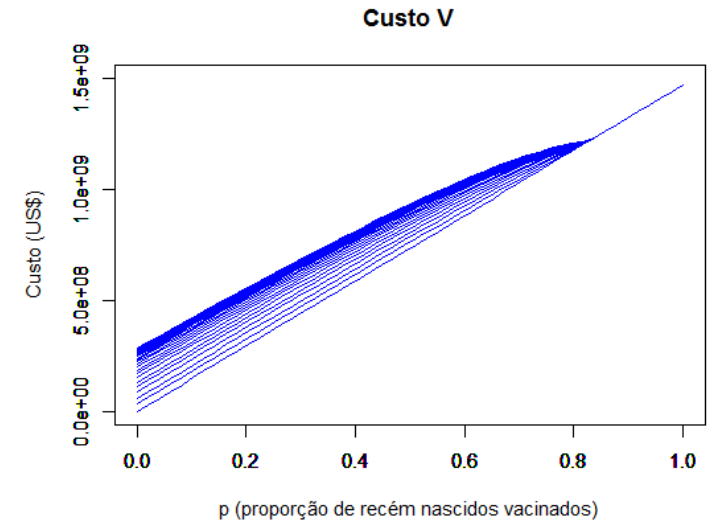

((b))

Figura 79 - Custo econômico 5 (DENV2-DENV3) versus: ((a)) $\nu_{h}$ e ((b)) $p$

\section{Custo esperado de vacinação por caso de infecção secundária por dengue sorotipos 2 e 3}

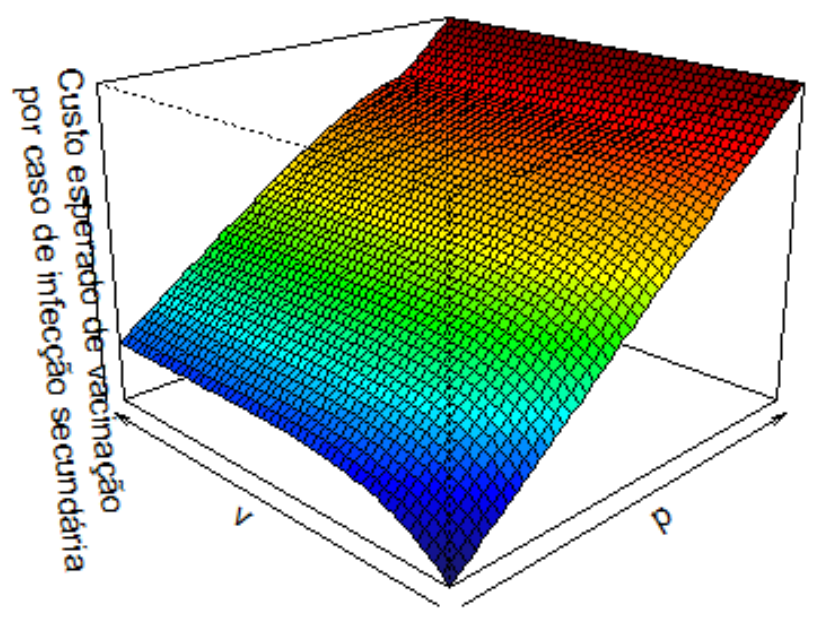

Figura 80 - Custo econômico 5 - DENV2-DENV3 - 3D 



\section{Berkeley Madonna}

\section{Curve Fitter}

Berkeley Madonna can automatically find the values of one or more parameters in your model that minimize the deviation between your model's output and a dataset. Before you use this feature, you should be able to run your model and be confident that it is working properly.

You should already have determined integration parameters that give accurate results while minimizing execution time.

To perform a curve fit, choose Curve Fit from the Parameters menu. You will see a fairly involved dialog box. Here's what you do with it:

1. Specify which variable in your model you are trying to fit to the external data.

2. Specify the dataset you want to fit the variable to. If you haven't imported the dataset yet, you can do so by clicking the Import Dataset button. See Importing Datasets 16 for details.

3. Specify one or more parameters in your model which you want to solve for. To do this, choose a parameter from the available list on the left and click Add. If you change your mind, click Remove.

4. For each parameter you have chosen, you must provide two initial guesses. To set guesses for a parameter, select its name in the parameter list and edit the values displayed in the Guess 1 and Guess 2 boxes.

5. You must also provide a minimum and maximum value for each parameter. Both guesses must be within this range. The curve fitter will not set the parameter outside of this range. 
6. Specify the fractional tolerance you desire in the solution. For example, if you want the parameter(s) solved to three significant figures, set the tolerance to 0.001. The tolerance must be greater than zero.

7. Once you are satisfied with your setup, click OK to begin the curve fit. Berkeley Madonna will run your model repeatedly until it finds a solution. If you get tired of waiting, click the Stop button to abort the fit.

8. When the fit is complete, Berkeley Madonna leaves the parameters set to the values that give the best fit. It then runs your model and plots the fit variable and dataset in a graph window.

While the curve fit is in progress, Berkeley Madonna displays the RMS deviation between the data and best run so far. The deviation is root mean square of the differences between individual data points in the dataset and the corresponding points in the run.

When the curve fit operation complete, Berkeley Madonna immediately closes the Running dialog. If you want the dialog to remain open after the curve fit completes, check the Pause After Curve Fit option in the General page of the Preferences dialog. This enables you to observe the RMS deviation of the best fit. To close the dialog, click the Done button. 